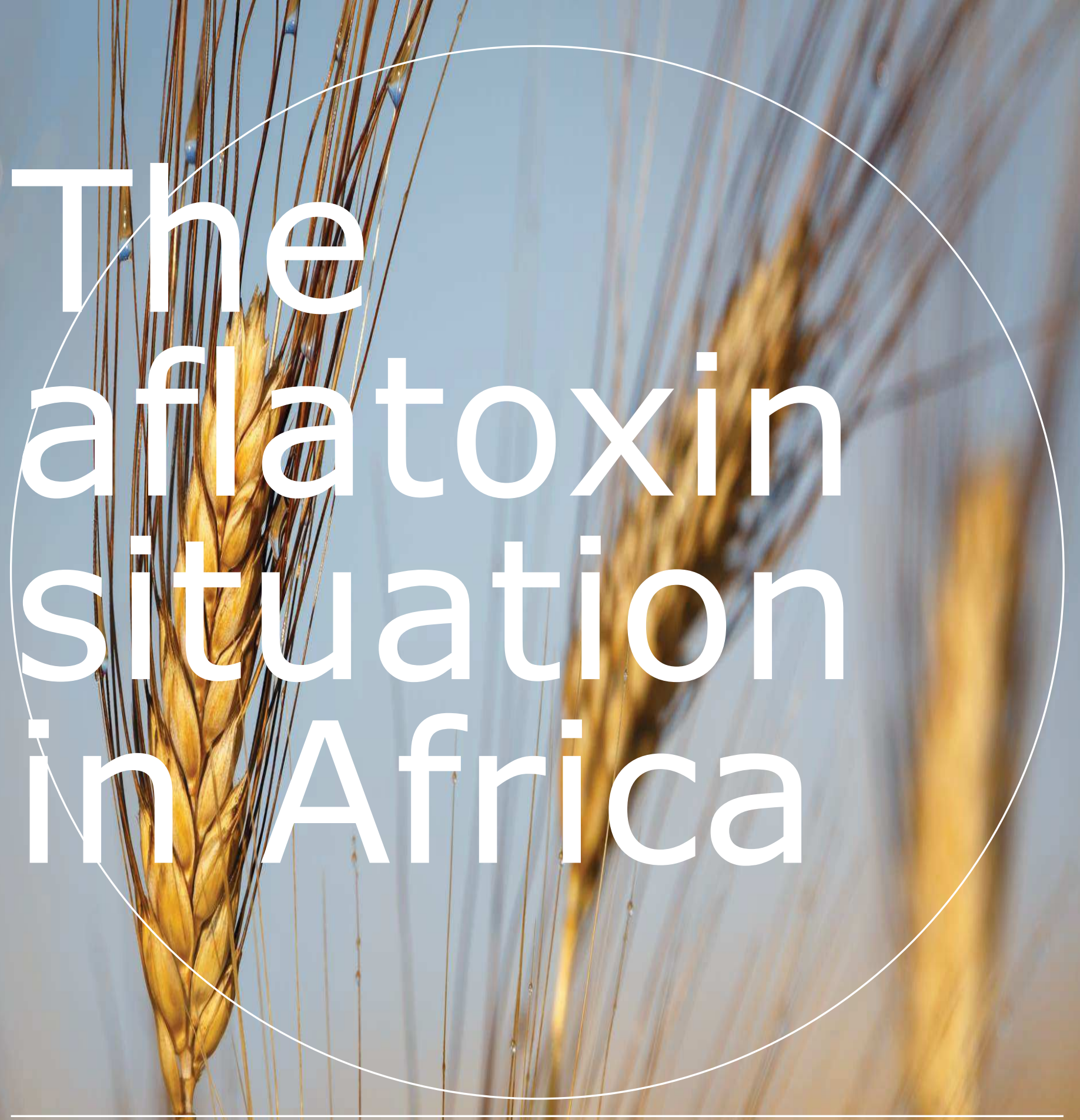

\title{
Systematic literature review
}

RIKILT report 2018.010

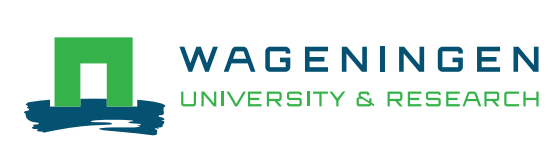

PACA

African (Onion) 


\title{
The aflatoxin situation in Africa
}

\author{
Systematic literature review
}

Nathan Meijer ${ }^{1}$, Gijs Kleter ${ }^{1}$, Rosa Amalia Safitri ${ }^{1}$, Monique de Nijs ${ }^{1}$, Marie-Luise Rau ${ }^{2}$, Ria Derkx ${ }^{3}$, Joke Webbink ${ }^{3}$, Marijn Post ${ }^{3}$, Yuca Waarts ${ }^{2}$, Ine van der Fels-Klerx ${ }^{1}$

1 RIKILT Wageningen University \& Research

2 Wageningen Economic Research

3 Wageningen University \& Research - Library

This research has been carried out by Wageningen University \& Research and financed by Partnership for Aflatoxin Control in Africa (PACA) through funds made available to PACA by the Bill and Melinda Gates Foundation and Mars, Incorporated (project number 1277360301). PACA acknowledges the contribution of the Technical Centre for Agricultural and Rural Cooperation (CTA) in producing this report which is a follow up to the CTA/PACA 2016 Working Paper "Improving the evidence base on aflatoxin contamination and exposure in Africa" written by Sheila Okoth. 
Project number: 1277360301

Project title: The aflatoxin situation in Africa

Project leader: Nathan Meijer

(C) 2018 African Union Commission / PACA.

This study was financed by Partnership for Aflatoxin Control in Africa (PACA) through funds made available to PACA by the Bill and Melinda Gates Foundation and Mars, Incorporated. PACA acknowledges the contribution of the Technical Centre for Agricultural and Rural Cooperation (CTA) in producing this report which is a follow up to the CTA/PACA 2016 Working Paper "Improving the evidence base on aflatoxin contamination and exposure in Africa" written by Sheila Okoth.

This report is published by RIKILT Wageningen University \& Research, institute within the legal entity Wageningen Research Foundation with the copyright holder's permission.

Without prior written permission from the copyright holder it is not allowed to:

a) publish parts of this report;

b) use this report or title of this report in conducting legal procedures, for advertising, acquisition or other commercial purposes;

c) use the name of RIKILT other than as the author of this report.

P.O. Box 230, 6700 AA Wageningen, The Netherlands, T +31 (0)317 4802 56, E info.RIKILT@wur.nl, www.wur.eu/rikilt. RIKILT is part of Wageningen University \& Research.

This report from RIKILT has been produced with the utmost care. However, RIKILT does not accept liability for any claims based on its contents.

This report can be downloaded for free at https://doi.org/10.18174/476846 or at www.wur.eu/foodsafety-research (under WFSR publications). 


\section{Table of Contents}

$\begin{array}{ll}\text { Preface and acknowledgements } & 5\end{array}$

$\begin{array}{lr}\text { Executive summary } & 6\end{array}$

$\begin{array}{llr}1 & \text { Introduction } & 14\end{array}$

$\begin{array}{lll}1.1 & \text { Framework as provided by the project sponsor } & 14\end{array}$

$\begin{array}{lll}1.2 & \text { Objectives } & 14\end{array}$

$\begin{array}{lll}1.3 & \text { Research questions and scope } & 15\end{array}$

$\begin{array}{lll}1.4 & \text { Structure of report } & 15\end{array}$

2.1 Scale and geographical spread of aflatoxin contamination in food, feed, and associated commodities/key value chains 16

$\begin{array}{lll}2.2 & \text { Scale of aflatoxin disease burden } & 18\end{array}$

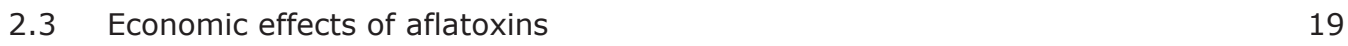

$\begin{array}{lll}2.4 & \text { Mitigation measures and cost-effectiveness } & 24\end{array}$

3

$\begin{array}{ll}\text { Methodology } & 26\end{array}$

$\begin{array}{lll}3.1 & \text { Introduction } & 26\end{array}$

$\begin{array}{lll}3.2 & \text { Literature search } & 27\end{array}$

$\begin{array}{ll}3.2 .1 & \text { Identification of relevant data sources }\end{array}$

$\begin{array}{ll}3.2 .2 \text { Search strategies } & 28\end{array}$

3.2.3 Benchmark citations $\quad 29$

3.2.4 Collection of references and initial screening 29

$\begin{array}{lll}3.3 & \text { Screening (inclusion/exclusion) } & 29\end{array}$

3.4 Analysis and synthesis of data 30

3.4.1 Code - "questionnaire" 30

3.4.2 Coding tool $\quad 30$

3.4.3 Data extraction and synthesis 30

4.1 Search strategies and pre-screening 31

4.1.1 Search strategies $\quad 31$

4.1.2 Pre-screening $\quad 32$

4.2 Screening 33

4.2.1 Screening title and abstract for relevance 33

4.2.2 Screening full text for relevance and categorization 34

$\begin{array}{lll}4.3 & \text { Coding } & 36\end{array}$

4.3.1 General questions 36

4.3.2 Scale and geographic spread of contamination 36

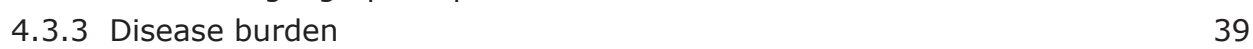

4.3.4 Economic impact $\quad 42$

$\begin{array}{ll}4.3 .5 & \text { Mitigation measures }\end{array}$

$\begin{array}{lll}4.4 & \text { Summary } & 46\end{array}$

$\begin{array}{lll}5.1 & \text { Scale and geographical spread of contamination } & 47\end{array}$

$\begin{array}{ll}5.1 .1 & \text { Scale of aflatoxin contamination }\end{array}$

5.1.2 Geographical spread and key value chains. $\quad 47$

5.2 Disease burden $\quad 53$

5.2.1 Disease burden expressed as DALY 53 
5.2.2 Disease burden expressed as the risk on adverse health effects resulting from exposure to aflatoxins

5.2.3 Biomarkers of exposure $\quad 54$

5.3 Economic impact $\quad 55$

5.3.1 Trade-related economic impact $\quad 55$

5.3.2 Firm-level economic impact $\quad 57$

5.3.3 Willingness to pay for aflatoxin-free products 58

5.3.4 Health-related economic impact $\quad 58$

5.4 Mitigation measures $\quad 59$

5.4.1 Plant breeding $\quad 59$

5.4.2 Agricultural practices $\quad 59$

$\begin{array}{ll}5.4 .3 \text { Post-harvest storage } & 61\end{array}$

$\begin{array}{ll}5.4 .4 \text { Processing } & 62\end{array}$

5.4.5 Reducing availability of aflatoxin from food by the use of binders 64

5.4.6 Reducing availability of aflatoxin from feed by the use of binders and other agents

5.4.7 Education and awareness raising about mitigation measures 66

6.1 Scale and geographical spread of contamination $\quad 67$

$\begin{array}{lll}6.2 & \text { Disease burden } & 67\end{array}$

$\begin{array}{lll}6.3 & \text { Economic impact } & 68\end{array}$

$\begin{array}{lll}6.4 & \text { Mitigation measures } & 69\end{array}$

6.5 Studies published after the literature review screening 70

$\begin{array}{lll}6.6 & \text { Limitations } & 70\end{array}$

$7 \quad$ Conclusion, knowledge gaps and recommendations

$\begin{array}{lll}7.1 & \text { Conclusion and knowledge gaps } & 71\end{array}$

$\begin{array}{lll}7.2 & \text { Recommendations } & 73\end{array}$

\section{References 74}




\section{Preface and acknowledgements}

This report on the aflatoxin situation in Africa was commissioned by the Partnership for Aflatoxin Control in Africa (PACA) at the Department of Rural Economy and Agriculture of the African Union Commission and Technical Centre for Agricultural and Rural Cooperation ACP-EU (CTA). The report is the result of a collaboration between RIKILT Wageningen University \& Research, Wageningen Economic Research, and the Wageningen University \& Research Library.

The authors wish to thank in particular Amare Ayalew (PACA), Judith Francis (CTA), and Jennie van der Mheen (Wageningen University \& Research, Corporate Strategy \& Accounts) for their valuable assistance during the project. 


\section{Executive summary}

\section{Introduction}

Aflatoxins are highly toxic fungal metabolites produced by certain strains of Aspergillus species. Aflatoxins thwart Africa's efforts at achieving food security, improving nutrition and health outcomes and attaining agricultural-led economic growth. They pose major risks to human and animal health, nutrition, as well as intra-regional and international trade. The difficulty African producers, traders and manufacturers face in sourcing high quality raw materials and producing high quality products hampers agribusiness development, job creation and economic growth. This makes the attainment of the UN Sustainable Development Goals (SDGs), especially as they pertain to food security, more challenging. They also undermine continental priorities such as the Malabo Declaration Commitments of 2014 of the African Union. Despite the fact that the above mentioned impacts of aflatoxin to the African situation are clear, quantitative evidence is lacking, and the information that is available is scattered.

The aim of this project was to provide insight into the aflatoxin situation in Africa. These insights can be used to enhance effective management of the major challenges to combat aflatoxin contamination. The following research questions have been defined for the systematic literature review:

1. What is the scale and geographical spread of aflatoxin contamination in food, feed, and associated commodities and key value chains in African countries?

2. What is the scale of aflatoxin disease burden for African countries?

3. What are the economic effects of aflatoxins on African countries?

4. What are current and additional possible mitigation measures and what is the costeffectiveness of mitigation of aflatoxin contamination in key commodities / value chains in African countries?

\section{Scientific background}

Scale and geographical spread of aflatoxin contamination in food, feed, and associated commodities/key value chains Widespread aflatoxin contamination of certain African staple foods, particularly maize, other cereals, groundnuts, and peanuts, had been reported prior to the year 2010, which marked the start of the considered review period in this report. In general, these crops which are particularly vulnerable to Aspergillus infection and aflatoxin contamination pre- and post-harvest showed high proportions of samples being positive, both in raw commodities as well as derived and processed products.

Regulations on maximum limits of aflatoxins in food vary among countries worldwide. Of a total of 55 countries in Africa, only 15 countries have established regulations on aflatoxins level. Some countries refer to EU regulation to set the limit for food for human consumption. In the EU, maximum limits for AFB1 range from $2 \mu \mathrm{g} / \mathrm{kg}$ for groundnuts (peanuts) and processed products thereof, intended for direct human consumption or use as an ingredient in foodstuffs, to $20 \mu \mathrm{g} / \mathrm{kg}$ for feed. It should be taken into account that aflatoxins are carcinogenic substances and concentrations in food should therefore be as low as reasonably achievable.

For maize in Africa, a majority of samples was contaminated with aflatoxins. Aflatoxin concentrations also commonly exceeded internationally established legal limits (EU, Codex) in a substantial fraction of the samples analysed. There were only a few reports of absence or very low levels of aflatoxins. Consumption of maize contaminated with high levels of aflatoxins accounted for large outbreaks of acute aflatoxicosis, particularly in Kenya in 2004, leading to morbidity and, in some cases, mortality. In that year, of the maize sold in markets in the affected four districts, seven percent turned out to be 
contaminated with more than 1,000 parts-per-billion $(\mu \mathrm{g} / \mathrm{kg})$ of aflatoxin, with a maximum of 46,400 $\mu \mathrm{g} / \mathrm{kg}$. For maize, the prevalence of aflatoxin, as reported, appears to be highest in Nigeria and Kenya. However, the mapping exercises also highlight a lack of studies on prevalence in other subSaharan countries. Whereas the environmental conditions appear to be favourable for mycotoxin contamination, yet the number of studies conducted in those countries is low.

In various African countries, other cereals derived products have been reported to contain elevated levels of aflatoxins, in particular sorghum, barley, millet, rice, teff, and wheat. In peanut, another important staple crop, inoculation with aflatoxigenic moulds occurs primarily in the soil, during the plant development stage in which the pod enters the soil and directly comes into contact with soilborne Aspergillus species. Cassava and derived products, such as flour and chips, generally show low aflatoxins contamination even in case of Aspergillus infection, with relatively rare cases of contaminations exceeding regulatory limits.

\section{Scale of aflatoxin disease burden}

Disease burden is generally defined as the impact of a health problem, and can be measured by indicators such as cost-of-illness, mortality or morbidity. The latter two are often combined and represented by Disability Adjusted Life Years (DALYs). Since aflatoxin is a genotoxic carcinogen there is no safe level of exposure, thus a tolerable daily intake (TDI) cannot be determined. Instead, a margin of exposure (MOE) approach can be used in the risk assessment, defining the difference between estimated intake levels (EDI) and the lower confidence limit of the benchmark dose (BMD) related to cancer induction (BMD/EDI).

Ingestion of aflatoxins via food can lead to both acute and chronic toxic effects in humans, depending on the concentration of aflatoxin in the diet. Long-term exposure to sub-acute concentrations of aflatoxins are related to various adverse health effects in humans. Particularly, the development of hepatocellular carcinoma (HCC) is related to chronic aflatoxin intake. It is well documented that people who are chronically infected with the hepatitis virus B (HBV) or C (HCV) are at high risk to develop hepatocellular carcinoma even when exposed to low concentrations of aflatoxins. There is an "extremely strong association between high AF-alb levels of aflatoxin-albumin adducts (AF-alb) in blood serum and stunted growth in children" (Gong et al., 2003).

Biomarkers can give an indication of exposure of a person to a certain mycotoxin at a certain time. The level of exposure can be estimated form the biomarker concentration only when the transfer rate (intake versus excretion) is validated in studies. Biomarkers of exposure can be measured in blood plasma and urine. There are no validated biomarkers of effect. In plasma, "AFB1-lysine is the most reliable biomarker of chronic aflatoxin exposure" (Vidal et al., 2018). Urinary biomarkers are more suitable for measuring short-term exposure.

\section{Economic effects of aflatoxins}

In published studies that focus on the economic effect of aflatoxin, the situation of aflatoxin is usually described, but not quantified. Some early studies investigated the effect of aflatoxin contamination in Africa and the measures imposed by developed countries, namely the legal maximum levels for aflatoxin in the European Union. Wilson and Otsuki (2001) estimated an annual loss amounting to USD 670 million for African food exporters from attempting to meet EU aflatoxin standards.

The cost of disease burden can be measured in the value of statistical life (VSL). However, the lack of data available on Africa restricts the analysis. At best, the health economic effect and the trade effect are estimated, but the production effect, the costs and overall loss for the economy were not determined due to the lack of data.

\section{Mitigation measures}

Prior to the period covered by the systematic bibliographic searches, various accounts of mitigation measures being implemented or developed specifically for African countries were already given. For peanut, breeding efforts towards resistance to Aspergillus infection and aflatoxin formation were well under way, yet total resistance still needs to be achieved. Another agronomic measure to prevent 
aflatoxin contamination in the field is 'biocontrol' through the use of non-aflatoxigenic mould strains that compete with Aspergillus for the same niche but that do not form aflatoxins.

Other agronomic measures already being tested and further elaborated in more recent years include for instance: crop rotation and chemical and biological control with pesticides or natural enemies to prevent pest insect damage that may facilitate mould infection as well as control of moulds. Further post-harvest measures include: drying of harvested seeds or grains and sorting and fractionation (e.g. flotation) of harvested seeds or grains. In addition, awareness raising, good practices for agricultural and hygienic food production, as well as regulation and enforcement have been forming part of contamination-mitigating strategies. Mitigation may also focus on preventing the health effects caused by aflatoxins in consumers.

\section{Methodology}

A systematic literature review is a 'structured process of review synthesis'. Systematic literature reviews rely on the following core principles: (i) systematic approach; (ii) reproducible; (iii) rigorous reviewing of literature; (iv) including the quality of studies when drawing conclusions. Compared to the narrative type of literature review commonly performed within research projects, systematic literature reviews have several benefits, including that a well-defined methodology reduces bias. The current literature review covered the period 2010-2018.

The guidelines for the qualified application of systematic review by the Evidence for Policy and Practice Information and Co-ordinating Centre (EPPI centre, University of London) and the Cochrane Handbook for Systematic Reviews of Interventions were followed. In particular, the software tool for systematic reviews designed by the EPPI, University of London was used.

For each research question, a search strategy was developed for identifying relevant studies. Bibliographic scientific databases (i.e. CAB Abstracts, Scopus, PubMed, AGRIS, EconLit) were searched for potentially relevant publications. Search terms originated from personal knowledge, searches on websites, screening key (review) papers, and screening the results of preliminary searches in bibliographic databases. In order to verify whether the use of the search queries indeed enabled retrieval of relevant references, the outcomes of preliminary searches with these queries were compared to benchmark collections. Collection of relevant references from the selected sources was done by use of Endnote reference citation management software. In addition to these searches for peer-reviewed literature, additional literature on economic effects was identified via 'snowballing', which refers to using the references of relevant studies with the aim to identifying further studies.

Inclusion and exclusion criteria were pre-defined and applied to the screening in order to ensure that relevant studies were identified. Outside of the scope of this study were studies: not written in English; not on aflatoxins (e.g. on other mycotoxins); not conducted in Africa; and studies focusing on general health effects of aflatoxins.

The screening resulted in a list of studies that are relevant for answering one or more the four research questions of the systematic review, and only those studies were assessed in detail. These studies were classified in order to create systematic maps of categories of studies that are part of the database. For instance, by assigning all studies on biomarkers to a specfic sub-category within the category disease burden. For the coding, a "questionnaire" was applied to the studies. In essence, using the key wording and coding, a high level understanding about the nature and contribution of the research was achieved. 


\section{Map of available literature}

In total, 6.374 references were collected. Of these, 2.467 studies (39\%) were published in the considered period of 2010 to 2018. After de-duplication; pre-screening; subsequent screening on title and abstract; and finally screening on full-text. A total of 361 studies was found to be relevant for synthesis. An overview of the subsequent steps followed in this project, and the respective number of identified studies per step, is shown in Figure 1 below.

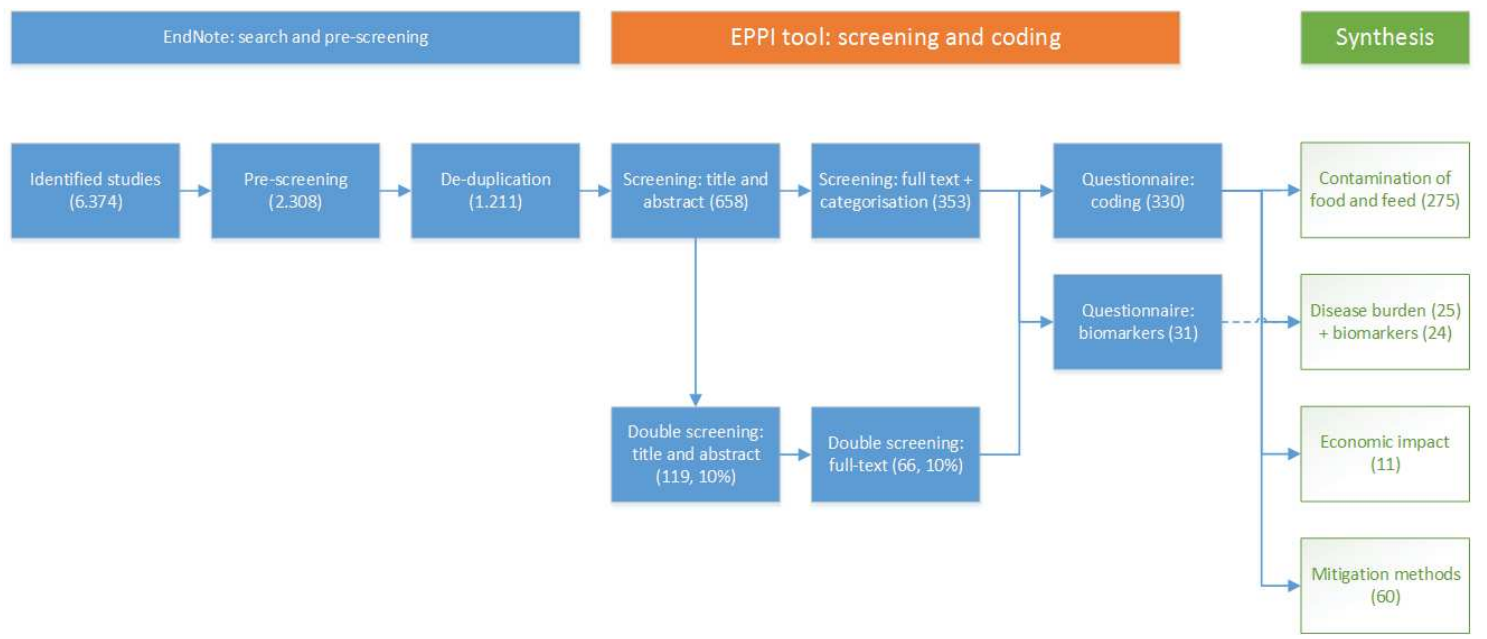

Figure 1: Overview of steps conducted in systematic review.

\section{Scale and geographic spread of aflatoxin contamination}

In total, 275 identified studies investigated the occurrence of aflatoxin in food and feed in Africa. Included studies were frequently for Nigeria (56 studies), followed by Egypt (41), and Kenya (33). Studies on food or feed of interest reported on sampling throughout the supply chain. Around half of the studies investigated products that were already processed and/or on the market (152 studies), while 69 studies reported the contamination on harvested or stored commodities. Samples from plants, and food and drinks for human consumption were most frequently reported in the included studies; accounting for $48 \%$ (plants, 132 studies) and $43 \%$ (food and drink for human consumption, 118 ) of the studies. Various analytical methods were used for aflatoxin detection. In general, the use of immunochemistry methods such as ELISA, dip stick test, sensor ( 82 studies, 30\%) and liquid chromatography (HPLC) $(85,31 \%)$ with fluorescence detection or post-column derivatization were most commonly reported, followed by detection using LC-MS (48, 17\%) and TLC (33, 12\%).

\section{Disease burden}

A total of 25 studies addressing disease burden were identified. An additional 24 studies focused on biomarkers. Most studies on disease burden were from Egypt, followed by Nigeria and Kenya. Most of the included studies focused on infants and children. Around 50\% (12) of the studies investigated consumption of plant-based foods (cereals, groundnuts, etc.), dairy products and breast milk (26\%), and other type of foods such as weaning food, meat, and food in general. Several included studies investigated disease symptoms in humans, most of them on hepatocellular carcinoma (33\%) and growth impairment in children (38\%).

Of the 24 included studies specifically for biomarkers, nine focused on urinary biomarkers and 17 on biomarkers in serum (e.g. AF-albumin adduct). The route of exposure for the biomarker studies was mostly via plant foods (e.g. peanuts, cereals, etc.).

\section{Economic impact}

In total, only 11 peer reviewed articles could be found related to the economic impact. Four of these included studies concerned results from Kenya. An econometric estimation was made in one study. Two studies measured the impact at firm level by assessing productivity losses due to contamination; four measured this via costs of managing aflatoxin at the farm level with regard to compliance costs. 


\section{Mitigation measures}

A total of 60 peer reviewed papers were related to mitigation measures, many of which were reported for Kenya (13), followed by Nigeria (9) and Egypt (7). The operators studied were largely small scale: smallholder farms, village processing, local middlemen and vendors, etc. Most mitigation measures from the included studies focused on agricultural (16) or biological (12) measures. The impact of mitigation measures in the included studies was described in varying manners. For six studies, the impact was described in monetary value, while many others did not quantitatively address the effectiveness of the mitigation measure. The cost-effectiveness expressed as investment per benefit gained (e.g. USD/DALY) was described in only a single study, which assessed the impacts of aflatoxin contamination of maize and groundnut in Tanzania and Nigeria on agriculture \& food security, trade, and public health (Narayan et al., 2014).

\section{Results}

\section{Scale and geographic spread of aflatoxin contamination}

AFB1 was the most studied aflatoxin for all countries, followed by B2, G1, and G2, which are usually analysed together with AFB1 by using a multi-toxin analysis. In 27 studies, AFB1 was quantified in various products, with maize as the most frequently studied product in nine publications. Almost all studies indicated mean AFB1 levels in maize exceeding $5 \mu \mathrm{g} / \mathrm{kg}$, which is the legal limit for AFB1 in the EU. Six included studies that investigated peanuts, found the AFB1 contamination concentrations in peanut to be relatively high $(>15 \mu \mathrm{g} / \mathrm{kg}$ ), with samples from Algeria only having a mean concentration of $6.3 \mu \mathrm{g} / \mathrm{kg}$. The highest mean AFB1 was recorded in maize from Egypt; as high as $440 \mu \mathrm{g} / \mathrm{kg}$.

Nine out of eleven countries conducting studies on AFB1 had contaminations being high to very high. Sudan and Tunisia were the only studied countries with a very low levels of contamination. Maize and peanut tend to be heavily contaminated. Animal feeds also tend to have high levels of contamination as shown by studies in Ethiopia, Kenya, and Nigeria. With regard to AFM1, only four studies reported concentrations in milk. One study on milk samples in South Africa showed concentrations above 0.5 $\mu \mathrm{g} / \mathrm{kg}$ (the maximum limit set by CODEX). Mean concentrations reported from other countries, i.e. Morocco, Ethiopia and Kenya were below $0.5 \mu \mathrm{g} / \mathrm{kg}$. Notable is that for Egypt and Kenya, the included studies focused largely on processed / retail / marketed products. The part of the production chain (e.g. at the farm or in retail) studied is more evenly distributed among studies conducted in Nigeria.

\section{Disease burden}

Havelaar et al. (2015) was the only study that estimated disease burden expressed as DALYs. For all global sub-regions used by WHO for the global assessment of disease burden, the median rates for aflatoxin related DALY varied between 0.04 to 28 DALY per 100,000 population. Almost all countries report the burden of aflatoxin as premature mortality (YLL), and that the burden of aflatoxin lays in the group older than 5 years of age. Aflatoxin was considered an important hazard with a high disease burden in the sub-region AFR-D, which mostly encompasses West Africa. In that area, the median rates of aflatoxin related DALY per 100,000 population were 28 (7-78), while for East Africa (AFR-E), this was $3(1-8)$.

Four included studies focused on disease burden expressed as the risk of adverse health effects resulting from exposure to aflatoxins via food. All of these studies described a partial risk assessment on aflatoxins in food in the respective regions. They all concluded that the risk of aflatoxin warrants policy interventions.

\section{Economic impact}

Only a few relevant peer reviewed studies that estimate the economic impact of aflatoxins in Africa were found. Data needed is not readily available, and collecting the data necessary for gauging the economic impact is costly and not straightforward. This complexity of economic analyses may add to the explanation of the gap in the literature.

The trade-related impact of aflatoxin contamination is mainly evaluated from the standpoint of how stringent aflatoxin regulation (mainly EU legal limits) affects products imported from developing 
countries, including Africa. One finding showed that even when adopting the limits advised by CODEX (that are more lenient than EU standards), 83\% of African exporters were still non-compliant. Thus, even a less strict legal limit might not cause a better impact for groundnut trade from Africa to the EU.

Considering the firm-level impact for the peanut marketing chain, the purchase price, selling price, and storage cost were considered as the most important factors contributing to business revenue. Thus, an economic incentive was deemed very important for the chain actors to adopt measures to reduce aflatoxin level in the peanut products. The willingness to pay for the products produced with AflaSafe ${ }^{\circledR}$ (a biocontrol strategy to mitigate aflatoxin contamination) was equal or larger than the original price of the product. Lack of awareness and usage experience were considered as the main reasons why farmers did not want to pay. Two studies investigated the awareness of consumers to aflatoxin contamination and estimated the willingness to pay for aflatoxin-free products in Kenyan market. Both studies showed that consumers were interested in aflatoxin-free certified products, specifically milk (average WTP of $9.7 \mathrm{kSh} /$ litre) and maize (clean-untested maize for $31 \mathrm{KSh} / 2 \mathrm{~kg}$ ). Based on an assessment of end market, regulation, and awareness levels; aflatoxin-related health problems contributed the largest impact of aflatoxin contamination.

\section{Mitigation measures}

For mitigation of mycotoxin contamination, a wide range of options at the various stages of food production, consumption and the general population are available. Measures specifically applied to the African situation in the included studies were divided into the following categories, according to the chain-step in which the intervention was tested: plant breeding, agricultural practices, post-harvest storage, processing, and reducing availability of aflatoxin from food and feed by the use of binders.

Various studies indicated that selection of maize and other crop varieties for resistance to fungal infection, by using 'kernel infection rate' as a selective criterion, has started to take off in Africa. In addition, several studies indicated the enhanced effectiveness against mould infection and mycotoxin formation of a combination of fertilizer regime with the planting of resistant varieties. At the farm stage before harvest, studied effective measures described for Africa in literature include the use of non-aflatoxigenic fungal strains, also including strains that have been locally sourced, which will compete with the ones forming aflatoxin and therefore resulting in an infected crop with relatively low levels of Aflatoxin. Findings also suggested a correlation between a reduced aflatoxin contamination of maize and various agronomic practices, such as time of planting seeds, non-mechanical weed removal, and use of insectides.

Post-harvest measures that were successfully applied to reduce aflatoxin contamination of maize, sorghum and peanut include drying of the harvested product above ground or on particular surfaces, or sorting out of visibly contaminated kernels or other products, and ventilated storage. In addition, storage of cereals and groundnuts in certain types of plastic bags (PICS, polypropylene) has been shown to help reduce post-harvest aflatoxin formation. A wide variety of processing techniques, depending on the product in question, can be applied to effectively mitigate aflatoxin formation, as shown in several of the included studies. Several studies also indicated that combinations of processing techniques can further reduce mycotoxin contamination, such as cooking or fermentation combined with chemical treatment (ammoniation, oxidation). Examples of techniques, of which effectiveness was demonstrated in multiple studies, include roasting and decortication of groundnuts/peanuts, and various forms of microbial fermentation, such as of various local, maize gruel/porridge or yoghurt fermented with lactic acid bacteria. The experimental use of binders, particularly clay, has shown to help in reducing availability of aflatoxins from food and feed. Use in food appears to reduce the level of aflatoxin biomarkers, but potential side-effects are unknown. Most studies on the effects of binders in feed focused on aqua-feed for cultured fish. Interventions substantially reduced aflatoxin contamination as compared to the positive control fed AFB1-tainted diets. In addition, fast detection methods such as immunochemical tests (e.g. dipstick) and thin-layer chromatography may be used in local settings for screening for potentially contaminated samples, prior to the technically more demanding confirmatory laboratory analyses if needed. 


\section{Discussion}

Scale and geographical spread of aflatoxin contamination in food, feed, and associated commodities/key value chains

The included studies reported most commonly on the commodities maize and peanuts, and animal feed - which are generally the products most commonly associated with aflatoxigenic mould contamination in Africa. All studies indicated mean AFB1 in maize $>5 \mu \mathrm{g} / \mathrm{kg}$ which is over the EU legal limit for AFB1. The results imply that reduction of overall aflatoxin levels in food and feed in Africa is still a major challenge. The included studies give insight in the geographic areas and foods that were studied, but extrapolation or generalization of specific results to other areas is difficult.

A large number of the included studies was assessed to be relevant for the question on scale and geographical spread of aflatoxin contamination in Africa, but a much smaller number of studies gave quantitative results (36). Included studies were frequently for Nigeria, followed by Egypt, and Kenya. Although the included studies do give insight in the studied areas and foods; there is a lack of prevalence studies in certain countries.

\section{Scale of aflatoxin disease burden}

Populations in Africa can be exposed to high concentrations of aflatoxin via food, causing acute aflatoxicoses, even to this day. For various reasons it is likely that this problem might be larger than described since diseases in the developing world may often go unreported, thus the described cases in the included studies on acute toxicity may represent only a portion of the problem. Incidents in Kenya and Tanzania with human fatalities in 2004 and 2016 were analysed by specialised investigation teams and lessons learned were published. This approach should be encouraged and will contribute significantly to early warning systems, and prevent fatalities.

Diseases related to chronic aflatoxin exposure may result from more causes and/or diseases can be enhanced when people are chronically exposed to aflatoxins, which complicates the estimation of the disease burden. This systematic review did reveal relatively many studies on biomarkers for aflatoxins. Although biomarkers may give a good indication of current and recent exposure to aflatoxins, they do not relate to the source or exposure earlier in life. Biomarker studies may be useful to study the impact of mitigation strategies, however.

\section{Economic effects of aflatoxins}

In general, little evidence was found in this systematic literature review on the economic effects of aflatoxin contamination and a conclusive result on the trade-related impacts of aflatoxins regulations for African exporters could not be determined. In general, the limited number of studies estimating economic impacts of aflatoxins contamination points out a gap in literature. The bottom line in this literature gap is the lack of available data for the estimations, particularly for health-related impacts.

At the country level, most economic impacts studies were conducted in Kenya. According to the results of multiple studies in this review, economic incentives are needed to reduce aflatoxin contamination and, subsequently, aflatoxin exposure to humans. Two studies in Kenya showed that awareness level of consumers and occurrence of aflatoxicosis in their region increased their willingness to pay for aflatoxin-free products. At the same time, awareness on reducing aflatoxins should also be built in producers' side to stimulate them implementing mitigation measures. Moreover, the additional costs of reducing aflatoxins should be equally distributed along the chain rather to put the burden on one side, for example, producers or consumers only.

\section{Mitigation measures}

Considering mitigation strategies, the systematic review further highlights the multitude of methods and stages from farm to fork, at which the contamination, exposure and adverse effects can be prevented, mitigated or reversed. Proof of cost-effectiveness, or even only the costs of the practices, appear to be lacking. Many included studies were on the use of 'biocontrol' agents, particularly the AflaSafe ${ }^{\circledR}$ product currently being applied to maize cultivation - but it has certain drawbacks, such as the need for yearly application. Other promising developments aiming at mitigation of aflatoxin 
contamination at various stages of the supply chain were identified. Dietary diversity to mitigate mycotoxin exposure should be encouraged.

\section{Conclusion, knowledge gaps and recommendations}

In this study, evidence from systematic literature review shows that different research areas have been covered by the four subtopics of contamination, economics, disease burden, and mitigation; illustrating the diversity of aspects of aflatoxin contamination of human food and animal feed. Given the results of this study, it is apparent that aflatoxins are a multi-faceted problem with a large contribution to a variety of negative health effects with high impact on society. This report underpins the need for effective management of the aflatoxin situation in Africa, in line with numerous previous reports [e.g. (Okoth, 2016; Udomkun et al., 2017; Wild et al., 2016)]. A number of mitigation measures have been developed, both on the production side to reduce contamination, and on the consumer side to reduce or mitigate the effects of exposure. It is clear however that aflatoxin levels in food and feed are too high, and the priority should therefore be to reduce these levels substantially.

Some general inferences can be drawn across the four subtopics. Much of the data for aflatoxins in Africa reported in the included studies in the last 10 years, were executed in studies in three countries, namely Egypt, Kenya, and Nigeria. With regard to the disease burden caused by aflatoxins; this cannot be easily estimated. A holistic approach focusing on a combination of co-occurring mycotoxins and other contaminants, rather than an isolated strategy, is required to increase the total quality of life. Many of the retrieved studies focusing on economic impacts focused on exportability of produce to the European Union in the light of the legal limits set there, or more generally on Codex Alimentarius limits. Given that much of the trade is intra-African, and also other markets besides the EU are being catered to, such as Asia and the Americas, it would be useful to have a more global broader view on the trade impacts.

For mitigation measures, the success may be measurable both in the short and long-term, given that, for example, the health impacts can be acute (aflatoxicosis) as well as chronic (e.g. liver cancer). The contribution to the latter may be difficult to establish, although it is conceivable that any measure reducing the exposure to aflatoxins will ultimately result in a decrease in disease burden. There is a broad range of mitigation measures that are possible, and have been tested. However, a limited number of these measures is practically feasible for small farmers and downstream chain actors up to rural households. These measures include, for example, using resistant plant varieties, bio-control agents, hand-sorting, and fermentation of food products. Moreover, only few publications have comprehensively considered the cost-effectiveness of measures, which makes it difficult to compare them. We therefore recommend research on the cost-effectiveness of intervention measures so that available resources can be directed as efficiently as possible. 


\title{
1.1 Framework as provided by the project sponsor
}

\begin{abstract}
Aflatoxins thwart Africa's efforts at achieving food security, improving nutrition and health outcomes and attaining agricultural-led economic growth. Aflatoxins are highly toxic fungal metabolites produced by certain strains of Aspergillus flavus and related Aspergillus species. They pose major risks to nutrition and human health as well as intra-regional and international trade. The difficulty African producers, traders and manufactures face in sourcing quality raw materials and producing high quality products (fresh and processed that meet local, regional and international standards for aflatoxin levels) hampers agribusiness development, job creation and economic growth. This unacceptable status quo makes the attainment of the UN Sustainable Development Goals (SDGs), especially as they pertain to food security, more challenging. They also undermine continental priorities such as the Malabo Declaration Commitments of 2014 of the African Union.
\end{abstract}

A recent report on "Improving the Evidence Base on Aflatoxin Contamination and Exposure in Africa: Strengthening the Agriculture Nutrition Nexus" was launched by CTA and PACA in November 2016. The report identified the challenges of aflatoxin contamination and mitigation in Africa. Contamination has been reported in fresh and processed cereals, including maize, nuts mainly groundnuts, and many other crops and crop products as well as in fish and animal products. This report will serve as a consolidated source of much needed information for users in Africa and beyond. However, the report was limited to a desk study of available literature and didn't critically address the issues for attracting increased investment towards more effective management of the aflatoxin challenge.

Critical knowledge gaps include: the actual or estimated monetary losses of rejections or lost trade in local, regional and export markets; the loss of income for producers and processors; the level of poverty, food insecurity and malnutrition as linked to aflatoxin contamination; and the costs of managing aflatoxins in the African continent. In addition, cost-benefit estimates for aflatoxin mitigation measures, including context-specific and regional approaches which have already ben piloted have direct practical application. Such high level quantitative data and assessments are crucial for informing decision-makers and mobilizing investments for sustainable mitigation of aflatoxins.

\subsection{Objectives}

The aim of this project was to obtain insights into quantitative peer reviewed data on the aflatoxin situation in Africa. These insights can be used to enhance effective management of the major challenges to combat aflatoxin contamination. Major components of the project were: a) estimating impact of aflatoxins including scale of the disease burden, and; b) economic impact; c) understanding the possible mitigation measures, their contribution to reduction of aflatoxin contamination and its associated impacts, and their cost-effectiveness; and d) generating evidence maps and evidence gap maps, where possible. In addition to enhance effective management of the situation, the identification of research gaps in these areas can assist in setting a future research agenda. Therefore, a systematic literature review was conducted in such a way to be as transparent and reproducible as possible.

Overall, this review is expected to replace some of the obsolete, arbitrary, and at times misleading figures on the impact of aflatoxins. Where reliable estimates exist, this work updates and builds upon those estimates. 


\subsection{Research questions and scope}

The following research questions have been defined to guide the review process:

1. What is the scale and geographical spread of aflatoxin contamination in food, feed, and associated commodities/key value chains, in African countries?

2. What is the scale of aflatoxin disease burden for African countries?

3. What are the economic effects of aflatoxins on African countries?

4. What are the existing and possible mitigation measures and what is the cost-effectiveness of mitigation of aflatoxin contamination in key commodities / value chains in African countries?

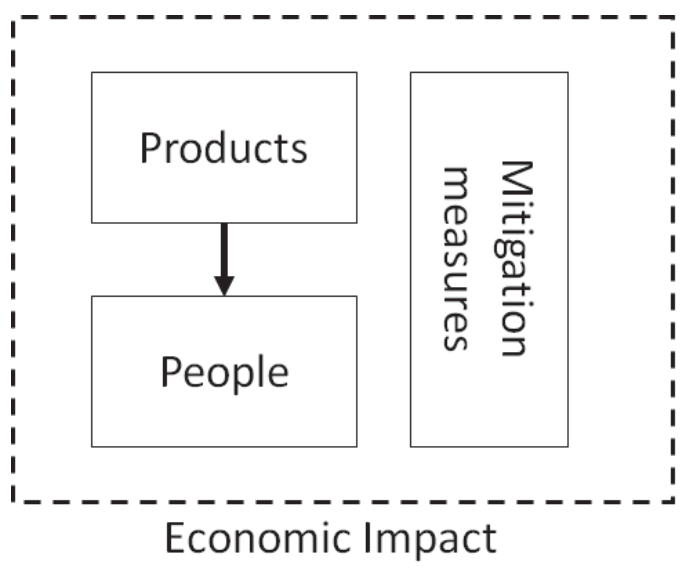

\section{Figure 2: Visual representation of the relation of the four research questions.}

The relation between these research questions is illustrated in Figure 2. In essence, research question \#1 focuses on the contamination of products, and question \#2 on the impact this contamination has on the people as far as diseases concern. Measures to mitigate both the impact on people as well as on products are assessed in research question \#4. The economic impact of all these factors was assessed: for the products and people in research question \#3, and for the mitigation measures (i.e. cost-effectiveness) in question \#4. In this manner, the full impact of aflatoxins on African countries was assessed.

\section{$1.4 \quad$ Structure of report}

This report consists of seven sections. In section 2, a background on the aflatoxin situation in Africa is presented. Described in this background are the results from benchmark studies from before 2010 and general information on aflatoxins in relation to the four research questins, from other literature reviews and 'grey literature' (i.e. not peer-reviewed literature). In section 3, the methodology of the systematic literature review is discussed. This section describes how the data was acquired, and extracted; and how the data was analysed and synthesised. The results are presented in two sections; section 4 includes a complete overview of the execution of the search strategy, screening, keywording, and data extraction steps. Also included are visual representations of the distribution of studies per category and key-words, per year of publication, and of the codes applied to the studies. Section 5 contains the technical output of the synthesis of results. All results are discussed in section 6. Finally, the conclusion, knowledge gaps, and recommendations are given in section 7. 


\section{Scientific background}

There have been various reviews published recently on various aspects related to aflatoxins in Africa (Darwish et al., 2014; Flores-Flores et al., 2015; Gibb et al., 2015; Shephard et al., 2013; Udomkun et al., 2017; Wild et al., 2016). However, most of these studies focus only on one aspect of the subject - e.g. geography, toxicity or social/economic impact. Udomkun and co-authors (Udomkun et al., 2017) have presented a study combining many of the aspects of interest, but only for the subSaharan regions (Udomkun et al., 2017). Finally, the effects and presence of aflatoxin contamination of foods in Africa are discussed in some reviews that discuss the occurence of multiple mycotoxins, rather than focusing only on aflatoxin [e.g. (Misihairabgwi et al., 2017; Wagacha \& Muthomi, 2008)].

\subsection{Scale and geographical spread of aflatoxin contamination in food, feed, and associated commodities/key value chains}

Widespread aflatoxin contamination of certain African staple foods, particularly maize, other cereals, groundnuts, and peanuts, had been reported prior to the year 2010, which marked the start of the period surveyed in this report. In general, these and other crops which are particularly vulnerable to Aspergillus infection and aflatoxin contamination showed high proportions of samples being positive, both in the raw commodity as well as derived and processed products. Various reviews summarized details of different studies on the aflatoxin contamination in Africa (Bankole et al., 2006; Darwish et al., 2014; Gnonlonfin et al., 2013; Misihairabgwi et al., 2017; Udomkun et al., 2017; Wagacha \& Muthomi, 2008). Results from Benin, Burkina Faso, Egypt, Cameroon, DR Congo, Kenya, Mali, Malawi, Morocco, Mozambique, Nigeria, Sierra Leone, Somalia, South Africa, Tanzania, Togo, Tunisia, Uganda, Zambia and Zimbabwe are highlighted by these reviews.

The incidence of aflatoxin contamination of commodities (both food and feed) was reported per region and per country by Okoth (2016), as well as by Darwish et al. (2014) for all mycotoxins. In a report by the International Livestock Research Institute (ILRI), the global prevalence of aflatoxins was mapped for the main associated commodities. They concluded that for maize, the prevalence is highest in Nigeria and Kenya (Atherstone et al., 2014). However, they also indicated that this mapping exercise highlighted a lack of studies on prevalence in other sub-Saharan countries - as the environmental conditions appeared to be favourable for mycotoxin contamination, yet the number of studies conducted in those countries was low.

For maize, a majority of samples was contaminated with aflatoxins in many of the surveys reviewed. Aflatoxin levels also commonly exceeded internationally established safe limits in a substantial fraction of the samples analysed. There were only a few reports of absence or very low levels of aflatoxins, namely in samples from Mozambiquan and Rwandan farmsteads and local markets (Probst et al., 2014), and both mould-infected and uninfected maize from South African subsistence farmers (Mogensen et al., 2011). Consumption of maize contaminated with excessive levels of aflatoxins accounted for large outbreaks of acute aflatoxicosis, particularly in Kenya in 2004 leading to morbidity and, in some cases, mortality. Of the maize sold in markets in the affected four districts, seven percent turned out to be contaminated with more than $1,000 \mu \mathrm{g} / \mathrm{kg}$ aflatoxin, with a maximum of $46,400 \mu \mathrm{g} / \mathrm{kg}$ (Lewis et al., 2005). In maize kept by affected households, the levels of aflatoxin were increased by an order of magnitude over controls, namely 355 versus $44 \mu \mathrm{g} / \mathrm{kg}$ (Azziz-Baumgartner et al., 2005). In another study in the same region of Eastern Kenya on maize samples from two subsequent outbreak years (2005-2006) and a non-outbreak year (2007), home-grown maize consistently showed higher levels of contamination over maize that had been purchased or that had been provided for relief (Daniel et al., 2011). The studies reviewed also showed that products derived from maize processing may retain aflatoxins. In Kenkey, which is a fermented and cooked maize 
dough product from two processing sites in Ghana, for example, aflatoxin levels reportedly reached up to $313 \mu \mathrm{g} / \mathrm{kg}$ (Kpodo et al., 1996).

In various African countries (Benin, Ethiopia, Malawi, Nigeria, South Africa, Togo, and Uganda), other cereals and derived products have been reported to contain aflatoxins, in particular sorghum, barley, millet, rice, teff, and wheat. Processed products such as wheat flour and beer brewed from sorghum malt showed aflatoxin contamination (Bankole et al., 2006; Darwish et al., 2014; Gnonlonfin et al., 2013; Misihairabgwi et al., 2017; Udomkun et al., 2017; Wagacha \& Muthomi, 2008).

For e.g. peanuts, inoculation with aflatoxigenic moulds occurs primarily in the soil, during the plant development stage in which the pod enters the soil and directly comes into contact with soil-borne Aspergillus. Following this, insect damage and plant stress facilitate infection of the seed and hence also aflatoxin contamination (Torres et al., 2014). In studies in various countries (e.g. Botswana, Kenya, Malawi, Nigeria Sudan, South Africa) prior to 2010, aflatoxins were identified in samples of raw materials as well as processed products, such as dry roasted nuts, peanut butter, peanut cake, and peanut oil, from farms, markets \& retail, whilst for the oil, the levels were relatively low (Bankole et al., 2006; Darwish et al., 2014; Gnonlonfin et al., 2013; Misihairabgwi et al., 2017; Udomkun et al., 2017; Wagacha \& Muthomi, 2008).

Cassava and derived products, such as flour and chips, generally show limited contamination with aflatoxins even in case of Aspergillus infection, with relatively rare cases of contents exceeding regulatory limits [e.g. (Misihairabgwi et al., 2017; Udomkun et al., 2017)]. Also other African food and feed products analysed prior to 2010 have shown contamination with aflatoxins, such as apple juice, spices, and animal feeds, as well as eggs and milk. The latter typically contains aflatoxin M1, a metabolite rendered by animal metabolism after aflatoxin uptake from feed and subsequently transferred to animal products (Darwish et al., 2014; Udomkun et al., 2017).

Regulations on maximum level of aflatoxins vary among countries worldwide, as shown in Table 1 below. Some countries such as the United States specify the level for total aflatoxins in food as maximum $20 \mu \mathrm{g} / \mathrm{kg}$, except for AFM1 in milk, without considering AFB1 level specifically. The EU has more rigorous and stringent limits among other countries by setting the maximum levels for AFB1 and total aflatoxins per product category. Findings of contaminant levels exceeding such limits will trigger regulatory measures, such as withdrawal of the product from the market, or products being rejected at the border. 
Table 1: Overview of aflatoxins regulations

\begin{tabular}{|l|l|c|c|c|c|c|}
\hline \multicolumn{1}{|c|}{ Product } & \multicolumn{1}{|c|}{ AF } & \multicolumn{5}{c|}{ Maximum levels $(\boldsymbol{\mu g} / \mathbf{k g})$} \\
\hline \multirow{2}{*}{ Maize } & AFB1 & CODEX & EU & US & Kenya & Egypt \\
\cline { 2 - 7 } & AF total & - & 5 & - & - & \\
\hline $\begin{array}{l}\text { Peanut } \\
\text { (groundnut) }\end{array}$ & AFB1 & - & $8^{\mathrm{a}} ; 2^{\mathrm{b}}$ & - & - & \\
\cline { 2 - 8 } & AF total & 15 & $15^{\mathrm{a}} ; 4^{\mathrm{b}}$ & 20 & 20 & \\
\hline Milk & AFM1 & 0.5 & 0.05 & 0.5 & - & \\
\hline Feed & AFB1 & - & 20 & - & & 10 \\
\hline & AF total & - & - & 20 to 300 & & 20 \\
\hline
\end{tabular}

$a=$ Groundnuts (peanuts), to be subjected to sorting, or other physical treatment, before human consumption or use as an ingredient in foodstuffs; $b=$ Groundnuts (peanuts) and processed products thereof, intended for direct human consumption or use as an ingredient in foodstuffs

Source: authors' compilation of EC No. 1881/2006 19 December 2006 for food; Directive No 2002/32/EC 7 May 2002 for feed; CODEX STAN 193-1995 last amendment 2017; CPG Sec. 683.100 for food and feed in the US; CPG Sec. 527.400 for milk in the US; Maximum levels in Egypt (in food Grace, et.al (2015); in maize Wu (2012)); maximum levels in Kenya (Nishimwe K et al, 2017); Mutegi et al (2009)).

Of a total of 55 countries in Africa, only 15 countries have regulations on aflatoxins level (PACA, 2013). Meanwhile CODEX only set a maximum AF level for peanut, tree nuts, and dry figs products. Some countries refer to EU regulation to set the limit for consumption. Generally, if no maximum level is set in African countries or CODEX, the EU standard is used as a benchmark (the most stringent standard), taking into account that aflatoxins are carcinogenic substances and levels should therefore be as low as reasonably achievable.

\subsection{Scale of aflatoxin disease burden}

Disease burden is generally defined as the impact of a health problem, and can be measured by indicators such as financial costs of illness, mortality or morbidity. The latter two are often represented by Disability Adjusted Life Years (DALYs) (Havelaar et al., 2015). DALY are estimated by adding the number of years lost due to the disease (YLLS) and the number of years a person lives with disability caused by the disease (YLD). Since one DALY represents the loss of one year of life lived in full health, diseases causing death or disabilities at a young age will have a significant impact in the ratings using DALY. DALY are relevant for comparing severity of hazards and can be useful as guideline for public health policy making. Disadvantages are that it requires large amounts of data on mortality and morbidity and results are difficult to interpret when diseases have multiple causes.

Disease burden can be evaluated via risk assessments. The outcomes are evaluated for regional diets for exposure and give policy makers an indication if mitigation actions are required. Since aflatoxin is a genotoxic carcinogen, there is no safe level of exposure, thus a tolerable daily intake (TDI) cannot be determined. Instead, a margin of exposure (MOE) approach can be used in the risk assessment, defining the difference between (estimated) intake levels (EDI) and the lower confidence limit of the benchmark dose (BMD) related to cancer induction (BMD/EDI) (Adetunji et al., 2017; Azaiez et al., 2015).

Acute intoxications after ingestion of aflatoxins with large numbers of fatalities are described for India (Krishnamachari et al., 1975), Malaysia (Lye et al., 1995), Kenya (Azziz-Baumgartner et al., 2005) and recently for Tanzania (Kamala et al., 2018). Cases had symptoms of impaired gastrointestinal system and acute liver failure, causing death. The most recent incidents occurred in households consuming 
home grown crops, unusual weather conditions during cropping season (severe drought and/or heavy rains at harvest) and poor post-harvest storage conditions.

Long-term exposure to sub-acute concentrations of aflatoxins are related to various adverse health effects in humans. Particularly, the development of hepatocellular carcinoma (HCC), is related to chronic aflatoxin intake (Probst et al., 2007; Udomkun et al., 2017; Yard et al., 2013). It is well documented that people chronically infected with the hepatitis virus B (HBV) or C (HCV) are at high risk to develop hepatocellular carcinoma when exposed to even low concentrations of aflatoxins (Kensler et al., 2011; Palliyaguru \& Wu, 2013; Wogan et al., 2012). Chronic exposure to aflatoxins also has an adverse effect on the immune system (Jiang et al., 2005; Shephard, 2008b; Wild et al., 2016). This causes a decreased resistance of the host to (food borne) infections and may adversely affect immunisation (Jiang et al., 2005; Kumar et al., 2017).

There is an "extremely strong association between increased AF-alb levels in blood serum, as a result of exposure to high levels of aflatoxin [exposure], and stunted growth in children". (Gong et al., 2003). Aflatoxins are negatively related to the growth of children by disturbing nutrient uptake (stunting), resulting in impaired height-for-age z-score (Smith et al., 2012; Umesha et al., 2017; Voth-Gaeddert et al., 2018). The relation between aflatoxin and impaired growth of children was established for situations in Africa and Guatemala but could not be established in Nepal (Mitchell et al., 2017). The mechanisms are not clear at this moment.

Biomarkers can give an indication of exposure of a person to a certain mycotoxin at a certain time or at a short time before the moment. Monitoring biomarkers can give insight in the effects of mitigation strategies, thus in changes in intake. The level of exposure can be estimated from the biomarker concentration only when the transfer rate (intake vs excretion) is validated in studies. Vidal et al. (2018) reviewed mycotoxin biomarkers of exposure. They indicate that "AFB1-lysine is the most reliable biomarker of chronic aflatoxin exposure in plasma". Other biomarkers of exposure are AFBN7-guanine in urine, and some others in urine, which are more suitable as a measure of short-term exposure. It cannot be excluded that persons with impaired health have a different transfer rate.

Children in many African countries are exposed to aflatoxins from the very early stages of life (Akbari et al., 2017; Wild et al., 2016). Aflatoxin B1 can be transferred to milk as the metabolite aflatoxin M1 and even cross the placenta barrier (Castelino et al., 2014). DNA adducts detected in cord blood samples of new born children shows exposure to aflatoxin M1 in utero (Groopman et al., 2014; Hernandez-Vargas et al., 2015). Infants consuming breast milk or milk from farm animals are thus exposed to aflatoxin M1 (Diaz \& Sánchez, 2015; Flores-Flores et al., 2015; Groopman et al., 2014; Guerre et al., 2000; Ortiz Martinez et al., 2016; van der Fels-Klerx \& Camenzuli, 2016). As soon as infants receive other foodsources, such as porridges, etc., there is a risk of being exposed to aflatoxins in addition to the earlier and/or simultaneous risk of exposure to aflatoxin M1 via (breast-)milk) (Gong et al., 2002; Gong et al., 2003; Gong et al., 2004).

\subsection{Economic effects of aflatoxins}

Estimation of economic impacts due to aflatoxin contamination in food and feed is an extensive area of research. This particular topic extends from primary producers to consumers side. Losses as implications of failure to meet importing countries' standard can be estimated in various functions, such as export losses due to border rejection (see $\mathrm{Wu}, 2004$ ). These are both economic losses in terms of value (including the fee that needs to be paid for the disposal of the contaminated products) and quantity losses. If a contaminated product can be sold on the market, the price for the contaminated product can be expected to be lower. In this case the prices could be used to estimate the economic loss due to aflatoxin contamination by comparing the price for products with and without aflatoxin contamination. When quantifying the losses due to aflatoxin contaminations, the compliance costs incurred by farmers, processors, and government to comply with aflatoxin regulations would need to be added. Such compliance costs are related to mitigation measures applied and expected to yield more profits compared to without mitigation. 
Different types of economic impact are measured in different ways and cannot be compared if not measured in the same manner. The economic impact is usually given in monetary terms (e.g. USD) as the value of products lost due to aflatoxin. The loss could also be expressed in terms of

volume/quantities, but usually the value is provided. That means that the quantity loss is evaluated at the market price of the respective products in order to provide an approximation of the monetary loss. Other economic indicators, such as productivity losses due to health issues caused by aflatoxin are more complex. The costs related to preventing and mitigating measures of aflatoxin are usually expressed in monetary terms, like costs of a certain technology that prevents aflatoxin.

This study focuses on the effects of aflatoxin contamination in Africa or measures taken in Africa. However, the effect due to preventive measures in other countries or at trade partners, namely the EU, are also considered. The economic impact for Africa can be considered threefold:

1) trade-related impact that determines if a product can be sold internationally, for example, exports of African products to trade partner countries, measured in terms of trade loss, and

2) firm-level impact in terms of costs of production to avoid aflatoxin contamination by mitigation measures or compliance to high standards;

3) Health impact leading to economic costs (cost of illness).

Some early studies investigated the effect of aflatoxin contamination in Africa and the measures imposed by developed countries, namely the residue levels for aflatoxin in the European Union. For example, Otsuki et al. (2001a) estimated an annual loss amounting to USD 670 million for African food exporters from attempting to meet EU aflatoxin standards. Looking at exports from EU partner countries, 21 of them developing countries, they find that a worldwide international standard for aflatoxin (B1) would increase nut and cereal trade by about USD 6.1 billion, compared with 1998 levels. Extrapolating the results for the world, the agreement on an international aflatoxin standard would lead to additional exports of USD 38.8 billion.

The key insights on the economic effect are summarised in Table 2. These studies systematically investigate the effect of aflatoxin by collecting the data in the respective country and following the same methodology. Specifically, they follow the measurement of the value of statistical life provided by OECD (2011). While designed to quantify the economic impact of aflatoxin in the respective countries under review, the lack of data available restricts the analysis. At best, the health economic effect and the trade effect are estimated, but the production effect, the costs and overall loss for the economy are not determined due to the lack of data. The details of the calculation method for VSL and other units of measurement are elaborated in Annex 1. 


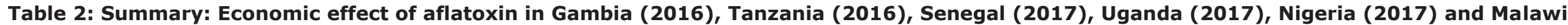
(2017)

\begin{tabular}{|c|c|c|c|c|c|}
\hline \multirow[t]{2}{*}{ Country } & \multirow[t]{2}{*}{ Crops } & \multirow[t]{2}{*}{ Exposure } & \multicolumn{2}{|l|}{ Economic effect } & \multirow[t]{2}{*}{ Comments } \\
\hline & & & $\begin{array}{l}\text { Health economic effect } \\
\text { DALYs = measure of disease burden expressed } \\
\text { in number of healthy life years lost due to } \\
\text { death/disability caused by a disease; } \\
\text { VSL = monetized life lost }\end{array}$ & Trade effect & \\
\hline Gambia (2016) & $\begin{array}{l}\text { Maize, } \\
\text { groundnuts, rice }\end{array}$ & $\begin{array}{l}\text { For groundnuts: } \\
\text { total number of cases of } \\
\text { liver cancer per year: } \\
160 \\
\text { Population risk for liver } \\
\text { cancer per year: } 100\end{array}$ & $\begin{array}{l}\text { Estimated annual heath impact due to death } \\
\text { with liver cancer: } \\
\text { Low: } \$ 5,874,080 \\
\text { High: } \$ 22,457,600 \text {, } \\
\text { i.e. } 0.6-2.2 \% \text { of GDP, respectively. }\end{array}$ & $\begin{array}{l}\text { In } 2012-2015,14 \text { rejections of exports of HPS } \\
\text { bird feed groundnuts due to high aflatoxin } \\
\text { contamination levels above the EU maximum } \\
\text { level allowed. } \\
\text { Total trade loss calculated: } 416 \text { million tons, } \\
\text { which are USD } 72,000 \text { using the respective } \\
\text { price }\end{array}$ & $\begin{array}{l}\text { The trade effect is calculated by taking } \\
\text { the difference in revenue that would } \\
\text { have been earned from selling HPS } \\
\text { Bird feed groundnuts and the actual net } \\
\text { revenue earned from selling crushed dil } \\
\text { and cakes that were produced from the } \\
\text { returned consignments }\end{array}$ \\
\hline $\begin{array}{l}\text { Tanzania } \\
\text { (2016) }\end{array}$ & $\begin{array}{l}\text { Maize, } \\
\text { groundnuts, rice }\end{array}$ & $\begin{array}{l}\text { Average of cases of } \\
\text { liver cancer: } 3334 \text {, with } \\
\text { about } 3167 \text { lethal }(95 \%)\end{array}$ & $\begin{array}{l}\text { Annual DALYs: } 96,686 \text { (year: } 2014) \\
\text { VSL, with the income elasticities in brackets: } \\
\text { (Elasticity }=1) \text { : } \\
\$ 263,767,554 \\
(\text { Elasticity }=1.5): \$ 40,572,960 \\
(\text { Elasticity }=2): \\
\$ 6,240,969\end{array}$ & - & $\begin{array}{l}\text { The exposure to aflatoxin was } \\
\text { measured by bio-markers. Different } \\
\text { income elasticities are considered so as } \\
\text { to provide a range of possible values } \\
\text { for VSL. }\end{array}$ \\
\hline Senegal (2017) & & $\begin{array}{l}\text { Average number of } \\
\text { cases of liver cancer: } \\
1213 \\
\text { Deaths due to liver } \\
\text { cancer: } 427\end{array}$ & $\begin{array}{l}\text { Annual DALYs: } 98,304 \text { (year } 2013 \text { ) } \\
\text { VSL, with the income elasticities in brackets: } \\
\text { (Elasticity }=1 \text { ): } \\
\$ 252,000,000 \\
\text { (Elasticity }=2 \text { ): } \\
\$ 65,000,000 \text {; } \\
\text { i.e. } 0,4 \%-1,7 \% \text { of GDP, respectively. }\end{array}$ & $\begin{array}{l}\text { Groundnuts: } \\
\text { Quantity affected at } 4 \mu \mathrm{g} / \mathrm{kg} \text { threshold: } \\
253,856 \text { tons - trade non-compliant : } 253,856 \\
\text { tons, which is } \$ 68,446,250 ; \\
\text { Quantity affected at } 20 \mu \mathrm{g} / \mathrm{kg} \text { threshold: } \\
709,691 \text { tons trade non-compliant : } 98,292 \\
\text { which is } \$ 27,378,500 ; \\
\text { Maize: } \\
\text { Quantity affected at } 4 \mu \mathrm{g} / \mathrm{kg} \text { threshold: } \\
223,234 \text { tons; trade non-compliant: } 163,697 \\
\text { tons, which is EUR } 42,770,000 ; \\
\text { Quantity affected at } 20 \mu \mathrm{g} / \mathrm{kg} \text { threshold: } \\
223,234 \text { tons; trade non-compliant : } 29,757 \\
\text { tons which is EUR } 8,555,000\end{array}$ & $\begin{array}{l}\text { The high aflatoxin values in groundnut } \\
\text { cake in Senegal were treated by } \\
\text { ammonium to reduce the level and } \\
\text { make the product compliant with the } \\
\text { legal limits of export markets. This } \\
\text { leads to additional production charges, } \\
\text { and a potential annual exports of } \\
60,000 \text { tons of groundnut cake, } \\
\text { amounting to } \$ 3,606,600 \text {. }\end{array}$ \\
\hline
\end{tabular}




\begin{tabular}{|c|c|c|c|c|c|}
\hline Uganda (2017) & $\begin{array}{l}\text { maize, } \\
\text { groundnuts, } \\
\text { sorghum }\end{array}$ & $\begin{array}{l}\text { Aflatoxin exposure: } \\
\text { Maize: } 86 \\
\text { Sorghum: } 177 \\
\text { Groundnuts: } 3.33 \\
\text { Combined: } 266\end{array}$ & $\begin{array}{l}\text { Average DALYs: } 269,198: \\
\text { Average for Women: } 162,813 \text {; average for } \\
\text { men: } 106,385 \\
\text { VSL with the income elasticities } 1.5 \text { (year: } \\
\text { 2014): US } \$ 3,500,000 \\
\text { Benefits of eliminating liver cancer associated } \\
\text { with aflatoxin } \\
\text { (year: } 2014 \text { ): (high income elasticity) } \\
\$ 144,300,000 \text { - (low income elasticity) } \\
\$ 577,200,000 \text {, which } 0.5 \text { and } 2.1 \% \text { of GDP, } \\
\text { respectively, and percent of total health sector } \\
\text { budget: about } 50 \% \text { and more than double, } \\
\text { respectively. }\end{array}$ & $\begin{array}{l}\text { Trade impact as provided by the results of the } \\
\text { simulation analysis: } \\
\text { Reduction of agri-food exports in tons and } \\
\text { reduction of prices, leading to the reduction of } \\
\text { export value: } \\
\text { Agri-food products: } \\
-0.5 \% \\
\text { Grains: }-1.09 \% \text {, and thereof resulting reduction } \\
\text { of overall trade profits: } \\
-1.35 \% \\
\text { Due to the foreign exchange effect and } \\
\text { substitution effects, import value also decrease. }\end{array}$ & $\begin{array}{l}\text { In the study a general equilibrium } \\
\text { simulation model for the Ugandan } \\
\text { economy is applied in order to gauge } \\
\text { the impact of aflatoxin contaminated } \\
\text { products sold both on the domestic and } \\
\text { on the international market. However, } \\
\text { on the international market the } \\
\text { contaminated products are rejected due } \\
\text { to non-compliance. }\end{array}$ \\
\hline Nigeria & $\begin{array}{l}\text { maize grains } \\
\text { for livestock } \\
\text { (feed) } \\
\text { groundnut }\end{array}$ & $\begin{array}{l}\text { Average of } 3,262 \text { cases } \\
\text { of liver cancer (with } \\
\text { average for men: } 3,691 \text {, } \\
\text { average for women: } \\
2,854 \text { ) }\end{array}$ & $\begin{array}{l}\text { DALYs: } 22,460,000 \\
\text { (with average for men: } 25,410,000 \text {, average for } \\
\text { women: } 19,650,000 \text { ) } \\
\text { Annual DALYs: } 42,573 \\
\text { Men: 48,1623; women: } 37,241 \\
\text { VSL } \\
\text { Lower limit: } \$ 427 \text { million } \\
\text { Upper limit: } \$ 1,599 \text { million } \\
\text { Men: lower limit: } \$ 483 \text { million \& upper limit: } \\
\text { \$1,809 million; women: lower limit: } \$ 374 \\
\text { million \& upper limit: } \$ 1,399 \text { million }\end{array}$ & $\begin{array}{l}\text { Laboratory results in 2017: For feeds, the rate } \\
\text { of compliance with EU standards that was } \\
\text { collected in various locations in Nigeria was } \\
\text { very low. The non-compliance rates of feed } \\
\text { were generally much high, ranging from } 81.8 \% \\
\text { for groundnut cake and } 38.5 \% \text { for maize. } \\
\text { The highest prevalence of samples meant for } \\
\text { human consumption that did not comply with } \\
\text { EU standard } \\
\text { Between } 1980 \text { and 2016, } 389 \text { Nigerian } \\
\text { agricultural export commodities were } \\
\text { seized/rejected by the EU } \\
\text { In } 2017 \text { (until October), the notifications of } \\
\text { seizure/rejections were } 39 \text { which are more } \\
\text { notifications than in the previous year. Overall, } \\
39 \% \text { of the product rejection was due to non- } \\
\text { compliance with the aflatoxin limits. }\end{array}$ & $\begin{array}{l}\text { The study differentiated between the } \\
\text { effect of aflatoxin for men and women. } \\
\text { It also provides information about the } \\
\text { effects in different regions, while we } \\
\text { present here only the average/national } \\
\text { figures. Details for the regions are } \\
\text { available. }\end{array}$ \\
\hline Malawi (2017) & $\begin{array}{l}\text { maize } \\
\text { groundnut }\end{array}$ & $\begin{array}{l}\text { Annual number of cases } \\
\text { of liver cancer/year } \\
78\end{array}$ & $\begin{array}{l}\text { Annual DALYs: } \\
\text { VSL, with the income elasticities in brackets: } \\
\text { (Elasticity = 1): } \\
\$ 180,827 ; \\
\text { (Elasticity = 1.5): }\end{array}$ & $\begin{array}{l}\text { The trade effect is estimated by calculation of } \\
\text { an index of trade competitiveness. It is not clear } \\
\text { if changes in competiveness and associated } \\
\text { changes in trade can be solely and directly } \\
\text { attributed to aflatoxin. The results are thus not }\end{array}$ & $\begin{array}{l}\text { Distribution of aflatoxin in maize } \\
\text { purchased/ collected from farm } \\
\text { homesteads and local markets in } \\
\text { different districts in Malawi. }\end{array}$ \\
\hline
\end{tabular}




\begin{tabular}{|c|c|c|c|c|c|}
\hline & & $\begin{array}{l}\text { (likely to be } \\
\text { underestimated due to } \\
\text { assumptions) }\end{array}$ & $\begin{array}{l}\$ 25,345 ; \\
\text { (Elasticity =2): } \\
\$ 3,552 ;\end{array}$ & $\begin{array}{l}\text { presented here, for details please refer to the } \\
\text { Malawi study. }\end{array}$ & $\begin{array}{l}\text { The study comprises a statistical } \\
\text { estimation of the production and } \\
\text { productivity in order to investigate the } \\
\text { determinants of groundnuts production } \\
\text { levels as well as the effect of the strict } \\
\text { EUI aflatoxin standards imposed in } \\
\text { 1997. }\end{array}$ \\
\hline Gambia (2016) & $\begin{array}{l}\text { Maize, } \\
\text { groundnuts, rice }\end{array}$ & $\begin{array}{l}\text { For groundnuts: } \\
\text { total number of cases of } \\
\text { liver cancer per year: } \\
160 \\
\text { Population risk for liver } \\
\text { cancer per year: } 100\end{array}$ & $\begin{array}{l}\text { Estimated annual heath impact due to death } \\
\text { with liver cancer: } \\
\text { Low: } \$ 5,874,080 \\
\text { High: } \$ 22,457,600 \text {, } \\
\text { i.e. } 0.6-2.2 \% \text { of GDP, respectively. }\end{array}$ & $\begin{array}{l}\text { In 2012-2015, } 14 \text { rejections of exports of HPS } \\
\text { bird feed groundnuts due to high aflatoxin } \\
\text { contamination levels above the EU maximum } \\
\text { level allowed. } \\
\text { Total trade loss calculated: } 416 \text { million tons, } \\
\text { which are USD } 72,000 \text { using the respective } \\
\text { price }\end{array}$ & $\begin{array}{l}\text { The trade effect is calculated by taking } \\
\text { the difference in revenue that would } \\
\text { have been earned from selling HPS } \\
\text { Bird feed groundnuts and the actual net } \\
\text { revenue earned from selling crushed oil } \\
\text { and cakes that were produced from the } \\
\text { returned consignments }\end{array}$ \\
\hline
\end{tabular}

Source: Studies commissioned by PACA. 


\subsection{Mitigation measures and cost-effectiveness}

Prior to the period covered by the systematic bibliographic searches, various accounts of mitigation measures being investigated or developed specifically for African countries were already given. With regard to agronomic measures to prevent aflatoxin contamination, breeding of resistant varieties provides an avenue. For example, Bankole et al. (2006) described inbred resistant maize lines with low aflatoxin accumulation from Central and Western Africa. These lines are part of the germplasm used for breeding under a joint initiative between IITA and the USDA-ARS Southern Regional Research Center. This breeding effort has already resulted in six lines being used as parents for hybrid crosses (TZAR101-TZAR106). Research into the factors underlying this resistance to Aspergillus infection and aflatoxin formation has shown that it is multi-genic. Two subtypes of resistance related to the resistance to infection of the pericarp and of the sub-pericarp of the maize kernel. Various genes have already been linked to resistance, such as those coding for cell wall degrading chitinase enzymes and trypsin inhibitor. These can thus be used as markers in the selection of maize germplasm with favourable resistance traits (Brown et al., 2016; Williams et al., 2015). For peanut, breeding efforts towards resistance to Aspergillus infection and aflatoxin formation were well under way before 2010, yet total resistance still needs to be achieved. Expressed sequence tags (ESTs) linked to resistance to infection and hence also to aflatoxin contamination had already been identified and served as basis for further research into the use of markers or genetic engineering to develop resistant peanut lines (Torres et al., 2014).

Another agronomic measure to prevent aflatoxin contamination in the field is 'biocontrol' through the use of non-aflatoxigenic mould strains that compete with Aspergillus for the same niche but that do not form aflatoxins. A successful example of its practical application is the commercial AF36 and AflaGuard preparations of competing strains used in cotton, maize, peanuts, and pistachio in the US. Addition of such non-aflatoxigenic strains to soil helps to reduce aflatoxin contamination both pre- and post-harvest. Before 2010, such non-aflatoxigenic had also been isolated in Nigeria and IITA, in collaboration with the German and US governments and World Bank, had successfully been field testing this amongst farmers in various parts of Nigeria. In the years to follow, the concept became commercialized under the brand name AflaSafe $\mathbb{R}$ and has been adopted by maize and groundnut farmers in various parts of Africa (Bandyopadhyay et al., 2016; Gnonlonfin et al., 2013; Torres et al., 2014).

Other agronomic measures already being tested before 2010 and further elaborated in more recent years include: crop rotation; chemical \& biological controls with pesticides or natural enemies to prevent pest insect damage that may facilitate mould infection as well as control of moulds using, for example, Fungistats, essential oils or anti-oxidants; water stress management through irrigation; early harvesting; and prevention of mechanical damage during harvest.

Further post-harvest measures could include: drying of harvested seeds or grains; sorting and fractionation (e.g. flotation) of harvested seeds or grains; storage under modified atmosphere; detoxification of aflatoxins through treatment with e.g. ozone and ammonia; certain food processing steps (e.g. nixtamalization of maize) and fermentation; food irradiation; cold storage; and the use of mineral and other binders to bind aflatoxin in the gastrointestinal tract. In addition, awareness raising, good practices for agricultural and hygienic food production, as well as regulation and enforcement have been forming part of contamination-mitigating strategies (Darwish et al., 2014; Gnonlonfin et al., 2013; Neme \& Mohammed, 2017; Torres et al., 2014; Wagacha \& Muthomi, 2008).

Besides reduction or prevention of contamination and exposure, mitigation may also focus on reducing the health effects caused by aflatoxins in consumers. Aflatoxin exposure is a co-factor besides hepatitis in the aetiology of hepatocellular carcinoma (HCC), an aggressive type of cancer with high fatality, often also concurring with liver cirrhosis. Through hepatitis B vaccination, for example, the development of HCC caused by the joint action of aflatoxins and hepatitis can be prevented. Before the start time of our literature survey, vaccination programs had already been in place in Africa, and research into its effectiveness was ongoing, such as in a large study in The Gambia. The effectiveness of vaccination can be further enhanced by vaccinating, for example, neonates or taking into account possible mother-to-child transfer during pregnancy and weaning. Also diagnostics for hepatitis are 
essential and subject to further improvements, such as the development of rapid and inexpensive test (Lemoine \& Thursz, 2017).

The degree to which the effects of interest are offset against the relative costs needed to achieve them. This is different from cost-benefit analysis in which the monetary input and outputs are compared, and for which a cost-benefit ratio would be favourable if this ratio is less than one, yielding positive returns on the investment. Methods for the cost-effectiveness of mitigation measures against mycotoxin-related diseases have been reviewed by IARC (Pitt et al., 2012). Cost effectiveness analysis (CEA) of interventions have become commonplace in, for example, the area of pharma-economics where the introduction of a new pharmaceutical. These may be expressed in incremental terms, i.e. the incremental cost effectiveness ratio (ICER), namely what would be the change in cost as compared to the change in effect induced by an intervention. Conversely, one could choose the least costly option for reaching the same effect size, i.e. the "least-cost" option. 


\section{Methodology}

\subsection{Introduction}

A systematic literature review is a 'structured process of review synthesis'. It attempts to "collate all empirical evidence that fits pre-specified eligibility criteria in order to answer a specific research question" (World Health Organization, 2011). Compared to the narrative type of literature review commonly performed within in a research project, systematic literature reviews have several benefits: a well-defined methodology reduces bias, as well as the option of using statistical techniques of metaanalyses (if the quantitative data necessary is reported in the studies) that can synthesise quantitative research findings by generalisation and providing trends. Overall, systematic reviews detect more studies and findings than common literature searches in isolation. Disadvantages of systematic literature reviews are that they are resource intensive, both in terms of required time as well as expertise; and that the method "may be limited to questions for which primary research (i.e. studies that generate primary data) is available" (EFSA, 2010).

Systematic literature reviews rely on the following core principles:

- $\quad$ Systematic approach;

- Transparent approach due to reporting on the process and results (reproducible);

- Rigorous reviewing of literature, including double checks by peer-reviewing;

- Including the quality of studies when drawing conclusions.

Guidelines on systematic reviews in various fields have been published by a number of organizations and authors (CRD, 2009; EFSA, 2010; FDA, 2009; Higgins \& Green, 2011; Pullin et al., 2018; Sargeant et al., 2005). In this study, the guidelines for the qualified application of systematic review by the Evidence for Policy and Practice Information and Co-ordinating Centre (EPPI centre, University of London) and the Cochrane Handbook for Systematic Reviews of Interventions were followed. In particular, the software tool for systematic reviews designed by the EPPI, University of London was used.

The essential processes of conducting systematic reviews, and their respective outcomes, consist of five phases - as shown in Table 3 below.

Table 3: Systematic review process for mapping the literature (based on Petersen et al, 2008)

\begin{tabular}{|l|l|l|l|l|l|}
\hline Number & \multicolumn{1}{|c|}{$\mathbf{1}$} & \multicolumn{1}{c|}{$\mathbf{2}$} & \multicolumn{1}{c|}{$\mathbf{3}$} & \multicolumn{1}{c|}{$\mathbf{5}$} \\
\hline Process & $\begin{array}{l}\text { Defining topics/ } \\
\text { themes and } \\
\text { framework for the } \\
\text { systematic review }\end{array}$ & Searches & $\begin{array}{l}\text { Screening of } \\
\text { papers }\end{array}$ & $\begin{array}{l}\text { Key wording on } \\
\text { full-text }\end{array}$ & $\begin{array}{l}\text { Data extraction of } \\
\text { studies for the } \\
\text { specific theme }\end{array}$ \\
\hline Outcome & $\begin{array}{l}\text { Scope of the } \\
\text { review }\end{array}$ & All papers & $\begin{array}{l}\text { Relevant } \\
\text { papers }\end{array}$ & $\begin{array}{l}\text { Literature body } \\
\text { with } \\
\text { Classification } \\
\text { scheme } \\
\text {-> Database of the } \\
\text { literature, } \\
\text { mapping of the } \\
\text { literature }\end{array}$ & $\begin{array}{l}\text { Synthesis of the } \\
\text { literature on specific } \\
\text { theme } \\
\text { reviews on the } \\
\text { specific themes }\end{array}$ \\
\hline
\end{tabular}


The different phases of the systematic review are briefly defined below. Note that phases 2, 3 and 4 constitute an iterative process with possible adjustments in order to ensure comprehensiveness.

1. Defining the research question: developing the literature search strategy including the search terms for the literature search and databases to be consulted; criteria for in- or exclusion of scanned literature; and developing a code for data extraction, i.e. a "questionnaire", which includes quality criteria.

2. Conducting searches of studies: Applying the search terms in a systematic literature search by using bibliographic databases and website searches.

3. Screening: the screening of papers by applying the exclusion/inclusion criteria to the papers that were found via the searches. First, screening of title, keywords and abstract, second, full text screening; exclusion of those studies that do not satisfy the predefined relevance and quality criteria.

4. Classification (using abstract and full texts): applying the classification/key-wording scheme for collecting the data for mapping the literature according to topics/themes covered. This generated an overview of the available publications. The studies identified can be used to answer specific questions of interest.

5. Data extraction: Applying the questionnaire to the papers identified as relevant. This is called "coding" in the context of systematic reviews. As mentioned, we apply the coding tool developed by the EPPI-Centre for the application of the code/questionnaire.

Thus, two outcomes can be distinguished: 1) map of the available literature, i.e. the studies identified in the search, and classified, synopsis describing the literature and themes covered as well as the quality of studies, and 2) extracted data for specific topics.

\subsection{Literature search}

\subsubsection{Identification of relevant data sources}

Bibliographic scientific databases were searched for potentially relevant publications. The subject specific databases CAB Abstracts, PubMed, AGRIS and EconLit were searched as well as the multidisciplinary database Scopus. Selected databases were partly different for the different research questions. For each research question two or three databases were used. The following bibliographies, to which the reviewers have access via institutional subscriptions, were considered to adequately cover the various scientific fields straddled by the four research questions, including agricultural science, plant science and microbiology, food science and nutrition, toxicology, medicine, analytical chemistry, and economics:

- CAB Abstracts on the Ovid Platform: covers literature on agriculture, veterinary and animal science, plant science, microbiology, parasitology, human health, environmental sciences, food science and nutrition and applied economics, including scientific literature published in serials and in other sources such as international organization reports, conference proceedings and books.

- Scopus is the largest abstract and citation database of peer-reviewed literature in the field of science, technology, medicine and social sciences. It includes scientific journals, books and conference proceedings.

- $\quad$ PubMed covers biomedical literature from MEDLINE (a prime medical bibliography covering not only biomedical and clinical sciences but also related life and environmental fields), life science journals, and online books. It includes the fields of biomedicine and health, covering portions of the life sciences, behavioural sciences, chemical sciences, and bioengineering.

- AGRIS on the Ovid Platform was created by the Food and Agriculture Organization of the United Nations (FAO) in 1974, to facilitate information exchange and to bring together world literature dealing with all aspects of agriculture. The database contains bibliographic material about all technical, economic and sociological aspects of agriculture, including forestry, animal husbandry, the aquatic sciences and fisheries, and human nutrition. The strength of AGRIS lays in the fact that non-conventional material (the so called 'grey literature') constitutes 
about $20 \%$ of the database. This material comprises scientific and technical reports, theses, conference papers, etc. This material is not covered by other databases. Geographical coverage is international with emphasis on developing countries.

- EconLit is an economics-focused scientific bibliography hosted by the American Economic Association containing over a million records, covering not only scientific articles but also conference proceedings, working papers, PhD theses and book reviews.

In addition, additional literature on economic effects was identified via 'snowballing'. Snowballing refers to using the references of relevant studies with the aim to identifying further studies, in addition to the literature review with search terms. These references complement the list of studies found via the bibliographic searches. Furthermore, websites of organizations, projects and other initiatives dedicated to mycotoxin toxicity, monitoring or health impacts were also searched for so called 'grey literature' studies. The information sources are listed in Annex 2.

\subsubsection{Search strategies}

For each research question (defined in section 1), a search strategy was developed for identifying relevant studies based on the key elements of each question (Annex 3). All search strategies have been built in a consistent way. Within each key element/concept of a specific search strategy, many related search terms were combined using the Boolean operator "OR" in order to retrieve a maximum number of relevant papers. The distinct elements have been combined using the Boolean operator "AND".

Search terms originated from personal knowledge, searches on websites, screening key (review) papers, and screening the results of preliminary searches in bibliographic databases. The CAB Thesaurus 2014 was additionally used to find terms, specific terminology and synonyms (http://www.cabi.org/cabthesaurus/).

In all databases truncation $\left(^{*}\right)$ was used to retrieve all possible suffix variations of the root word indicated. Given the different features of the different bibliographic databases used, specific additional functionalities were used.

\section{CAB Abstracts}

Searches in CAB Abstracts were done in title, abstract and all key word fields (.mp). The wild card character '?' was used in CAB Abstracts to substitute for one or no characters. The adjacency operator ADJ was used to indicate the maximum number of words between two search terms, e.g. "aflatoxin* adj3 free" means that a hit is included when aflatoxin* and free are within three words of each other, in any order. The explode command was used in CAB's hierarchal list of thesaurus terms. It tells Ovid to search for the thesaurus term itself, including all its narrower terms, down to all levels (http://www.cabi.org/?page=2044\&site=170 Advanced Searching of CAB Abstracts, p. 25, 28-29), e.g. "exp africa " not only searches for "africa" in the different keyword fields, but also for underlying terms like "Africa South of Sahara" and "Cameroon". CABICODES are classification codes applied to all records to indicate the broad subject areas within which they fall. Some CABICODES were used e.g. CC100 (Education and Training), CC200 (Extension and Advisory Work) and DD500 (Laws and Regulations). For some general terms in question \#4 (mitigation) searches were only done in the title.

\section{AGRIS}

AGRIS does not include CABICODES. Searches in AGRIS were done in title, abstract and all key word fields (.mp). For some general terms in question \#4 (mitigation) searches were only done in the title.

\section{Scopus}

Scopus automatically searches for singular and plural forms. The wild card character '?' can be used in Scopus to substitute for one character. The adjacency operator W/ was used to indicate the maximum number of words between two search terms, e.g. post-harvest W/3 control means that a hit is included when post-harvest and control are within three words of each other, in any order. Searches in Scopus were done in title, abstract and keywords (TITLE-ABS-KEY). For some general terms in question \#4 (mitigation) searches were only done in the title (TITLE). 


\section{PubMed}

As truncation $\left(^{*}\right)$ maximally results in 600 hits in PubMed, all letters of the alphabet were added to the search term health (healtha*, healthb* etc.) to be sure to not miss any relevant papers. For searches in PubMed MeSH (Medical Subject Headings) terms were used. MeSH is a comprehensive controlled vocabulary for the purpose of indexing journal articles and books. Additionally searches were done in abstract and title only using [tiab]. [tiab] was added, as PubMed searches in ALL FIELDS by default.

\section{EconLit}

The wild card character \# was used in EconLit to substitute for one or no characters, the wild card character '?' was used to replace for one character. Searches in EconLit were done in ALL TEXT.

\subsubsection{Benchmark citations}

In order to verify whether the use of the search queries indeed enabled retrieval of relevant references, the outcomes of preliminary searches with these queries were compared with benchmark collections. These are usually scientific journal articles that have been annotated by one or more of the bibliographic databases used. If retrieval was incomplete, i.e. less than $100 \%$ of the benchmark was covered by the outcomes of the search strategy, then the strategy was further modified so as to achieve $100 \%$ coverage. This was done, for example, by inspecting the references not covered by a search query and allocating typical terms and keywords that still need to be included in the search query. In case $100 \%$ coverage was achieved, the search string query was considered adequate. The benchmark citations for each questions are listed in Annex 4.

\subsubsection{Collection of references and initial screening}

Collection of relevant references from the selected sources was done by use of Endnote reference citation management software. Such records can be downloaded automatically from bibliographies to Endnote (desktop), but have to be entered manually for grey literature. Subsequently, these separate Endnote libraries for each research question were merged and de-duplicated so as to create a unique set of references, which were then uploaded to the online systematic review tool repository (EPPI). Further initial screening of the titles and abstracts of the collected references was carried out to check for relevance using standardized forms for data collection. This was to discard irrelevant records yet to maintain those that are relevant or for which relevance could not yet be unequivocally established, for full-text analysis as described in section 3.3.

\subsection{Screening (inclusion/exclusion)}

Inclusion and exclusion criteria were applied in the screening in order to ensure that relevant studies were identified for the database, the mapping of the literature as well as the synthesis of specific themes. This means that only those studies meeting the inclusion criteria were considered in the detailed assessment of the systematic review, or in other words the exclusion criteria ensured that irrelevant studies were excluded before the assessment of the studies.

General inclusion/exclusion criteria consisted of the following:

- Topic: Studies that do not consider aflatoxins specifically (e.g. focusing on general health effects of aflatoxins, rather on the disease burden in Africa, as well as studies that focused on mitigation measures outside of Africa, and studies on the population biology of fungi producing aflatoxins);

- Date: Publications pre-dating 2010;

- Geography: Data either do not specifically pertain to or are otherwise irrelevant for the aflatoxin situation in Africa (as a continent, region, country or locality);

- Language: studies that were not written in English;

The full list of selection (screening) criteria is included in Annex 5. 
The complete set of records was assessed by a single reviewer for each of the questions, and initial screenings of $10 \%$ of the total records were done jointly by at least two reviewers on the same references. Outcomes were compared and records for which conflicting results show up were discussed by the reviewers to resolve divergences and harmonize screening outcomes. If needed, the tests were repeated on a different set of references to check for consistency. Once agreement has been reached, the primary reviewer proceeded with screening until completion of the batch of records for the specific research question.

For references that still turned out to be irrelevant during this full-text screening, there was an option to exclude them from further study. Studies that provide facts on aflatoxins in Africa, but did not contain an analysis, with details of scientific evidence at first sight, were excluded (e.g. pamphlets, project information sheets, etc.).

\subsection{Analysis and synthesis of data}

According to the theme under review, a set of studies identified as relevant for the broad topic of Aflatoxins in Africa was coded in order to generate syntheses of specific results. Each theme was dealt with separately.

In general, coding refers to the recording of the detailed information provided in the studies identified. For the coding, a "questionnaire" is applied to the studies, i.e. questions about the relevant information are systematically answered by using the research findings of the studies. The questionnaire includes topics such as, for instance, type of publication (article in a scientific journal, book chapter, etc.) and technical details such as the type of aflatoxin being described in the study.

\subsubsection{Code - "questionnaire"}

The background presented in section 2 served as a starting point for developing the code. The questionnaire is provided in Annex 7.

In general, the code should be rigorous but flexible enough to allow for the possibility of adding open questions, rather than determine and thus presume answers or categories of questions. In essence, using the key wording and coding, a high level understanding about the nature and contribution of the research can be achieved.

\subsubsection{Coding tool}

For the coding, we used the tool designed by the Evidence for Policy and Practice Information and Coordinating Centre (EPPI, University of London), referred to as EPPI tool. More specifically, the "questionnaire" was programmed in the EPPI tool and subsequently used for data extraction by the reviewers.

\subsubsection{Data extraction and synthesis}

The data extraction delivers the information used for the analysis of the research evidence available and presented in a synthesis of the available studies. The synthesis presents frequencies but also other information to answer the questions under review.

The data gathered in a systematic literature review may be synthesized in a quantitative manner, using statistical methods (meta-analysis). The advantage of this method is that it may "provide a more precise estimate of a parameter or effect". However, the data needs to be homogenous and of a sufficiently large size, in order to be analysed statistically, and if applied to studies of poor quality it may 'propagate biases'. If the data is not suitable for meta-analysis, quantitative results may be discussed narratively and "may be presented in tables and/or charts" (EFSA, 2010). 


\section{Map of available literature}

\subsection{Search strategies and pre-screening}

\subsubsection{Search strategies}

In total, 6.374 references were collected (see Table 4). Based on the search strategies implemented in this study, the identified references were classified into three Endnote libraries, namely contamination (Question \#1), health (Question \#2), and economic (Question \#3). Meanwhile, references for Question \#4 were accommodated as a subset in either one or more of the three libraries. This is as a result of the search strategy for Question \#4 which was to combine the individual search queries for Question \#1 - 3 with Question \#4, rather than setting up separate search queries for Question \#4.

Almost half $(50 \%)$ of the references were related to the research question on the topic of contamination, $30 \%$ to health impact, and $25 \%$ to the research question on economic impact. In order to ensure that all relevant studies on the economic impact are included in the systematic review, additional searches of the grey literature were conducted as described in appendix 3 . This resulted in one additional study on the economic health effects that was identified as relevant.

The oldest identified references were published in 1961, while the newest ones were from $2018 ; 2.467$ (39\%) were published between year 2010 to 2018 (see Table 4). There were at least nine reference types, with around $95 \%$ being journal publications (see Table 5). The other reference types were: book section, book, generic, report, conference proceeding, serial, thesis, and manuscript. See Table 4 and Table 5 .

Table 4: Overview of results of initial data searches by year of publication (number of publications)

\begin{tabular}{|l|c|c|c|c|r|}
\hline Year of publication & Contamination & Economic & Health & Total & \% \\
\hline No year & 4 & 3 & 33 & 40 & $0.6 \%$ \\
\hline$<\mathbf{1 9 8 0}$ & 367 & 134 & 265 & 766 & $12.0 \%$ \\
\hline $\mathbf{1 9 8 0}-\mathbf{1 9 8 9}$ & 356 & 129 & 205 & 690 & $10.8 \%$ \\
\hline $\mathbf{1 9 9 0}-\mathbf{1 9 9 9}$ & 442 & 225 & 294 & 961 & $15.1 \%$ \\
\hline $\mathbf{2 0 0 0}-\mathbf{2 0 0 9}$ & 606 & 389 & 455 & 1450 & $22.7 \%$ \\
\hline $\mathbf{2 0 1 0}-\mathbf{2 0 1 8}$ & 1076 & 701 & 690 & 2467 & $38.7 \%$ \\
\hline Total & $\mathbf{2 8 5 1}$ & $\mathbf{1 5 8 1}$ & $\mathbf{1 9 4 2}$ & $\mathbf{6 3 7 4}$ & $\mathbf{1 0 0 . 0 \%}$ \\
\hline
\end{tabular}

Table 5: Overview of results of initial data searches by reference types (number of publications)

\begin{tabular}{|l|c|c|c|c|r|}
\hline \multicolumn{1}{|c|}{ Reference type } & Contamination & Economic & Health & Total & \% \\
\hline Journal & 2739 & 1450 & 1854 & 6043 & $94.8 \%$ \\
\hline Report & 13 & 18 & 13 & 44 & $0.7 \%$ \\
\hline Conference proceeding & 5 & 4 & 3 & 12 & $0.2 \%$ \\
\hline Book section & 60 & 44 & 49 & 153 & $2.4 \%$ \\
\hline Book & 1 & 46 & 1 & 48 & $0.8 \%$ \\
\hline Generic & 33 & 16 & 10 & 59 & $0.9 \%$ \\
\hline Manuscript & 0 & 2 & 0 & 2 & $0.0 \%$ \\
\hline Thesis & 0 & 1 & 0 & 1 & $0.0 \%$ \\
\hline Serial & 0 & 0 & 12 & 12 & $0.2 \%$ \\
\hline Total & $\mathbf{2 8 5 1}$ & $\mathbf{1 5 8 1}$ & $\mathbf{1 9 4 2}$ & $\mathbf{6 3 7 4}$ & $\mathbf{1 0 0 . 0 \%}$ \\
\hline
\end{tabular}


The pre-defined benchmark citations (Annex 4) were checked. All benchmark citations from Question \#1 and 2 were identified. However, the following benchmark citations from Question \# 3 and 4 were not identified:

- Wu, F., 2015. Global impacts of aflatoxin in maize: trade and human health. World Mycotoxin Journal 8(2), 137-142.

- Khlangwiset, P., Wu, F., 2010. Costs and efficacy of public health interventions to reduce aflatoxin-induced human disease. Food Additives and Contaminants Part A 27, 998-1014.

Those were missed because they were global studies, and thus did not particularly mention "Africa" in their title, abstract, or keywords.

\subsubsection{Pre-screening}

Pre-screening was made based on year of publication, and some other criteria which were considered irrelevant for this study, such as if the studies were conducted for animal studies, not in Africa, or not written in English. The majority of references published since 2010 (40\%) were used with considerations of their up-to-date research methods, latest data. Older publications were likely to have been cited in the more recent publications. Moreover, the situations described in literature published before 2010 may not be applicable anymore to the current situation.

After removing the labelled references, a total of 2,308 references from year 2010-2018 were included for the next steps. These 2,308 publications were related to one or more research questions. Subsequently, the Endnote files were merged, and the references were categorised based on which search queries a study was retrieved from. A reference was categorised as single record if it was found only by one search query. Likewise, double record (or duplicate) and triple record (or triplicate) were for studies found by two and three search queries respectively. The studies found by more than one search queries might be relevant to more than one research questions.

The categorisation step resulted in 14 new Endnote files (see Table 6) with each separate file uploaded into EPPI tool. This strategy enabled records keeping of the references used in further steps. Almost half of the references were duplicates, $19 \%$ were triplicates, and $34 \%$ were single records. Following which there was a large reduction from 2.308 to 1.211 references, with 1.097 duplicates and triplicates studies removed.

Table 6: Categorisation of Endnote folders uploaded to the EPPI tool

\begin{tabular}{|c|c|c|}
\hline Endnote folder & Search query & Number of records \\
\hline \multirow[t]{6}{*}{ Single record } & Contamination & 118 \\
\hline & Contamination + mitigation & 143 \\
\hline & Health & 21 \\
\hline & Health + mitigation & 96 \\
\hline & Economic & 12 \\
\hline & Economic + mitigation & 24 \\
\hline \multicolumn{2}{|r|}{ Subtotal of single record } & 414 \\
\hline \multirow[t]{6}{*}{ Double-record } & Contamination \& Economy & 79 \\
\hline & Contamination \& Economy + Mitigation & 230 \\
\hline & Contamination \& Health & 20 \\
\hline & Contamination \& Health + Mitigation & 222 \\
\hline & Economic \& Health & 2 \\
\hline & Economic \& Health + Mitigation & 16 \\
\hline \multicolumn{2}{|r|}{ Subtotal of double record } & 569 \\
\hline \multirow[t]{2}{*}{ Triple record } & Contamination \& Health \& Economic & 13 \\
\hline & Contamination \& Health \& Economic + Mitigation & 215 \\
\hline
\end{tabular}




\section{$4.2 \quad$ Screening}

\subsubsection{Screening title and abstract for relevance}

The EndNote folders containing 1,211 publications from 2010-2018 were loaded into EPPI. Of these, 19 references, mistakenly not de-duplicated, were removed. The remaining 1,192 publications were subsequently screened on title and abstract by four reviewers using the exclusion criteria.

Of the total number of publications to be screened on title and abstract, $10 \%$ of the total number of publications (119) was double-screened by two different reviewers independently. In case of disagreement between the two reviewers, the study was re-assessed by both reviewers or other reviewers and the disagreements were reconciled. The following cases were considered as disagreement by EPPI tool:

- Disagreement to exclude or include a study;

- Both reviewers excluded a study, but different exclusion criteria were selected;

- Both reviewers excluded/ included a study with similar criteria, but a note was added;

- Both reviewers excluded a study, but one of the reviewers selected more than one criteria.

Table 7 shows that the disagreement rate among reviewers was $43 \%$, or 51 out of 119 studies. $25 \%$ of the disagreement were due to different opinion whether to include or exclude. Meanwhile, $75 \%$ of the disagreements could be considered as false disagreement because principally both reviewers agree to exclude or include a study.

Table 7: Number of disagreement and reconciliation records for double screening on title and abstract

\begin{tabular}{|c|c|c|c|c|c|c|c|c|}
\hline \multirow{2}{*}{$\begin{array}{l}\text { Pair } \\
\text { group }\end{array}$} & \multirow{2}{*}{$\begin{array}{l}\text { Total } \\
\text { studies }\end{array}$} & \multirow{2}{*}{$\begin{array}{c}\text { Total } \\
\text { disagreement }\end{array}$} & \multicolumn{4}{|c|}{ Disagreement criteria } & \multicolumn{2}{|c|}{ Reconciliation } \\
\hline & & & $\begin{array}{l}\text { Include } \\
\text { or } \\
\text { exclude }\end{array}$ & $\begin{array}{l}\text { Different } \\
\text { exclusion } \\
\text { criteria }\end{array}$ & $\begin{array}{l}\text { Same } \\
\text { inclusion / } \\
\text { exclusion } \\
\text { criteria, } \\
\text { note } \\
\text { added }\end{array}$ & $\begin{array}{l}\text { One of the } \\
\text { reviewer } \\
\text { selected > } \\
1 \\
\text { exclusion } \\
\text { criteria }\end{array}$ & Included & Excluded \\
\hline 1 & 34 & 16 & 5 & 5 & 3 & 3 & 3 & 13 \\
\hline 2 & 35 & 15 & 3 & 6 & 5 & 1 & 3 & 12 \\
\hline 3 & 50 & 20 & 5 & 5 & 0 & 10 & 1 & 19 \\
\hline Total & 119 & 51 & 13 & 16 & 8 & 14 & 7 & 44 \\
\hline
\end{tabular}

Screening for title and abstracts resulted in 45\% reduction in number of studies from 1.211 to 658 relevant studies as following:

- Total publications EXCLUDED on title and abstract: $(534)^{1}$

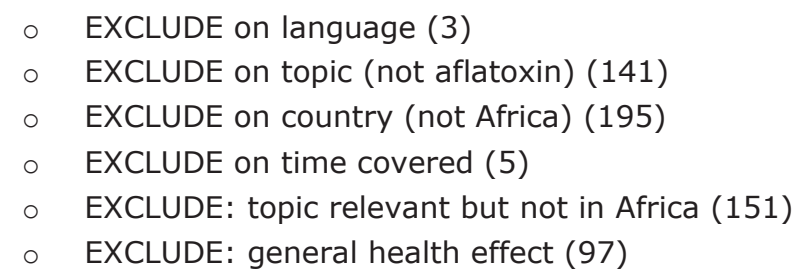

- Total publications INCLUDED on title and abstract (658)

\footnotetext{
${ }^{1}$ Some publications were excluded for multiple reasons.
} 
The distribution of the excluded studies is shown in Figure 3.

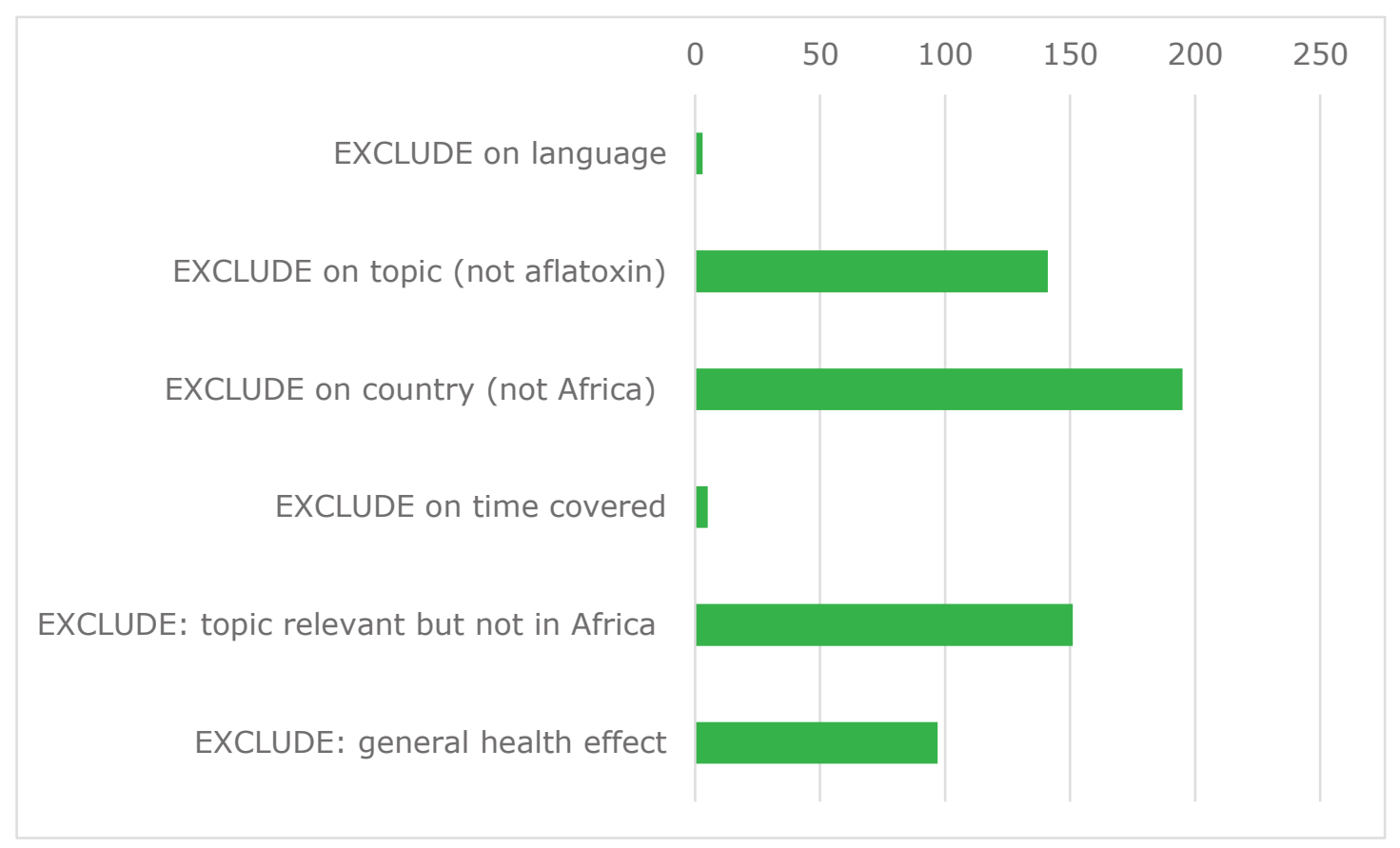

Figure 3: Distribution of excluded studies per exclusion criterion (\%)

\subsubsection{Screening full text for relevance and categorization}

The 658 publications that were thought to be relevant based on the title and abstract were assessed for relevance based on the full texts and, if still found to be relevant, categorized as relevant for one or more of the research questions.

Likewise the double screening performed for screening title and abstract, double screening was also performed for 66 studies (10\%) for full text and categorisation. During full text screening, an option was available to indicate whether included studies were grey literature. Categorisation of studies was done to assign the studies to the relevant categories for questionnaire coding, i.e. contamination, disease burden, economic impact and mitigation. The category biomarkers was added as a subset of disease burden.

Disagreement criteria are similar to those for screening title and abstract. In addition, if a reviewer only indicated a study as grey literature but did not include/ exclude it, the system also recognized it as disagreement. Table 8 and Table 9 below show that the disagreement rate for double screening full text and categorisation are $38 \%$ and $50 \%$ for full text screening and categorization, respectively. The different opinions to exclude or include were mainly attributed by studies on the feasibility to use certain plants or substances to tackle aflatoxins contaminations in food products or farmed fish, but would be premature to include them for mitigation measures. The reviewers agreed to exclude these type of studies. Meanwhile, difference on categorization was primarily attributed by assigning studies into more than one category, mostly to mitigation. A large number of studies focused on contamination and discussed or suggested possible mitigation measures. However, the mitigation measures were not the focus of the studies and were discussed only to a lesser extent. These studies were not relevant for the mitigation research question. 
Table 8: Number of disagreement and reconciliation records of double screening on full text

\begin{tabular}{|c|c|c|c|c|c|c|}
\hline $\begin{array}{c}\text { Pair } \\
\text { group }\end{array}$ & $\begin{array}{c}\text { Total } \\
\text { studies }\end{array}$ & $\begin{array}{c}\text { Total } \\
\text { disagreement }\end{array}$ & \multicolumn{2}{|c|}{ Disagreement criteria } & \multicolumn{2}{c|}{ Reconciliation } \\
\cline { 3 - 7 } & & $\begin{array}{l}\text { Include } \\
\text { or } \\
\text { exclude }\end{array}$ & $\begin{array}{l}\text { One of the } \\
\text { reviewers only } \\
\text { indicate grey } \\
\text { literature, but did } \\
\text { not include/ } \\
\text { exclude }\end{array}$ & Included & Excluded \\
\hline $\mathbf{1}$ & 45 & 15 & 10 & 5 & 5 & 10 \\
\hline $\mathbf{2}$ & 21 & 10 & 10 & 0 & 3 & 7 \\
\hline Total & 66 & 25 & 20 & 5 & 8 & 17 \\
\hline
\end{tabular}

Table 9: Number of disagreement and reconciliation records of double screening on categorisation

\begin{tabular}{|c|c|c|c|c|c|c|}
\hline \multirow[t]{3}{*}{ Pair group } & \multirow{3}{*}{$\begin{array}{c}\text { Total } \\
\text { studies }\end{array}$} & \multirow{3}{*}{$\begin{array}{c}\text { Total } \\
\text { disagreement }\end{array}$} & \multicolumn{2}{|c|}{ Disagreement criteria } & \multicolumn{2}{|c|}{ Reconciliation } \\
\hline & & & \multirow[t]{2}{*}{$\begin{array}{l}\text { Different } \\
\text { categories }\end{array}$} & \multirow{2}{*}{$\begin{array}{l}\text { One of the } \\
\text { reviewers } \\
\text { selected }>1 \\
\text { categories }\end{array}$} & & \\
\hline & & & & & $\begin{array}{l}\text { One } \\
\text { category } \\
\text { selected }\end{array}$ & $\begin{array}{l}>1 \\
\text { categories } \\
\text { selected }\end{array}$ \\
\hline 1 & 29 & 17 & 2 & 15 & 17 & 0 \\
\hline 2 & 21 & 8 & 7 & 1 & 8 & 0 \\
\hline Total & 50 & 25 & 9 & 16 & 25 & 0 \\
\hline
\end{tabular}

Screening of full text resulted in a $50 \%$ reduction in the number of studies from 658 to 353 relevant studies, as following:

- Total publications EXCLUDED on full text screening: 312

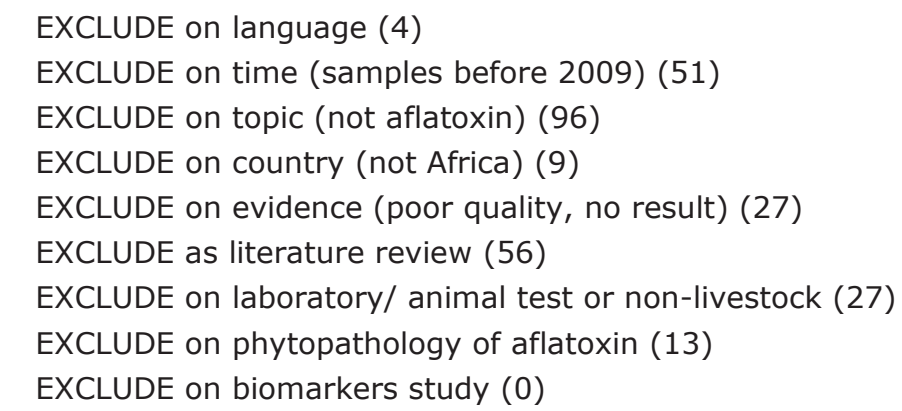

- Total publications INCLUDED on full text screening (353)

There were 28 grey literature studies included after screening on title and abstract, of which 10 were included for full text coding after screening on full text. In addition to screening the full text, the included studies were categorized to the relevant research question. The 31 studies that were initially excluded because they only discussed biomarkers, were reassessed; and 24 of them were included into the total number of included studies. A new questionnaire (separate from the questionnaire on disease burden) was developed and applied to these studies, see Annex 7. Studies can be assigned to more than one category. The 353 publications that were included, were categorized as follows:

- Contamination of food/feed (275)

- $\quad$ Disease burden (25)

- Biomarkers (24)

- Economic impact (11)

- Mitigation methods (60) 
Of 23 publications, the full text could not be located and these were thus not screened nor coded. In total, 330 studies were included for data extraction (coding). The full list of these publications can be found in Annex 8.

\subsection{Coding}

As many as 330 relevant studies from full text screening were extracted by means of coding. The questionnaire consisted of two main parts; general questions and specific questions corresponding to each research question. General questions were applicable for each publication regardless of its category. These questions considered the type of publication, type of aflatoxins studied, etc.

\subsubsection{General questions}

AFB1 was the most frequently reported with 179 publications (58\%), followed by AFB2 (36\%), AFG1 (34\%), and AFG2 (32\%). Around $30 \%$ of the publications focused on aflatoxin in general, while around $19 \%$ studied AFM1, and two publications (2\%) investigated AFM2 and AFP1. Multiple publications reported more than one type of aflatoxin in their studies. The distribution of aflatoxins studied is shown in Figure 4.

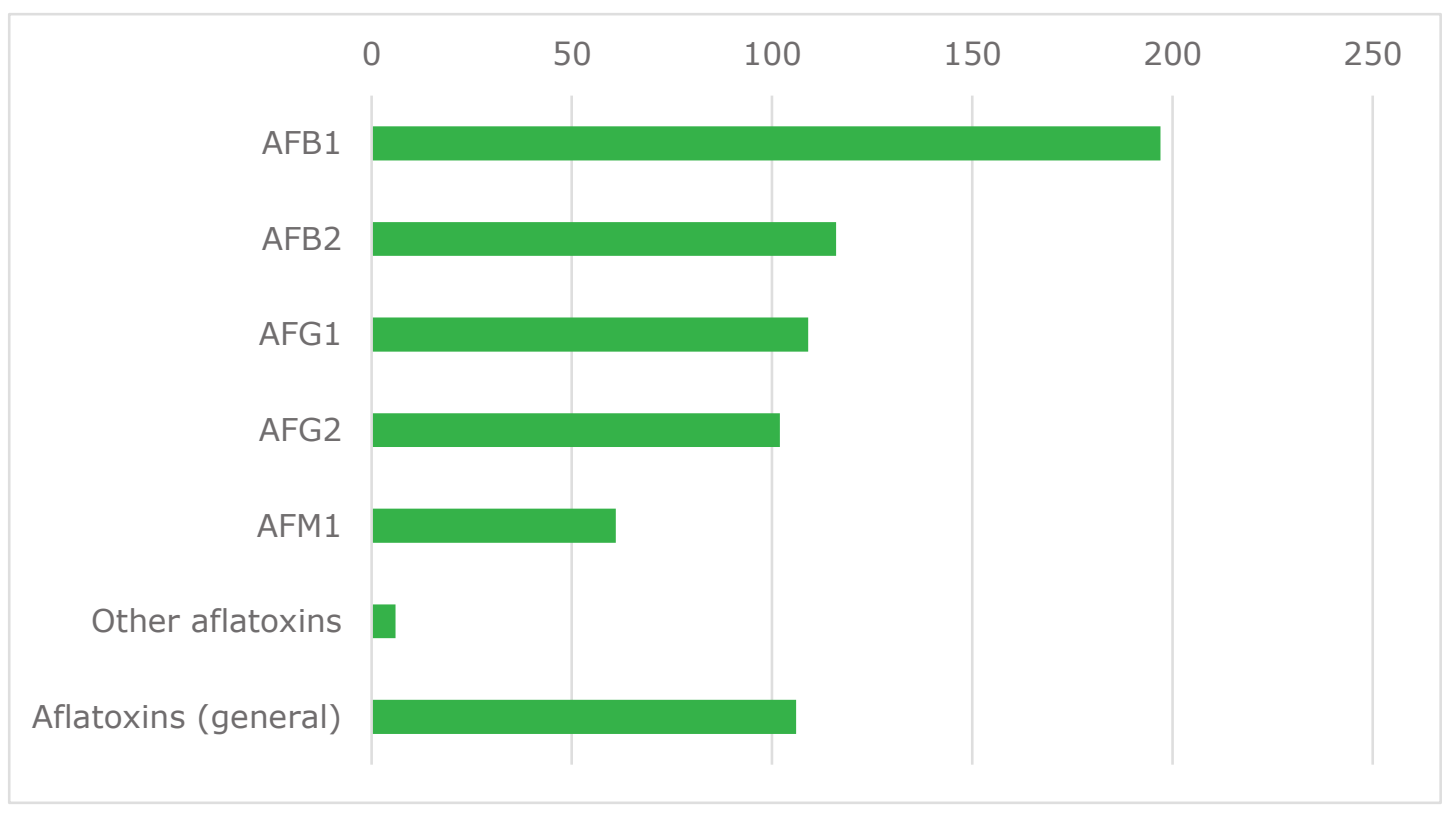

Figure 4: Distribution of number of included studies on a specific type of aflatoxin

\subsubsection{Scale and geographic spread of contamination}

In total, 275 studies investigated aflatoxin occurrence in food and feed in Africa. Included studies were most frequently for Nigeria (56 studies), followed by Egypt (41), and Kenya (33). Around half of the included studies (145) were on a variety of other African countries such as Morocco, Tanzania, Ghana, and South Africa. Multiple studies also reported on aflatoxin contamination in more than one country. The full distribution of included publications per country (for all research questions) is shown in Annex 9. 


\section{Supply chain and type of products}

Studies on food or feed of interest reported on sampling throughout the supply chain. Around half of the studies investigated products that were already processed and/or on the market (152 studies), while 69 studies reported the contamination on harvested or stored commodities, followed by food and feed ready for consumption at household or animal farm (56). Food or feed during transportation were the least studied (8). Figure 5 shows the number of studies published carried out in the various part of supply chains investigated in the studies.

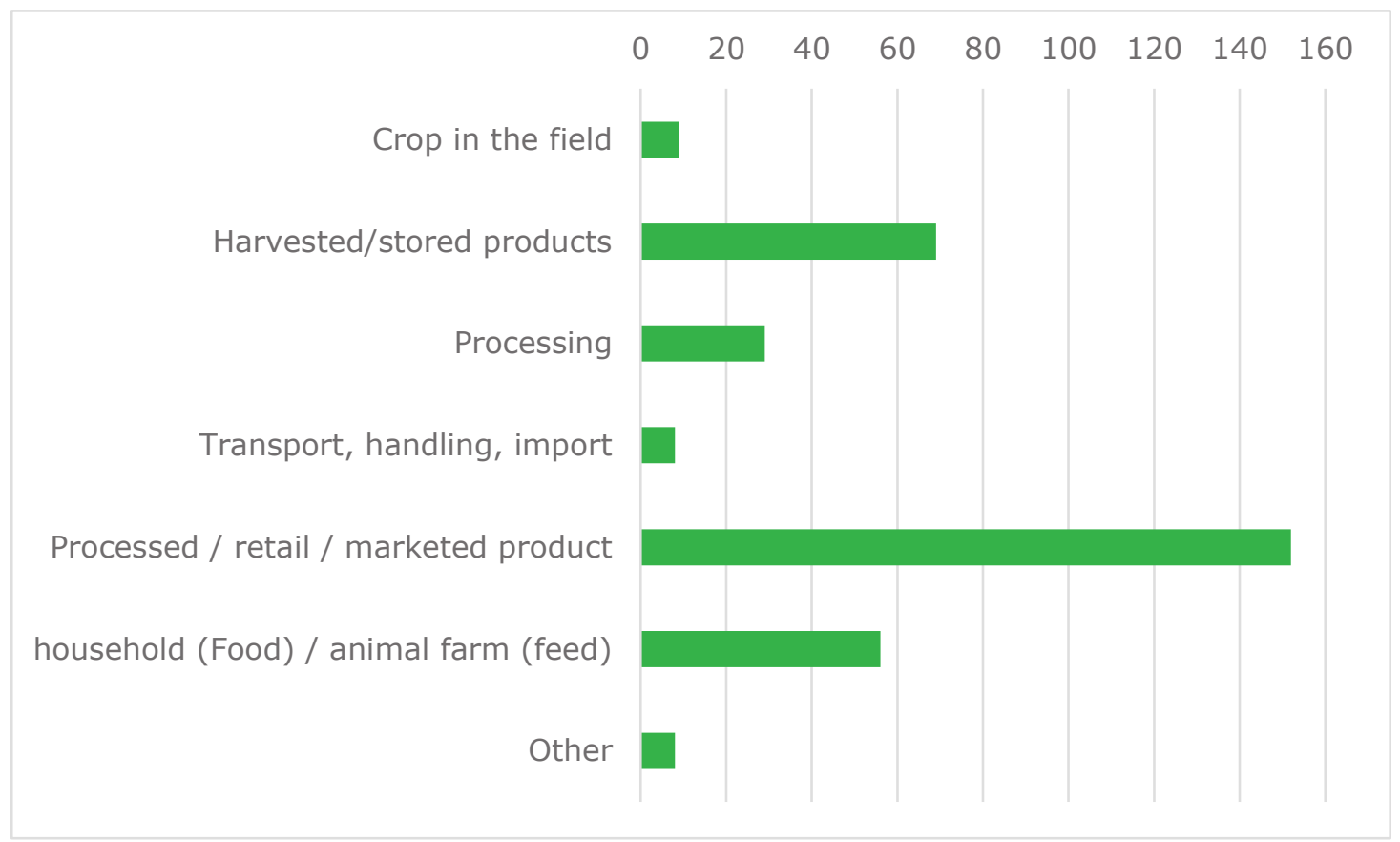

Figure 5: Number of included studies for each part of the supply chain

The type of products sampled in the studies were distinguished into four generic categories; namely plant or plant parts (raw or stored commodity), animal products (raw, non-processed, and/ or stored), food and drinks for human consumption, and animal feed. Samples from plants and food and drink for human consumptions were most frequently reported in the included studies; accounting for $48 \%$ ( 132 studies) and $43 \%$ (118) of the studies respectively. Meanwhile, samples from animal products and animal feed represented $12 \%$ (34) each, while $3 \%$ (7) remaining focused on other kind of samples such as breast milk of lactating mothers and student hostels.

Table 10 shows the number of studies that were included on specific samples taken from each generic category. Some studies discuss multiple commodities, which is why the sum of the indicated percentages exceeds $100 \%$. For studies that measured aflatoxins contamination in plants or plantbased products; the majority reported on cereal products $(82,62 \%)$ and nuts $(41,31 \%)$. Meanwhile, milk was the most frequently studied from the animal products category $(22,65 \%)$. From the food and drink category, there was a significant number of other products that were not defined in the questionnaire $(44,37 \%)$, including breast milk, vegetable oils, baby food, complementary and weaning foods, peanut butter, etc. Apart from these foods, local African dishes and dairy products were also frequently studied, representing 16\% (19 studies) and 10\% (12 studies) of the publications respectively. 
Table 10 : Distribution of samples mentioned in the included studies from each generic category

\begin{tabular}{|c|c|c|c|c|c|c|c|c|}
\hline \multicolumn{3}{|c|}{$\begin{array}{l}\text { Plants as raw agricultural } \\
\text { Commodity }(132)\end{array}$} & \multicolumn{3}{|c|}{$\begin{array}{c}\text { Animal parts/ products } \\
\text { (34) }\end{array}$} & \multicolumn{3}{|c|}{ Food and drink (118) } \\
\hline Name & $\mathbf{N}$ & $\%$ & Name & $\mathbf{N}$ & $\%$ & Name & $\mathbf{N}$ & $\%$ \\
\hline a. Cereals & 82 & $62 \%$ & i. Milk & 22 & $65 \%$ & $\begin{array}{l}\text { a. African } \\
\text { dishes }\end{array}$ & 19 & $16 \%$ \\
\hline i. Maize & 71 & $54 \%$ & ii. Meat & 3 & $9 \%$ & $\begin{array}{l}\text { b. Beverages } \\
\text { and drinks }\end{array}$ & 1 & $1 \%$ \\
\hline ii. Barley & 3 & $2 \%$ & iii. Fish & 2 & $6 \%$ & $\begin{array}{l}\text { c. Fruits (fresh } \\
\text { and processed }\end{array}$ & 3 & $3 \%$ \\
\hline iii. Millet & 7 & $5 \%$ & iv. Other & 4 & $12 \%$ & d. Spices & 8 & $7 \%$ \\
\hline iv. Rice & 7 & $5 \%$ & & & & e. Dairy & 12 & $10 \%$ \\
\hline v. Sorghum & 17 & $13 \%$ & & & & i. Milk & 9 & $8 \%$ \\
\hline vi. Wheat & 9 & $7 \%$ & & & & $\begin{array}{l}\text { ii. Processed / } \\
\text { reconstituted milk }\end{array}$ & 11 & $9 \%$ \\
\hline vii. Other & 7 & $5 \%$ & & & & f. Meat & 3 & $3 \%$ \\
\hline b. Cocoa & 1 & $1 \%$ & & & & i. Meat & 2 & $2 \%$ \\
\hline c. Coconut & 0 & $0 \%$ & & & & ii. Processed Meat & 4 & $3 \%$ \\
\hline d. Coffee & 1 & $1 \%$ & & & & g. Fish & 1 & $1 \%$ \\
\hline e. Fruits & 1 & $1 \%$ & & & & $\begin{array}{l}\text { i. Fish (whole, } \\
\text { fillet) }\end{array}$ & 0 & $0 \%$ \\
\hline $\begin{array}{l}\text { f. Legumes and } \\
\text { oilseed }\end{array}$ & 12 & $9 \%$ & & & & ii. Processed fish & 1 & $1 \%$ \\
\hline i. Beans & 5 & $4 \%$ & & & & $\begin{array}{l}\text { h. Breakfast } \\
\text { products }\end{array}$ & 1 & $1 \%$ \\
\hline $\begin{array}{l}\text { ii. Sesame and } \\
\text { sesame oil }\end{array}$ & 5 & $4 \%$ & & & & i. Snacks & 9 & $8 \%$ \\
\hline $\begin{array}{l}\text { iii. Soybean and } \\
\text { soybean oil }\end{array}$ & 2 & $2 \%$ & & & & j. Soups & 3 & $3 \%$ \\
\hline $\begin{array}{l}\text { iv. Sunflower and } \\
\text { sunflower oil }\end{array}$ & 0 & $0 \%$ & & & & k. Other & 44 & $37 \%$ \\
\hline
\end{tabular}




\section{Analytical methods and outcome}

Various analytical methods were used for aflatoxin detection as shown in Figure 6. In general, the use of immunochemistry methods such as ELISA, dip stick test, sensor (82 studies, 30\%) and liquid chromatography (HPLC) $(85,31 \%)$ with fluorescence detection or post-column derivatization were most commonly reported, followed by detection using LC-MS (48, 17\%) and TLC (33, 12\%). Fifteen percent of the studies reported the use of other methods such as UPLC (ultra-high liquid chromatography), GC-MS (gas chromatography-mass spectrometry), use of immuno-affinity columns for clean-up, and some others which were not clearly specified. 88\% (242) of the studies reported quantitative outcomes, while the remaining reported qualitative results (or non-applicable).

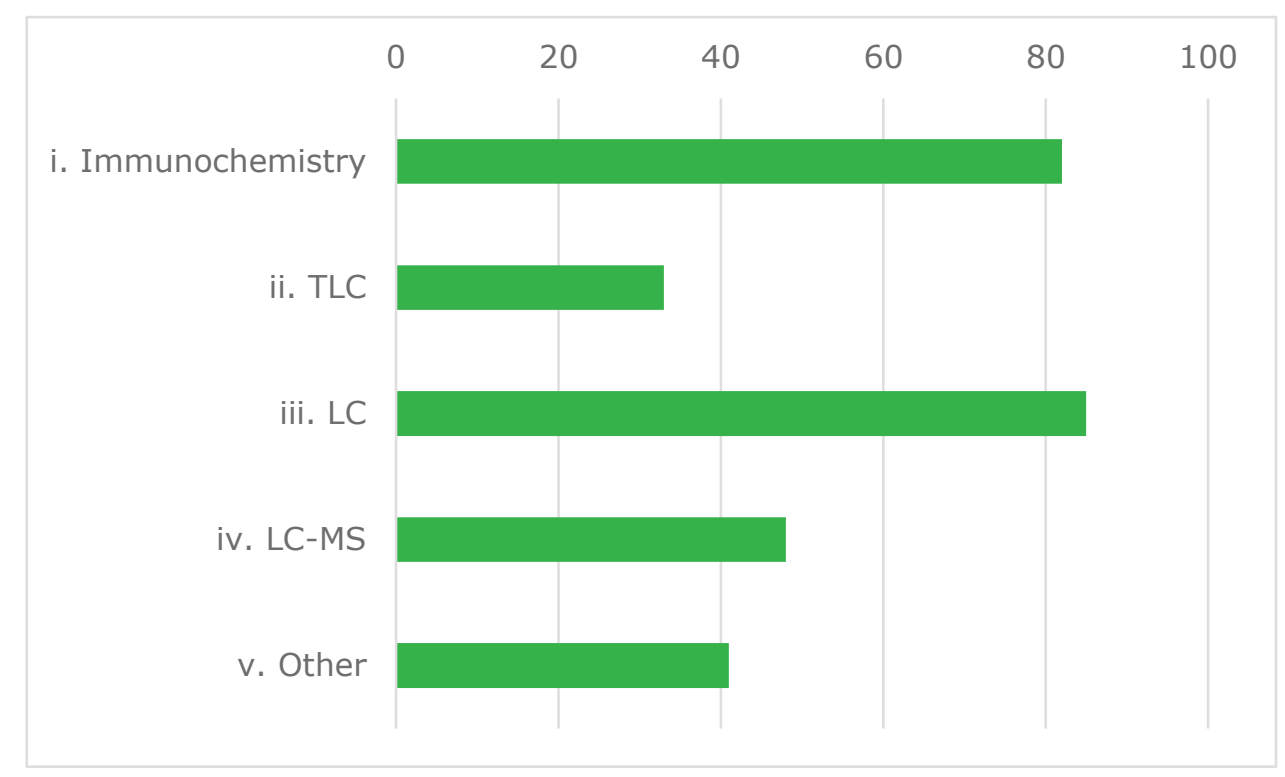

Figure 6: Distribution of number of analytical methods reported in the included studies for analysis of aflatoxin detection

\section{Quality appraisal}

Included studies for the category scale and geographical spread of aflatoxin contamination were appraised for quality: based on sampling procedures, analytical methods, and presentation of results. Around $83 \%$ of the included studies presented clear and general details of the sampling procedures, such as how and which materials were sampled, size and number of samples taken. Almost half of the studies $(48 \%)$ also reported storage conditions of the samples preventing increase of mycotoxin contamination before analysis, such as by refrigeration. It must be noted that some studies may have taken these precautions but did not mention them; or that analysis followed sampling immediately. Only $24 \%$ of the studies specifically reported both samples size and population.

With regard to analytical methods, clear details on analytical methods, such as using validated or official analytical method, calibration of the method has been done was provided in $80 \%$ of the included studies. Meanwhile, the remaining studies did not describe the methods clearly, such as only mentioning which machine was used, or very limited elaboration. The vast majority of the studies (98\%) presented quantitative data, while the remaining provided extractable quantitative data such as supplementary spreadsheets. Of the total number of studies (275) that was assessed to be relevant for the question on scale and geographical spread of aflatoxin contamination in Africa, a much smaller number of studies gave quantitative results of sufficient quality (36). Only those 36 studies are discussed in section 5.1 below.

\subsubsection{Disease burden}

In total, 25 studies were relevant for the research question disease burden. An additional 24 studies were relevant for biomarkers, which were coded separately. Most studies were identified in Egypt followed by Nigeria, Kenya, and other countries such as Ghana, Tanzania, and Uganda. 
Certain members of the population may pose higher risk to aflatoxin exposure, thus causing increased health risks. Studies on disease burden could be targeted to various population groups of interest. The distribution of the population presented in the included studies is shown in Figure 7. In general, most included studies focused on infants \& children.

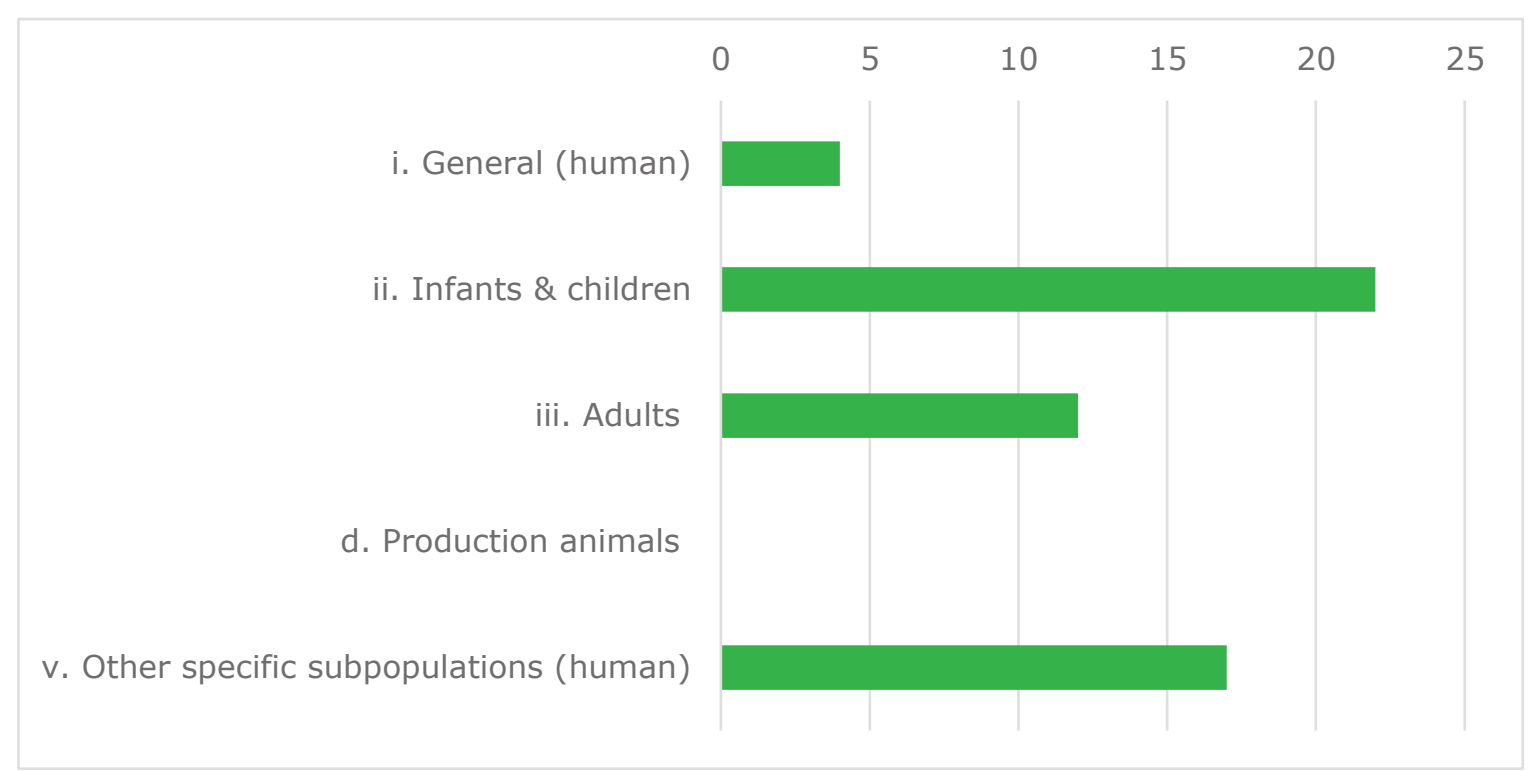

Figure 7: Distribution in the included studies of target population (\%)

Meanwhile, humans in general and specific subpopulations were also reported with less frequency, for examples rural population, patients with liver cancers and other liver diseases, lactating mothers, etc.

Exposure to aflatoxin is attributed to various routes, mainly from human diets. Around $50 \%$ (12) of the included studies investigated consumption of plant-based foods (cereals, groundnuts, etc.), dairy products and breast milk (26\%), and other type of foods such as weaning food, meat, and food in general.

\section{Disease symptoms and outcomes for disease occurrence}

Several included studies investigated disease symptoms in humans. Most included studies in hepatocellular carcinoma (33\%) and growth impairment in children (38\%) (Figure 8). Other diseases associated with aflatoxins were not found, such as liver/ spleen enlargement, acute aflatoxicosis.

Two included studies reported on DALY calculations, while no parameters for QALY calculation were presented in the identified studies. 


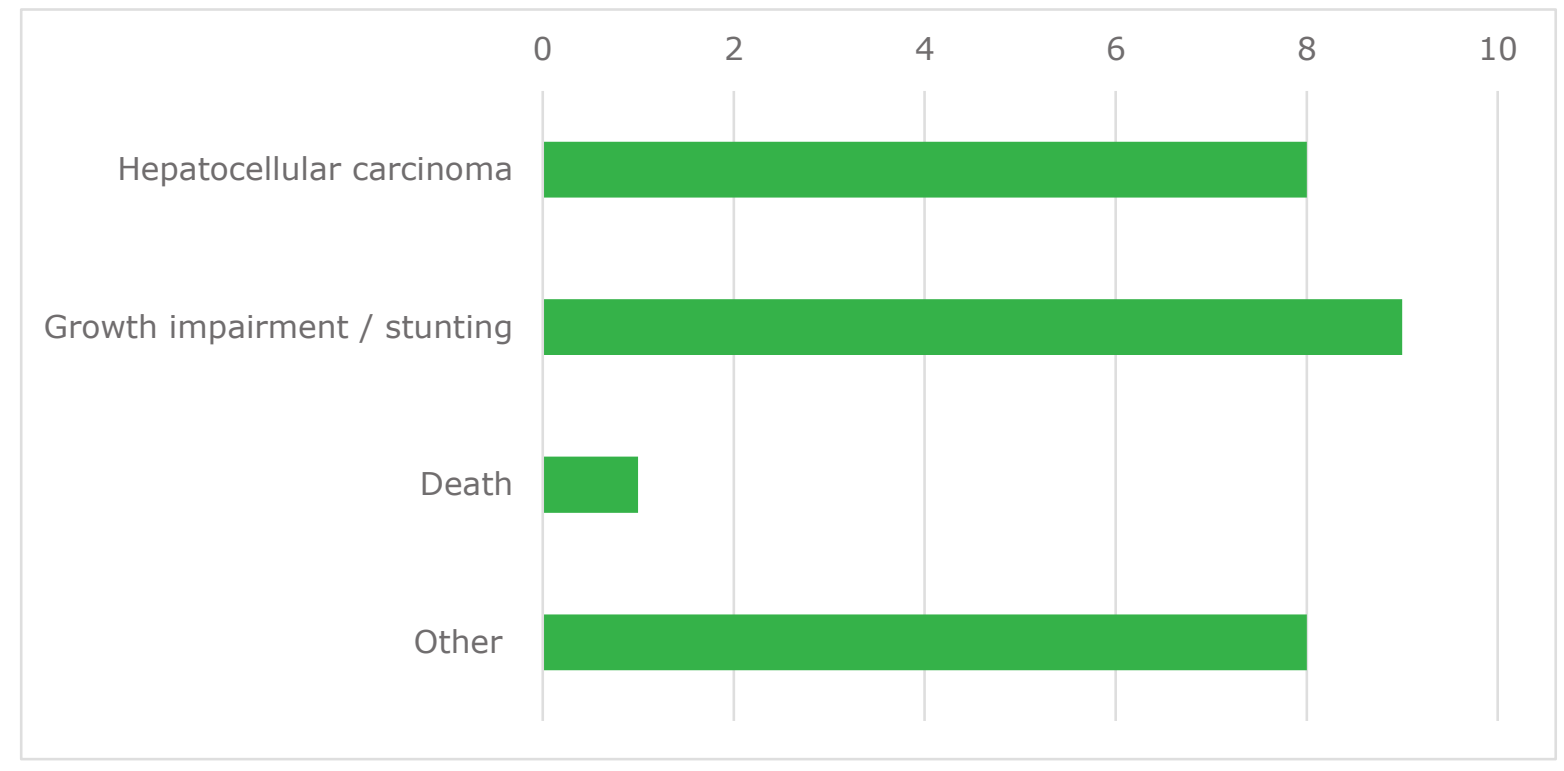

Figure 8: Number of included publications discussing specific disease symptoms

Nine included studies report on the estimation of exposure to aflatoxin via biomarkers, via consumption data for aflatoxin-contaminated foods in 12 studies, and 3 studies estimated it in a different manner. The manner via which identified studies estimated disease occurrence are shown in Figure 9. Most studies (9) indicated the outcome by physical parameters (body height, weight), followed by epidemiology (incidence/prevalence) and other (5), and not applicable (3).

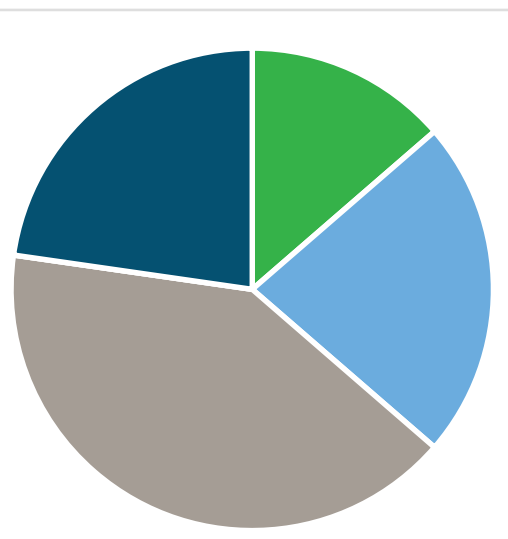

- Not applicable

- Epidemiology (incidence/prevalence)

- Physical (body height, weight)

- Clinical (liver / spleen size)

- Other

Figure 9: Distribution of number of included studies outcome of disease occurrence related to aflatoxin 
With regard to the parameters given for DALY calculation, the number of publications indicating those are shown in Figure 10. The number of publications reporting DALY parameters related to aflatoxin exposure is two. No studies reporting QALY parameters were identified.

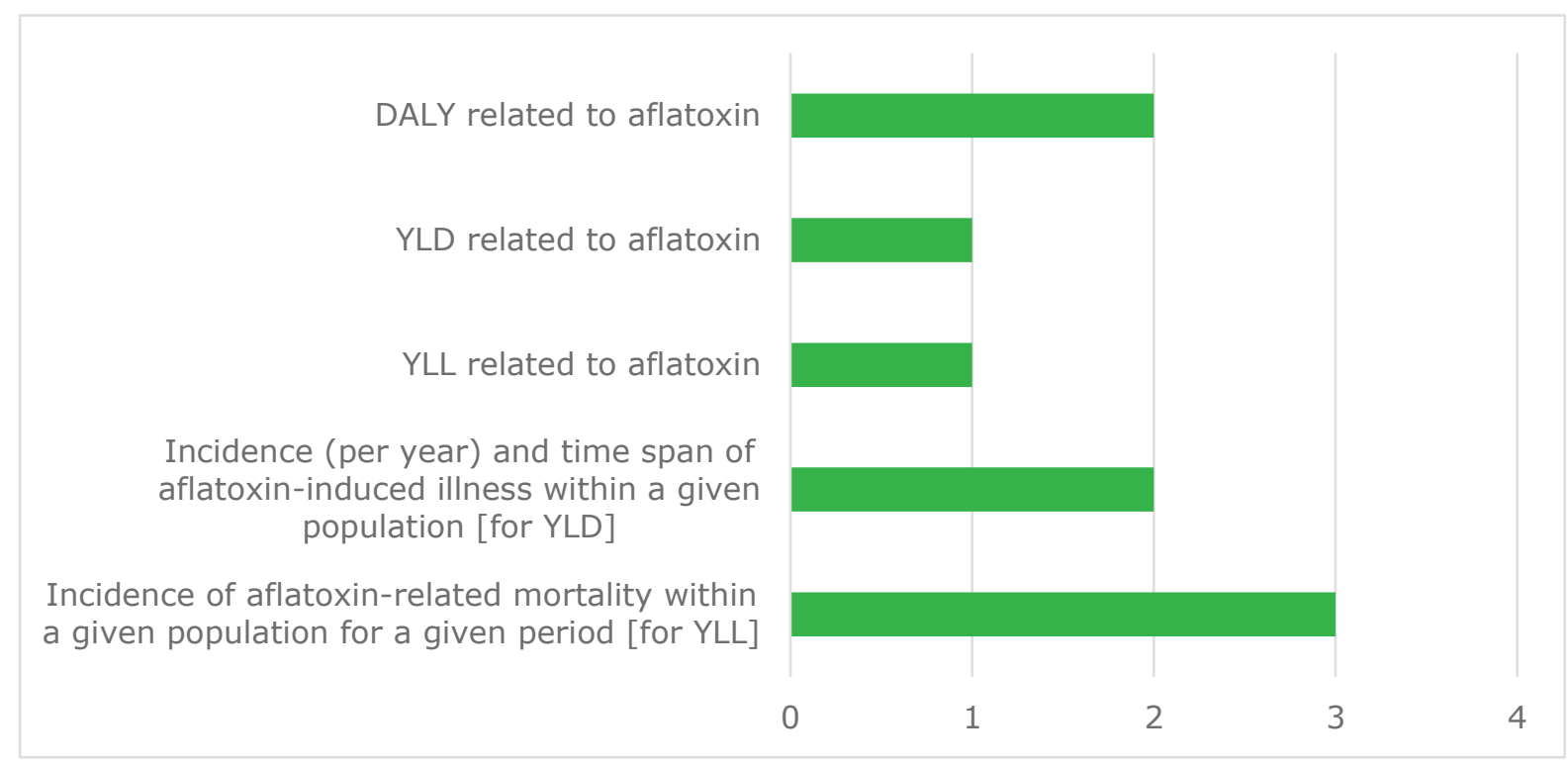

Figure 10: Number of included publications giving parameters for DALY calculation

\section{Biomarkers}

Of the 24 included studies specifically for biomarkers, nine focused on urinary biomarkers and 17 on biomarkers in serum (e.g. AF-albumin adduct). The route of exposure for the biomarker studies was mostly via plant foods (e.g. peanuts, cereals, etc.) (11 studies), or not specified (9 studies). In one case the investigated route of exposure was dairy products and in three cases other routes of exposure than oral were assessed. The method of analysis was immunochemistry (e.g. ELISA, dip stick test, sensor) in 11 cases; HPLC and LC-MS/MS in 5 cases each; and another analytical method was used in 4 cases.

\section{Quality appraisal}

With regard to the selection of populations, a rationale for the selection of the population (e.g. highrisk, history of disease incidence) is provided in 20 studies; this was done in another way for 2 studies. With regard to the disease being clearly linked to aflatoxin exposure (e.g. correlation with biomarkers or with consumption of aflatoxin-contaminated foods), this was done in 13 studies while the disease occurrence has truly been measured (rather than being estimated) in 10 studies. In 3 studies, other causes or interacting factors had been taken into account. With regard to disease burden, the impact of disease is expressed quantitatively beyond prevalence/incidence alone as DALYS/QALYs, VSLs for 3 studies while this was done in a different way in 11 studies. Finally, in 21 studies quantitative data has been reported - in one study this data was extractable.

\subsubsection{Economic impact}

In total, 11 studies were included to be related to economic impact; 10 studies from bibliographical searches and 1 study was from additional searches. Most included studies concerned Kenya (4); 2 studies Malawi and Nigeria, and a single study each for Egypt, Tanzania and Benin. One study (Xiong \& Beghin, 2012) investigated the economic impact on nine leading groundnut exporters including Chad, Egypt, Gambia, Mali, Nigeria, Sudan, Senegal, South Africa and Zimbabwe. Two included studies investigated the economic impacts on trade-related effects. Eight included studies did so for the impact at firm level. One included study investigated the health impact.

\section{Trade-related effects}

The exports reduced due to legal limits of other developing countries (importing countries); and other effects were all described in 1 study each respectively. An econometric estimation was made in one included study, two studies estimated these effects in a different manner. 


\section{Impact at firm level}

Two included studies measured the impact at firm level by assessing productivity loss due to contamination; four measured this via costs of managing aflatoxin at the farm level - compliance costs; and three did so in another manner. Four studies estimated this impact via an econometric estimation; the same number of studies did this in a quantitative manner, e.g. a questionnaire; one study measured this in a different manner.

\section{Quality appraisal}

The quality appraisal criteria and the number of publications that were coded as such, are shown in Figure 11. As can be seen, all studies focused on products relevant for aflatoxins. Confounding factors were taken into account in only 4 studies.

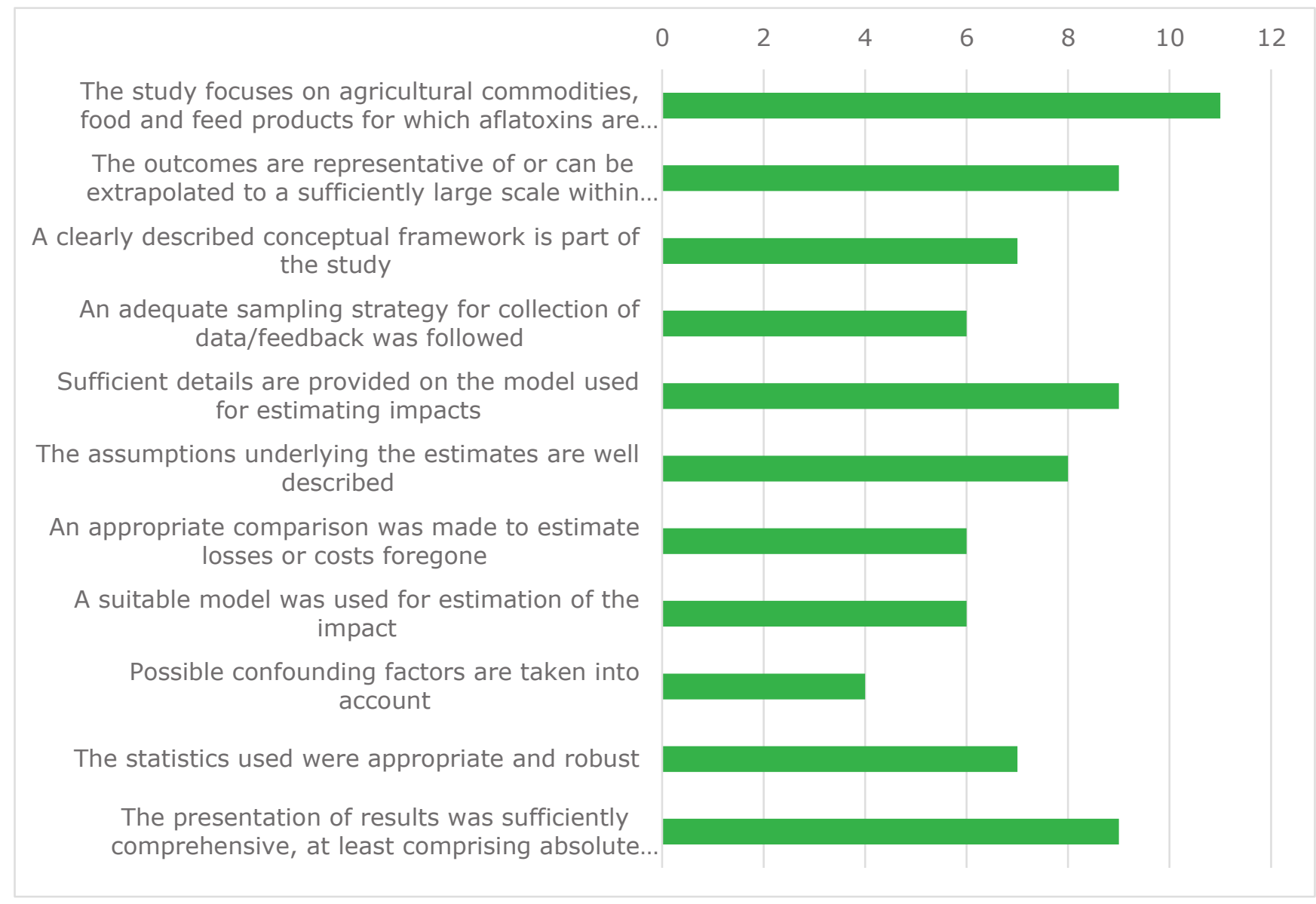

Figure 11: Number of included publications coded per quality appraisal criterion.

\subsubsection{Mitigation measures}

In total, 60 studies were included related to mitigation measures. Included studies were mainly reported for Kenya (13); followed by Egypt (7), and Nigeria (9).

\section{Scope - economic operators concerned and production stage considered}

The economic operators concerned for the mitigation measures described in the included studies were largely small scale, local: smallholder farms, village processing, local middlemen and vendors, etc. (28). Four were large-scale/industrial economic operators and 16 were other. The number of included publications per production stage is shown in Figure 12. Most publications considered agricultural production (17) or post-harvest storage (16); followed by processing (14). 


$\begin{array}{llllllllll}0 & 2 & 4 & 6 & 8 & 10 & 12 & 14 & 16 & 18\end{array}$

Agricultural production (e.g. resistant crop varieties, pre-harvest crop production, on-farm...

\section{Post-harvest storage}

Logistics/transport

Food and feed processing

Consumption and diet (e.g. raising consumers' awareness of toxicity of mold-infected foods; ... Clinical (e.g. immunization against aflatoxins in livestock and vaccination against hepatitis...

\section{Retailers \\ Other}

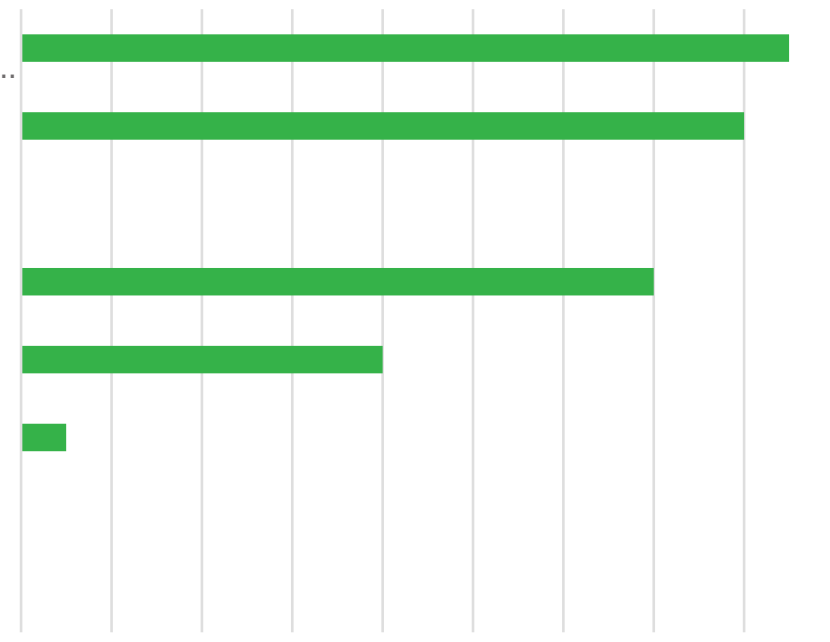

Figure 12: Number of included publications per production stage.

\section{Mitigation measure and outcome}

The number of included publications per type of mitigation measure is shown in Figure 13. Most mitigation measures from the included studies focus on agricultural (16) or biological (12) measures, or other (16) practices. The number of included publications per type of outcome described is shown in Figure 13. Most included studies focused on reducing aflatoxin contamination.

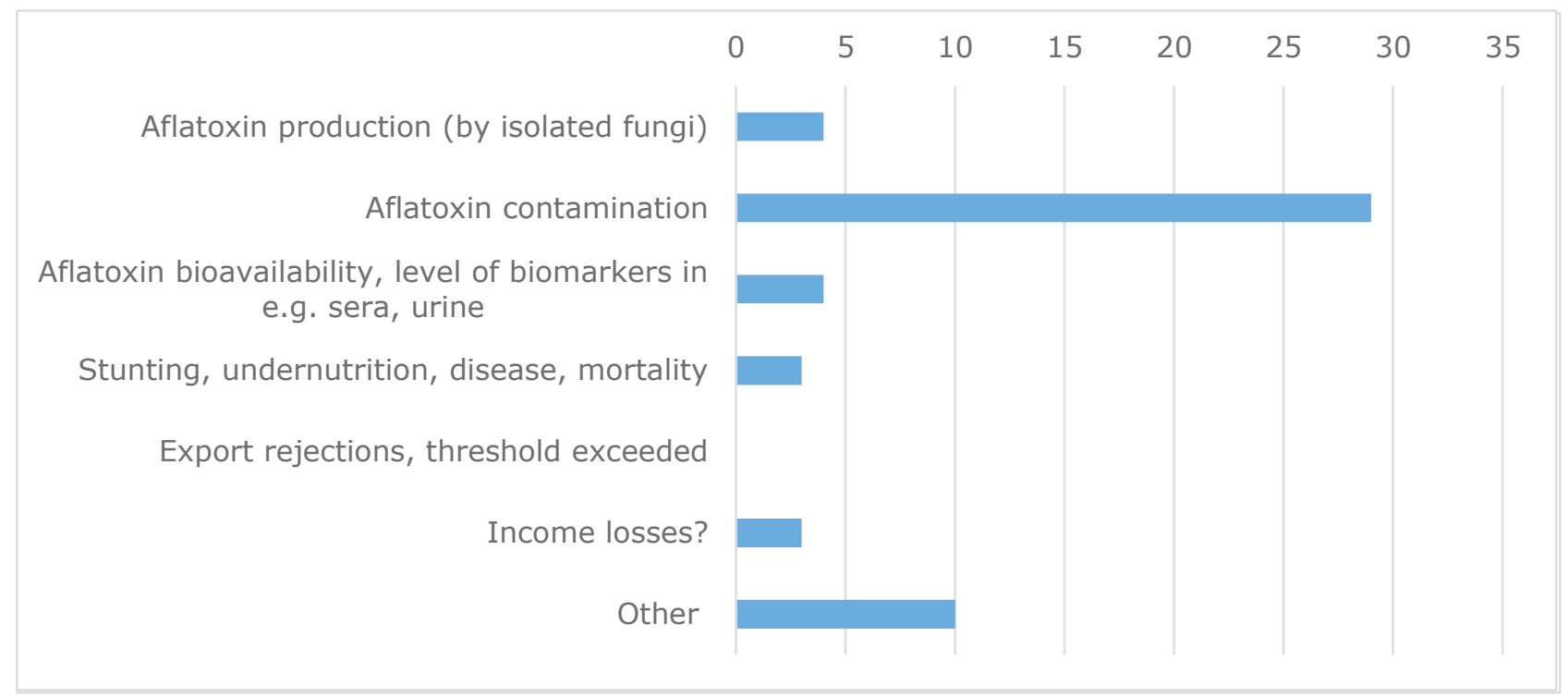

Figure 13: Number of included publications per type of outcome described.

\section{Impacts}

The impact of mitigation measures described in the included studies was done in varying manners. For six studies the impact was described in a monetary value. It appears that most studies did not describe the impact of the mitigation measure.

The baseline comparator used in most studies (26) was parallel: non-treated control samples / populations. For 11 included studies this was done in a sequential manner (change from previous situation in same population); and for 9 in another manner.

Costs/inputs were described in a monetary value in 6 studies, and a non-monetary value in the case of 24 studies. 


\section{Quality appraisal}

The number of included publications coded per quality appraisal criterion is shown in Figure 14. Approximately $75 \%$ (46) of the included studies focuses on agricultural commodities, food and feed products for which aflatoxins are known to be problematic, or on human or animal health problems to which aflatoxins are known to substantially contribute. Just over $2 / 3$ of the total included studies propose mitigation measures that were tested under or relevant to African conditions. The cost effectiveness expressed as investment per benefit gained (e.g. USD/DALY) was described in only a single study.

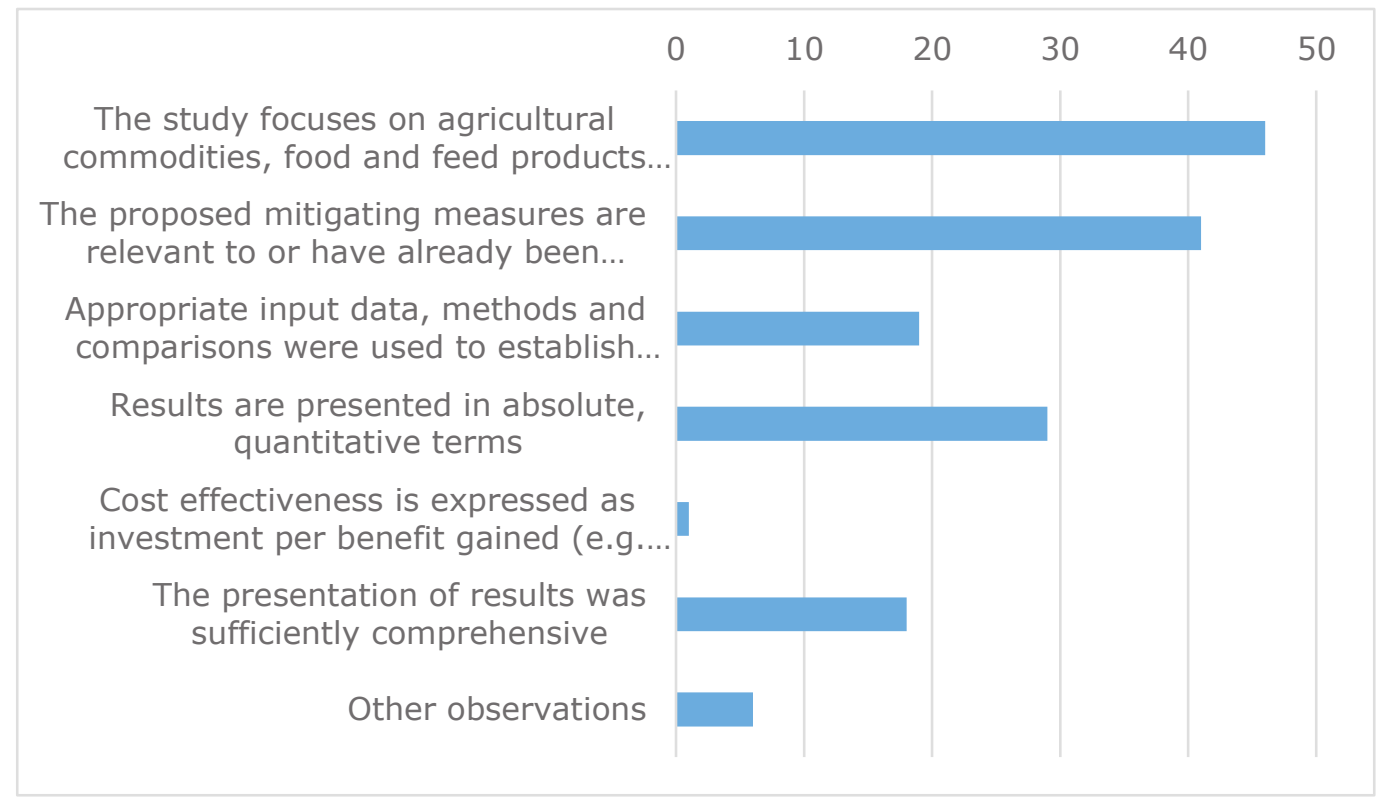

Figure 14: Number of included publications coded per quality appraisal criterion. 


\subsection{Summary}

The sequential results of the screening and extraction protocol is shown in Figure 15.

EndNote: search and pre-screening

EPPI tool: screening and coding

Identified studies

(6.374)

Pre-screening

(2.308)

De-duplication

(1.211)
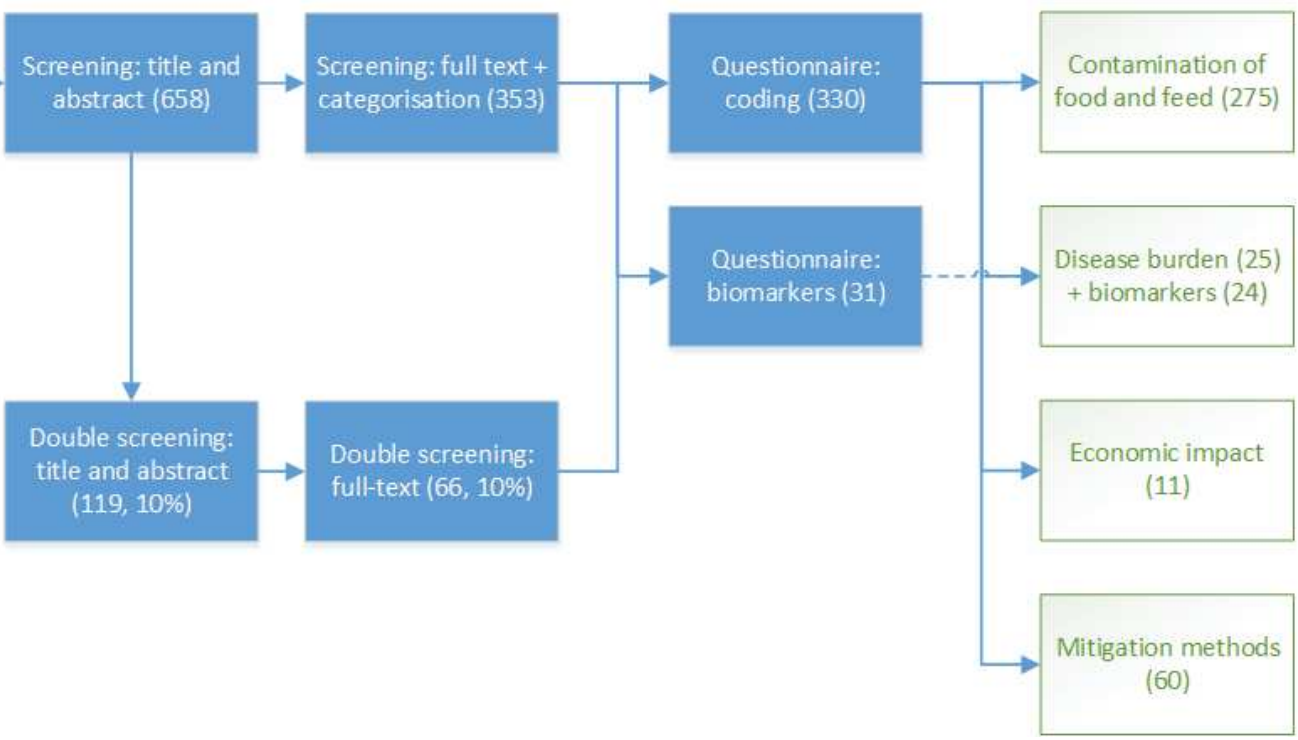

Figure 15: Overview of steps conducted in systematic review. 


\section{$5 \quad$ Results}

\subsection{Scale and geographical spread of contamination}

\subsubsection{Scale of aflatoxin contamination}

In 27 included studies, AFB1 was quantified in various products, with maize as the most frequently studied product in 9 publications. All studies indicated mean AFB1 in maize $>5 \mu \mathrm{g} / \mathrm{kg}$, which is the legal limit for AFB1 in EU regulation, except one study by Mngqawa et al. (2016) in South Africa and one by Diedhiou et al. (2011) in Senegal in which AFB1 levels were below $1 \mu \mathrm{g} / \mathrm{kg}$. Not all studies reported the prevalence of positive samples, but the highest prevalence was $67.1 \%$ (total samples 70 ) in Nigeria (Adetunji et al., 2014) and the lowest prevalence rate was $0 \%$ in South Africa; specifically samples from Gert Sibande District Municiality (GDSM, Mpumalanga Province) in sampling time year 2011 (Mngqawa et al., 2016).

Six included studies that investigated peanuts found AFB1 concentrations in peanut to be relatively high ( $>15 \mu \mathrm{g} / \mathrm{kg}$ set by CODEX), with only samples from Algeria having a lower mean concentration of $6.3 \mathrm{\mu g} / \mathrm{kg}$ (Magembe et al., 2016a, 2016b; Magembe et al., 2016c; Oyedele et al., 2017; Riba et al., 2013). Meanwhile, four included studies estimated AFB1 in African dishes, such as dagwa and kurukuru (both are groundnut based snacks) and fufu (maize dish) in Cameroon; iru, ogiri and peanut cake in Nigeria. Ogiri, kuru-kuru, and dagwa contained mean AFB1 $>5 \mu \mathrm{g} / \mathrm{kg}$, concentrations in peanut cake ranged from 2,824 to $13 \mu \mathrm{g} / \mathrm{kg}$, and only fufu and iru contained low concentrations of 0.9 $\mu \mathrm{g} / \mathrm{kg}$ and $<0.3 \mu \mathrm{g} / \mathrm{kg}$ respectively (Abia et al., 2017; Abia et al., 2013b; Adedeji et al., 2017; Ezekiel et al., 2013; Nishimwe et al., 2017).

In general, AFB1 contamination in various products measured in multiple countries were relatively high, with the highest mean AFB1 concentration recorded in maize from Egypt; $440 \mu \mathrm{g} / \mathrm{kg}$ (ElShanshoury et al., 2014). The highest specific concentration found was $6,738 \mu \mathrm{g} / \mathrm{kg}$ detected in Nigeria in 2012 (Adetunji et al., 2014). Only few studies indicated relatively low mean AFB1 <1 $\mu \mathrm{g} / \mathrm{kg}$; i.e. sugarcane juice from Egypt (Abdallah et al., 2016), maize from GDSM-Mpumalanga, South Africa (Mngqawa et al., 2016), sesame from Nigeria (Ezekiel et al., 2012b), fufu (maize dish) from Cameroon (Abia et al., 2017), iru from Nigeria (Adedeji et al., 2017), maize and sesame in Senegal (Savannah Guinea zone- Kolda and Sedhiou) and sesame from Sudan Savannah zone Kaffrine and Nioro (Diedhiou et al., 2011), wheat in Egypt (El-Shanshoury et al., 2014), sesame from Sudan (Idris et al., 2010). Levels in samples of animal feed taken from manufacturers were between $<1$ and 4,682 $\mu \mathrm{g} / \mathrm{kg}$ (Senerwa et al., 2016).

Total AF was also analysed in seven included studies, mostly in maize, with a relatively wide contamination range from 0 to $4,839 \mu \mathrm{g} / \mathrm{kg}$, with the highest contamination levels in Benin, Niger, Kenya, and Malawi (Bakoye et al., 2017; Kana et al., 2013; Mutiga et al., 2014; Mwalwayo \& Thole, 2016).

AFM1 was estimated in seven studies in milk, maize and animal feeds. The highest mean contamination in milk was in samples from rural area in South Africa with a mean level $2.38 \mu \mathrm{g} / \mathrm{kg}$, while the maximum level was detected in Kenya, which was as high as $6.99 \mu \mathrm{g} / \mathrm{kg}, 140$ times higher than the maximum level set by CODEX for AFM1 in milk of $0.5 \mu \mathrm{g} / \mathrm{kg}$ (Mwanza et al., 2015; Senerwa et al., 2016).

\subsubsection{Geographical spread and key value chains.}

As is shown in section 4.3.2 and Annex 9, the three countries from which most studies were included were Nigeria (56 studies), Egypt (41) and Kenya (33). Raw data of the geographical spread of characteristics of selected included studies are shown in Annex 10. Table 36 (Annex 10) shows the type of aflatoxin per included study per country. AFB1 is the most studied metabolite for all countries, followed by B2, G1, and G2, which are usually analysed by way of a multi-toxin analysis. Table 11 
below shows the overlap between the aflatoxin types studied. In approximately 105 studies, more than one aflatoxin type (AFB1, B2, G1, or G2) was analysed. The number of included studies in which a full multi-toxin analysis was done of at least those four metabolites was 95 . The overlap between these four metabolites and studies analysing AFM1 is much lower ( 25 for AFB1 and 16 for the three other metabolites), and the number of included studies in which all five aflatoxins were analysed was 15.

Table 11: Number of included studies showing overlap in aflatoxin type studied

\begin{tabular}{|l|c|c|c|c|c|c|}
\hline & AFB1 & AFB2 & AFG1 & AFG2 & AFM1 & $\begin{array}{l}\text { Aflatoxins, } \\
\text { general }\end{array}$ \\
\hline AFB1 & $\mathrm{x}$ & 109 & 104 & 96 & 25 & 3 \\
\hline AFB2 & 109 & $\mathrm{x}$ & 101 & 95 & 16 & 2 \\
\hline AFG1 & 104 & 101 & $\mathrm{x}$ & 97 & 16 & 1 \\
\hline AFG2 & 96 & 95 & 97 & $\mathrm{x}$ & 16 & 1 \\
\hline AFM1 & 25 & 16 & 16 & 16 & $\mathrm{x}$ & 0 \\
\hline $\begin{array}{l}\text { Aflatoxins, } \\
\text { general }\end{array}$ & 3 & 2 & 1 & 1 & 0 & $\mathrm{x}$ \\
\hline
\end{tabular}

In Table 37 (Annex 10) the part of the production chain studied per country is shown. Notable is that for Egypt and Kenya, the included study focus is largely on processed / retail / marketed products. The part of the production chain that studies focus on is more evenly distributed among studies conducted in Nigeria. The general lack of studies focusing on crops in the field can be explained because those studies appeared to focus more on types and contamination levels of aflatoxin producing moulds - these types of studies were excluded during screening because the research focus was on aflatoxin contamination.

Table 38 (Annex 10) shows the generic category of products analysed in the included studies per country. Table 39 (Annex 10) shows the results for cereals and Table 40 (Annex 10) shows the results for legumes and oilseed and nuts - the three generic categories of raw agricultural products studied most often for aflatoxins. In almost all 26 African countries for which aflatoxin levels were reported in the included studies, at least one study focused on levels in maize - with the exception of Algeria, Libya, and Mali. Of the remaining countries, 20 had 1-5 studies focusing on maize. Outliers are Nigeria (8 included studies), Tanzania (11), and Kenya (14). For peanuts (39 studies of 41 studies on nuts in total), the number of included studies per country is also relatively evenly distributed: of the 17 countries that investigated aflatoxin contamination in peanuts, all had between 1-5 studies focusing on peanuts. Table 41 (Annex 10) shows the number of studies per country for animal products (raw) and food of animal origin. Only 13 of 26 of countries in the included studies that investigated aflatoxin levels, did so for animal products. The highest number of studies for the animal product (raw) milk was for Kenya (6 studies), but for the combined total of all studies investigating milk, the highest number was for Egypt (11 in total; 7 for Kenya). Relatively few included studies explored aflatoxin levels in meat (6) and fish (3), and these studies were almost all done in Egypt (4/6 for meat; $1 / 3$ for fish).

The majority of included studies focusing on African dishes were conducted in Nigeria (11/18). A single study on these types of products was performed in Benin, Ethiopia, Ghana, Morocco, and Tanzania each. Two studies were conducted in Cameroon. The African dishes/snacks reported were all plantbased and were largely peanut-based (peanut cake, kulikuli) or fermented cereals (Gbodo, fufu, ogi, ogi-baba) or fermented seeds (ogiri, iru, ugba).

For the 36 included studies, the primary reported findings were extracted, per commodity or product, per type of aflatoxin (B1, B2, G1, G2, M1, aflatoxins in general), and - if specified - per subpopulation studied. The full results are shown in Table 42 in Annex 11. A summary of this is shown in Table 12 and Table 13 below. Aflatoxin concentrations were classified: very low: mean (x) <LOD/LOQ (usually <1 $\mu \mathrm{g} / \mathrm{kg}$ ); low: $1<x<5 \mu \mathrm{g} / \mathrm{kg}$; high: $5<\mathrm{x}<100 \mu \mathrm{g} / \mathrm{kg}$; Very high: $>100 \mu \mathrm{g} / \mathrm{kg}$. With regard to AFB1 contamination, most studies (6) were conducted in Nigeria followed by Ethiopia and Tanzania (4 each). Nine out of eleven countries conducting studies on AFB1 had high to very high 
contamination. Sudan and Tunisia were the only countries with very low contamination level. Maize and peanut tend to be heavily contaminated. Animal feed also tend to have high level of contamination as shown by studies in Ethiopia, Kenya, and Nigeria. It must be noted that the number of studies (and samples taken per study) highly differed per country, which makes it difficult to draw conclusions from this comparison.

Meanwhile, contamination levels for AFB in general are relatively low in Algeria, Malawi, Cameroon, and Tanzania. Other countries, i.e. Benin, Kenya, Niger, Senegal have low to high level of contamination, while Nigeria has very high level of contamination. Samples used for estimating AFB in general were primarily maize and peanut.

With regard to AFM1, only four studies reported the contamination levels in cow-milk. One study in South Africa indicated contamination level $>0.5 \mu \mathrm{g} / \mathrm{kg}$ in milk samples (the maximum limit set by CODEX) (Mwanza et al., 2015). Mean contamination levels in other countries, i.e. Morocco, Ethiopia and Kenya were below 0.5 mg/kg (Dawit et al., 2016; El-Marnissi et al., 2012; Senerwa et al., 2016). 
Table 12 : Overview of AFB1 contamination levels (The full results are shown in Table 42 in Annex 11)

\begin{tabular}{|c|c|c|c|c|c|c|}
\hline No & Country & $\begin{array}{c}\text { Number } \\
\text { of } \\
\text { studies }\end{array}$ & Samples & Contamination level* & Notes & Reference \\
\hline 1 & Algeria & 2 & peanut, spices & High & - & (Azzoune et al., 2016; Riba et al., 2013) \\
\hline 2 & Cameroon & 3 & $\begin{array}{l}\text { maize, peanut, dagwa and } \\
\text { kurukuru (peanut based } \\
\text { snacks), fufu (maize dish) }\end{array}$ & high & $\begin{array}{l}\text { all AFB } 1 \\
\text { levels }>5 \\
\mu \mathrm{g} / \mathrm{kg} \text { except } \\
\text { in fufu }\end{array}$ & (Abia et al., 2017; Abia et al., 2013b; Ediage et al., 2014) \\
\hline 3 & Egypt & 3 & $\begin{array}{l}\text { maize, peanut, wheat, } \\
\text { sugarcane (fruit and juice), } \\
\text { dried dates }\end{array}$ & high/ very high & $\begin{array}{l}\text { high level } \\
\text { contamination } \\
\text { on sugarcane } \\
\text { fruit, and } \\
\text { very high on } \\
\text { maize and } \\
\text { peanut. No } \\
\text { positive } \\
\text { samples in } \\
\text { wheat }\end{array}$ & (Abdallah et al., 2016, 2018; El-Shanshoury et al., 2014) \\
\hline 4 & Ethiopia & 4 & Maize, animal feed, sorghum & high & - & (Dawit et al., 2016; Getachew et al., 2018; Taye et al., 2018) \\
\hline 5 & Kenya & 1 & animal feeds & high/ very high & - & (Senerwa et al., 2016) \\
\hline 6 & Nigeria & 6 & $\begin{array}{l}\text { maize, sesame oil, animal } \\
\text { feeds, peanut and peanut } \\
\text { based products (peanut } \\
\text { cake, ogiri, iru) }\end{array}$ & very low/high- very high & $\begin{array}{l}\text { very low } \\
\text { contamination } \\
\text { in iru and } \\
\text { sesame; high } \\
\text { and very high } \\
\text { on the rest of } \\
\text { the products }\end{array}$ & $\begin{array}{l}\text { (Adetuniji et al., 2014; Adetunji et al., 2014; Ezekiel et al., 2012a; } \\
\text { Ezekiel et al., 2013; Ezekiel et al., 2012b; Ezekiel et al., 2012c; } \\
\text { Oyedele et al., 2017) }\end{array}$ \\
\hline 7 & Rwanda & 1 & maize & high & - & (Nishimwe et al., 2017) \\
\hline 8 & South Africa & 1 & maize & low/ high & - & (Mngqawa et al., 2016) \\
\hline 9 & Sudan & 1 & sesame oil & very low & - & (Idris et al., 2010) \\
\hline
\end{tabular}




\begin{tabular}{|c|c|c|c|c|c|c|}
\hline No & Country & $\begin{array}{c}\text { Number } \\
\text { of } \\
\text { studies }\end{array}$ & Samples & Contamination level* & Notes & Reference \\
\hline 10 & Tanzania & 4 & maize, peanut & high/ very high & - & $\begin{array}{l}\text { (Kamala et al., 2015; Magembe et al., 2016a, 2016b; Magembe et } \\
\text { al., 2016c) }\end{array}$ \\
\hline 11 & Tunisia & 1 & sorghum & Very low & - & (Oueslati et al., 2014) \\
\hline
\end{tabular}

*: very low: mean $(\mathrm{x})<\mathrm{LOD} / \mathrm{LOQ}$ (usually $<1 \mu \mathrm{g} / \mathrm{kg}$ ); low: $1<\mathrm{x}<5 \mu \mathrm{g} / \mathrm{kg}$; high: $5<\mathrm{x}<100 \mu \mathrm{g} / \mathrm{kg}$; Very high: $>100 \mu \mathrm{g} / \mathrm{kg}$

Table 13 : Overview of Aflatoxins in general/ total (The full results are shown in Table 42 in Annex 11)

\begin{tabular}{|c|c|c|c|c|c|c|}
\hline No & Country & $\begin{array}{l}\text { Number of } \\
\text { studies }\end{array}$ & Samples & $\begin{array}{c}\text { Contamination } \\
\text { level* }\end{array}$ & Notes & Reference \\
\hline 1 & Algeria & 1 & peanut & low & & (Riba et al., 2013) \\
\hline 2 & Benin & 1 & maize & $\begin{array}{l}\text { very low to very } \\
\text { high }\end{array}$ & $\begin{array}{l}\text { Mean level was not } \\
\text { indicated, only the } \\
\text { range } 0-3000 \mu \mathrm{g} / \mathrm{kg}\end{array}$ & (Bakoye et al., 2017) \\
\hline 3 & Cameroon & 1 & animal feeds & low & $\begin{array}{l}\text { mean } 2 \mu \mathrm{g} / \mathrm{kg} ; \\
\text { maximum range } \\
\text { detected } 950 \mu \mathrm{g} / \mathrm{kg}\end{array}$ & (Kana et al., 2013) \\
\hline 4 & Kenya & 1 & maize & low to very high & $\begin{array}{l}\text { Mean level was not } \\
\text { indicated, only the } \\
\text { range } 8-4839 \mu \mathrm{g} / \mathrm{kg}\end{array}$ & (Mutiga et al., 2014) \\
\hline 5 & Malawi & 1 & maize & low & & (Mwalwayo \& Thole, 2016) \\
\hline
\end{tabular}




\begin{tabular}{|c|c|c|c|c|c|c|}
\hline No & Country & $\begin{array}{l}\text { Number of } \\
\text { studies }\end{array}$ & Samples & $\begin{array}{c}\text { Contamination } \\
\text { level* }\end{array}$ & Notes & Reference \\
\hline 6 & Niger & 1 & maize & $\begin{array}{l}\text { very low to very } \\
\text { high }\end{array}$ & $\begin{array}{l}\text { Mean level was not } \\
\text { indicated, only the } \\
\text { range } 0-3000 \mu \mathrm{\mu g} / \mathrm{kg} \\
\text { same study as in Benin }\end{array}$ & (Bakoye et al., 2017) \\
\hline 7 & Nigeria & 1 & peanut & very high & & (Oyedele et al., 2017) \\
\hline 8 & Senegal & 1 & maize, sesame & $\begin{array}{l}\text { very low to very } \\
\text { high }\end{array}$ & $\begin{array}{l}\text { Except from maize } \\
\text { samples from SG zone/ } \\
\text { Nioro and Kaffrine, all } \\
\text { other samples are very } \\
\text { low contaminated }\end{array}$ & (Diedhiou et al., 2011) \\
\hline 9 & Tanzania & 1 & maize & low & & (Suleiman et al., 2017) \\
\hline
\end{tabular}




\subsection{Disease burden}

\subsubsection{Disease burden expressed as DALY}

Havelaar et al. (2015) was the only included study discussing disease burden expressed as 'disabilityadjusted life years' (DALYs). The study is based on datasets obtained in 2010. Median rates of aflatoxin related DALY per 100,000 population were calculated for the global sub-regions used by WHO for the assessment of global disease burden that include the countries on the African continent: AFR$\mathrm{D}^{2,3}: 28$ (7-78); AFR-E ${ }^{4},: 3$ (1-8); EMR-B ${ }^{6},{ }^{7}: 0.7$ (0.2-3); and EMR-D $: 5$ (1-17). For all global subregions, the median rates for aflatoxin related DALY varied between 0.04 to 28 DALY per 100,000 population. The study showed that aflatoxins are considered the fourth cause of non-diarrheal foodborne deaths, after Salmonella Typhi, Taenia solium and hepatitis A virus. Almost all countries report the burden of aflatoxin as premature mortality (YLL), and that that the burden of aflatoxin lays in the group older than 5 years of age. Aflatoxin was considered an important hazard in the African countries in the sub-region EMR-D of which 6 countries in Africa (Egypt, Sudan, South Sudan, Djibouti, Somalia, and Morocco). Aflatoxin was by far the most important in the group of the chemical hazards under investigation: aflatoxins, cassava cyanide and dioxins. The authors indicate that incidence data are difficult to obtain and that extrapolating from neighbouring countries was used for the estimations (Havelaar et al., 2015).

Narayan et al. (2014) estimated for males in Nigeria 12.3 DALY per HCC case and for females 13.8 DALY per HCC case. They estimate that if hepatitis B prevalence was reduced to zero, the incidence of HCC would drop with a three-fold form $4.9 \%$ to $1.7 \%$ per 1000 persons. The same data were presented by Ndenn et al. (2015) at the PACA First Africa Symposium of Mycotoxicology in 2015.

\subsubsection{Disease burden expressed as the risk on adverse health effects resulting from exposure to aflatoxins}

Ediage et al. (2014) estimated exposure of the Cameroun population to aflatoxin intake from maize, peanut, and cassava. These authors compared aflatoxin intake of the population to a concentration of $0.15 \mathrm{ng} / \mathrm{kg}$ bw per day, which was calculated from the mean of the range $0.11-0.19 \mathrm{ng} / \mathrm{kg}$ bw per day estimated in 1995, for African and Asian populations possible predisposed to HBV infection. This what they call a "TDI" was defined as a cancer risk level of 10-5, which was considered to pose a negligible risk to health. It should be noted that TDI does not apply to carcinogens. They concluded that exposure could exceed the "TDI" by $10^{4}-10^{5}$ fold (Ediage et al., 2014).

Adetunji et al. (2017) based their risk assessment for Nigeria on the margin of exposure (MOE) approach, the state-of-the-art assessment for genotoxic carcinogens (Adetunji et al., 2017). If this margin between the benchmark dose lower limit $\left(B M D L 10^{9}\right.$ ) and the exposure is below 10,000 , this indicates a reason for concern and mitigation strategies must be explored. The authors used the BMDL of $170 \mathrm{ng} / \mathrm{kg}$ bw per day as established by the European Food Safety Authority in 2007 (EFSA, 2007). The study revealed that the MOE for aflatoxins in Nigeria were below two in all four agro ecological zones for infants, children and adults when using the probably daily intake (PDI) approach for exposure assessment. Infants and young children (IYC) are at high risk. Mitigation strategies would be

\footnotetext{
${ }^{2}$ AFR-D: Algeria; Angola; Benin; Burkina Faso; Cameroon; Cape Verde; Chad; Comoros; Equatorial Guinea; Gabon; Gambia; Ghana; Guinea; Guinea-Bissau; Liberia; Madagascar; Mali; Mauritania; Mauritius; Niger; Nigeria; Sao Tome and Principe; Senegal; Seychelles; Sierra Leone; Togo.

3 Stratum D: high child and adult mortality,

${ }^{4}$ AFR-E: Botswana; Burundi; Central African Republic; Congo; Côte d'Ivoire; Democratic Republic of the Congo; Eritrea; Ethiopia; Kenya; Lesotho; Malawi; Mozambique; Namibia; Rwanda; South Africa; Swaziland; Uganda; United Republic of Tanzania; Zambia; Zimbabwe.

${ }^{5}$ Stratum E: high child mortality and very high adult mortality

${ }^{6}$ EMR-B: Bahrain; Iran (Islamic Republic of); Jordan; Kuwait; Lebanon; Libyan Arab Jamahiriya; Oman; Qatar; Saudi Arabia; Syrian Arab Republic; Tunisia; United Arab Emirates.

7 Stratum B: low child mortality and very low adult mortality

8 EMR-D: Afghanistan; Djibouti; Egypt; Iraq; Morocco; Pakistan; Somalia; South Sudan; Sudan; Yemen.

${ }^{9}$ 95\% lower confidence limit of the benchmark dose for a $10 \%$ increase in cancer incidence
} 
to encourage breast-feeding in first 6 months of life, and complementary foods should be diverse to include other foods less prone to mycotoxins (Adetunji et al., 2017).

Magoha et al. (2016) performed a risk assessment on aflatoxins for infants $<6$ month of age in Northern Tanzania consuming maize flour $(\mathrm{N}=98)$. Based on the BMDL10 of $170 \mathrm{ng} / \mathrm{kg}$ bw per day, calculated by the European Food Safety Authority in 2007, the MOE was well below 10,000 for the range of exposure (Magoha et al., 2016).

A study among 249 infants 6-12 months of age, in three agro-ecological zones in Tanzania revealed that the estimated intake of aflatoxin resulted in an estimated average MOE of 1.3 This really low MOE makes aflatoxin a priority for risk management and mitigation studies must be explored. This means that $100 \%$ of the population is at risk which highlights the need for urgent action (Kamala et al., 2017). They further studied the co-occurrence of other mycotoxins in the food.

The complexity of the situation is described by Shephard (2008a). In the paper, the liver cancer risk caused by aflatoxin is estimated at 11 and 0.0015 cancers per year per 100,000 population in Kenya and France respectively. However, the actual incidence of liver cancer in the EU in 1995 was estimated at 10 and 3.3 per 100,000 population for males and females respectively by Bray et al. (2002). This could indicate that that in the EU, liver cancer is induced by other causes than aflatoxin, but it might also result from lack of data on disease.

\subsubsection{Biomarkers of exposure}

Magoha et al. (2014) calculated the probable daily intake (PDI) of infants in Northern Tanzania to aflatoxin M1 via breast milk. AFM1 was detected in $100 \%$ of the breast milk samples and the PDI was estimated in the range of $1.13-66.79 \mathrm{ng} / \mathrm{kg}$ bw per day for the infants (Wambui et al., 2017).

Ayelign et al. (2017) studied aflatoxins in urine of 200 children age 1-4 in Ethiopia in 2016. Aflatoxins B2 (4.5\%), G1 (2.5\%), G2 (3\%) and M1 (7\%) were detected in $17 \%$ of the urines indicating exposure of the young children to aflatoxins (Ayelign et al., 2017).

A study was carried out in Egypt by Tomerak et al. (2011) on aflatoxin M1 occurrence in breast milk of 150 mothers of infants fed exclusively on breastmilk. AFM1 was detected in $65 \%$ of the breast milk samples above $0.05 \mu \mathrm{g} / \mathrm{L}$ and these mothers and infants were considered as positive group. Blood of both mothers and children in the positive group contained significantly more liver enzymes alanine aminotransferase (ALT) and aspartate aminotransferase (AST) than blood of both mothers and infants in the negative group. Elevated liver enzymes may indicate liver damage and be an alarm towards future development of HCC biomarkers of effect (Tomerak et al., 2011).

Onyemelukwe et al. (2012) detected aflatoxins more often and at higher concentration in blood and urine from children in Nigeria suffering from protein energy malnutrition (PEM) as compared to frequency and concentration in body fluids from healthy children. It is still uncertain if the elevated levels are results of higher exposure or impaired excretion (Onyemelukwe et al., 2012).

A study carried out in Egypt showed a correlation between increased Aflatoxin M1 levels in blood and high HCV titer in patients with chronic liver disease (El-Shahat et al., 2012).

Asiki et al. (2014) found that in Uganda in 2011 all of 100 adults and 92 of 96 children under 3 years of age had detectable levels of AF-alb adduct in their blood. Among the children were five babies that were exclusively breast-fed (Asiki et al., 2014).

Castelino et al. (2015) determined AF-alb adducts, IGF1 and IGFBP3 in blood of 99 schoolchildren in Kenya. They found that children with the highest AF-alb adducts were shorter than children with lower AF-alb adduct concentration in their blood. In addition, AF-alb adducts were inversely related to IGF1 and IGFBP3. It was calculated that IGF1 levels explained about $16 \%$ of the impact of aflatoxin exposure on child height $(\mathrm{p}=0.052)$. They concluded that aflatoxin induced changes in IGF protein levels could contribute to growth impairment when aflatoxin exposure is high (Castelino et al., 2015). 
Afum et al. (2016) pointed out the difficulties in relating aflatoxin to HCC. Since it may take up to two decades to develop HCC, it is difficult to relate HCC to current exposure to aflatoxins as almost all volunteers had positive aflatoxin M1. They raise the fact that females are partly protected from developing HCC because of the suppression of interleukin 6 (IL-6) production by oestrogen. IL-6 promotes inflammation in response to liver injury such as hepatitis B virus (Afum et al., 2016).

In anddition to aflatoxin $\mathrm{M} 1$, weaning children are exposed to aflatoxins via the weaning foods. Obade et al. (2015) showed that weaning children in Kenya might be at risk for aflatoxin exposure. All foods, except cassava, that are assumed to be used as weaning food, were contaminated with aflatoxins (Obade et al., 2015).

Comparing the probably daily intake (PDI) of aflatoxins via dates, with the PDI as calculated by the European Food Safety Authority (EFSA) in 2007 (EFSA, 2007), was used by Azaiez et al. (2015) to get insight in the contribution of contaminated dates to the exposure of Tunisian people to aflatoxins. They compared their estimated PDI of $0.29 \mathrm{ng} / \mathrm{kg}$ bw per day for aflatoxin in dates in Tunisia with the PDI of 0.69-1.934 ng/kg bw per day aflatoxins from all food for the EU population. It was emphasised that their study was limited to PDI of dates only and did not include other sources of aflatoxin; also comparing PDIs is not generally accepted as a proper exposure assessment study for the risk assessment (Azaiez et al., 2015).

\subsubsection{Overview of biomarker levels}

Table 43 in Annex 12 gives an overview of 23 peer reviewed included studies on biomarkers in African populations. Surveys were used in which AF-alb adduct in serum was measured and/or aflatoxin M1 in the urine. In general, AF-alb adduct or aflatoxin M1 was detected in almost all individuals in each group under investigation, meaning all the persons were exposed to aflatoxins at the time of the survey. The biomarkers are present in a large range of concentrations. Extremely high concentrations of aflatoxin M1 in urine were detected for a group children in Ghana. It must be taken into consideration that some groups represent persons with a specific condition, which may influence the rate of transfer of mycotoxins from food to urine.

\subsection{Economic impact}

In the literature search, only few included studies that estimate the economic impact of aflatoxins in Africa were found. While the data needed is not readily available, collecting the data necessary for gauging the economic impact is costly and not straightforward. This complexity of the economic analyses may add to the explanation of the gap in the literature.

Overall, the research submitted to peer reviewed journals on the economic impact of aflatoxins in Africa but also in other countries is very limited. The studies identified in this systematic literature review mainly the impact from the perspective of African producer or consumer at micro-level, while other studies look at the trade-related impact. For the trade-related studies the main focus is on the effect of regulation of aflatoxin in industrialised countries, often the EU, and the impact of these regulations on African exporters. Only one study investigates the health-related economic effect of aflatoxin, e.g. in terms of disease burden.

\subsubsection{Trade-related economic impact}

Two primary studies evaluate the trade-related impact of aflatoxin contamination, i.e. Edelman and Aberman (2015b) and Xiong and Beghin (2012). Edelman and Aberman (2015b) estimate the limiting factors of groundnut export to countries with legal limits of aflatoxin, such as EU and South Africa, by means of qualitative methods (semi-structured interview and forum group discussion) and trade data from 2004-2014. However, they did not quantify the loss in monetary value. The findings showed that Malawi tends to trade with countries enforcing less strict or no aflatoxin legal limits. Export to countries with lower than EU aflatoxin legal limits accounted only 4\% in 2014. However, Malawi's trading partners in Africa are currently working towards stricter common legal limits for aflatoxin. 
Thus, without promoting low-aflatoxin exports, there could be at least two consequences; decrease of export leading to fall in domestic price and increase of informal exports leading to loss on tax revenue and foreign exchange. Exporters are considered as the key actors in the chain of the Malawi groundnut sector, thus increasing price incentives for them to export low-aflatoxin groundnuts could also generate incentives to other upstream actors, including the farmers.

In addition, Senerwa et al. (2016) discussed direct market loss due to aflatoxin contamination in the Kenyan dairy chain, in feed (feed manufacturers and dairy farmers) and milk (dairy farmers). This study lacks an elaboration on method and results, but indeed mentioned the estimated loss. By estimating the proportion of samples exceeding aflatoxin legal limits, the losses were estimated as a function of annual production. The estimated losses were USD 22.2 million, USD 37.4 million, and USD 113.2 million for feed manufacturers, feed used by dairy farmers, and milk produced by dairy farmers (Senerwa et al., 2016).

The trade-related impact of aflatoxin contamination is mainly evaluated from the standpoint of aflatoxin regulation affecting products imported from developing countries, including Africa. The aflatoxin regulation investigated is mainly the EU legal limits that seems to have caught much attention in research of the quantitative effects of aflatoxin. In addition to study by Xiong and Beghin (2012), several studies evaluated the impact of EU regulation to African exporters since the year 2001. They were cited as the main source of qualitative results, as reported in many studies that were identified as relevant and thus identified by means of our snowballing strategy. The overview of these studies is presented in Table 14.

Table 14: Included studies analysing EU legal limits of aflatoxin in an econometric analysis.

\begin{tabular}{|c|c|c|c|c|}
\hline Study & Analytical method & Countries & Products & Data \\
\hline $\begin{array}{l}\text { (Otsuki et al., } \\
\text { 2001a) }\end{array}$ & $\begin{array}{l}\text { Econometric estimation - } \\
\text { Gravity model \& } \\
\text { simulation to estimate } \\
\text { the change of import } \\
\text { value due to new } \\
\text { harmonized EU standard } \\
\text { relative to CODEX and } \\
\text { pre-harmonized standard }\end{array}$ & $\begin{array}{l}\text { EU- } 15 \text { member states } \\
\text { Africa- } 9 \text { leading } \\
\text { exporters; } \\
\text { Chad, Egypt, the } \\
\text { Gambia, Mali, Nigeria, } \\
\text { Senegal, South Africa, } \\
\text { Sudan, Zimbabwe }\end{array}$ & $\begin{array}{l}\text { Cereals, } \\
\text { dried fruit } \\
\text { and nuts }\end{array}$ & $\begin{array}{l}1989- \\
1998\end{array}$ \\
\hline $\begin{array}{l}\text { (Otsuki et al., } \\
2001 b)\end{array}$ & $\begin{array}{l}\text { Econometric estimation - } \\
\text { Gravity model }\end{array}$ & $\begin{array}{l}\text { EU- } 14 \text { member states } \\
\text { and Switzerland; } \\
\text { Africa- } 9 \text { leading } \\
\text { groundnut exporters }\end{array}$ & Groundnut & $\begin{array}{l}1989- \\
1998\end{array}$ \\
\hline (Wu, 2004) & $\begin{array}{l}\text { Econometric estimation - } \\
\text { simulation model }\end{array}$ & $\begin{array}{l}\text { Worldwide top groundnut } \\
\text { exporters- Africa; South } \\
\text { Africa, the Gambia, } \\
\text { Senegal }\end{array}$ & Groundnut & $\begin{array}{l}2002- \\
2003\end{array}$ \\
\hline $\begin{array}{l}\text { (Xiong \& } \\
\text { Beghin, 2012) }\end{array}$ & $\begin{array}{l}\text { Econometric estimation } \\
\text { ex post harmonized } \\
\text { regulation - Gravity } \\
\text { model }\end{array}$ & $\begin{array}{l}\text { EU- } 14 \text { member states } \\
\text { and Switzerland; } \\
\text { Africa- } 9 \text { leading } \\
\text { groundnut exporters }\end{array}$ & Groundnut & $\begin{array}{l}1989- \\
2006\end{array}$ \\
\hline
\end{tabular}

The World Bank studies by Otsuki et al. (2001a); Otsuki et al. (2001b) can be considered as the benchmark of studies on this topic. The background of these studies was a new EU regulation on aflatoxins. In 1998, European Commission announced the new harmonized aflatoxin standards which were implemented in 2002. This EU legal limits for aflatoxin have been more stringent than the CODEX standards. Meeting the EU harmonized aflatoxin legal limit would decrease African exports by $64 \%$ or USD 670 million, and more specifically for African groundnut exporters by $63 \%$. However, a later study by (Wu, 2004) found that the losses of African groundnut exporters due to EU regulation on aflatoxin was lower because the trade between Africa and EU was not as large as estimated by (Otsuki et al., 2001b). This finding was later corroborated by (Xiong \& Beghin, 2012) as the issues of groundnut exports were on domestic supplies rather than EU market access. Narayan et al. (2014) 
also found that in case of Tanzania and Nigeria, particularly in 2010-2011 the majority of maize and groundnuts were for domestic consumption (food, feed, and re-planting) and only a negligible percentage for export.

In addition to the above-mentioned studies with econometric estimations, (Rios \& Jaffe, 2008) looked at the EU rejections of groundnuts imports from Africa. Data were taken from the EU RASFF database for the years 2000-2006. Since the quantity of rejected goods was not reported in RASFF, volume data were obtained from experts' opinion. The finding shows that even when adopting the limits advised by CODEX, more lenient than EU standards, $83 \%$ of African exporters were still non-compliant. While the focus of the study was on the EU regulation, the same impact is likely to happen in other export destinations that apply CODEX standards. In addition, with respect to maize commodity countries worldwide tend to trade with other countries enforcing similar or closely-similar aflatoxin regulations. Therefore, due to the relatively low quantity of maize export from Africa to EU, it is not likely that African maize export would be adversely affected by EU aflatoxin limits (Wu \& Guclu, 2012).

Furthermore, Munasib (2013) presented a study case about aflatoxin legal limits in maize, but they did not quantify the economic losses due to compliance with the standards. In their case study, they only signalled that poor countries and African exporters were significantly affected due to the differences in standards, i.e. the absent or low legal limits in exporting countries, and the high legal limits in importing countries. This results points out to the differences between aflatoxin limits in developed and developing countries (Munasib, 2013).

Agyekum (2017) investigated the EU aflatoxins legal limits for peanut. The focus of their case study was not on Africa per se. Africa is part of the rest of the world (ROW) together with Latin America and Asia, probably due to less significant trade volume. African countries considered were Egypt, South Africa, Senegal, Sudan, Malawi, and Gambia. The sample period covered 1995-2007. Result is however not conclusive for Africa, given the rest of the world aggregate (Agyekum \& Jolly, 2017).

\subsubsection{Firm-level economic impact}

Six studies evaluating firm-level impact (producer side) were identified, with five studies assessing the impact on costs of managing aflatoxin (compliance cost) and one assessed productivity loss due to aflatoxin contamination. However, none of these studies estimated the similar effect and/ or product using the same analytical method, thus no comparison could be performed.

\section{Cost of managing aflatoxins}

Note that the studies by Moser et al. (2014) and Hoffmann and Moser (2017) are based on the same research and presented the respective findings. The former is a conference paper and the latter is a journal publication. Both studies were conducted in Kenya to investigate the relationship between maize flour price, brand equity, and aflatoxin contamination. The finding showed that products with a higher price tend to be less contaminated than products sold with a lower price. Thus, when managing aflatoxin levels in foods and building its brand reputation as a safe food producer, a firm can charge a higher price than other firms without this value. However, the costs of compliance to aflatoxin regulation were not estimated in this research (Hoffmann \& Moser, 2017; Moser et al., 2014).

Ayedun et al. (2017) estimated the willingness to pay of Nigerian farmers for AflaSafe $®$ goods, as

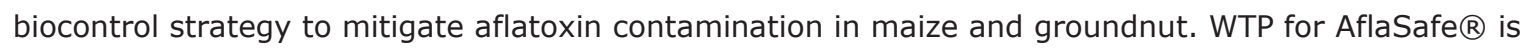

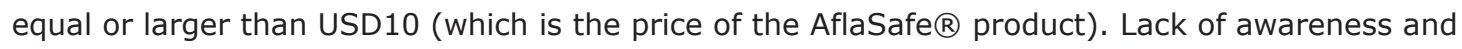
usage experience were considered as the main reasons why farmers did not want to pay for AflaSafe ${ }^{\circledR}$ (Ayedun et al., 2017).

N'Dede et al. (2012) investigated the financial risk associated with several steps contributing to aflatoxin reduction along the peanut marketing chain in Benin, such as sorting and storing for example. Purchase price, selling price, and storage cost were considered as the most important factors contributing to business revenue. Thus, an economic incentive was deemed very important for the chain actors to adopt measures to reduce aflatoxin level in the peanut products (N'Dede et al., 2012). 
Ayyat et al. (2014) examined the effect of several treatments to alleviate the effect of aflatoxin contamination in feed of Nile tilapia in Egypt. The results showed that feed treated with absorbent materials could reduce the effect of aflatoxins in Nile tilapia and increased body weight resulting in higher price. The economic analysis shows a profitable result of using feed with absorbent materials (Ayyat et al., 2014).

\section{Productivity losses}

Tsusaka et al. (2016) estimated post-harvest loss resulting from quantity and quality loss in Malawi groundnut production as much as USD 189 per hectare or $13.7 \%$ of total harvest. However, this number was not only attributable to aflatoxin contamination as other factors were also identified, such as environmental condition and pest attacks. Aflatoxin contamination was one of the main contributors to quantity loss in groundnut production. Thus, this study focused on general factors of post-harvest losses rather than due to aflatoxin contamination. The contribution of aflatoxin contamination to total loss was not further estimated (Tsusaka et al., 2016).

\subsubsection{Willingness to pay for aflatoxin-free products}

Two studies investigated the awareness of consumers to aflatoxin contamination and estimated the willingness to pay for aflatoxin-free products in Kenyan market; see Mtimet et al. (2015) and de Groote et al. (2016). Both studies showed that consumers were interested in aflatoxin-free certified products, specifically milk and maize.

Mtimet et al. (2015) argued that most consumers were aware of aflatoxins in milk, although significant numbers of consumers did not know how to avoid consumption of aflatoxin-contaminated milk. WTP was estimated using choice experiment and showed a WTP of on average $9.7 \mathrm{KSh} /$ litre aflatoxin-free certified milk. WTP was estimated using choice experiment and showed that consumers who were aware of aflatoxins were willing to pay higher premium than those who were not aware, with average WTP $162 \mathrm{KSh} /$ litre and $99 \mathrm{KSh} /$ litre aflatoxin-free certified milk, respectively (Mtimet et al., 2015).

de Groote et al. (2016) showed that most Kenyan rural consumers were aware of aflatoxin contamination in maize products but did not understand the health implications. Willingness for aflatoxin-free labelled maize was estimated with the Becker-DeGroot-Maschak mechanisms. Consumers were willing to pay for clean-untested maize for $31 \mathrm{KSh} / 2 \mathrm{~kg}$ and the premium increased to $43 \mathrm{KSh} / 2 \mathrm{~kg}$. The result also showed that consumers asked for at least $50 \%$ discount price if the maize was visibly contaminated with moulds. The premium was higher for consumers with high education and in regions where aflatoxicosis outbreaks occurred (de Groote et al., 2016).

\subsubsection{Health-related economic impact}

Narayan et al. (2014) assessed the impacts of aflatoxin contamination of maize and groundnut in Tanzania and Nigeria on agriculture \& food security, trade, and public health. However, based on the assessment of end market, regulation, and awareness levels, aflatoxin-related health problems contributed the largest impact of aflatoxin contamination. The VSL for Tanzania and Nigeria were estimated using VSL of US as the base value, extrapolated using a transfer approach and adjusted for income per capita differences. Ranges of VSL in Tanzania were US $\$ 32,000$ and US $\$ 118,000$, and US\$ 49,000 to USD 285,000 in Nigeria (Narayan et al., 2014).

The burden of disease was estimated based on aflatoxin-induced HCC cases. Contamination of maize in Tanzania was relatively lower compared to the aflatoxin contamination of maize in Nigeria, although exposure to aflatoxins could still be significant due to large consumption of maize. The findings show that in Tanzania exposure to $5 \mu \mathrm{k} / \mathrm{kg}$ to $10 \mu \mathrm{k} / \mathrm{kg}$ of AFB1 $1^{10}$ contributed to 546 to 1,092 annual HCC cases respectively, and translated into 7,127 to 14,253 DALY respectively. The estimated monetized burden of disease (or cost of illness) values were between USD 17 million to USD 205 million.

\footnotetext{
${ }^{10}$ Aflatoxin limit for maize in Tanzania is $5 \mu \mathrm{g} / \mathrm{kg}$ for AFB1 and $10 \mu \mathrm{g} / \mathrm{kg}$ for aflatoxins total. On national level, AFB1 level in maize and groundnut range from $5.3-159.5 \mu \mathrm{g} / \mathrm{kg}$ and $5.2-38.3 \mu \mathrm{g} / \mathrm{kg}$, with $14 \%$ and $19 \%$ of the samples are above 5 $\mu \mathrm{g} / \mathrm{kg}$. Nigeria does not have AFB1 standard, but acknowleged safety standard of $4 \mu \mathrm{g} / \mathrm{kg}$ for human consumption
} 
However this estimated value would be higher when the contamination level is higher, and estimated at $100 \mu \mathrm{g} / \mathrm{kg}$ the monetized burden were between USD 350 million to USD 2 billion (Narayan et al., 2014).

Aflatoxin exposure due to contaminated maize and groundnut in Nigeria caused 7,761 HCC cases resulting in 100,965 DALY estimated and monetized burden of disease values between USD 380 million to USD 2.2 billion. These estimations were based on the assumption that all HCC cases would result in death within the same year, without taking into account the morbidity or cost of illness with the assumption that access to medication in these countries was limited (Narayan et al., 2014).

Other research on the health-related effect was conducted in a likely still ongoing project for PACA. The project covers six African countries as prototype cases: Ndenn et al. (2015) (The Gambia, Nigeria, Senegal) and Kimanya et al. (2015) (Malawi, Tanzania, Uganda).

Project reports with details could not be found in the search effort of our review but presentations were found in the grey literature search, see appendix 3. Ndenn et al. (2015) estimated the health-impact by monetizing DALY value for aflatoxin-induced HCC in Gambia resulting US\$ 94.4 million. Health-related economic impact constitutes to $98 \%$ of total losses, much greater than international trade impact for 2\%. Meanwhile, DALY monetization was also estimated in Nigeria as between US\$ 112 to US\$942 million or $+/-0.5 \%$ of Nigeria's GDP. In addition, in Senegal VSL was estimated between US\$ 91 million ( $\min$ ) and US\$ 161 million (max). Kimanya et al. (2015) estimated the health-related losses in Tanzania ranged between US\$ 93 million to US\$ 757 million.

\subsection{Mitigation measures}

\subsubsection{Plant breeding}

Okoth et al. (2017) describe the successful field testing of three maize varieties bred with a particular focus on Aspergillus ear rot resistance and reduction of aflatoxin formation in both South Africa and Kenya. The selection for these traits is new in the field of African maize breeding (Okoth et al., 2017). Interestingly, a Ugandan initiative described by Kwemoi et al. (2010) gives an account of research into inbred maize varieties with decreased "kernel infection rate" that can be used for breeding resistant varieties. Manoza et al. (2017) describe the combination of maize fertilizer regime with the use of resistant varieties against Aspergillus flavus infection and subsequent aflatoxin formation. Various phenotypic characteristics correlated with resistance, particular drooped ears (Manoza et al., 2017). In a field trial in two sites in Eastern Kenya with 205 maize lines, Mutiga et al. (2017) observed that aflatoxin tended to be higher in plants on a low nitrogen-fertilizer regime, in late-maturing varieties, and in dent as compared to flint varieties. These findings could help to guide towards a choice of variety and agronomic practices that mitigate aflatoxin contamination.

\subsubsection{Agricultural practices}

Marechera and Ndwiga (2014) surveyed farmers in lower Eastern Kenya for mitigation practices. Particular practices applied by many farmers (approx. 50\%) were crop rotation, use of resistant varieties, and pest control on the farm. Irrigation, bio-control, and smearing of cobs with soil were less commonly employed (Marechera \& Ndwiga, 2014). In a survey of Tanzanian maize farmers from three different climatic zones, it was observed that early and mid-planting resulted in lower aflatoxin levels than late planting. This also held true for hand-hoeing and ox-tillage versus tractor tillage, as well as for the use of insecticides (Kamala et al., 2016; Nyangi et al., 2016).

Akoto et al. (2017) studied aflatoxins and aflatoxigenic moulds being formed in the crop environment via peanut husks used as mulching materials. As a model system for testing mitigation, they used aflatoxin-contaminated peanut meal. As an intervention, composting of this meal was studied, including the use of starter cultures (3) and an accelerator (1). Aflatoxin (B1, B2, G1, G2) contamination plus moulds ( $A$. flavus and $A$. parasiticus) were measured from start until end ( 6 weeks), besides e.g. elemental composition, temperature, $\mathrm{pH}$, ammonia. The results showed a 
reduction of aflatoxins through composting, whilst the influence of starter cultures was variable, i.e. a reduction or none, but no major impact of the accelerator (Akoto et al., 2017).

Atehnkeng et al. (2016) tested four native atoxigenic Aspergillus flavus strains (L morphotype, endemic), formulated them with sorghum, and applied them to soil of maize fields in different agroecological zones of Nigeria during two flowerings. The analysis focused on mould strains in soil and on maize; aflatoxin content of maize; ear rot assessment; post-harvest stored maize cobs (ear rot) and grains (aflatoxins). The results indicated that moulds from the applied Vegetable Compatibility Groups could be detected in soil and maize after application. A reduced aflatoxin concentration (reduced by up to $95 \%$ ) of maize grains was observed after treatment at harvest but also following post-harvest storage (continued effect) (Atehnkeng et al., 2016).

Surveying maize farmers in three different agro-ecological zones of Tanzania, Kamala et al. (2016) found correlations between aflatoxin contamination of maize and various agronomic practices. E.g. drying harvested maize on the ground was correlated with higher odds of aflatoxin contamination than drying the harvest on a plastic sheet, elevated sheet, or a veranda. The odds were also significantly affected by other practices that help to reduce aflatoxin contamination, such as hand-sorting of kernels by farmers to remove discoloured, damaged or mouldy ones from the batch to be handled further, and the use of insecticides to fend off insect storage pests, which can carry spores of fungi, increase humidity through their activity and inflict wounds that act as point of entry for moulds (Kamala et al., 2016).

Similarly, in a controlled trial, Taye et al. (2018) studied the impact of threshing on fungal infection and aflatoxin contamination in harvested sorghum. They observed that threshing the sorghum on dry ground would eventually lead to the highest aflatoxin contamination both at threshing and after five months of storage, but still below East African limits, as compared to other methods including threshing on concrete asphalt, on cow-dung-painted ground, or on canvas. The last showing the lowest aflatoxin contamination, i.e. 0.70-1.23 $\mu$ AFB $_{1} / \mathrm{kg}$ versus $1.30-1.97 \mu \mathrm{g} / \mathrm{kg}$, respectively (Taye et al., 2018).

Boaz et al. (2017) surveyed West-Kenyan groundnut farmers for their agronomic practices and awareness of aflatoxin issues. They also checked for possible correlations with aflatoxin residues in harvested and stored groundnut samples, as well as for aflatoxigenic fungi in these samples and the farm soil. A statistically significant correlation was found between drought during cultivation and the state of storage, i.e. in-shell versus unshelled, with the latter showing lower aflatoxin levels than shelled groundnuts. In addition, if groundnuts were grown in rotation with maize, the population of moulds capable of forming aflatoxin was high. This may relate to the susceptibility of maize to infection by such moulds as well (Boaz et al., 2017). Whilst aflatoxin contamination was not particularly high, awareness of aflatoxin issues and mitigation turned out to be low (Boaz al., 2017).

With regard to awareness, Johnson et al. (2017) performed a survey amongst previous users of AflaSafe $\AA$, a commercial preparation of non-aflatoxigenic $A$. flavus used for competitive exclusion of aflatoxigenic strains in maize fields. It was this observed that awareness of the human and livestock health impacts of aflatoxin amongst farmers apparently did not influence their decision to re-buy AflaSafe ${ }^{\circ}$ or not (Johnson et al., 2017). Okike et al. (2015) describe how farmers may use a byproduct of cassava, i.e. cassava peels, to produce AflaSafe $\AA$ instead of using sorghum kernels typically used for this product. Marechera and Ndwiga (2015) found that $82 \%$ of lower Eastern Kenyan farmers would be likely to buy AflaSafe $($ based on criteria such as awareness of biocontrol agents, distance to nearest agro-input dealer, age of the household head, wealth, education, and income, (Marechera \& Ndwiga, 2015).

For the cost-effectiveness of mitigation measures, it is important to know the lifespan of the options available for low-cost options that need to be replaced regularly, such as drying on tarpaulins, as opposed to long-term solutions, such as the use of silos made from metal or plastic (Narrod, 2013). For biocontrol solutions, such as AflaSafe ${ }^{\circledR}$, the lifespan is not known. Assuming this to be one year, this would not be a cost-effective solution (Narrod, 2013; Njoroge et al., 2016). 
Seetha et al. (2017) describe how training of Tanzanian farmers in certain techniques of handling harvested groundnuts could aid in preventing the formation of aflatoxins. These techniques include the use of the "Mandela cork" method for ventilated drying of pods in the field, drying of groundnuts on plastic sheets to prevent contact with the ground (and hence infection with moulds), hand-sorting of kernels prior to processing, minimization of wet-shelling (to 5-10 minutes of soaking), and ventilated, moisture-free storage of dried groundnuts. They showed that in the subsequent season after farmers had applied these methods, aflatoxin contamination of the harvested crop decreased from $44 \%$ of samples above the recommended maximum level of $10 \mu \mathrm{g} / \mathrm{kg}$ in the first year to $6 \%$ in the second. In addition, the average aflatoxin B1 concentration in the harvested crop decreased from 116 to 23 $\mu \mathrm{g} / \mathrm{kg}$ (Seetha et al., 2017).

Wambui et al. (2017) estimated the impact of various mitigation strategies on the incidence of hepatocellular carcinoma (HCC) in Kenya's rural population caused by consumption of maize and groundnuts. The baseline estimate, based on the estimated intake (fixed proportion of energy requirement within an age group) and contamination of Kenyan maize and groundnut measured in previous studies, amounted to approximately 2,000 cases of HCC annually within a population of 100,000 . The risk of HCC and also chronic hepatitis B was higher for the younger population segments such as adolescents. For various pre- and post-harvest prevention strategies of contamination the reduction of HCC cases was also estimated based on the reported reductions of aflatoxin contamination. For groundnut, these pre-harvest measures included application of cereal crop residues (containing natural antifungal compounds), farmyard manure, or lime to crop fields, whilst for maize, these included the use of atoxigenic strains. Reductions in HCC presence by $83 \%$ could in some cases be achieved, correlating with decreased contamination, such as for combination of farmyard manure and lime in groundnut and aflatoxigenic strains in maize (Wambui et al., 2017).

The impact of sorting on aflatoxin contamination of subsequently prepared peanut butter is exemplified by the work of Njoroge et al. (2016), who observed that peanut butters commercialized within Western countries contain much less than local brands sold in Africa. These authors relate this phenomenon to stringent enhancement of the regulations of importing nations (Njoroge et al., 2016).

Tedihou et al. (2012) observed that following intercropping of a relatively susceptible maize variety with cowpea, stored maize kernels tended to be more slowly contaminated with aflatoxin than kernels from fields cropped with maize alone. As a possible explanation, the authors hypothesized that the maize from intercropped fields would have been infected in ways different from that via the surrounding soil in maize fields without the cover crop, such as mould propagules transported towards the plant by air, infection via the silk of the maize plant during the pollination period, or transfer via insects (Tedihou et al., 2012).

\subsubsection{Post-harvest storage}

Eastern Kenyan maize farmers surveyed by Marechera and Ndwiga (2014) indicated that they particularly (78-100\%) used proper storage, proper drying, sorting, and post-harvest as post-harvest measures, whilst food processing, ammoniation and hydrogel sorbents (for animal feed) were used to a much lower extent (Marechera \& Ndwiga, 2014).

Using a batch of mouldy white maize from a market in Malawi, Matumba et al. (2015) tested various methods for their effectiveness in reducing the contents of mycotoxins such as aflatoxins, including flotation, hand-sorting and de-hulling. It was observed that particularly hand-sorting had the capacity to reduce the mycotoxin contamination by approximately $95 \%$ (Matumba et al., 2015). In cowpea and pigeon pea from Malawi, Matumba et al. (2017) observed that flotation was effective in removing aflatoxins by $95 \%$.

Purdue Improved Crop Storage (PICS) bags have been developed for storage of legume and cereal crop seeds for periods up to longer than a year. These bags consist of three plastic layers (including a woven polypropylene casing with inner linings of high-density polyethylene), and may effectively protect the bagged harvest from infestation by storage pest insects. Baoua et al. (2014) compared PICS with woven polypropylene bags for their protection of stored against various endemic, common 
storage pests in various maize-producing sites in Western Africa including northern Ghana, Benin, and Burkina Faso. Unlike PICS bags, woven polypropylene bags can still be penetrated by insects via the polypropylene fibre meshwork. They showed that PICS bags showed no increase in infestation with the three pest insects identified, such as from the start of storage period, unlike the woven bags which particularly showed a high increase in Sitophilus zeamais in many locations (Baoua et al., 2014).

Ng'ang'a et al. (2016) compared PICS, polypropylene, and jute bags for storage of maize kernels for 35 weeks. If moisture content of the produce within the bag was below 14\%, mould was unable to grow and no aflatoxin accumulation was observed in the produce stored in the PICS bags. This was unlike the increase of aflatoxins in the produce by two orders of magnitude in the two other types of bag (Ng'ang'a et al., 2016). Using maize from Eastern Kenyan farmers, Maina et al. (2016) tested the use of PICS bags versus polypropylene bags for storage during three months. They observed that the presence of Aspergillus flavus and A. parasiticus was reduced in PICS versus polypropylene bags, as well as aflatoxin levels in the produce on average by $-55 \%$ (Maina et al., 2016). Mutegi et al. (2013), however, observed that groundnuts stored in plastic (polypropylene and polyethylene) bags over a period of 6 months tended to be more contaminated than those in jute bags. The authors attributed this difference to the heat development within the plastic bags (Mutegi et al., 2013).

Interestingly, in a survey of maize storage practices and aflatoxin awareness among farmers in various production zones of Ghana, Sugri et al. (2015) observed that farmers considered the combined infestation of stored maize with insects, moulds and rodents a great challenge. Most of the storage was done in jute or polypropylene bags, whereas the share of PICS bags, which had just been introduced, was still marginal (1\%). Various strategies were applied to control the infestations, including integrated pest management with cocktails of pesticides, amongst others, with other farmers used agro-chemicals acquired in many cases from untrained vendors. Whilst $78 \%$ of the farmers had heard of aflatoxins, most of them (68\%) did not think of this as being problematic. The authors therefore recommend intensified collaboration amongst partners to make progress on the topic (Sugri et al., 2015).

Christie et al. (2015) described how a successful training program aimed at both male and female members of Ugandan smallholder farm households had effectively changed practices geared towards reducing aflatoxin contamination in groundnuts. These included drying of harvested groundnuts on above-ground platforms rather than on the ground, as well as sorting visibly contaminated nuts from others. For the awareness raising, these researchers had taken into account the important role that particularly women have in post-harvest practices, and the awareness raising strategies had been specifically geared towards them. Participants had been asked to map out the path of the peanut production, and extension workers could then focus on the various critical steps in the process drawn by the subject (Christie et al., 2015).

In a survey of Tanzanian farmers, Magembe et al. (2016a) observed that various forms of groundnut storage were used, including bags, cribs, heaps and tins. Amongst the bags, nylon and polypropylene could be distinguished. During a nine-month period, aflatoxin levels were lowest in polypropylene bags as compared to nylon bags and tins at each of the three-month intervals measured. Also wood ash used as a protectant effectuated lower aflatoxin levels. Given the impact of grain protectants, the authors recommend dried neem leaf powder, given its antifungal effect (Magembe et al., 2016a).

\subsubsection{Processing}

Using samples of dried yam chips bought at Nigerian markets, Omojasola and Sanu (2013) could not detect aflatoxin B1 in any of the samples during storage at room temperature for 6 months. These authors concluded that this hygienic quality probably related to its processing in the dry season as opposed to the wet season (no data for the latter) (Omojasola \& Sanu, 2013).

Comparing the aflatoxin B1 levels of custom-prepared Nigerian snacks with the invariably higher level in maize used as source material, Olayiwola et al. (2013) concluded, without further details, that most likely the combination of different processing techniques (i.e., fermentation, wet milling, cooking) reduces aflatoxin better than any of these processing steps by itself (Olayiwola et al., 2013). 
Groundnut/maize processing (roasting/decortication)

Kilonzo et al. (2014) compared aflatoxin levels in maize kernels, decorticated kernels (muthokoi), and maize meal in households in an Eastern Kenya. It thus showed that the contamination of maize kernels was on average higher than that of muthokoi and meal. This can be accounted for by the removal of toxins through detachment of the kernel cover during processing. Using consumption data from the households surveyed and the measured levels of aflatoxin, the intake of aflatoxin was estimated. It thus showed that the average intake from maize kernels was higher than from muthokoi. Based on previously published work on the impact of cleaning on aflatoxin contamination, it was shown that the estimated intake of aflatoxins could be further reduced indeed by the use of additional cleaning steps before cooking, i.e. cleaning of kernels and treatment of muthokoi with ammonium persulfate, by approximately $40 \%$ and $30 \%$ respectively (Kilonzo et al., 2014).

Following training of mothers in rural Gambian households, Xu et al. (2017) gives an account of how sorting out mouldy groundnuts by these women by hand and subsequent roasting could contribute to aflatoxin reduction. Based on samples from 25 volunteers shelling and sorting $5 \mathrm{~kg}$ of peanuts, handsorting reduced the median aflatoxin from 0.49 to $0.28 \mu \mathrm{g} / \mathrm{kg}$ product, which was further reduced to $0.17 \mu \mathrm{g} / \mathrm{kg}$ by roasting. A survey amongst the women showed that they already applied sorting and washing in practice and that awareness of aflatoxin toxicity was high (88\%) (Xu et al., 2017).

Afolabi et al. (2015) studied groundnuts from South Western Nigeria, for the impact of de-coating and roasting at the processing stage as an intervention to reduce aflatoxin contamination. Samples of groundnut were obtained from markets. The analysis included interviews of vendors on, e.g., handling and processing; characterization of strains of Aspergillus section Flavi of which propagules were found on the groundnuts and their aflatoxigenic capacity; and aflatoxin content. A comparison was made between raw versus roasted groundnuts, coated versus de-coated. The results showed that many samples were contaminated with aflatoxins above regulatory limits. There was a significant reduction in aflatoxin levels in roasted versus non-roasted groundnuts (Afolabi et al., 2015).

\section{Food irradiation}

Akueche et al. (2012) tested the impact of food irradiation on sesame grains from markets in Nigeria. As an intervention, they applied irradiation at increasing doses: 0-3-6-9-12-15 kGy. The analysis included the counting of moulds, and the measurement of the aflatoxin (total) content. The results showed that aflatoxin and OTA were reduced at $15 \mathrm{kGy}$, while the reduction was inconsistent at lower doses (Akueche et al., 2012).

\section{Ozone treatment}

Sahab et al. (2013) tested the use of gaseous ozone on peanut samples obtained from different governorates from Egypt in a laboratory experiment to destroy aflatoxins yet to preserve protein and fat contents. It thus showed that exposure to up to $400 \mathrm{ppm}\left(856 \mathrm{mg} / \mathrm{m}^{3}\right)$ ozone during 10 minutes resulted in a reduction of aflatoxin contamination by $95 \%$ or more without significantly affecting protein and fat contents (Sahab et al., 2013).

\section{Fermentation}

Chelule et al. (2010) checked laboratory-prepared samples of amahewu, a fermented porridge from maize meal typically consumed in Kwazulu Natal, South Africa, for aflatoxin content. No residues of aflatoxin could be detected in amahewu prepared from aflatoxin-contaminated maize meal, pointing to a reducing effect of lactic acid fermentation (Chelule et al., 2010).

Okeke et al. (2015) verified the impact of steeping of maize, a bacterial fermentation process prior to obtaining gruel for ogi (fermented maize) production on the reduction of aflatoxin. Whilst steeping for 48 hours reduced the AFB1 and AFB2 contents by approximately $60 \%$ and $80 \%$, respectively, prolongation did reverse part of this. AFM1 was completely removed by this treatment (Okeke et al., 2015).

In laboratory prepared togwa, a typical Tanzanian fermented maize gruel, the use of lactic acid bacteria starters or natural fermentation for 24 hours caused an AFB1 reduction between $45 \%$ and 
$56 \%$, whilst back-slopping (adding residue from the previous fermentation) even reduced AFB1 by $68 \%$ (Nyamete et al., 2016).

Likewise, Ghislaine et al. (2016) observed a decrease of AFM1 content during the production of leben, a traditional North-African yogurt-type dairy product, experimentally produced in an industrial facility from milk employing fermentation by lactic acid bacteria. It thus showed that AFM1 contents in the milk used as source material, both raw and pasteurized, declined by $93-96 \%$ during fermentation, inversely correlated with the acidification of the product (Ghislaine et al., 2016).

Another application of lactic acid bacteria is as a binder of aflatoxins per se. Nduti et al. (2016) describe how children in eastern Kenya received an experimental yogurt produced in a local kitchen and containing three probiotic strains, which were shown to bind aflatoxins in-vitro, or a control (milk), for 21 days. Their exposure to aflatoxins was verified through analysis of aflatoxins in children's urine. It thus showed that after 21 days of consumption, the aflatoxins detected in urine (AFB2, AFM1, AFG1) decreased across the board (Nduti et al., 2016).

\section{Sorting}

Stasiewicz et al. (2017) tested the applicability of a laboratory-scale hyperspectral sorter machine, which could also be installed in a more industrial setting before the hammer mill at the local level in rural African communities. The sorter employed reflected light of both visible and near-infra-red wavelengths to identify aflatoxin-contaminated (>10 ng/g) maize kernels. The outcomes also showed the previously identified skewedness of contamination, with a few kernels with very high levels of contamination contributing substantially to the overall average contamination. Discoloration, toxinrelated fluorescence, insect damage, and relatively low kernel weight ( $10^{\text {th }}$ percentile) were associated with higher odds for mycotoxin contamination. Using the sorter, a reduction of aflatoxin by $83 \%$ in the accepted lot was achieved (Stasiewicz et al., 2017).

\section{Multiple techniques}

As previously discussed for cultivation, Wambui et al. (2017) estimated the impact of various pre- and post-harvest measures against aflatoxin contamination of groundnut and maize on the risk of HCC in the rural Kenyan population. For groundnuts, these measures included sorting, roasting, densitybased separation, deskinning, grinding and aspiration into glycerol, whilst for maize, these included sorting, de-hulling and fermentation, and treatment with chemical solutions (hypochlorite, alkaline minerals, propionic/acetic acid, carbonates, and nixtamalization). Whilst blanching/deskinning and grinding only had a modest predicted impact on HCC risk (reduction by $4-16 \%$ ), reductions by $46-$ $95 \%$ could be achieved with the other methods, particularly for removal of kernels floating in water , as well as sorting in groundnut, and for nixtamalization and fermentation in maize (Wambui et al., 2017).

\section{Fast detection}

Mwanza et al. (2015) compared different rapid detection methods for aflatoxins that can be used in the field without having a fully equipped laboratory within direct reach. These methods included thinlayer chromatography (TLC), immunochemical dip stick tests, and enzyme-linked immunosorbent assay (ELISA), which were tested for the detection of AFM1 in samples of Egyptian and South African milk. It was considered that the dip stick test may miss relatively low concentrations of AFM1. ELISA was shown to identify less AFM1-containing samples than TLC, probably due to loss during an immunoaffinity preparation step. Quantification with TLC might, on the other hand, be more challenging. These authors recommend a strategy consisting of either TLC or dip stick tests, followed by a confirmatory analysis with high-performance liquid chromatography (HPLC) (Mwanza et al., 2015).

\subsubsection{Reducing availability of aflatoxin from food by the use of binders}

Awuor et al. (2017) carried out an intervention study entailing the intake of clay (ACCS100, calcium montmorillonite clay), to reduce bioavailability of AFB1. In a human clinical trial in Kenya, 2014, referred to as a "pilot study", subjects received clay. Urine AFM1 and serum albumin-AFB1 adducts were measured as biomarkers of exposure. This was actually an extension of previous trials in USA on 
safety of the clay itself and reduction of aflatoxin-exposure-associated biomarkers in blood and urine in a human clinical Phase IIa trial. The dose consisted of 3 packets (1-g sachets) / day (40-95 kg body weight). The subjects were subsistence farmers living on a primarily maize-based diet, from villages that had suffered multiple aflatoxicosis outbreaks in the past. Both test and placebos were administered. Inclusion criteria were: subject had to be older than 18 years, and at least 4 times per week consume peanut and/or maize. A survey was held amongst participants on, i.e., source of maize, and its shelf life. The analyses included AFM1 (urine, first 7 days), AFB1-serum albumin lysine adduct (serum, day 0 and 20). The results indicated that there were no adverse effects that could related to intake of test material or placebo. A reduction of AFM1 in urine was observed in the ACCS100 group, and also a reduction in AFB1-lysine adducts in serum albumin in both placebo and ACCS100-treated subjects. With regard to palatability, the placebo scored better, and the acceptability was high as participants were willing to take ACCS100 it if it prevents aflatoxicosis. An identified knowledge gap is that it is not known if it also works with high doses of ACCS100, such as during aflatoxicosis outbreaks (Awuor et al., 2017).

In the Northern Ashanti region of Ghana, Mitchell et al. (2013) tested calcium montmorillonite clay (UPSN) as a binder of aflatoxins on adult human volunteers from five villages in a cross-over design. UPSN was provided twice a day, in 1.5-g doses incorporated into breakfast (with corn porridge) and dinner meals (with corn dough), and urine samples were taken from the subjects to track aflatoxin bio-availability. Controls consisted of calcium carbonate placebos administered to the same subjects before or after the administration of the UPSN test material. It thus showed that the urinary AFM1 levels during UPSN-treatment were substantially lower than during placebo treatment, with a median reduction of $45-55 \%$ (Mitchell et al., 2013). Another trial with UPSN in children ( $1.5 \mathrm{~g} /$ day) during two weeks showed a 52\% reduction in urinary AFM1 compared with control (Mitchell et al., 2014).

\subsubsection{Reducing availability of aflatoxin from feed by the use of binders and other agents}

Whilst binders are known to be widely used in feeds for a wide range of farmed animal species, there was a preponderance of studies on aqua-feed for cultured fish in the literature retrieved specifically for Africa. In cultured Nile tilapia, Abdel Rahman et al. (Abdel Rahman et al., 2017) tested a mitigation method that entailed dietary supplementation with fennel essential oil (contains, e.g. limonene, fenchone, vitamin C), at $1 \mathrm{ml} / \mathrm{kg}$ diet. Its purpose was to suppress AFB1-induced toxicity (immunosuppression, liver toxicity, inflammation) in cultured Tilapia by mycotoxin binding with yeast (Saccharomyces cerevisiae) at $1 \mathrm{~g}$ (10E9 cells) / kg diet. This was applied at the feed stage for consumption by animals. Diets were provided twice daily, during one month. Blood was collected after one month of feeding. Measurements included serum markers of oxidative stress (MDA, catalase) and liver/kidney toxicity measured (e.g., ALT, creatinine), protein (total, albumin, globulin), and phagocytic activity in blood samples taken after one month of feeding. AFB1 was measured in tissues (liver, muscle). The outcomes showed decreased catalase, proteins and phagocytic activity; increased ALT, creatinine, MDA and tissues residues in animals fed AFB1-enriched diets. Effects of aflatoxins were mitigated by addition of fennel oil and yeast, whilst combination of both was not more effective, with fennel being the most effective (Abdel Rahman et al., 2017).

Ayyat et al. (Ayyat et al., 2013) used Nile tilapia to test aflatoxin B1 toxicity in a controlled experiment in aquaria. The interventions included the following:

- $\quad$ Ozone treatment of aquarium water ( $5 \mathrm{~min} /$ day)

- Bentonite clay $(20 \mathrm{~g} / \mathrm{kg}$ diet)

- Coumarin supplementation of diet (5 g / diet)

The diets contained e.g. fish meal, soybean meal, maize, wheat bran, alfalfa hay, sunflower oil, minerals, and vitamins. Aflatoxins were added to the diet or not, and 98 days was the experimental period. The analysis included performance, serum chemistry, haematology, water quality, aflatoxin contamination of fish bodies, and economic estimates. Results showed that there was a reduction of weight and growth, as well as red blood cells and platelets, protein, albumin, ALT, AST and urea-N 
caused by AFB1, higher FCR and mortality. All three interventions substantially reduced aflatoxin contamination of Nile tilapia fish bodies as compared to the positive control fed AFB1-tainted diets. It also improved weight and daily gain but not Feed Conversion Rare, as well as serum protein, as compared to control (Ayyat et al., 2013).

Ayyat et al. (2014) performed a similar test with probiotics containing Lactobacilly acidophilus, Streptococcus thermophilus, Saccharomyces cerevisiae (metabolism and binding); ozone; vitamin E; and clay. Also the results were very similar to that of Ayyat et al. (Ayyat et al., 2013), whilst also creatinine, body fat were reduced by AFB1, and body ash were increased

Mehrim et al. (2016) studied the possible mitigation of toxic effects of AFB1 in tilapia diets by addition of the antioxidant compound glutathione. Addition of glutathione at the highest dose (200 mg/ kg diet) to diets artificially spiked with AFB1 $(150 \mu \mathrm{g} / \mathrm{kg})$ resulted in partial recovery of weight, serological and haematological parameters, and liver histopathology affected by AFB1, as well as restoration of antioxidant status in tissues such as liver (Mehrim et al., 2016).

\subsubsection{Education and awareness raising about mitigation measures}

Whilst the technical measures elaborated above may have proven successful within experimental or practical settings, their transposition into practice and/or different geographies and contexts is likely to require the information, awareness raising and education of suppliers, farmers, households, processors, traders, etc. who will have to implement them.

In an educational effort in Malawi, for example, mothers of children in the transitional period between breastfeeding and complementary foods were instructed in food preparation, hygiene and food safety. Amongst others, they were trained in separating contaminated maize kernels from good-quality ones, besides other practices promoting the hygiene of home-prepared food and drinking water. It was thus observed that in a 21-day period following the instructions, wasting and underweight scores in the children of mothers who had received training improved significantly compared to those of mothers who had not had the training. In addition, wasting was positively correlated with aflatoxin contamination, indicating that indeed a reduction in aflatoxin exposure would likely reduce the odds and impact of wasting (Seetha et al., 2018).

A pilot awareness-raising effort in Egypt about HCC, hepatitis, pesticides \& aflatoxins showed that participants, once informed, were intent on proper storage of food so as to prevent mould growth and to seek medical advice, when applicable, on HCC and hepatitis (Saleh et al., 2015). 


\subsection{Scale and geographical spread of contamination}

The most commonly investigated commodities in the included papers, were maize and peanuts, and animal feeds - which are generally the products most commonly associated with aflatoxigenic mould contamination in Africa. All studies indicated mean AFB1 concentration in maize $>5 \mu \mathrm{g} / \mathrm{kg}$, which is above the legal limit in the EU for AFB1. The highest mean concentration of AFB1 was recorded in maize from Egypt; as high as $440 \mu \mathrm{g} / \mathrm{kg}$. The highest specific concentration found in maize was 6,738 $\mu \mathrm{g} / \mathrm{kg}$, detected in Nigeria in 2012. The results imply that reduction of overall aflatoxin levels in food in Africa is still a major challenge.

Included studies were frequently conducted in Nigeria, Egypt, and Kenya. The included studies give insight in the areas and foods the studies were carried out on, but extrapolation or generalization of specific results to other areas is difficult. This finding is consistent with Atherstone et al. (2014) and Wild et al. (2016) who mention that there is a lack of prevalence studies in certain countries. For 28 African countries, no studies were included from the systematic review on scale and geographical spread of contamination. Research on aflatoxin contamination requires a substantial budget for sampling, storage, transport, analysis of the samples, interpretation of the outcome and publishing the results in peer reviwed journals. Socio-economic situation in a country or area may hinder mapping of the actual aflatoxin situation and special circumstances may lead to prioritising aflatoxin after other health issues. Nevertheless, the, lack of data does not imply that aflatoxins are not a problem in those countries.

\subsection{Disease burden}

Populations in Africa can be exposed to high concentrations of aflatoxin via food causing acute aflatoxicoses, even to this day (Kamala et al., 2018). For various reasons it is likely that this problem might be larger than described, since diseases in the developing world may often go unreported, thus the described cases of acute toxicity may represent only a portion of the problem (Strosnider et al., 2006). Incidents in Kenya and Tanzania with human fatalities in 2004 and 2016 were analysed by specialised investigation teams and lessons learned were published (Kamala et al., 2018; Probst et al., 2007). This approach should be encouraged and will contribute significantly to early warning systems and prevent fatalities.

Diseases related to chronic aflatoxin exposure may result from more causes or diseases and can be enhanced when people are chronically exposed to aflatoxins, which complicates the estimation of the disease burden. This can be illustrated by the incidence of hepatocellular carcinoma (HCC). It may take up to two decades to develop HCC (Afum et al., 2016) but being chronically exposed to aflatoxin and hepatitis B may shorten this period. A study from the Africa Liver Cancer Consortium shows that HCC tends to develop at a younger age in Africa than in other regions of the world (Yang et al., 2017) but the relation between HCC and aflatoxin exposure was not studied.

The disease burden caused by aflatoxin cannot be easily estimated. Impaired health and growth are caused by multiple factors which should be addressed simultaneously. The studies from Dewey and Adu-Afarwuah (2008) and Bhutta et al. (2013) illustrate that successful feeding interventions in populations showed average rates of a $20-40 \%$ reduction in stunting in children in the best performing countries (Bhutta et al., 2013; Dewey \& Adu-Afarwuah, 2008), meaning other factors play an important role in stunting. The IARC working group on mycotoxin control in low- and middle-income countries concluded that aflatoxin might be one of several significant contributions to stunting (Wild et al., 2016). No additional evidence for a causal relationship between stunting and exposure to AFB1 was identified among the included studies. It must be mentioned that the pathology of AFB1 exposure in humans was outside of the scope of the research. 


\subsection{Economic impact}

Economic impacts of aflatoxin contamination could be estimated along the supply chain and extended to consumers and after consumptions (particularly for health-related impacts). Three strands of literature on economic impacts of aflatoxins were identified in this systematic review: 1) studies on the trade effect, 2) micro-level studies from the producer and consumer perspective and 3) studies on the health-related economic effects. The topic on health-related economic impact is not well studied in Africa, with only one publication with sufficient quality being identified.

In general, there is little evidence in literature on the economic effects of aflatoxins contamination. It should be noted that for the trade impact of aflatoxins regulation in international context, EU regulations were in the spotlight particularly due to the relative stringency of certain legal limits, compared to CODEX as international guidelines. One of the first studies that estimated the effect of harmonized EU legal limits is Wilson and Otsuki (2001). Other studies followed, for instance Rios and Jaffee (2008) Wilson and Otsuki (2001). The argumentation by Rios and Jaffee points to a different counterfactual for measuring the trade impact than the one used in Wilson and Otsuki. In conclusion, it can be stated that many countries lack the capacity to produce products that comply with the EU standards. If non-compliant products are produced and exported to other markets than the EU with its strict standards, one could think about the effect in terms of the loss of export opportunities, expressed in monetary values as trade loss.

Trade impacts were estimated in various ways, including econometric (gravity analysis and simulation models) and explanatory approaches using trade data and EU RASFF database. Maize and peanut were most frequently reported in the studies. The results depend on the analytical methods, data and assumptions used, e.g. products, countries and years. Thus, these studies do not find a conclusive result on the trade-related impacts of aflatoxins regulations for African exporters.

The trade impacts on micro-levels, i.e. firm levels at producers' side were investigated by assessing various type of effects, for example by identifying the costs of compliance, willingness to pay for aflatoxins control, and productivity losses. However, not all of the effects were quantified in monetary values. Another complexity arose when the losses were not only attributable to aflatoxins, but also to other causes; such as rodents and spillage during transport. Moreover, none of these studies reported similar effects in the same products, using the same analytical methods. Thus, no comparison could be performed.

At country level, most economic impacts studies were conducted in Kenya. In the Kenyan dairy chain, dairy farmers bore the highest losses from lower productivity due to aflatoxin contaminated feed and discarded milk, amounting to US\$150.7 million. However, this estimation was calculated on the assumption that all milk exceeding AFM1 level of $0.05 \mathrm{ug} / \mathrm{kg}$ would be discarded. In order to justify the accuracy of this estimation, the enforcement of aflatoxin regulation in Kenya should be taken into account. Two studies in Kenya showed that awareness level of consumers and occurence of aflatoxicosis in their region increased their willingness to pay for aflatoxin-free product in milk by $64 \%$ and maize by 50\% (de Groote et al., 2016; Mtimet et al., 2015). At the same time, awareness on reducing aflatoxins should also be built in producers' side to stimulate them implementing mitigation measures. Moreover, the additional costs of reducing aflatoxins should be equally distributed along the chain rather to put the burden on one side, for example, producers or consumers only.

Studies on health-related economic impacts for African countries were not found in the included scientific publications. Additionally, some grey literature was found, i.e. a project report and presentation files for a meeting (Kimanya, 2015; Narayan et al., 2014; Ndenn et al., 2015) quantifying the economic losses due to aflatoxins-related public health problems, particularly for liver cancer, in terms of DALY and VSL. The same studies and a study by Senerwa et al (Senerwa et al., 2016) also recently estimated the trade-related impacts in country levels, instead of estimating the impacts on African level. These findings indicate that studies on these topic already started, particularly by regional organisations, although the results were not yet published in scientific journals. 
In general, the limited number of studies estimating economic impacts of aflatoxins contamination points out a gap in peer-reviewed literature. The bottom line in this literature gap is the availability of the data for the estimations, particularly for health-related impacts. This finding is in agreement with previous studies indicating that economic impacts of mycotoxins (including aflatoxins) are difficult to assess due to lack of data on health costs and mycotoxin-induced human illness (Coulibaly et al., 2008; DohImann, 2003). For example, in order to estimate the cost of illness for aflatoxins-related HCC, various data sources are needed including the epidemiology, medication costs, etc. These data might not be readily available in many African countries.

\subsection{Mitigation measures}

Whilst the literature search performed for this report focused on mitigation measures reported specifically for Africa, a wide range of mycotoxin-reducing methods that have been described more globally or for other regions might also be of interest. Examples include: i) the implementation of good practices for agriculture, processing and food production quality assurance, ii) fungicide and insecticide use; iii) modelling and prediction of mycotoxin formation in crops based on meterological and agronomic data; iv) dietary inclusion of chlorophyll, chlorophyllin, and other agents (e.g. lactobacilli, yeast glucan); v) nixtamalization, i.e. alkaline soaking of maize meal; and vi) chemoprevention with dietary ingredients such as green tea polyphenols (Wild et al., 2016)

With regard to mitigation specifically in Africa, this review of recent studies further highlights the multitude of methods and stages from farm to fork and beyond at which the contamination, exposure and adverse effects can be prevented, mitigated or reversed. A number of conclusions can be drawn from the references reviewed that appeared to be particularly applicable to the situation on the African continent, much in line with previous observations in other reviews e.g. Udomkun et al. (2017) and Okoth (2016) who concluded that "no single technology or intervention emerges as a standalone strategy for wide-scale adoption in Africa". In particular however, proof of cost-effectiveness or even costs alone of the practices is lacking.

At the stage of crop cultivation, for example, many included studies were on the use of biocontrol agents, particularly the AflaSafe $\AA$ product currently being applied to maize cultivation. It must be noted that this practice is relatively easily studied under research conditions and is underpinned by a clear commercial interest and, therefore, may be subject of relatively a large amount of included studies. Drawback of the use of biocontrol agents, and thus also of the use of AflaSafe ${ }_{\text {, }}$ is that this is not a permanent mitigation strategy. It must be applied on a yearly basis, making the practice less attractive each year for household or small scale farmers.

The literature retrieved shows that the different lines of mitigation already existing pre-2010 were further elaborated for specific African scenarios during the time period considered, including measures related to breeding, crop cultivation, harvest and post-harvest storage and processing. In addition, records of ongoing research and practical application of aflatoxin binders for the human and animal gastrointestinal tract were found. Much of the grey literature found, including book chapters, conference proceedings, flyers, etc. corroborated the findings of the systematic literature search. Although the cost aspect was not often quantitatively addressed, it appeared that the following measures are particularly effective:

- $\quad$ Resistant plant varieties adapted to the local agro-ecological situation would be favourable. They do not require any changes to the infrastructure of the supply chain for crop breeding companies and farmers alike;

- Awareness raising and education of farmers, farmers' wifes, and other associates, both in general terms, such as for the importance of good and hygienic (storage) practices, as well as for e.g. hand sorting and separation of good from bad kernels;

- Promotion of the use of competing, nonaflatoxigenic moulds which have proven to be able to substantially lower aflatoxin levels in the product (maize, peanuts);

- Storage conditions appear to have a big impact, such as that of still humid products in hermetically sealed plastic bags, whereas proper use of these bags could actually protect the 
product against factors conducive to aflatoxin formation such as damage by insects or rodents, for example;

- Introduction of good practices and enforceable food safety standards to protect public health. This needs to be facilitated, for example by a price premium for farmers and other chain actors growing, handling and processing a higher-quality and/or safer product. Enforcement and good practices will also be facilitated by the availability of inexpensive, rapid methods to control for the presence of aflatoxins.

- Dietary diversity to mitigate mycotoxin exposure: in particular to encourage breast-feeding in first 6 months of life, and complementary foods should be diverse to include other foods less prone to mycotoxins.

These recommendations are in line with those by Adegoka and Letuma for mycotoxin mitigation in developing countries (Adegoke \& Letuma, 2013). They also fall within the range of options offered by the PACA paper on impacts and potential solutions (PACA, 2015), and those indicated by Okoth (2016).

\subsection{Studies published after the literature review screening}

The literature search was performed in March 2018. Any studies published after this date were thus not reviewed. However, several studies published since then that presented interesting results have been identified. It must be noted that these studies were not reviewed in the manner described in the methodology, and are therefore not part of the evidence basis that is presented in this report. The supplementary studies are presented in Annex 13 of this report. These studies touch upon a variety of topics.

\subsection{Limitations}

This study focused on publications written in the English language. Therefore, publications in, for instance, French journals were automatically excluded. No estimate could be made on the number of studies that were not identified due to this limitation. Secondly, this literature review's focus was specifically on high quality, peer-reviewed literature. Attempts have been made to locate additional relevant publications from trusted sources (included in Annex 2), but due to the risk of introducing bias, these were kept separate from the peer-reviewed publications. The disadvantage of this approach is that certain findings, which could be of added value, are not included in this study because they were not published in a peer-reviewed journal. In addition, the inherent disadvantages of a systematic literature review [as discussed in EFSA (2010)] apply, which are that they are time, resource, and expertise intensive and primarily suitable for questions for which primary research is available. An inherent issue with literature reviews is that there is a bias towards publishing positive findings in literature (Haidich, 2010). Finally, because only studies from 2010-2018 were included in this review, the findings are inherently limited to that time period. 


\section{Conclusion, knowledge gaps and recommendations}

\subsection{Conclusion and knowledge gaps}

Different research areas have been covered by the four subtopics of contamination, economics, disease burden, and mitigation; illustrating the diversity of aspects of aflatoxin contamination of human food and animal feed. The systematic approach followed within the research carried out was to comprehensively cover all good-quality studies available on these topics. This way, an overview of the actual knowledge on the situation of aflatoxins in Africa, its spread and impacts and ways to counter its adverse effects, was created, and knowledge gaps were identified. The data considered have been retrieved from included scientific literature, complemented with grey-literature data of acceptable quality where this could provide useful additions.

Estimation of economic impacts due to aflatoxin contamination in foods and feeds is an extensive area of research. Most scientific publications on trade impacts estimated the losses as consequences of African exporters in failing to meet aflatoxins regulations of importing countries, mainly the EU regulations, which are considered as more stringent than CODEX guidelines. These studies however did not yield a conclusive result due to variability in data, and assumptions used. Other trade-related impacts were observed in various effects, including cost of compliance, willingness to pay (WTP) for aflatoxin controls, productivity loss, and WTP for aflatoxins-free products. However, some studies only indicated the rationale behind the losses without quantifying the monetary losses. Analysis of healthrelated economic impacts was not covered by included publications. However, recent studies in this topic were reported in grey literature, along with studies estimating the trade impacts on country level. These findings indicated that studies on these topics may exist, although the results were not yet published into scientific publications.

Creating economic incentives could be a strategy to reduce aflatoxin contamination in products. It can be initiated by raising awareness on producers and consumers. It is expected that when the contamination levels decrease, the exposure will also decrease thus reducing the disease burden and economic impacts thereof, which would improve the competitiveness of the commodities in global trade.

Based on the outcomes, it becomes apparent that aflatoxins are a multi-faceted problem, for which a holistic approach addressing the wide variety of aspects will be needed to prevent, mitigate or reverse aflatoxin-related negative impacts. This report shows that more emphasis should be put in studies on evidence based cost-effective mitigation strategies for aflatoxins, on the scale and spread of the problem and its impacts on public health and economics for use in evidence based policies. It must be strongly encouraged to publish results in transparent peer reviewed platforms.

Some general strategies can be drawn across the four subtopics:

- Much of the data for aflatoxins in Africa reported in the included studies in the last 10 years, comes from three countries, namely Egypt, Kenya, and Nigeria. Other countries that were covered by the included studies, to a lesser extent, included Algeria, Burkina Faso, Cameroon, Ethiopia, Malawi, South Africa, Tanzania, and Uganda. It must be pointed out that studies can only be carried out and published in (peer reviewed) literature if sufficient budget can be made available. Governments must consider many socio-economic factors when prioritising budgets for various studies. Unless data extrapolation to other countries within the same or similar agro-ecological zones is possible, this may indicate a knowledge gap, if nation-specific data is needed.

- The governmental institutions of these countries acknowledge the problem and made enough resource available to invest in scientific studies and publish those studies in peer reviewed 
journals. Studies on mitigation may successfully be carried out in these countries. The outcomes should be carefully monitored for cost-effectiveness.

- The disease burden caused by aflatoxins cannot be easily estimated. Impaired health and growth are caused by multiple factors which should be addressed to simultaneously.

- A holistic approach focusing on a combination of co-occurring mycotoxins and other contaminants, rather than an isolated strategy, is required to increase the total quality of life;

- Many of the included studies focused on maize (cereal) and peanut/groundnut (nut) as source of aflatoxin contamination, exposure, and mitigation. This is obvious as both crops have a major role in African diets as staple crops, and also given their susceptibility to fungal infection and mycotoxin contamination both pre- and post-harvest. Interestingly, many publications also focus on contamination of typical African products and meals. As there are recent trends and policies towards food diversification and cultivation of other cereals, such as sorghum used for beer-brewing, and rice, data on these crops would also be helpful. Various ways of food preservation, such as fermentation, actually were shown to have a mitigating impact on aflatoxin contamination. Animal-derived products including meat and particularly dairy products from livestock that may have been exposed to aflatoxin via animal feed. A number of publications also considered the potential impacts on health and productivity of cultured fish (tilapia), for example, receiving contaminated fish diets.

More specifically the following observations could be made:

- Many of the retrieved studies focusing on economic impacts focused on exportability of produce to the European Union in the light of the legal limits set there, or more generally on Codex Alimentarius limits. Given that much of the trade is intra-African, and also other markets besides the EU are being catered to, such as Asia and the Americas, it would be useful to have a more global broader view on the trade impacts.

- Biomarkers of exposure were extensively studied in a range of settings and populations, as well as in food-producing animals. Obviously, such data could provide a useful tool to gauge the impact of mitigation measures by establishing a baseline and subsequently measure their trends so as to verify if these measures have the desired effect on exposure and related health impacts.

- For mitigation measures, the success may be measurable both in the short and long-term, given that, for example, the health impacts can be acute (aflatoxicosis) as well as chronic (e.g. liver cancer). The contribution to the latter may be difficult to establish, although it is conceivable that any measure reducing the exposure to aflatoxins will ultimately result in a decrease in disease burden.

- There is a broad range of mitigation measures that are possible, and have been tested. However, a limited number of these measures is practically feasible for small farmers and downstream chain actors up to rural households. Moreover, only few publications have comprehensively considered the cost-effectiveness of measures, which makes it difficult to compare them.

The knowledge gaps identified from the here presented literature include:

- Only a limited number of relevant research studies is published in peer reviewed journals;

- Relatively many studies have investigated biomarkers, underpinning the wide spread of exposure to aflatoxin in all ages and groups of society. Studies showing causation between exposure and lifelong health effects such as impaired growth in children were lacking;

- The number of studies that we found in the peer reviewed literature for economic impact was limited - particularly for health-related economics; additional recent studies on health-related economic impacts conducted by regional organisations and published as project reports or papers at conference were found in grey literature;

- Trade impacts considered particularly African-EU trade whereas intra-African and external trade with non-EU countries might be relevant as well;

- Cost-effectiveness was not assessed for many mitigation measures;

- No studies on the impact of mitigation on chronic impacts were found, such as for vaccination as a mitigation measure on aflatoxin-related liver cancer. 


\subsection{Recommendations}

This report underpins the need for effective management of the aflatoxin situation in Africa, in line with numerous previous reports [e.g. (Okoth et al., 2017; Udomkun et al., 2017; Wild et al., 2016)]. A number of mitigation measures have been developed, both on the production side to reduce contamination, and on the consumer side to reduce or mitigate the effects of exposure. It is clear however that aflatoxin levels in food and feed are currently too high in many geographic regions in Africa, and the priority should therefore be to reduce these levels substantially.

Economic incentives, both on the producer as well as the consumer side, could be a strategy to reduce aflatoxin contamination in products and reduce the impact on all investigated subtopics. The number of identified studies specifically on the economic impact of aflatoxins in Africa was low. Overall, background information must be available, transparent and easily accessible for policy makers to achieve this goal. Studies by local authorities can be of great importance to mitigate aflatoxins but are difficult to include in decision-making when not published. It is therefore recommended that more focus is placed on publishing results of studies in peer reviewed open source journals.

With regard to mitigation measures, it appears feasible to implement various low-key interventions to prevent or reduce mycotoxin contamination and its impacts. For example, manual or mechanical sorting out infected or contaminated seeds, pods or other harvested items, has shown to have a major effect. Also conditions under which harvests are dried and stored post-harvest, such as drying of seed batches elevated from the ground and storage of dried seeds in multi-layered PICS bags, could well fit into mitigation strategies. Awareness raising has been cited as a conduit to successful implementation not only at the farmers' levels, but also at the level of food preparation in rural households. For all this, also the practical role of women in the implementation of such measures has to be acknowledged. Bio-control methods that employ atoxigenic mould strains appear to be effective in reducing the aflatoxin content in agricultural crops, and the willingness to pay appears to be there among farmers, but this method also has drawbacks. The identified studies have investigated a variety of mitigation measures, but the relative costs and cost effectiveness are under- or unreported. It is therefore recommended that these aspects are studied more extensively for existing mitigation measures, and included in the study design for the effectiveness of new measures. 


\section{References}

Abdallah, M. F., Krska, R., \& Sulyok, M. (2016). Mycotoxin contamination in sugarcane grass and juice: first report on detection of multiple mycotoxins and exposure assessment for aflatoxins B1 and G1 in humans. Toxins, 8(11). doi:dx.doi.org/10.3390/toxins8110343

Abdallah, M. F., Krska, R., \& Sulyok, M. (2018). Occurrence of ochratoxins, fumonisin B2, aflatoxins (B1 and B2), and other secondary fungal metabolites in dried date palm fruits from Egypt: A mini-survey. Journal of Food Science, 83(2), 559-564. doi:10.1111/1750-3841.14046

Abdel Rahman, A. N., Abdellatief, S. A., \& Mahboub, H. H. H. (2017). Protection of Nile tilapia, Oreochromis niloticus from aflatoxin B1 toxicity by dietary supplementation with Fennel essential oil and Saccharomyces cerevisiae. Egyptian Journal of Aquatic Research, 43(3), 235-240. doi:10.1016/j.ejar.2017.09.006

Abia, W. A., Warth, B., Ezekiel, C. N., Sarkanj, B., Turner, P. C., Marko, D., . . Sulyok, M. (2017). Uncommon toxic microbial metabolite patterns in traditionally home-processed maize dish (fufu) consumed in rural Cameroon. Food and Chemical Toxicology, 107(Part A), 10-19. doi:dx.doi.org/10.1016/j.fct.2017.06.011

Abia, W. A., Warth, B., Sulyok, M., Krska, R., Tchana, A., Njobeh, P. B., . . Moundipa, P. F. (2013a). Biomonitoring of mycotoxin exposure in Cameroon using a urinary multi-biomarker approach. Food and Chemical Toxicology, 62, 927-934. doi:dx.doi.org/10.1016/j.fct.2013.10.003

Abia, W. A., Warth, B., Sulyok, M., Krska, R., Tchana, A. N., Njobeh, P. B., . . Moundipa, P. F. (2013b). Determination of multi-mycotoxin occurrence in cereals, nuts and their products in Cameroon by liquid chromatography tandem mass spectrometry (LC-MS/MS). Food Control, 31(2), 438-453. doi:dx.doi.org/10.1016/j.foodcont.2012.10.006

Adedeji, B. S., Ezeokoli, O. T., Ezekiel, C. N., Obadina, A. O., Somorin, Y. M., Sulyok, M., .... Krska, R. (2017). Bacterial species and mycotoxin contamination associated with locust bean, melon and their fermented products in south-western Nigeria. International Journal of Food Microbiology, 258, 7380. doi:dx.doi.org/10.1016/j.ijfoodmicro.2017.07.014

Adegoke, G. O., \& Letuma, P. (2013). Strategies for the Prevention and Reduction of Mycotoxins in Developing Countries. In H. Makun (Ed.), Mycotoxin and Food Safety in Developing Countries (pp. 123-136). London, UK: InTechOpen.

Adetuniji, M. C., Atanda, O. O., Ezekiel, C. N., Dipeolu, A. O., Uzochukwu, S. V. A., Oyedepo, J., \& Chilaka, C. A. (2014). Distribution of mycotoxins and risk assessment of maize consumers in five agroecological zones of Nigeria. European Food Research and Technology, 239(2), 287-296. doi:dx.doi.org/10.1007/s00217-014-2221-0

Adetunji, M., Atanda, O., Ezekiel, C. N., Sulyok, M., Warth, B., Beltran, E., . . . Chilaka, C. A. (2014). Fungal and bacterial metabolites of stored maize (Zea mays, L.) from five agro-ecological zones of Nigeria. Mycotoxin Research, 30(2), 89-102. doi:dx.doi.org/10.1007/s12550-014-0194-2

Adetunji, M. C., Atanda, O. O., \& Ezekiel, C. N. (2017). Risk assessment of mycotoxins in stored maize grains consumed by infants and young children in Nigeria. Children (Basel), 4(7). doi: $10.3390 /$ children4070058

Afolabi, C. G., Ezekiel, C. N., Kehinde, I. A., Olaolu, A. W., \& Ogunsanya, O. M. (2015). Contamination of groundnut in South-Western Nigeria by aflatoxigenic fungi and aflatoxins in relation to processing. Journal of Phytopathology, 163(4), 279-286. doi:dx.doi.org/10.1111/jph.12317

Afum, C., Cudjoe, L., Hills, J., Hunt, R., Padilla, L. A., Elmore, S., . . . Jolly, P. E. (2016). Association between aflatoxin $\mathrm{M} 1$ and liver disease in $\mathrm{HBV} / \mathrm{HCV}$ infected persons in Ghana. International Journal of Environmental Research and Public Health, 13(4). doi:dx.doi.org/10.3390/ijerph13040377

Agyekum, M., \& Jolly, C. M. (2017). Peanut trade and aflatoxin standards in Europe: Economic effects on trading countries. Journal of Policy Modeling, 39(1), 114-128. doi:https://doi.org/10.1016/j.jpolmod.2016.08.004

Akbari, P., Braber, S., Varasteh, S., Alizadeh, A., Garssen, J., \& Fink-Gremmels, J. (2017). The intestinal barrier as an emerging target in the toxicological assessment of mycotoxins. Archives of Toxicology, 91(3), 1007-1029. doi:10.1007/s00204-016-1794-8

Akoto, E. Y., Klu, Y. A. K., Lamptey, M., Asibuo, J. Y., Davis, J., Phillips, R., . . Chen, J. (2017). Use of peanut meal as a model matrix to study the effect of composting on aflatoxin decontamination. World Mycotoxin Journal, 10(2), 131-141. doi:10.3920/wmj2016.2155

Akueche, E. C., Anjorin, S. T., Harcourt, B. I., Kana, D., Adeboye, E., Shehu, I., . . Adesanmi, C. A. (2012). Studies on fungal load, total aflatoxins and ochratoxin A contents of gamma-irradiated and nonirradiated Sesamum indicum grains from Abuja markets, Nigeria. Kasetsart Journal, Natural Sciences, 46(3), 371-382.

Asiki, G., Seeley, J., Srey, C., Baisley, K., Lightfoot, T., Archileo, K., . . Gong, Y. Y. (2014). A pilot study to evaluate aflatoxin exposure in a rural Ugandan population. Tropical Medicine and International Health, 19(5), 592-599. doi:dx.doi.org/10.1111/tmi.12283

Atehnkeng, J., Donner, M., Ojiambo, P. S., Ikotun, B., Augusto, J., Cotty, P. J., \& Bandyopadhyay, R. (2016). Environmental distribution and genetic diversity of vegetative compatibility groups determine biocontrol strategies to mitigate aflatoxin contamination of maize by Aspergillus flavus. Microbial Biotechnology, 9(1), 75-88. doi:dx.doi.org/10.1111/1751-7915.12324

Atherstone, C., Grace, D., Waliyar, F., Lindahl, J., \& Osiru, M. (2014). Aflatoxin literature synthesis and risk mapping: Special emphasis on sub-Saharan Africa. Nairobi, Kenya: International Livestock Research Institute.

Awuor, A. O., Yard, E., Daniel, J. H., Martin, C., Bii, C., Romoser, A., . . Lewis, L. S. (2017). Evaluation of the efficacy, acceptability and palatability of calcium montmorillonite clay used to reduce aflatoxin 
B1 dietary exposure in a crossover study in Kenya. Food Additives and Contaminants A, 34(1), 93102. doi:dx.doi.org/10.1080/19440049.2016.1224933

Ayedun, B., Okpachu, G., Manyong, V., Atehnkeng, J., Akinola, A., Abu, G. A., . . Abdoulaye, T. (2017). An assessment of willingness to pay by maize and groundnut farmers for aflatoxin biocontrol product in northern Nigeria. Journal of Food Protection, 80(9), 1451-1460. doi:dx.doi.org/10.4315/0362028X.JFP-16-281

Ayelign, A., Woldegiorgis, A. Z., Adish, A., de Boevre, M., Heyndrickx, E., \& de Saeger, S. (2017). Assessment of aflatoxin exposure among young children in Ethiopia using urinary biomarkers. Food Additives and Contaminants A, 34(9), 1606-1616.

Ayyat, M. S., Abd Rahman, G. A., El-Marakby, H. I., El-Hakem, N. A. B., \& Hessan, A. A. A. (2014). Toxicity and biochemical hazards induced by exposure of Nile tilapia to aflatoxin and their amelioration. Global Journal of Environmental Sciences and Toxicology, 1, 1-19.

Ayyat, M. S., Abd Rahman, G. A., El-Marakby, H. I., Mahmoud, H. K., \& Hessan, A. A. A. (2013). Reduction the aflatoxin toxicity in Nile tilapia fish. Egyptian Journal of Nutrition and Feeds, 16 (2 (Special Issue), 469-479.

Azaiez, I., Font, G., Manes, J., \& Fernandez-Franzon, M. (2015). Survey of mycotoxins in dates and dried fruits from Tunisian and Spanish markets. Food Control, 51, 340-346. doi:dx.doi.org/10.1016/j.foodcont.2014.11.033

Azziz-Baumgartner, E., Lindblade, K., Gieseker, K., Schurz Rogers, H., Kieszak, S., Njapau, H., . . . the Aflatoxin Investigative Group. (2005). Case-Control Study of an Acute Aflatoxicosis Outbreak, Kenya, 2004. Environmental Health Perspectives, 113(12), 1779-1783. doi:10.1289/ehp.8384

Azzoune, N., Mokrane, S., Riba, A., Bouras, N., Verheecke, C., Sabaou, N., \& Mathieu, F. (2016). Contamination of common spices by aflatoxigenic fungi and aflatoxin $B<$ sub $>1</$ sub $>$ in Algeria. Quality Assurance and Safety of Crops \& Foods, 8(1), 137-144. doi:dx.doi.org/10.3920/QAS2014.0426

Bakoye, O. N., Baoua, I. B., Seyni, H., Amadou, L., Murdock, L. L., \& Baributsa, D. (2017). Quality of maize for sale in markets in Benin and Niger. Journal of Stored Products Research, 71, 99-105. doi:dx.doi.org/10.1016/j.jspr.2017.02.001

Bandyopadhyay, R., Ortega-Beltran, A., Akande, A., Mutegi, C., Atehnkeng, J., Kaptoge, L., ... Cotty, P. J. (2016). Biological control of aflatoxins in Africa: current status and potential challenges in the face of climate change. World Mycotoxin Journal, 9(5), 771-789. doi:DOI: 10.3920/WMJ2016.2130

Bankole, S., Schollenberger, M., \& Drochner, W. (2006). Mycotoxins in food systems in Sub Saharan Africa: A review. Mycotoxin Research, 22(3), 163-169. doi:10.1007/bf02959270

Baoua, I. B., Amadou, L., Ousmane, B., Baributsa, D., \& Murdock, L. L. (2014). PICS bags for post-harvest storage of maize grain in West Africa. (Special Issue: Hermetic storage of grain in developing nations.). Journal of Stored Products Research, 58, 20-28. doi:dx.doi.org/10.1016/j.jspr.2014.03.001

Bhutta, Z. A., Das, J. K., Rizvi, A., Gaffey, M. F., Walker, N., Horton, S., . . Black, R. E. (2013). Evidencebased interventions for improvement of maternal and child nutrition: what can be done and at what cost? The Lancet, 382(9890), 452-477. doi:https://doi.org/10.1016/S0140-6736(13)60996-4

Boaz, N., Wachira, P., Kagot, V., \& Okoth, S. (2017). Susceptibility of locally cultivated groundnut (Arachis hypogaea) varieties to aflatoxin accumulation in Homa Bay County, Kenya. African Journal of Microbiology Research, 11(33), 1329-1337. doi:dx.doi.org/10.5897/ajmr2017.8606

Bray, F., Sankila, R., Ferlay, J., \& Parkin, D. M. (2002). Estimates of cancer incidence and mortality in Europe in 1995. European Journal of Cancer, 38(1), 99-166. doi:Doi 10.1016/S09598049(01)00350-1

Brown, R., Williams, W., Windham, G., Menkir, A., \& Chen, Z. Y. (2016). Evaluation of African-Bred Maize Germplasm Lines for Resistance to Aflatoxin Accumulation. Agronomy, 6(2), 24.

Castelino, J. M., Dominguez-Salas, P., Routledge, M. N., Prentice, A. M., Moore, S. E., Hennig, B. J., . . . Gong, Y. Y. (2014). Seasonal and gestation stage associated differences in aflatoxin exposure in pregnant Gambian women. Tropical Medicine and International Health, 19(3), 348-354. doi:dx.doi.org/10.1111/tmi.12250

Castelino, J. M., Routledge, M. N., Wilson, S., Dunne, D. W., Mwatha, J. K., Gachuhi, K., ... Gong, Y. Y. (2015). Aflatoxin exposure is inversely associated with IGF1 and IGFBP3 levels in vitro and in Kenyan schoolchildren. Molecular Nutrition and Food Research, 59(3), 574-581. doi:10.1002/mnfr.201300619

Chauhan, Y., Tatnell, J., Krosch, S., Karanja, J., Gnonlonfin, B., Wanjuki, I., . . Harvey, J. (2015). An improved simulation model to predict pre-harvest aflatoxin risk in maize. Field Crops Research, 178, 91-99. doi:dx.doi.org/10.1016/j.fcr.2015.03.024

Chelule, P. K., Mbongwa, H. P., Carries, S., \& Gqaleni, N. (2010). Lactic acid fermentation improves the quality of amahewu, a traditional South African maize-based porridge. Food Chemistry, 122(3), 656-661. doi:dx.doi.org/10.1016/j.foodchem.2010.03.026

Chen, G., Gong, Y. Y., Kimanya, M. E., Shirima, C. P., \& Routledge, M. N. (2017). Comparison of urinary aflatoxin $\mathrm{M} 1$ and aflatoxin albumin adducts as biomarkers for assessing aflatoxin exposure in Tanzanian children. Biomarkers, 1-6. doi:10.1080/1354750x.2017.1285960

Chilaka, C. A., Kock, S. d., Phoku, J. Z., Mwanza, M., Egbuta, M. A., \& Dutton, M. F. (2012). Fungal and mycotoxin contamination of South African commercial maize. Journal of Food, Agriculture \& Environment, 10(2 Part 1), 296-303.

Christie, M. E., Kyamureku, P., Kaaya, A., \& Devenport, A. (2015). Farmers, peanuts, and aflatoxins in Uganda: a gendered approach. Development in Practice, 25(1), 4-18. doi:dx.doi.org/10.1080/09614524.2015.983459

Coulibaly, O., Hell, K., Bandyopadhyay, R., Hounkponou, S., \& Leslie, J. F. (2008). Economic impact of aflatoxin contamination in SubSaharan Africa. In J. Leslie, R. Bandyopadhyay, \& A. Visconti (Eds.), Mycotoxins detection methods, management, public health and agricultural trade (1st ed.) (pp. 6776). Cambridge: CABI.

CRD. (2009). Systematic Reviews. York, UK: Centre for Reviews and Dissemination, University of York. 
Daniel, J. H., Lewis, L. W., Redwood, Y. A., Kieszak, S., Breiman, R. F., Flanders, W. D., . .. McGeehin, M. A. (2011). Comprehensive assessment of maize aflatoxin levels in Eastern Kenya, 2005-2007. Environmental Health Perspectives, 119(12), 1794-1799. doi:dx.doi.org/10.1289/ehp.1003044

Darwish, W. S., Ikenaka, Y., Nakayama, S. M. M., \& Ishizuka, M. (2014). An overview on mycotoxin contamination of foods in Africa. Journal of Veterinary Medical Science, 76(6), 789-797. doi:dx.doi.org/10.1292/jvms.13-0563

Dawit, G., Szonyi, B., Azage, T., Hanson, J., \& Grace, D. (2016). Aflatoxin contamination of milk and dairy feeds in the Greater Addis Ababa milk shed, Ethiopia. Food Control, 59, 773-779. doi:dx.doi.org/10.1016/j.foodcont.2015.06.060

de Groote, H., Narrod, C., Kimenju, S. C., Bett, C., Scott, R. P. B., Tiongco, M. M., \& Gitonga, Z. M. (2016). Measuring rural consumers' willingness to pay for quality labels using experimental auctions: The case of aflatoxin-free maize in Kenya. Agricultural Economics (United Kingdom), 47(1), 33-45. doi: 10.1111 /agec. 12207

Dewey, K. G., \& Adu-Afarwuah, S. (2008). Systematic review of the efficacy and effectiveness of complementary feeding interventions in developing countries. Maternal \& Child Nutrition, 4(s1), 2485. doi:doi:10.1111/j.1740-8709.2007.00124.x

Diaz, G. J., \& Sánchez, M. P. (2015). Determination of aflatoxin M1 in breast milk as a biomarker of maternal and infant exposure in Colombia. Food Additives \& Contaminants: Part A, 32(7), 1192-1198. doi:10.1080/19440049.2015.1049563

Diedhiou, P. M., Bandyopadhyay, R., Atehnkeng, J., \& Ojiambo, P. S. (2011). Aspergillus colonization and aflatoxin contamination of maize and sesame kernels in two agro-ecological zones in Senegal. Journal of Phytopathology, 159(4), 268-275. doi:dx.doi.org/10.1111/j.1439-0434.2010.01761.x

Dohlmann, E. (2003). Mycotoxin hazards and regulations: Impacts on food and animal feed crop trade. In J. Buzby (Ed.), International Trade and Food Safety: Economic Theory and Case Studies. Washington DC: United States Department of Agriculture, Economic Research Service.

Edelman, B., \& Aberman, N.-L. (2015a). Malawi Strategy Support Program: Promoting Exports of LowAflatoxin groundnut from Malawi. In. Malawi: IFPRI.

Edelman, B., \& Aberman, N. L. (2015b). Promoting exports of low-aflatoxin groundnut from Malawi (MASSP Policy Note 21). In (Vol. 2018). Washington DC, USA: International Food Policy Research Institute.

Ediage, E. N., Hell, K., \& de Saeger, S. (2014). A comprehensive study to explore differences in mycotoxin patterns from agro-ecological regions through maize, peanut, and cassava products: a case study, Cameroon. Journal of Agricultural and Food Chemistry, 62(20), 4789-4797. doi:dx.doi.org/10.1021/jf501710u

Ediage, E. N., Mavungu, J. D. d., Song, S., Sioen, I., \& Saeger, S. d. (2013). Multimycotoxin analysis in urines to assess infant exposure: a case study in Cameroon. Environment International, 57(58), 5059. doi:dx.doi.org/10.1016/j.envint.2013.04.002

EFSA. (2007). Opinion of the scientific panel on contaminants in the food chain [CONTAM] related to the potential increase of consumer health risk by a possible increase of the existing maximum levels for aflatoxins in almonds, hazelnuts and pistachios and derived products. EFSA Journal, 5(3). doi:10.2903/j.efsa.2007.446

EFSA. (2010). Application of systematic review methodology to food and feed safety assessments to support decision making. EFSA Journal, 8(6), 1637. doi:DOI: 10.2903/j.efsa.2010.1637

El-Marnissi, B., Belkhou, R., Morgavi, D. P., Bennani, L., \& Boudra, H. (2012). Occurrence of aflatoxin M1 in raw milk collected from traditional dairies in Morocco. Food and Chemical Toxicology, 50(8), 28192821. doi:dx.doi.org/10.1016/j.fct.2012.05.031

El-Shahat, E. S. A., Swelim, M. A., Mohamed, A. F., \& Abdel-Wahhab, M. A. (2012). Correlation study between aflatoxin M 1 and hepatitis $C$ virus in Egyptian patients with chronic liver disease. World Journal of Medical Sciences, 7(4), 224-231. doi:10.5829/idosi.wjms.2012.7.4.63169

El-Shanshoury, A. E. R., El-Sabbagh, S. M., Emara, H. A., \& Saba, H. A. E. (2014). Occurrence of moulds, toxicogenic capability of Aspergillus flavus and levels of aflatoxins in maize, wheat, rice and peanut from markets in central Delta provinces, Egypt. International Journal of Current Microbiology and Applied Sciences, 3(3), 852-865.

Ezekiel, C. N., Bandyopadhyay, R., Sulyok, M., Warth, B., \& Krska, R. (2012a). Fungal and bacterial metabolites in commercial poultry feed from Nigeria. Food Additives and Contaminants A, 29(8), 1288-1299.

Ezekiel, C. N., Sulyok, M., Babalola, D. A., Warth, B., Ezekiel, V. C., \& Krska, R. (2013). Incidence and consumer awareness of toxigenic Aspergillus section Flavi and aflatoxin B1 in peanut cake from Nigeria. Food Control, 30(2), 596-601. doi:10.1016/j.foodcont.2012.07.048

Ezekiel, C. N., Sulyok, M., Warth, B., \& Krska, R. (2012b). Multi-microbial metabolites in fonio millet (acha) and sesame seeds in Plateau State, Nigeria. European Food Research and Technology, 235(2), 285293. doi:dx.doi.org/10.1007/s00217-012-1755-2

Ezekiel, C. N., Sulyok, M., Warth, B., Odebode, A. C., \& Krska, R. (2012c). Natural occurrence of mycotoxins in peanut cake from Nigeria. Food Control, 27(2), 338-342. doi:dx.doi.org/10.1016/j.foodcont.2012.04.010

Ezekiel, C. N., Warth, B., Ogara, I. M., Abia, W. A., Ezekiel, V. C., Atehnkeng, J., . . Bandyopadhyay, R. (2014). Mycotoxin exposure in rural residents in northern Nigeria: a pilot study using multi-urinary biomarkers. Environment International, 66, 138-145. doi:dx.doi.org/10.1016/j.envint.2014.02.003

FDA. (2009). Guidance for Industry: Evidence-Based Review System for the Scientific Evaluation of Health Claims. Silver Spring MD, USA: U.S. Food and Drug Administration.

Flores-Flores, M. E., Lizarraga, E., López de Cerain, A., \& González-Peñas, E. (2015). Presence of mycotoxins in animal milk: A review. Food Control, 53, 163-176.

Getachew, A., Chala, A., Hofgaard, I. S., Brurberg, M. B., Sulyok, M., \& Tronsmo, A. M. (2018). Multimycotoxin and fungal analysis of maize grains from south and southwestern Ethiopia. Food Additives and Contaminants: Part B Surveillance, 11(1), 64-74. doi:10.1080/19393210.2017.1408698 
Ghislaine, D. A., Imene, B. A., Zohra, E. F., Samira, M., Bouziane, A., \& Mohammed, B. (2016). Influence of lactic ferments on Aflatoxin M1 in the industrial manufacture of the Algerian Leben. Der Pharmacia Lettre, 8(19), 329-338.

Gibb, H., Devleesschauwer, B., Bolger, P. M., Wu, F., Ezendam, J., Cliff, J., . . . Bellinger, D. (2015). World Health Organization estimates of the global and regional disease burden of four foodborne chemical toxins, 2010: a data synthesis. F1000Research, 4, 1393. doi:doi: 10.12688/f1000research.7340.1. eCollection 2015

Gnonlonfin, G. J. B., Hell, K., Adjovi, Y., Fandohan, P., Koudande, D. O., Mensah, G. A., . . . Brimer, L. (2013). A Review on Aflatoxin Contamination and Its Implications in the Developing World: A SubSaharan African Perspective. Critical Reviews in Food Science and Nutrition, 53(4), 349-365. doi: $10.1080 / 10408398.2010 .535718$

Gong, Y. Y., Cardwell, K., Hounsa, A., Egal, S., Turner, P. C., Hall, A. J., \& Wild, C. P. (2002). Dietary aflatoxin exposure and impaired growth in young children from Benin and Togo: cross sectional study. British Medical Journal, 325(7354), 20-21. doi:10.1136/bmj.325.7354.20

Gong, Y. Y., Egal, S., Hounsa, A., Turner, P. C., Hall, A. J., Cardwell, K. F., \& Wild, C. P. (2003). Determinants of aflatoxin exposure in young children from Benin and Togo, West Africa: the critical role of weaning. International Journal of Epidemiology, 32(4), 556-562. doi:10.1093/ije/dyg109

Gong, Y. Y., Hounsa, A., Egal, S., Turner, P. C., Sutcliffe, A. E., Hall, A. J., . . . Wild, C. P. (2004). Postweaning exposure to aflatoxin results in impaired child growth: A longitudinal study in Benin, west Africa. Environmental Health Perspectives, 112(13), 1334-1338. doi:10.1289/ehp.6954

Groopman, J. D., Egner, P. A., Schulze, K. J., Wu, L. S. F., Merrill, R., Mehra, S., . . Christian, P. (2014). Aflatoxin exposure during the first 1000 days of life in rural South Asia assessed by aflatoxin B(1)lysine albumin biomarkers. Food and chemical toxicology : an international journal published for the British Industrial Biological Research Association, 74, 184-189. doi:10.1016/j.fct.2014.09.016

Guerre, P., Bailly, J. D., Benard, G., \& Burgat, V. (2000). Milk excretion of the mycotoxins : which risks for the consumer? Revue de Médecine Vétérinaire, 151(1), 7-22.

Haidich, A. B. (2010). Meta-analysis in medical research. Hippokratia, 14(Suppl 1), 29-37.

Hammitt, J. K. (2000). Valuing Mortality Risk: Theory and Practice. Environmental Science \& Technology, 34(8), 1396-1400. doi:10.1021/es990733n

Hammitt, J. K., \& Robinson, L. A. (2011). The income elasticity of the Value per Statistical Life -transferring estimates between high and low income populations. Journal of Benefit-Cost Analysis, 2(1), 1-29. doi:Doi: $10.2202 / 2152-2812.1009$

Havelaar, A. H., Kirk, M. D., Torgerson, P. R., Gibb, H. J., Hald, T., Lake, R. J., . . Zeilmaker, M. (2015). World Health Organization Global Estimates and Regional Comparisons of the Burden of Foodborne Disease in 2010. PLoS Medicine, 12(12). doi:10.1371/journal.pmed.1001923

Hernandez-Vargas, H., Castelino, J., Silver, M. J., Dominguez-Salas, P., Cros, M.-P., Durand, G., . . Routledge, M. N. (2015). Exposure to aflatoxin B(1 )in utero is associated with DNA methylation in white blood cells of infants in The Gambia. International Journal of Epidemiology, 44(4), 1238-1248. doi: 10.1093/ije/dyv027

Higgins, J. P. T., \& Green, S. (2011). Cochrane Handbook for Systematic Reviews of Interventions, Version 5.1.0 (Updated March 2011): The Cochrane Collaboration.

Hoffmann, V., \& Moser, C. (2017). You get what you pay for: the link between price and food safety in Kenya. Agricultural Economics, 48(4), 449-458. doi:dx.doi.org/10.1111/agec.12346

Idris, Y. M. A., Mariod, A. A., Elnour, I. A., \& Mohamed, A. A. (2010). Determination of aflatoxin levels in Sudanese edible oils. Food and Chemical Toxicology, 48(8/9), 2539-2541. doi:dx.doi.org/10.1016/j.fct.2010.05.021

Jiang, Y., Jolly, P. E., Ellis, W. O., Wang, J.-S., Phillips, T. D., \& Williams, J. H. (2005). Aflatoxin B1 albumin adduct levels and cellular immune status in Ghanaians. International Immunology, 17(6), 807-814.

Johnson, A., Abdoulaye, T., Ayedun, B., Fulton, J. R., Widmar, N. O., Adebowale, A., ... Manyong, V. (2017). A survey of aflatoxin and AflaSafe awareness and management among Nigerian maize farmers. In Working Paper - Department of Agricultural Economics, Purdue University; 2017. (1703):33 pp. 21 ref. West Lafayette: Department of Agricultural Economics, Purdue University.

Jolly, P. E., Akinyemiju, T. F., Jha, M., Aban, I., Gonzalez-Falero, A., \& Joseph, D. (2015). Temporal variation and association of aflatoxin B1 albumin-adduct levels with socio-economic and food consumption factors in HIV positive adults. Toxins, 7(12), 5129-5140.

Kamala, A., Kimanya, M., Haesaert, G., Tiisekwa, B., Madege, R., Degraeve, S., ... de Meulenaer, B. (2016). Local post-harvest practices associated with aflatoxin and fumonisin contamination of maize in three agro ecological zones of Tanzania. Food Additives and Contaminants A, 33(3), 551-559. doi:dx.doi.org/10.1080/19440049.2016.1138546

Kamala, A., Kimanya, M., Lachat, C., Jacxsens, L., Haesaert, G., Kolsteren, P., . . . de Meulenaer, B. (2017). Risk of exposure to multiple mycotoxins from maize-based complementary foods in Tanzania. Journal of Agricultural and Food Chemistry, 65(33), 7106-7114. doi:dx.doi.org/10.1021/acs.jafc.6b03429

Kamala, A., Ortiz, J., Kimanya, M., Haesaert, G., Donoso, S., Tiisekwa, B., \& de Meulenaer, B. (2015). Multiple mycotoxin co-occurrence in maize grown in three agro-ecological zones of Tanzania. Food Control, 54, 208-215. doi:dx.doi.org/10.1016/j.foodcont.2015.02.002

Kamala, A., Shirima, C., Jani, B., Bakari, M., Sillo, H., Rusibamayila, N., . . the investigation team. (2018). Outbreak of an acute aflatoxicosis in Tanzania during 2016. World Mycotoxin Journal, 11(3), 311320. doi:10.3920/wmj2018.2344

Kana, J. R., Gnonlonfin, B. G. J., Harvey, J., Wainaina, J., Wanjuki, I., Skilton, R. A., \& Teguia, A. (2013). Assessment of aflatoxin contamination of maize, peanut meal and poultry feed mixtures from different agroecological zones in Cameroon. Toxins, 5(5), 884-894. doi:dx.doi.org/10.3390/toxins5050884

Kensler, T. W., Roebuck, B. D., Wogan, G. N., \& Groopman, J. D. (2011). Aflatoxin: A 50-year Odyssey of mechanistic and translational toxicology. Toxicological Sciences, 120(SUPPL.1), S28-S48. doi: $10.1093 /$ toxsci/kfq283 
Kilonzo, R. M., Imungi, J. K., Muiru, W. M., Lamuka, P. O., \& Njage, P. M. K. (2014). Household dietary exposure to aflatoxins from maize and maize products in Kenya. Food Additives and Contaminants $A, 31(12)$, 2055-2062. doi:dx.doi.org/10.1080/19440049.2014.976595

Kimanya, M., Mpolya, E., Tiisekwa, B., Kaaya, A. N., Atukwase, A., Tumuhimbise, G. A., . .. Kankwamba, H. (2015). Economic Impact of Aflatoxins to Africa: The Case of Malawi, Tanzania, and Uganda. Paper presented at the First Africa Symposium of Mycotoxicology, Livingstone, Zambia.

Kimanya, M. E. (2015). The health impacts of mycotoxins in the eastern Africa region. Current Opinion in Food Science, 6, 7-11. doi:10.1016/j.cofs.2015.11.005

Kpodo, K., Sørensen, A. K., \& Jakobsen, M. (1996). The occurrence of mycotoxins in fermented maize products. Food Chemistry, 56(2), 147-153. doi:https://doi.org/10.1016/0308-8146(95)00155-7

Krishnamachari, K. A. V. R., Nagarajan, V., Bhat, R. V., \& Tilak, T. B. G. (1975). Hepatitis due to aflatoxicosis: An outbreak in Western India. Lancet, 305(7915), 1061-1063. doi:https://doi.org/10.1016/S0140-6736(75)91829-2

Kumar, P., Mahato, D. K., Kamle, M., Mohanta, T. K., \& Kang, S. G. (2017). Aflatoxins: A global concern for food safety, human health and their management. Frontiers in Microbiology, 7, 2170-2170. doi:10.3389/fmicb.2016.02170

Kumi, J., Dotse, E., Asare, G. A., \& Ankrah, N. A. (2015). Urinary aflatoxin M1 exposure in Ghanaian children weaned on locally prepared nutritional food. African Journal of Science and Research, 4(6), 28-32.

Kwemoi, D. B., Okori, P., \& Asea, G. (2010). Characterization of a diverse set of maize germplasm for resistance to infection by Aspergillus flavus and accumulation of aflatoxin. (RUFORUM Working Document Series No.5). Second RUFORUM Biennial Regional Conference on "Building capacity for food security in Africa", Entebbe, Uganda.

Lemoine, M., \& Thursz, M. R. (2017). Battlefield against hepatitis B infection and HCC in Africa. Journal of Hepatology, 66(3), 645-654. doi:https://doi.org/10.1016/j.jhep.2016.10.013

Leroy, J. L., Wang, J. S., \& Jones, K. (2015). Serum aflatoxin $B_{1}$-lysine adduct level in adult women from Eastern Province in Kenya depends on household socio-economic status: A cross sectional study. Social science \& medicine (1982), 146, 104-110. doi:10.1016/j.socscimed.2015.10.039

Lewis, L., Onsongo, M., Njapau, H., Schurz-Rogers, H., Luber, G., Kieszak, S., . . the Kenya Aflatoxicosis Investigation Group. (2005). Aflatoxin Contamination of Commercial Maize Products during an Outbreak of Acute Aflatoxicosis in Eastern and Central Kenya. Environmental Health Perspectives, 113(12), 1763-1767. doi:10.1289/ehp.7998

Lye, M. S., Ghazali, A. A., Mohan, J., Alwin, N., \& Nair, R. C. (1995). An outbreak of acute hepatic encephalopathy due to severe aflatoxicosis in Malaysia. American Journal of Tropical Medicine and Hygiene, 53(1), 68-72.

Magembe, K. S., Mwatawala, M. W., \& Mamiro, D. P. (2016a). Mycotoxin contamination in stored maize and groundnuts based on storage practices and conditions in subhumid tropical Africa: the case of Kilosa District, Tanzania. Journal of Food Protection, 79(12), 2160-2166. doi:dx.doi.org/10.4315/0362028X.JFP-15-550

Magembe, K. S., Mwatawala, M. W., \& Mamiro, D. P. (2016b). Spatial and temporal variations in contamination of mycotoxins in sub-humid, semi-arid areas of eastern central Tanzania. Archives of Phytopathology and Plant Protection, 49(17/18), 445-455.

Magembe, K. S., Mwatawala, M. W., Mamiro, D. P., \& Chingonikaya, E. E. (2016c). Assessment of awareness of mycotoxins infections in stored maize (Zea mays L.) and groundnut (Arachis hypogea L.) in Kilosa District, Tanzania. International Journal of Food Contamination, 3(12).

Magoha, H., Kimanya, M., de Meulenaer, B., Roberfroid, D., Lachat, C., \& Kolsteren, P. (2014). Association between aflatoxin $M$ exposure through breast milk and growth impairment in infants from northern Tanzania. World Mycotoxin Journal, 7(3), 277-284. doi:10.3920/wmj2014.1705

Magoha, H., Kimanya, M., de Meulenaer, B., Roberfroid, D., Lachat, C., \& Kolsteren, P. (2016). Risk of dietary exposure to aflatoxins and fumonisins in infants less than 6 months of age in Rombo, Northern Tanzania. Maternal and Child Nutrition, 12(3), 516-527. doi:dx.doi.org/10.1111/mcn.12155

Maina, A. W., Wagacha, J. M., Mwaura, F. B., Muthomi, J. W., \& Woloshuk, C. P. (2016). Postharvest practices of maize farmers in Kaiti District, Kenya and the impact of hermetic storage on populations of Aspergillus spp. and aflatoxin contamination. Journal of Food Research, 5(6), 53-66. doi:dx.doi.org/10.5539/jfr.v5n6p53

Manoza, F. S., Mushongi, A. A., Harvey, J., Wainaina, J., Wanjuki, I., Ngeno, R., . . Massomo, S. M. S. (2017). Potential of using host plant resistance, nitrogen and phosphorus fertilizers for reduction of Aspergillus flavus colonization and aflatoxin accumulation in maize in Tanzania. Crop Protection, 93, 98-105.

Marechera, G., \& Ndwiga, J. (2014). Farmer perceptions of aflatoxin management strategies in lower Eastern Kenya. Journal of Agricultural Extension and Rural Development, 6(12), 382-392.

Marechera, G., \& Ndwiga, J. (2015). Estimation of the potential adoption of AflaSafe among smallholder maize farmers in lower eastern Kenya. African Journal of Agricultural and Resource Economics, $10(1), 72-85$.

Matumba, L., Singano, L., Pungulani, L., Mvula, N., Matumba, A., Singano, C., \& Matita, G. (2017). Aflatoxins, discolouration and insect damage in dried cowpea and pigeon pea in Malawi and the effectiveness of flotation/washing operation in eliminating the aflatoxins. Mycotoxin Research, 33(2), 129-137. doi:dx.doi.org/10.1007/s12550-017-0272-3

Matumba, L., van Poucke, C., Ediage, E. N., Jacobs, B., \& de Saeger, S. (2015). Effectiveness of hand sorting, flotation/washing, dehulling and combinations thereof on the decontamination of mycotoxin-contaminated white maize. Food Additives and Contaminants A, 32(6), 960-969. doi:dx.doi.org/10.1080/19440049.2015.1029535

McMillan, A., Renaud, J. B., Burgess, K. M. N., Orimadegun, A. E., Akinyinka, O. O., Allen, S. J., . . . Sumarah, M. W. (2018). Aflatoxin exposure in Nigerian children with severe acute malnutrition. Food and Chemical Toxicology, 111, 356-362. doi:dx.doi.org/10.1016/j.fct.2017.11.030 
Mehrim, A. I., Refaey, M. M., \& Elmeleigy, K. M. (2016). Glutathione-enhancerTM against foodborne aflatoxicosis of Oreochromis niloticus (Linnaeus, 1758). Journal of Fisheries and Aquatic Science, 11(2), 131-146. doi:http://dx.doi.org/10.3923/jfas.2016.131.146

Misihairabgwi, J. M., Ezekiel, C. N., Sulyok, M., Shephard, G. S., \& Krska, R. (2017). Mycotoxin contamination of foods in Southern Africa: A 10-year review (2007-2016). Critical Reviews in Food Science and Nutrition, 1-16. doi:10.1080/10408398.2017.1357003

Mitchell, N. J., Kumi, J., Aleser, M., Elmore, S. E., Rychlik, K. A., Zychowski, K. E., . . Ankrah, N. A. (2014). Short-term safety and efficacy of calcium montmorillonite clay (UPSN) in children. American Journal of Tropical Medicine and Hygiene, 91(4), 777-785. doi:10.4269/ajtmh.14-0093

Mitchell, N. J., Kumi, J., Johnson, N. M., Dotse, E., Marroquin-Cardona, A., Wang, J. S., .... Phillips, T. D. (2013). Reduction in the urinary aflatoxin M1 biomarker as an early indicator of the efficacy of dietary interventions to reduce exposure to aflatoxins. Biomarkers, 18(5), 391-398. doi: $10.3109 / 1354750 x .2013 .798031$

Mitchell, N. J., Riley, R. T., Egner, P. A., Groopman, J. D., \& Wu, F. (2017). Chronic aflatoxin exposure in children living in Bhaktapur, Nepal: Extension of the MAL-ED study. Journal of Exposure Science and Environmental Epidemiology, 27(1), 106-111. doi:10.1038/jes.2015.87

Mngqawa, P., Shephard, G. S., Green, I. R., Ngobeni, S. H., Rijk, T. C. d., \& Katerere, D. R. (2016). Mycotoxin contamination of home-grown maize in rural northern South Africa (Limpopo and Mpumalanga Provinces). Food Additives and Contaminants B, Surveillance, 9(1), 38-45. doi:dx.doi.org/10.1080/19393210.2015.1121928

Mogensen, J. M., Sørensen, S. M., Sulyok, M., van der Westhuizen, L., Shephard, G. S., Frisvad, J. C., .. . Nielsen, K. F. (2011). Single-kernel analysis of fumonisins and other fungal metabolites in maize from South African subsistence farmers. Food Additives \& Contaminants: Part A, 28(12), 17241734. doi: $10.1080 / 19440049.2011 .611823$

Moser, C., Hoffmann, V., \& Ordonez, R. (2014). Evidence from aflatoxin tests in Kenya, Firm heterogeneity in food safety provision.

Mtimet, N., Walke, M., Baker, D., Lindahl, J., Hartmann, M., \& Grace, D. (2015). Kenyan awareness of aflatoxin: An analysis of processed milk consumers. Paper presented at the 29th International Conference of Agricultural Economists, "Agriculture in an Interconnected World", Milan, Italy. https://ageconsearch.umn.edu/bitstream/212504/2/MtimetKenyan\%20awareness\%20of\%20aflatoxin-675.pdf

Munasib, A. (2013). Notariff Barriers as Bridge to Cross. Minneapolis MN: University of Minnesota.

Mutegi, C. K., Wagacha, J. M., Christie, M. E., Kimani, J., \& Karanja, L. (2013). Effect of storage conditions on quality and aflatoxin contamination of peanuts (Arachis hypogaea L.). International Journal of AgriScience, 3(10), 746-758.

Mutiga, S. K., Morales, L., Angwenyi, S., Wainaina, J., Harvey, J., Biswanath, D., \& Nelson, R. J. (2017). Association between agronomic traits and aflatoxin accumulation in diverse maize lines grown under two soil nitrogen levels in Eastern Kenya. Field Crops Research, 205, 124-134. doi:dx.doi.org/10.1016/j.fcr.2017.02.007

Mutiga, S. K., Were, V., Hoffmann, V., Harvey, J. W., Milgroom, M. G., \& Nelson, R. J. (2014). Extent and drivers of mycotoxin contamination: inferences from a survey of Kenyan maize mills. Phytopathology, 104(11), 1221-1231. doi:dx.doi.org/10.1094/PHYTO-01-14-0006-R

Mwalwayo, D. S., \& Thole, B. (2016). Prevalence of aflatoxin and fumonisins (B1+B2) in maize consumed in rural Malawi. Toxicology Reports, 3, 173-179. doi:10.1016/j.toxrep.2016.01.010

Mwanza, M., Abdel-Hadi, A., Ali, A. M., \& Egbuta, M. (2015). Evaluation of analytical assays efficiency to detect aflatoxin M1 in milk from selected areas in Egypt and South Africa. Journal of Dairy Science, 98(10), 6660-6667. doi:dx.doi.org/10.3168/jds.2014-9220

N'Dede, C. B., Jolly, C. M., Vodouhe, S. D., \& Jolly, P. E. (2012). Economic risks of aflatoxin contamination in marketing of peanut in Benin. Economics Research International, 1-12.

Narayan, T., Belova, A., \& Haskell, J. (2014). Aflatoxins: A negative nexus between agriculture, nutrition and health. Paper presented at the Agricultural \& Applied Economics Association's 2014 AAEA Annual Meeting, Mineeapolis MN, USA.

https://ageconsearch.umn.edu/bitstream/170568/2/Aflatoxins_narayanbelovahaskell.pdf

Narrod, C. (2013). Reducing aflatoxins in Africa's crops: experiences from the Aflacontrol project. (Research Program on Agriculture for Nutrition and Health. 20-20 Focus Brief). In L. Unnevehr \& D. Grace (Eds.). Washington DC, USA: International Food Policy Research Institute.

Ndenn, J., Diedhou, P., \& Atanda, O. (2015). Presentation on the economic impact of aflatoxins in West Africa: the case of Gambia, Nigeria and Senegal Paper presented at the Regional workshop on "Revamping the groundnut value chain of West Africa through aflatoxin mitigation", 01-02 September 2015, Dakar, Senegal. https://www.aflatoxinpartnership.org/sites/default/files/201806/2.3\%20-\%20Economic\%20impact\%20of\%20aflatoxin\%20in\%20West\%20Africa.pdf

Nduti, N., McMillan, A., Seney, S., Sumarah, M., Njeru, P., Mwaniki, M., \& Reid, G. (2016). Investigating probiotic yoghurt to reduce an aflatoxin B1 biomarker among school children in eastern Kenya: preliminary study. International Dairy Journal, 63, 124-129. doi:dx.doi.org/10.1016/j.idairyj.2016.07.014

Neme, K., \& Mohammed, A. (2017). Mycotoxin occurrence in grains and the role of postharvest management as a mitigation strategies. A review. Food Control, 78, 412-425. doi:https://doi.org/10.1016/j.foodcont.2017.03.012

Ng'ang'a, J., Mutungi, C., Imathiu, S., \& Affognon, H. (2016). Effect of triple-layer hermetic bagging on mould infection and aflatoxin contamination of maize during multi-month on-farm storage in Kenya. Journal of Stored Products Research, 69, 119-128.

Nishimwe, K., Wanjuki, I., Karangwa, C., Darnell, R., \& Harvey, J. (2017). An initial characterization of aflatoxin $\mathrm{B} 1$ contamination of maize sold in the principal retail markets of Kigali, Rwanda. Food Control, 73(Part B), 574-580.

Njoroge, S. M. C., Matumba, L., Kanenga, K., Siambi, M., Farid, W., Maruwo, J., \& Monyo, E. S. (2016). A case for regular aflatoxin monitoring in peanut butter in sub-Saharan Africa: lessons from a 3-year 
survey in Zambia. Journal of Food Protection, 79(5), 795-800. doi:dx.doi.org/10.4315/0362028X.JFP-15-542

Nyamete, F. A., Bennink, M., \& Mugula, J. K. (2016). Potential of lactic acid fermentation in reducing aflatoxin B1 in Tanzania maize-based gruel. (Special Issue: Aflatoxins in Eastern Africa.). African Journal of Food, Agriculture, Nutrition and Development, 16(3), 11139-11151. doi:dx.doi.org/10.18697/ajfand.75.ILRI12

Nyangi, C., Beed, F., Mugula, J. K., Boni, S., Koyano, E., Mahuku, G., . . . Bekunda, M. (2016). Assessment of pre-harvest aflatoxin and fumonisin contamination of maize in Babati District, Tanzania. (Special Issue: Aflatoxins in Eastern Africa.). African Journal of Food, Agriculture, Nutrition and Development, 16(3), 11039-11053. doi:dx.doi.org/10.18697/ajfand.75.ILRI06

Obade, M. I., Andang'o, P., Obonyo, C., \& Lusweti, F. (2015). Exposure of children 4 to 6 months of age to aflatoxin in Kisumu County, Kenya. African Journal of Food, Agriculture, Nutrition and Development, 15(2), 9949-9963.

Obuseh, F. A., Jolly, P. E., Kulczycki, A., Ehiri, J., Waterbor, J., Desmond, R. A., . . . Piyathilake, C. J. (2011). Aflatoxin levels, plasma vitamins A and e concentrations, and their association with HIV and hepatitis B virus infections in Ghanaians: A cross-sectional study. Journal of the International AIDS Society, 14(1). doi:10.1186/1758-2652-14-53

OECD. (2012). Mortality Risk Valuation in Environment, Health and Transport Policies. Paris: Organization for Economic Cooperation and Development.

Okeke, C. A., Ezekiel, C. N., Nwangburuka, C. C., Sulyok, M., Ezeamagu, C. O., Adeleke, R. A., ... Krska, R. (2015). Bacterial diversity and mycotoxin reduction during maize fermentation (steeping) for ogi production. Frontiers in Microbiology, 6(December).

Okike, I., Samireddypalle, A., Kaptoge, L., Fauquet, C., Atehnkeng, J., Bandyopadhyay, R., .... Blummel, M. (2015). Technical innovations for small-scale producers and households to process wet cassava peels into high quality animal feed ingredients and AflaSafe substrate. Food Chain, 5(1/2), 71-90.

Okoth, S. (2016). Improving the Evidence Base on Aflatoxin Contamination and Exposure in Africa: Strengthening the Agriculture-Nutrition Nexus (CTA Working Paper 16/13). Brussels, Belgium \& Wageningen, The Netherlands: CTA.

Okoth, S., Rose, L. J., Ouko, A., Beukes, I., Sila, H., Mouton, M., . . Viljoen, A. (2017). Field evaluation of resistance to aflatoxin accumulation in maize inbred lines in Kenya and South Africa. Journal of Crop Improvement, 31(6), 862-878. doi:10.1080/15427528.2017.1391915

Olayiwola, I. O., Oganah, B. C., Oguntona, C. R. B., Popoola, A. R., Sanni, S. A., \& Sam-Wobo, S. O. (2013). Status of aflatoxin and anti-nutritional contents of standardized maize-based dishes/snacks consumed in Nigeria. Discourse Journal of Agriculture and Food Sciences, 1(5), 93-96.

Oluwafemi, F. T. (2012). Aflatoxin M1 levels in lactating mothers in two Nigerian cities. Archives of Clinical Microbiology, 3(4). doi:10.3823/257

Omojasola, P. F., \& Sanu, F. T. (2013). Microbiological quality assessment of dried yam chips (Dioscorea rotundata) during storage. Journal of Microbiology, Biotechnology and Food Sciences, 3(3), 208213.

Onyemelukwe, G. C., Ogoina, D., Ibiam, G. E., \& Ogbadu, G. H. (2012). Aflatoxins in body fluids and food of Nigerian children with protein-energy malnutrition. African Journal of Food, Agriculture, Nutrition and Development, 12(5), 6553-6566.

Ortiz Martinez, R., Valdivia Flores, A. G., De Luna Lopez, M., Quezada Tristan, T., Miranda Castañeda, C. A., Rangel Muñoz, E. J., \& Cruz Vazquez, C. (2016). Occurrence of aflatoxins in milk since dairy farms until consumers: An exploratory study. Toxicology Letters, 258, S87-S88. doi:https://doi.org/10.1016/j.toxlet.2016.06.1390

Otsuki, T., Wilson, J. S., \& Sewadeh, M. (2001a). Saving two in a billion: quantifying the trade effect of European food safety standards on African exports. Food Policy, 26(5), 495-514. doi:10.1016/S0306-9192(01)00018-5

Otsuki, T., Wilson, J. S., \& Sewadeh, M. (2001b). What price precaution? European harmonisation of aflatoxin regulations and African groundnut exports. European Review of Agricultural Economics, 28(3), 263-284.

Oueslati, S., Blesa, J., Molto, J. C., Ghorbel, A., \& Manes, J. (2014). Presence of mycotoxins in sorghum and intake estimation in Tunisia. Food Additives and Contaminants A, 31(2), 307-318.

Oyedele, O. A., Ezekiel, C. N., Sulyok, M., Adetunji, M. C., Warth, B., Atanda, O. O., \& Krska, R. (2017). Mycotoxin risk assessment for consumers of groundnut in domestic markets in Nigeria. International Journal of Food Microbiology, 251, 24-32. doi:dx.doi.org/10.1016/j.ijfoodmicro.2017.03.020

PACA. (2013). PACA Strategy 2013-2022. Addis Ababa: Partnershoip for Aflatoxin Control in Africa.

PACA. (2015). Aflatoxin Impacts and Potential Solutions in Agriculture, Trade, and Health. Addis Abeba, Ethiopia: Partnership for Aflatoxin Control in Africa.

Palliyaguru, D. L., \& Wu, F. (2013). The global geographical overlap of aflatoxin and hepatitis C: Controlling risk factors for liver cancer worldwide. Food Additives \& Contaminants. Part A, Chemistry, Analysis, Control, Exposure \& Risk Assessment, 30(3), 534-540. doi:10.1080/19440049.2012.751630

Piekkola, S., Turner, P. C., Abdel-Hamid, M., Ezzat, S., El-Daly, M., El-Kafrawy, S., . . El-Nezami, H. (2012). Characterisation of aflatoxin and deoxynivalenol exposure among pregnant Egyptian women. Food Additives and Contaminants A, 29(6), 962-971. doi:dx.doi.org/10.1080/19440049.2012.658442

Pitt, J. I., Wild, C. P., Baan, R. A., Gelderblom, W. C. A., Miller, J. D., Riley, R. T., \& Wu, F. (2012). Improving Public Health through Mycotoxin Control (IARC Scientific Publication No. 158). Lyon, France: IARC.

Probst, C., Bandyopadhyay, R., \& Cotty, P. J. (2014). Diversity of aflatoxin-producing fungi and their impact on food safety in sub-Saharan Africa. International Journal of Food Microbiology, 174, 113-122. doi:https://doi.org/10.1016/j.ijfoodmicro.2013.12.010

Probst, C., Njapau, H., \& Cotty, P. J. (2007). Outbreak of an acute aflatoxicosis in Kenya in 2004: Identification of the causal agent. Applied and Environmental Microbiology, 73(8), 2762-2764. doi:10.1128/aem.02370-06 
Pullin, A. S., Frampton, G. K., Livoreil, B., \& Petrokofsky, G. (2018). Guidelines and Standards for Evidence Synthesis in Environmental Management, Version 5.0. Bangor, UK: Collaboration for Environmental Evidence.

Riba, A., Matmoura, A., Mokrane, S., Mathieu, F., \& Sabaou, N. (2013). Investigations on aflatoxigenic fungi and aflatoxins contamination in some nuts sampled in Algeria. African Journal of Microbiology Research, 7(42), 4974-4980.

Rios, L. B. D., \& Jaffe, S. (2008). Barrier, catalyst, or distraction? Standards, competitiveness, and Africa's groundnut exports to Europe Washington DC: World Bank.

Routledge, M. N., Kimanya, M. E., Shirima, C. P., Wild, C. P., \& Gong, Y. (2014). Quantitative correlation of aflatoxin biomarker with dietary intake of aflatoxin in Tanzanian children. Biomarkers, 19(5), 430435. doi:dx.doi.org/10.3109/1354750X.2014.924998

Saad-Hussein, A., Beshir, S., Moubarz, G., Elserougy, S., \& Ibrahim, M. I. M. (2013a). Effect of occupational exposure to aflatoxins on some liver tumor markers in textile workers. American Journal of Industrial Medicine, 56(7), 818-824.

Saad-Hussein, A., Taha, M. M., Beshir, S., Shahy, E. M., Shaheen, W., \& Elhamshary, M. (2014). Carcinogenic effects of aflatoxin B1 among wheat handlers. International Journal of Occupational and Environmental Health, 20(3), 215-219.

Saad-Hussein, A., Taha, M. M., Fadl, N. N., Awad, A. H., Mahdy-Abdallah, H., Moubarz, G., ... El-Shamy, K. A. (2016). Effects of airborne Aspergillus on serum aflatoxin B1 and liver enzymes in workers handling wheat flour. Human \& Experimental Toxicology, 35(1), 3-9.

Saad-Hussein, A., Zayed, M. F., Hussein, J. S., Hafez, S. F., Shahy, E. M., Ibrahim, K. S., \& Ibrahim, M. I. M. (2013b). The effect of Aflatoxin M1 exposure on oxidant/antioxidant status of the flour millers with emphasis on 8-hydroxy-2-deoxyguanosine. Journal of Applied Sciences Research, 9(6), 3750-3757.

Sahab, A. F., Hassanien, F. R., El-Nemr, S. E., Abdel-Alim, H. A., \& Abdel-Wahhab, M. A. (2013). Effect of ozone gaseous on aflatoxin degradation and fat and protein content in peanut seeds. Journal of Applied Sciences Research, 9(3), 2170-2175.

Saleh, D. A., Amr, S., Jillson, I. A., Wang, J. H. Y., Crowell, N., \& Loffredo, C. A. (2015). Preventing hepatocellular carcinoma in Egypt: Results of a Pilot Health Education Intervention Study. BMC Research Notes, 8(1). doi:10.1186/s13104-015-1351-1

Sargeant, J. M., Del Rocio Amezcua, M., Rajic, A., \& Waddell, L. (2005). A Guide to Conducting Systematic Reviews in Agri-food Public Health: J.M. Sargeant.

Seetha, A., Munthali, W., Msere, H. W., Swai, E., Muzanila, Y., Sichone, E., . . Okori, P. (2017). Occurrence of aflatoxins and its management in diverse cropping systems of central Tanzania. Mycotoxin Research, 33(4), 323-331. doi:dx.doi.org/10.1007/s12550-017-0286-x

Seetha, A., Tsusaka, T. W., Munthali, T. W., Musukwa, M., Mwangwela, A., Kalumikiza, Z., ... Okori, P. (2018). How immediate and significant is the outcome of training on diversified diets, hygiene and food safety? An effort to mitigate child undernutrition in rural Malawi. Public Health Nutrition, 1-11. doi: $10.1017 / \mathrm{s} 1368980017003652$

Senerwa, D. M., Sirma, A. J., Mtimet, N., Kang'ethe, E. K., Grace, D., \& Lindahl, J. F. (2016). Prevalence of aflatoxin in feeds and cow milk from five counties in Kenya. (Special Issue: Aflatoxins in Eastern Africa.). African Journal of Food, Agriculture, Nutrition and Development, 16(3), 11004-11021. doi:dx.doi.org/10.18697/ajfand.75.ILRI04

Shephard, G. S. (2008a). Impact of mycotoxins on human health in developing countries. Food Additives \& Contaminants: Part A, 25(2), 146-151. doi:10.1080/02652030701567442

Shephard, G. S. (2008b). Risk assessment of aflatoxins in food in Africa. Food Additives \& Contaminants: Part A, 25(10), 1246-1256. doi:10.1080/02652030802036222

Shephard, G. S., Kimanya, M. E., Kpodo, K. A., Gnonlonfin, G. J. B., \& Gelderblom, W. C. A. (2013). The risk management dilemma for fumonisin mycotoxins. Food Control, 34(2), 596-600. doi:https://doi.org/10.1016/j.foodcont.2013.05.019

Shirima, C. P., Kimanya, M. E., Kinabo, J. L., Routledge, M. N., Srey, C., Wild, C. P., \& Gong, Y. (2013). Dietary exposure to aflatoxin and fumonisin among Tanzanian children as determined using biomarkers of exposure. Molecular Nutrition \& Food Research, 57(10), 1874-1881.

Shirima, C. P., Kimanya, M. E., Routledge, M. N., Srey, C., Kinabo, J. L., Humpf, H. U., . . . Gong, Y. (2015). A prospective study of growth and biomarkers of exposure to aflatoxin and fumonisin during early childhood in Tanzania. Environmental Health Perspectives, 123(2), 173-178.

Smith, L. E., Mbuya, M. N. N., Prendergast, A. J., Turner, P. C., Ruboko, S., Humphrey, J. H., . . . Stoltzfus, R. J. (2017). Determinants of recent aflatoxin exposure among pregnant women in rural Zimbabwe. Molecular Nutrition \& Food Research, 61(9). doi:dx.doi.org/10.1002/mnfr.201601049

Smith, L. E., Stoltzfus, R. J., \& Prendergast, A. (2012). Food Chain Mycotoxin Exposure, Gut Health, and Impaired Growth: A Conceptual Framework. Advances in Nutrition, 3(4), 526-531. doi:10.3945/an.112.002188

Stasiewicz, M. J., Falade, T. D. O., Mutuma, M., Mutiga, S. K., Harvey, J. J. W., Fox, G., ... Muthomi, J. W. (2017). Multi-spectral kernel sorting to reduce aflatoxins and fumonisins in Kenyan maize. Food Control, 78, 203-214. doi:dx.doi.org/10.1016/j.foodcont.2017.02.038

Strosnider, H., Azziz-Baumgartner, E., Banziger, M., Bhat, R. V., Breiman, R., Brune, M. N., ... Wilson, D. (2006). Workgroup report: Public health strategies for reducing aflatoxin exposure in developing countries. Environmental Health Perspectives, 114(12), 1898-1903. doi:10.1289/ehp.9302

Sugri, I., Osiru, M., Larbi, A., Buah, S. S. J., Nutsugah, S. K., Asieku, Y., \& Lamini, S. (2015). Aflatoxin management in Northern Ghana: current prevalence and priority strategies in maize (Zea mays $L$ ). Journal of Stored Products and Postharvest Research, 6(6), 48-55.

Suleiman, R. A., Rosentrater, K. A., \& Chove, B. (2017). Understanding postharvest practices, knowledge, and actual mycotoxin levels in maize in three agroecological zones in Tanzania. Journal of Stored Products and Postharvest Research, 8(7), 73-84.

Taye, W., Ayalew, A., Dejene, M., \& Chala, A. (2018). Fungal invasion and mycotoxin contamination of stored sorghum grain as influenced by threshing methods. International Journal of Pest Management, 64(1), 66-76. doi:10.1080/09670874.2017.1327681 
Tedihou, E., Olatinwo, R., Hell, K., Hau, B., \& Hoogenboom, G. (2012). Effects of variety, cropping system and soil inoculation with Aspergillus flavus on aflatoxin levels during storage of maize. Tropical Plant Pathology, 37(1), 25-36. doi:dx.doi.org/10.1590/S1982-56762012000100003

Tomerak, R. H., Shaban, H. H., Khalafallah, O. A., \& El Shazly, M. N. (2011). Assessment of exposure of Egyptian infants to aflatoxin M1 through breast milk. Journal of the Egyptian Public Health Association, 86(3-4), 51-55. doi:10.1097/01.Epx.0000399138.90797.40

Torres, A. M., Barros, G. G., Palacios, S. A., Chulze, S. N., \& Battilani, P. (2014). Review on pre- and postharvest management of peanuts to minimize aflatoxin contamination. Food Research International, 62, 11-19. doi:https://doi.org/10.1016/j.foodres.2014.02.023

Tsusaka, T. W., Singano, C., Seetha, A., \& Kumwenda, N. (2016). On-farm assessment of post-harvest losses: the case of groundnut in Malawi. In Socioeconomics Discussion Paper Series - International Crops Reearch Institute for the Semi-Arid Tropics (ICRISAT); 2016. (43):37 pp. many ref. Patancheru: International Crops Research Institute for the Semi-Arid Tropics (ICRISAT).

Udomkun, P., Wiredu, A. N., Nagle, M., Bandyopadhyay, R., Muller, J., \& Vanlauwe, B. (2017). Mycotoxins in Sub-Saharan Africa: present situation, socio-economic impact, awareness, and outlook. Food Control, 72(Part A), 110-122.

Umesha, S., Manukumar, H. M. G., Chandrasekhar, B., Shivakumara, P., Kumar, J. S., Raghava, S., . . . Prakash, H. S. (2017). Aflatoxins and food pathogens: impact of biologically active aflatoxins and their control strategies. Journal of the Science of Food and Agriculture, 97(6), 1698-1707. doi: $10.1002 /$ jsfa.8144

van der Fels-Klerx, H. J., \& Camenzuli, L. (2016). Effects of milk yield, feed composition, and feed contamination with aflatoxin B1 on the aflatoxin M1 concentration in dairy cows' milk investigated using Monte Carlo simulation modelling. Toxins, 8(10), 290. doi:10.3390/toxins8100290

Vidal, A., Mengelers, M., Yang, S., De Saeger, S., \& De Boevre, M. (2018). Mycotoxin biomarkers of exposure: A comprehensive review. Comprehensive Reviews in Food Science and Food Safety, $17(5), 1127-1155$. doi:10.1111/1541-4337.12367

Voth-Gaeddert, L. E., Stoker, M., Torres, O., \& Oerther, D. B. (2018). Association of aflatoxin exposure and height-for-age among young children in Guatemala. Int J Environ Health Res, 28(3), 280-292. doi:10.1080/09603123.2018.1468424

Wagacha, J. M., \& Muthomi, J. W. (2008). Mycotoxin problem in Africa: Current status, implications to food safety and health and possible management strategies. International Journal of Food Microbiology, 124(1), 1-12. doi:https://doi.org/10.1016/j.ijfoodmicro.2008.01.008

Wambui, J. M., Karuri, E. G., Ojiambo, J. A., \& Njage, P. M. K. (2017). Application of probabilistic modeling to quantify the reduction levels of hepatocellular carcinoma risk attributable to chronic aflatoxins exposure. Nutrition and Cancer, 69(1), 1-13. doi:dx.doi.org/10.1080/01635581.2017.1247892

Watson, S., Chen, G., Sylla, A., Routledge, M. N., \& Gong, Y. (2016). Dietary exposure to aflatoxin and micronutrient status among young children from Guinea. Molecular Nutrition \& Food Research, 60(3), 511-518. doi:dx.doi.org/10.1002/mnfr.201500382

Wild, C. P., Miller, J. D., \& Groopman, J. D. (2016). Mycotoxin control in low- and middle-income countries. Lyon: International Agency for Research on Cancer.

Williams, W. P., Krakowsky, M. D., Scully, B. T., Brown, R. L., Menkir, A., Warburton, M. L., \& Windham, G. L. (2015). Identifying and developing maize germplasm with resistance to accumulation of aflatoxins. (Special Issue: Aflatoxins in maize and other crops.). World Mycotoxin Journal, 8(2), 193-209. doi:dx.doi.org/10.3920/WMJ2014.1751

Wilson, J. S., \& Otsuki, T. (2001). Global Trade and Food Safety - Winners and Losers in a Fragmented System. Washington DC, USA: World Bank.

Wogan, G. N., Kensler, T. W., \& Groopman, J. D. (2012). Present and future directions of translational research on aflatoxin and hepatocellular carcinoma. A review. Food Additives \& Contaminants. Part A, Chemistry, Analysis, Control, Exposure \& Risk Assessment, 29(2), 249-257. doi:10.1080/19440049.2011.563370

Wondimeneh, T., Amare, A., Alemayehu, C., \& Mashilla, D. (2016). Aflatoxin B1 and total fumonisin contamination and their producing fungi in fresh and stored sorghum grain in East Hararghe, Ethiopia. Food Additives and Contaminants B, Surveillance, 9(4), 237-245. doi:dx.doi.org/10.1080/19393210.2016.1184190

World Health Organization. (2011). Handbook - How to Conduct Systematic Reviews of Health Policy and Systems Research in Low- and Middle-Income Countries. Santiago, Chile: WHO Methodology Centre for Systematic Reviews of Health Policy and System Research in LMICs, c/o Pontificia Universidad Católica de Chile.

Wu, F. (2004). Mycotoxin risk assessment for the purpose of setting international regulatory standards. Environmental Science \& Technology, 38(15), 4049-4055. doi:10.1021/es035353n

Wu, F., \& Guclu, H. (2012). Aflatoxin regulations in a network of global maize trade. PLoS ONE, 7(9), e45151. doi:10.1371/journal.pone.0045151

Xiong, B., \& Beghin, J. (2012). Does European aflatoxin regulation hurt groundnut exporters from Africa? European Review of Agricultural Economics, 39(4), 589-609. doi:dx.doi.org/10.1093/erae/jbr062

Xu, Y., Doel, A., Watson, S., Routledge, M. N., Elliott, C. T., Moore, S. E., \& Gong, Y. Y. (2017). Study of an educational hand sorting intervention for reducing aflatoxin $B<$ sub $>1</$ sub $>$ in groundnuts in rural Gambia. Journal of Food Protection, 80(1), 44-49.

Yang, F., Zhao, H., \& Carroll, A. R. (2017). Tropane alkaloids from the Australian plant Triunia montana (Proteaceae). Tetrahedron Letters, 58(8), 736-739. doi:10.1016/j.tetlet.2017.01.021

Yard, E. E., Daniel, J. H., Lewis, L. S., Rybak, M. E., Paliakov, E. M., Kim, A. A., . . Sharif, S. K. (2013). Human aflatoxin exposure in Kenya, 2007: a cross-sectional study. Food Additives \& Contaminants. Part A, Chemistry, Analysis, Control, Exposure \& Risk Assessment, 30(7), 1322-1331. doi:10.1080/19440049.2013.789558 


\section{Annex 1 Methods for calculating economic impact}

\section{Trade-related impact}

Trade-related economic impacts are calculated as losses due to border rejection at receiving country, lower price, and the cost of compliance that leads to higher prices of traded goods, as follows:

- Exports lost due to detection of aflatoxin in the product at the border of importing countries;

- Exports reduced due to rejection of non-compliant commodities, i.e. that the residues of aflatoxin in foreign products are found to be above legal limits at the border.

For the latter case, the EU aflatoxin legislation has been investigated because the EU legal limits are considered most strict. The EU legal limits for aflatoxin have been harmonised across the EU member states, and thus the harmonisation was used as a particular interesting case study with the possibility of comparing before and after the harmonisation. Given the comparatively low legal limits for aflatoxin in the EU (see Table 2 above), we would expect a trade-restricting negative effect on exports into the EU. The studies on the economic effect of aflatoxin in specific African countries commissioned by PACA provide the general indication that non-compliance rates tend to be much lower in branded (i.e. commercial) products, which could be due to them being closely regulated by certification agencies. The cost of border rejections is calculated as follows:

$$
\text { Export } \operatorname{loss}_{i, j, k}=P_{i}{ }^{*} W_{i, j}{ }^{*} r_{i, j, k}
$$

- $\quad P_{i}$ is the world price for food crop i per unit weight;

- $W_{i, j}$ is the total export amount (in metric tons) of product i from country $j$;

- $r_{i, j, k}$ is the fraction of export volume of product $i$ from country $j$ being rejected at international standard $\mathrm{k}(\mathrm{Wu}, 2004)$.

Note that the calculation does not account for the costs for transportation, handling, and storage. Non-compliant products do not meet the maximum limit set by the importing country, and are hence rejected at the border. Once rejected, the consignment is returned with the exporter bearing the freight and handling charges representing additional losses. They are returned with rapid alerts issued by the EU; the freight and handling charges of the transport of the consignment are lost.

\section{Required data:}

- Crop of interests (highly affected by aflatoxin, most important crops for export)

- Trade partners

- Annual quantity of export, percentage of rejection

- Transportation, handling, storage costs

It should generally be noted that the effect on exports can have spill-over effects on imports such that the effect is actually larger than only the loss of exports. According to economic principles, a decrease of a country's exports leads to a decrease of the foreign exchange in the country. This means excess demand for the foreign exchange, which in turn causes a depreciation of the local currency. With the deprecation, imports become more expensive and hence imports decrease while the consumption of domestic products increase with lower prices, given the substitutability between imports and domestic products. 
2. Impact at the micro level (producers and consumers)

The micro level impact refers to impacts at the firm level, the domestic production level (studies of farm economics, business and technologies) (link to mitigation) as well as at the consumer level. The studies are based on micro-economics.

- Loss of crops to be sold on the domestic market

- Costs of managing aflatoxin at the farm level - compliance costs

Consideration of special attention: Can a lot infected by aflatoxin that is thus unsuitable to be consumed by humans be used as animal feed?

\section{Compliance costs}

- Any expenses incurred by the firms, processor, governments to comply with the aflatoxin regulation. It is related to the mitigation or intervention measures applied by different level of stakeholders.

\section{Lower price for domestic consumption (food and feed)}

- It can be estimated from the amount of returned export merchandises which is then sold for domestic consumptions. However, if losses due to border rejections are already estimated, this calculation is not relevant because it can cause double counting.

- If the lower price is caused by the awareness of domestic market regarding the damage caused by aflatoxin and not from returned products, losses due to lower price could be relevant to estimate in comparison with normal price. The empirical evidence of such price effects has not been provided, and further research would be interesting. For example, according to a study on Gambia commissioned by PACA the impact of aflatoxin on domestic trade does not affect prices, or marketing and pricing (Ndenn et al., 2015).

\section{Consumer effects}

- $\quad$ For example willingness to pay studies to identify the willingness of consumers to pay for aflatoxin-free products. The empirical evidence is missing from the consumer side, but may be awareness of aflatoxin issues may indicate.

\section{Health economic impact}

- Health costs in terms of treatment;

- $\quad$ Reduced contribution of ill people, household income;

- $\quad$ Death

The health-related economic impacts can be calculated as Value of Statistical Life (VSL) and cost of illness, both of which are presented in monetary value (see Figure 16 below).

\section{Value of Statistical Life (VSL)}

VSL is considered as an important parameter analysis for policy making, including for food safety measures, and its estimate is pervasively extrapolated across countries with different income levels particularly due to lack of studies conducted in low income countries (Hammitt \& Robinson, 2011).

The idea of estimating VSL is that with regard to an intervention, one cannot know whose life is saved. Thus, VSL estimates the monetized value of small changes in mortality risk across a population by measuring individual willingness to pay to reduce a mortality risk due to certain condition using either revealed or stated preference (Hammitt, 2000). For example, an intervention that costs USD 5 million per prevented fatality implies that the VSL is at least USD 5 million (OECD, 2012). 


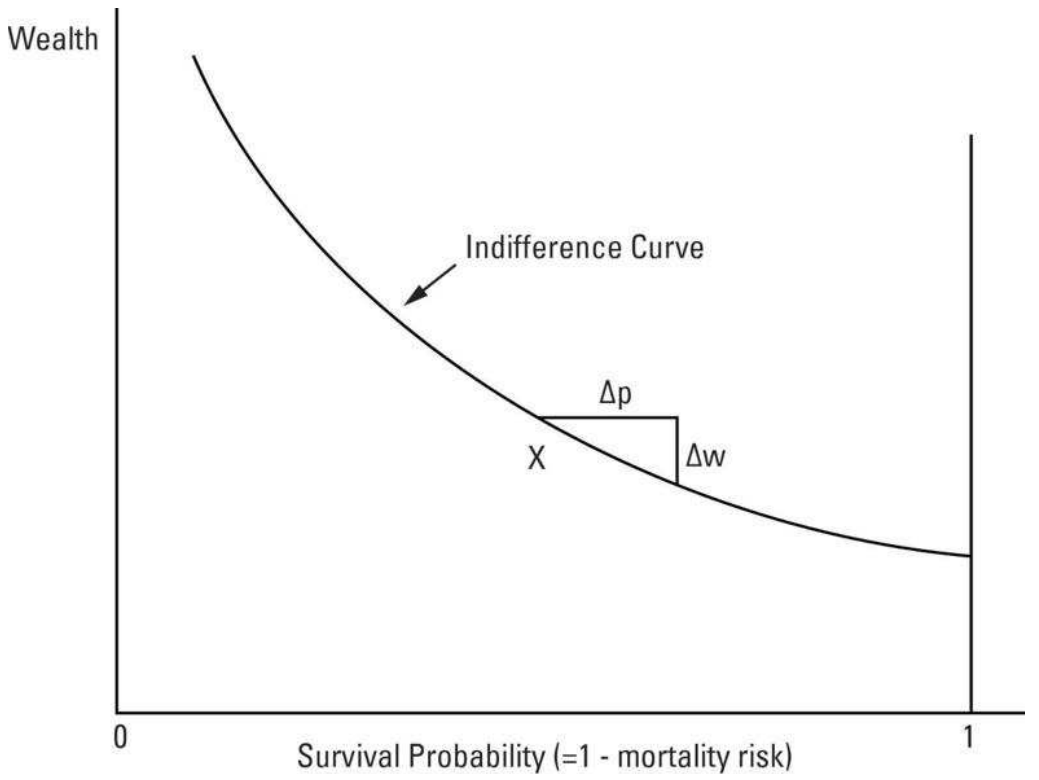

Figure 16: Relation between the utility/wealth and the mortality risk

Assuming that the person's utility depends on wealth levels and mortality risk, the curve (denoted indifference curve) depicts the relation between the utility/wealth and the mortality risk. The slope of the curve is the VSL, i.e. a person is willing to pay one unit of his/her wealth to reduce the risk of morality. For a very low probability of mortality and thus safe (no risk) the person is willing to pay most. For a high probability (almost 1 ) the person pays least. The range of base VSL can be sourced from past studies in the US, European, or OECD countries. Studies in the US are mainly based on revealed preference using wage-risk studies, while studies in Europe, Canada and Australia relied on stated preference by measuring the willingness to pay $(O E C D, 2012)$. In addition, due to disparity on income level between higher and lower income countries, income elasticity can be justified to adjust the base VSL. Hammitt and Robinson (2011) suggested that elasticities higher than one might be appropriate when transferring VSL to very low income countries.

\section{Cost of Illness}

Cost of illness is used to estimate the costs of a particular illness in a given time (usually in a 1-year period) to provide insights into annual costs caused by an illness or disease, including those caused by foodborne diseases. Aflatoxins, particularly AFB1 is considered as a risk factor of liver cancer. Thus, it is relevant to estimate cost of illness of aflatoxin-induced liver cancer as an approach to estimate the health-related economic losses due to aflatoxins contamination.

\section{Cost of illness $=$ Direct medical cost + Direct non-medical cost + Indirect non-medical cost}

Direct medical cost (DMC) estimates the costs for cases using medical treatments. Meanwhile, cases without medical treatment are not included in the estimation. Direct non-medical cost (DNMC) estimates the costs incurred along with the medical treatments, but not the expenses for the treatment itself, for example the transport cost, costs for changing diets, etc. Indirect non-medical cost (INMC) estimates the value of productivity loss as consequences to the illness, for example temporary absence from work, disability, or premature mortality. Various data are needed to estimate the cost of illness for a particular disease. 
Table 15: Methods of calculating and data requirements for the health- related economic impacts of aflatoxin - VSL and cost of illness

\begin{tabular}{|c|c|}
\hline VSL & Cost of illness \\
\hline $\begin{array}{l}\text { To express the economic value to reduce a } \\
\text { mortality risk within a population. }\end{array}$ & $\begin{array}{l}\text { To estimate annual costs from a particular illness; capture } \\
\text { medical costs, other cost come along during the treatment } \\
\text { and economic loss with regard to lost productivity. }\end{array}$ \\
\hline 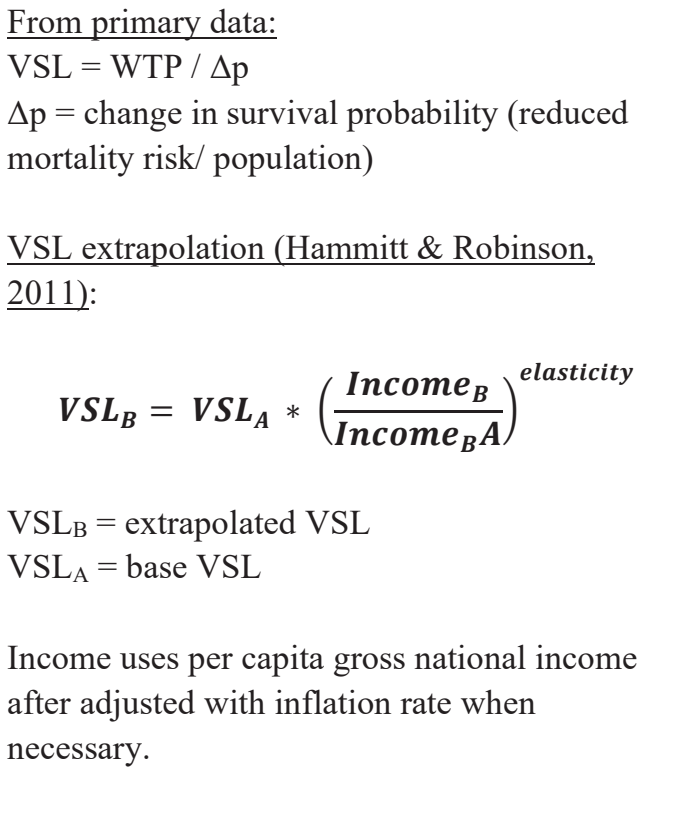 & $\begin{array}{l}\text { Cost of Illness }=\mathrm{DMC}+\mathrm{DNMC}+\mathrm{INMC} \\
\qquad D M C=\sum_{i} m_{i} x p_{i} x c_{i} \\
\mathrm{~m}_{\mathrm{i}}=\text { cases using medical service } \mathrm{i} \\
\mathrm{p}_{\mathrm{i}}=\text { number of medical services i per case } \\
\mathrm{c}_{\mathrm{i}}=\text { cost per medical service } \mathrm{i} \\
\qquad D N M C=\sum_{j} r_{j} \times q_{j} x c_{j} \\
\mathrm{r}_{\mathrm{j}}=\text { cases using non-medical service } \mathrm{j} \\
\mathrm{q}_{\mathrm{j}}=\text { number of non-medical services } \mathrm{j} \text { per case } \\
\mathrm{c}_{\mathrm{j}}=\text { cost per non-medical service } \mathrm{j} \\
\mathrm{INMC}=\mathrm{s} \mathrm{x} \mathrm{u} \mathrm{x} \mathrm{v} \\
\mathrm{s}=\text { cases of sickness leave } \\
\mathrm{u}=\text { duration of sickness leave } \\
\mathrm{v}=\text { wage costs per day }\end{array}$ \\
\hline $\begin{array}{l}\text { From primary data: } \\
\text { - } \quad \text { WTP for the reduction in death risk (stated/ } \\
\text { revealed preference) } \\
\text { - } \quad \text { Reduced mortality risk } \\
\text { - } \quad \text { Number of population } \\
\text { From secondary data: } \\
\text { - } \quad \text { Base VSL from past studies } \\
\text { - } \quad \text { GNI and inflation rate }\end{array}$ & $\begin{array}{l}\text { For DMC: Epidemiology includes: } \\
\text { 1. } \begin{array}{l}\text { Estimated annual incidence of aflatoxicosis or } \\
\text { aflatoxin-related liver cancer or other short-term/ } \\
\text { minor illnesses due to aflatoxin contamination }\end{array} \\
\text { 2. Type of medical treatments and number of cases } \\
\text { using each medical treatment; medicines, visiting } \\
\text { GP, getting hospitalized or specific treatments } \\
\text { - Cost per type of medical treatment } \\
\text { For DNMC: } \\
\text { - Types of Direct non-medical services and number of } \\
\text { cases using them } \\
\text { Cost for each DNM service } \\
\text { For INMC: } \\
\text { - } \\
\text { Cases of sickness leave due to the illness } \\
\text { Duration of the sickness leave } \\
\text { Average wage per day }\end{array}$ \\
\hline
\end{tabular}

Note that in this systematic review, no calculations from primary data were performed, as these would require extensive work on gathering the primary data. 


\section{Annex 2 Grey literature data sources}

Table 16: Grey literature data sources: general data on aflatoxins toxicity, and prevention, mitigation \& control.

\begin{tabular}{|c|c|c|}
\hline Name & Type of information & Hyperlink \\
\hline $\begin{array}{l}\text { Partnership for aflatoxin } \\
\text { control in Africa (PACA) }\end{array}$ & $\begin{array}{l}\text { Under the auspices of the } \\
\text { African Union Commission, } \\
\text { PACA brings together expertise } \\
\text { on aflatoxins in Africa from } \\
\text { various different angles and in } \\
\text { collaboration with different } \\
\text { international and regional } \\
\text { organizations. It pursues the } \\
\text { establishment of aflatoxin-free } \\
\text { value chains. Its website } \\
\text { provides information leaflet and } \\
\text { summaries of impacts of } \\
\text { mitigating strategies explored } \\
\text { and implemented. }\end{array}$ & $\begin{array}{l}\text { http://www.aflatoxinpartnershi } \\
\text { p.org/ }\end{array}$ \\
\hline $\begin{array}{l}\text { Food and Agriculture } \\
\text { Organization (FAO) }\end{array}$ & $\begin{array}{l}\text { FAO publishes reports on } \\
\text { analysis, prevention and } \\
\text { control of aflatoxin } \\
\text { contamination in a range of } \\
\text { crops }\end{array}$ & http://www.fao.org/home/en/ \\
\hline $\begin{array}{l}\text { FAO/WHO Codex } \\
\text { Alimentarius }\end{array}$ & $\begin{array}{l}\text { Codex Alimentarius is an } \\
\text { international body developing } \\
\text { standards (e.g. on } \\
\text { contaminants and toxins such } \\
\text { as aflatoxins) and codes of } \\
\text { good practice (e.g. for } \\
\text { prevention and reduction of } \\
\text { aflatoxins in peanuts) }\end{array}$ & $\begin{array}{l}\text { http://www.fao.org/fao-who- } \\
\text { codexalimentarius/en/ }\end{array}$ \\
\hline $\begin{array}{l}\text { JECFA (World Health } \\
\text { Organization and FAO) }\end{array}$ & $\begin{array}{l}\text { The WHO website features } \\
\text { reports on e.g. public health } \\
\text { strategies towards prevention } \\
\text { of aflatoxin exposure in } \\
\text { consumers, and carries out risk } \\
\text { assessments contaminants on } \\
\text { foods via the JECFA meetings } \\
\text { (Joint FAO/WHO Expert } \\
\text { Committee on Food Additives) }\end{array}$ & $\begin{array}{l}\text { - } \frac{\text { http://www.fao.org/food/fo }}{\text { od-safety-quality/scientific- }} \\
\text { - } \underline{\text { advice/jecfa/en/ }} \\
\text { http://www.who.int/ }\end{array}$ \\
\hline $\begin{array}{l}\text { European Food Safety } \\
\text { Authority (EFSA) }\end{array}$ & $\begin{array}{l}\text { Risk assessments on, a.o. } \\
\text { aflatoxins are carried out by } \\
\text { the CONTAM panel of EFSA. }\end{array}$ & https://www.efsa.europa.eu/ \\
\hline $\begin{array}{l}\text { European Union Reference } \\
\text { Laboratory -Mycotoxins \& } \\
\text { plant toxins }\end{array}$ & $\begin{array}{l}\text { The European Union Reference } \\
\text { Laboratory for mycotoxins } \\
\text { reports on analytical methods } \\
\text { for mycotoxins in a wide range } \\
\text { of commodities, as well as fact } \\
\text { sheets with useful links }\end{array}$ & $\begin{array}{l}\text { https://www.wur.nl/en/Researc } \\
\text { h-Results/Research- } \\
\underline{\text { Institutes/rikilt/Reference- }} \\
\underline{\text { laboratory.htm }}\end{array}$ \\
\hline
\end{tabular}




\begin{tabular}{|c|c|c|}
\hline Name & Type of information & Hyperlink \\
\hline $\begin{array}{l}\text { International Agency for } \\
\text { Research on Cancer (IARC) }\end{array}$ & $\begin{array}{l}\text { Classification of agents, } \\
\text { cancers studies, studies on } \\
\text { specific topics related to cancer } \\
\text { and occurrence. }\end{array}$ & https://www.iarc.fr/ \\
\hline $\begin{array}{l}\text { International Livestock } \\
\text { research Institute (ILRI) }\end{array}$ & $\begin{array}{l}\text { Research on livestock nutrition } \\
\text { and health in Africa, a.o. } \\
\text { aflatoxins. }\end{array}$ & https://www.ilri.org/ \\
\hline Mycotoxins.info & $\begin{array}{l}\text { This website, established with } \\
\text { the help of various analytical } \\
\text { companies contains summary } \\
\text { information on various aspects } \\
\text { of mycotoxins, including, for } \\
\text { example, regulatory thresholds } \\
\text { set for mycotoxins in foods and } \\
\text { feeds across the world }\end{array}$ & www.mycotoxins.info \\
\hline $\begin{array}{l}\text { Technical Centre for } \\
\text { Agricultural and Rural } \\
\text { Cooperation (CTA) }\end{array}$ & $\begin{array}{l}\text { An international institution in } \\
\text { which the EU collaborates with } \\
\text { African, Caribbean and Pacific } \\
\text { countries focused in the } \\
\text { provision of information to } \\
\text { smallholder farmers so as to } \\
\text { promote innovation and } \\
\text { sustainable agriculture. Many } \\
\text { of its publications are open- } \\
\text { access }\end{array}$ & http://www.cta.int \\
\hline MycoKey & $\begin{array}{l}\text { MycoKey is a research project } \\
\text { funded by the EU Horizon } 2020 \\
\text { program. Its aim is to provide } \\
\text { ICT tools for the control and } \\
\text { prevention of mycotoxin } \\
\text { contamination along the } \\
\text { production chains. It is also to } \\
\text { disseminate new and existing } \\
\text { information on mycotoxin } \\
\text { research to stakeholders, for } \\
\text { example by publishing open- } \\
\text { access research data }\end{array}$ & http://www.mycokey.eu/ \\
\hline $\begin{array}{l}\text { MyToolBox ("Safe Food and } \\
\text { Feed through an Integrated } \\
\text { ToolBox for Mycotoxin } \\
\text { Management") }\end{array}$ & $\begin{array}{l}\text { This project funded by the EU } \\
\text { Horizon } 2020 \text { program } \\
\text { elaborates a comprehensive } \\
\text { approach for mycotoxin } \\
\text { management not only "from } \\
\text { farm to fork" but also beyond, } \\
\text { such as for waste by-products } \\
\text { of food production. It covers an } \\
\text { array of possible measures, } \\
\text { such as mitigation measures } \\
\text { and control measures, } \\
\text { including but not limited to } \\
\text { resistant crops, alternatives for } \\
\text { fungicides, sorting out of } \\
\text { infected crop commodities, } \\
\text { predictive models for } \\
\text { contamination during } \\
\text { cultivation and storage, and } \\
\text { mycotoxin analysis }\end{array}$ & https://www.mytoolbox.eu/ \\
\hline
\end{tabular}




\begin{tabular}{|c|c|c|}
\hline Name & Type of information & Hyperlink \\
\hline $\begin{array}{l}\text { MYTOX (association } \\
\text { research platform } \\
\text { 'Mycotoxins and Toxigenic } \\
\text { Moulds') } \\
\text { MyTox south specifically } \\
\text { work with African partners }\end{array}$ & $\begin{array}{l}\text { A consortium of research units } \\
\text { (from Belgium) working on } \\
\text { different aspects including } \\
\text { mycotoxin-producing moulds, } \\
\text { mycotoxins, and their human } \\
\text { and animal health impacts }\end{array}$ & http://mytox.be/ \\
\hline The ASPERGILLUS website & $\begin{array}{l}\text { A collaboration between the } \\
\text { Fungal Infection Trust and the } \\
\text { University of Manchester. } \\
\text { Whilst its focus is on patients of } \\
\text { human infections with } \\
\text { Aspergillus and its various } \\
\text { toxins (not only aflatoxin), its } \\
\text { proprietary database also } \\
\text { contains references on } \\
\text { Aspergillus in foods, among } \\
\text { others }\end{array}$ & http://www.aspergillus.org.uk/ \\
\hline $\begin{array}{l}\text { FARMD - Forum for } \\
\text { Agricultural Risk } \\
\text { Management in } \\
\text { Development }\end{array}$ & $\begin{array}{l}\text { Network fostering agricultural } \\
\text { risk management in developing } \\
\text { countries through the } \\
\text { promotion of dialogue, } \\
\text { partnerships, and sharing of } \\
\text { information and experiences in } \\
\text { this field. Its website also } \\
\text { features a section on aflatoxins } \\
\text { as a topic. FARMD is supported } \\
\text { by the Swiss and Dutch } \\
\text { governments and the World } \\
\text { Bank }\end{array}$ & $\begin{array}{l}\text { http://www.agriskmanagement } \\
\text { forum.org/fstory/featured- } \\
\text { topic-aflatoxin-risk-sub- } \\
\underline{\text { saharan-africa }}\end{array}$ \\
\hline
\end{tabular}

Table 17: Grey literature data sources: monitoring data

\begin{tabular}{|l|l|l|}
\hline Name & Type of information & Hyperlink \\
\hline Rapid Alert System for Food & $\begin{array}{l}\text { The European Commission's } \\
\text { RASFF database provides an } \\
\text { overview of notifications filed } \\
\text { by its members (particularly } \\
\text { member states' food control } \\
\text { agencies) regarding food risks } \\
\text { observed, including those in } \\
\text { imported commodities (for } \\
\text { which country of origin will also } \\
\text { be provided) }\end{array}$ & hty//rasff en \\
\hline ChemKAP & $\begin{array}{l}\text { The KAP database contains } \\
\text { annual summaries of data on } \\
\text { residues of contaminants such } \\
\text { as aflatoxins measured in a } \\
\text { wide range of commodities, } \\
\text { including those imported from } \\
\text { Africa, during monitoring in the } \\
\text { Netherlands }\end{array}$ & pics/C/ChemKAP/ \\
\hline
\end{tabular}




\begin{tabular}{|l|l|l|}
\hline Name & Type of information & Hyperlink \\
\hline $\begin{array}{l}\text { US Food and Drug } \\
\text { Import Alerts }\end{array}$ & $\begin{array}{l}\text { Contains information on import } \\
\text { detentions of imported, FDA- } \\
\text { regulated products, due to e.g. } \\
\text { excessive residues of } \\
\text { contaminants such aflatoxins }\end{array}$ & $\begin{array}{l}\underline{\text { https://www.accessdata.fda.go }} \\
\text { v/cms ia/default.html }\end{array}$ \\
\hline $\begin{array}{l}\text { US Department of } \\
\text { Agriculture Recall Archive }\end{array}$ & $\begin{array}{l}\text { Recalls issued by the inspection } \\
\text { services of the USDA are listed } \\
\text { and summarized per year }\end{array}$ & $\begin{array}{l}\text { https://www.fsis.usda.gov/wps } \\
\text { Lportal/fsis/topics/recalls-and- } \\
\text { public-health-alerts }\end{array}$ \\
\hline FAO & $\begin{array}{l}\text { GEMS/Food database - } \\
\text { Restricted access! }\end{array}$ & $\underline{\underline{\text { https://extranet.who.int/gemsf }}}$ \\
\hline ood/
\end{tabular}

Table 18: Grey literature data sources: health statistics

\begin{tabular}{|c|c|c|}
\hline Name & Type of information & Hyperlink \\
\hline Cancer Atlas & $\begin{array}{l}\text { A collaboration of the American } \\
\text { Cancer Society, the } \\
\text { International Agency for } \\
\text { Research on Cancer and the } \\
\text { Union for International Cancer } \\
\text { Control to provide decision } \\
\text { makers and other stakeholders } \\
\text { with an overview of cancer } \\
\text { prevalence, the associated risk } \\
\text { factors and measures for } \\
\text { prevention and control. Data } \\
\text { are viewable as interactive } \\
\text { maps with statistics of the } \\
\text { prevalence of particular types } \\
\text { of cancer such as liver cancer } \\
\text { linked to aflatoxin consumption }\end{array}$ & http://canceratlas.cancer.org/ \\
\hline African office of the WHO & $\begin{array}{l}\text { The African office of the WHO } \\
\text { provides materials for training } \\
\text { and instructions to health } \\
\text { professionals in order to help } \\
\text { control and reduce the burden } \\
\text { of cancer in Africa }\end{array}$ & $\begin{array}{l}\text { http://www.afro.who.int/health } \\
\text {-topics/cancer }\end{array}$ \\
\hline Cancercontrol.info & $\begin{array}{l}\text { A platform providing } \\
\text { information on cancer care } \\
\text { (including studies on } \\
\text { prevalence, control and } \\
\text { prevention) in developing } \\
\text { countries }\end{array}$ & $\begin{array}{l}\text { http://www.cancercontrol.info/ } \\
\underline{\text { sample-page/ }}\end{array}$ \\
\hline $\begin{array}{l}\text { Global Cancer Observatory } \\
\text { and Cancer Today }\end{array}$ & $\begin{array}{l}\text { Databases on the occurrence of } \\
\text { cancer in five continents }\end{array}$ & $\begin{array}{l}\text { http://gco.iarc.fr/ } \\
\text { http://gco.iarc.fr/today/home }\end{array}$ \\
\hline
\end{tabular}


Table 19: Grey literature data sources: economic data

\begin{tabular}{|c|c|c|}
\hline Name & Type of information & Hyperlink \\
\hline $\begin{array}{l}\text { International Food Policy } \\
\text { Research Institute -e- } \\
\text { library }\end{array}$ & $\begin{array}{l}\text { IFPRI analyses options for and } \\
\text { impacts of policy decisions in } \\
\text { the field of agriculture, } \\
\text { nutrition, agricultural markets, } \\
\text { and governance. Its prime } \\
\text { targets of research are poverty } \\
\text { reduction, ending hunger and } \\
\text { malnutrition, and } \\
\text { environmental sustainability }\end{array}$ & $\begin{array}{l}\frac{\text { http://ebrary.ifpri.org/cdm/lan }}{\text { dingpage/collection/p15738coll }} \\
\underline{2}\end{array}$ \\
\hline World Bank & $\begin{array}{l}\text { While the World Bank provides } \\
\text { financial support through } \\
\text { various mechanisms (such as } \\
\text { the International Development } \\
\text { Aid - IDA) to support e.g. } \\
\text { agricultural development in the } \\
\text { poorest countries, it also } \\
\text { carries out research on } \\
\text { effective measures and the } \\
\text { impact of market and trade } \\
\text { standards on countries' } \\
\text { incomes }\end{array}$ & http://www.worldbank.org \\
\hline USAID African Trade Hubs & $\begin{array}{l}\text { Sponsored by the federal US } \\
\text { development aid agency. These } \\
\text { centres explore ways to boost } \\
\text { trade and investment in Africa }\end{array}$ & https://www.satradehub.org/ \\
\hline
\end{tabular}




\section{Annex 3 Search queries}

Table 20: Search query for question \#1 in CAB Abstracts and AGRIS

\begin{tabular}{|c|c|c|}
\hline Concept & Line & Query \\
\hline aflatoxin & 1 & $\begin{array}{l}\text { (Aflatoxi* or } A F B 1 \text { or } A F B 2 \text { or } A F M 1 \text { or } A F M 2 \text { or } A F G 1 \text { or } A F G 2 \text { or } \\
\text { AFQ1).mp1 }\end{array}$ \\
\hline africa & 2 & $\begin{array}{l}\text { (exp africa or africa* or africa south of the sahara* or atlas or } \\
\text { igboland or maghreb or maghrib or maputaland or mayombe or nile or } \\
\text { nubia* or sahara* or sahel or sahrawi or sub-sahara* or subsahara* } \\
\text { or gariep or incomaputo or incomati or juba or shabelli or komati or } \\
\text { kunene or limpopo or okavango or orange river or ruvuma or (lake } \\
\text { adj1 victoria) or volta or zambezi or algeria* or angol* or ascension } \\
\text { island or benin* or botswan* or burkina fas* or burund* or } \\
\text { cameroon* or cameroun* or cabo verder or cape verd* or capeverd* } \\
\text { or central african republic* or chad* or comor* or congo* or cote } \\
\text { d'ivoire or djibout* or egypt* or eritrea* or ethiopia* or gabon* or } \\
\text { gambia* or ghan* or guinea* or guinea-bissau or guine-bissau or } \\
\text { guinee or ivory coast* or kenya* or lesoth* or liberia* or libya* or } \\
\text { madagasc* or malawi* or mali* or maroc or marocco or morocc* or } \\
\text { maurice or mauritania* or mauriti* or mayott* or mo?ambiqu* or } \\
\text { namibia* or niger* or nigeria* or republique centrafricain* or reunion } \\
\text { or rhodesia* or rwand* or saint helena or (sao tome and principe) or } \\
\text { senegal* or seychelles or sierra leone or somalia* or somaliland* or } \\
\text { south africa* or south sudan* or sudan* or swazi* or tanzania* or } \\
\text { tchad* or togo* or tunisia* or ugand* or zambia* or zimbabw*).mp1 }\end{array}$ \\
\hline $\begin{array}{l}\text { food and } \\
\text { feed }\end{array}$ & 3 & $\begin{array}{l}\text { (cereal? or crop* or feed* or fodder* or food* or herb* or legum* or } \\
\text { pulse? or spice? or staple or vegetable? or bean? or fruit? or grain? or } \\
\text { kernel? or leaf or leaves or nut? or oilseed? or seed? or beer? or } \\
\text { beverage? or biscuit? or chips or chocolate or cigar? or cigarette? or } \\
\text { cornflakes or coffee or copra or drink? or flour or lafun or madidi or } \\
\text { malt or meal? or ogiri or pasta or popcorn or porridge or snack? or } \\
\text { snuff or soup? or tapioca or tobacco or acha or afang or airama or ajja } \\
\text { or ariwo or anise* or baobab or barley or beniseed? or bitter apple? or } \\
\text { cacao or cashew or cassava or cayenne or chilli* or cinnamon or } \\
\text { clove? or cocoa or coconut? or coffea or coriander or corn or cotton or } \\
\text { cowpea? or cumin or ehiri or ehuru or emmer or fennel or fonio or } \\
\text { garlic or ginger or groundnut? or hazelnut? or hot chili or iburu or } \\
\text { lentil or lubushi or maize or mango or manioc or marjoram or melon? } \\
\text { or millet? or molokhia or nutmeg or oat? or ochro or okra or okro or } \\
\text { onion? or oregano or palm or paprika or peanut? or pepper? or } \\
\text { peppermint or pigeon pea? or pistachio or pomegranate? or rice or rye } \\
\text { or sesame or sorghum or soy or soya bean? or soybean? or spelt or } \\
\text { sunflower? or teff or tomato* or turmeric or walnut? or watermelon? } \\
\text { or wheat or yam? or Abelmoschus esculentus or Adansonia digitata or } \\
\text { Allium cepa or Allium sativum or Anacardium occidentale or Arachis } \\
\text { hypogaea or Arachis hypogea or Avena abyssinica or Avena sativa or } \\
\text { Brachiaria deflexa or Brachiaria stigmatisata or Cajanus cajan or } \\
\text { Capsicum or Carum carvi or Cinnamomum or Citrullus colocynthis or } \\
\text { Citrullus lanatus or Citrullus vulgaris or Cocos nucifera or Colocynthis } \\
\text { citrullus or Corchorus olitorius or Coriandrum sativum or Cucumis } \\
\text { melo or Cuminum cyminum or Curcuma longa or Digitaria exilis or } \\
\text { Digitaria iburua or Dioscorea or Eleusine coracana or Elaeis guineensis }\end{array}$ \\
\hline
\end{tabular}




\begin{tabular}{|c|c|c|}
\hline Concept & Line & Query \\
\hline & & 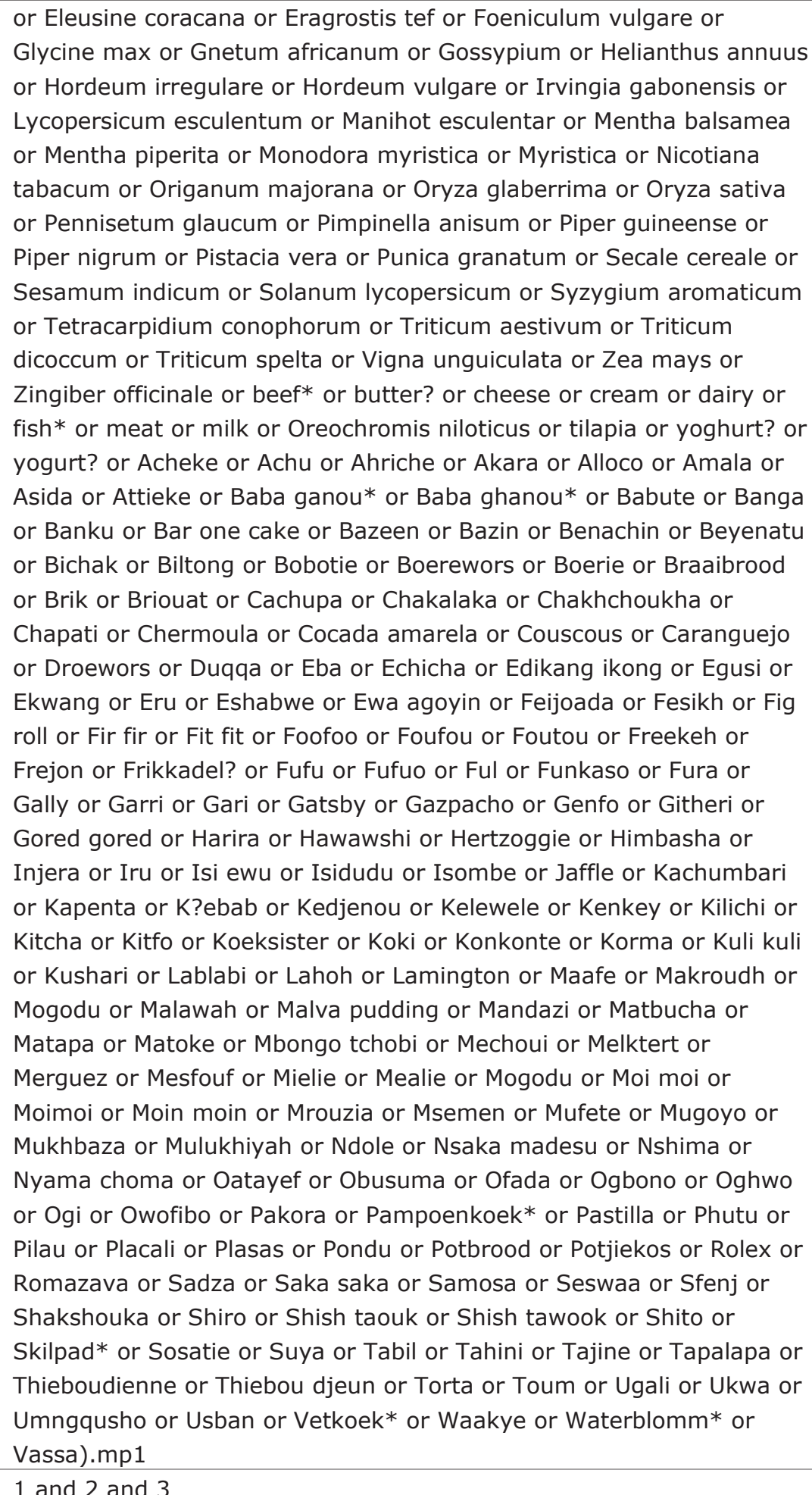 \\
\hline
\end{tabular}

Concept 3 includes general terms (food, vegetable etc.), plant parts (grain, nut), plant products (beer, flour), common plant names, scientific plant names, dairy, and African dishes.

$1 \mathrm{mp}$ : searching in abstract, title, original title, broad terms, heading words, identifiers, cabicodes 
Table 21: Search query for question \#1 in Scopus

\begin{tabular}{|c|c|c|}
\hline Concept & Line & Query \\
\hline aflatoxin & 1 & $\begin{array}{l}\text { TITLE-ABS-KEY(Aflatoxi* or AFB1 or AFB2 or AFM1 or AFM2 or AFG1 } \\
\text { or AFG2 or AFQ1) }\end{array}$ \\
\hline Africa & 2 & $\begin{array}{l}\text { TITLE-ABS-KEY(africa* or "africa south of the sahara*" or atlas or } \\
\text { igboland or maghreb or maghrib or maputaland or mayombe or nile or } \\
\text { nubia* or sahara* or sahel or sahrawi or "sub-sahara*" or subsahara* } \\
\text { or gariep or incomaputo or incomati or juba or shabelli or komati or } \\
\text { kunene or limpopo or okavango or "orange river" or ruvuma or (lake } \\
\text { W/1 victoria) or volta or zambezi or algeria* or angol* or "ascension } \\
\text { island" or benin* or botswan* or "burkina fas*" or burund* or } \\
\text { cameroon* or cameroun* or "cabo verder" or "cape verd*" or } \\
\text { capeverd* or "central african republic*" or chad* or comor* or congo* } \\
\text { or "cote d'ivoire" or djibout* or egypt* or eritrea* or ethiopia* or } \\
\text { gabon* or gambia* or ghan* or guinea* or "guinea-bissau" or "guine- } \\
\text { bissau" or guinee or "ivory coast*" or kenya* or lesoth* or liberia* or } \\
\text { libya* or madagasc* or malawi* or mali* or maroc or marocco or } \\
\text { morocc* or maurice or mauritania* or mauriti* or mayott* or } \\
\text { mozambiqu* or namibia* or niger* or nigeria* or "republique } \\
\text { centrafricain*" or reunion or rhodesia* or rwand* or "saint helena" or } \\
\text { ("sao tome" and principe) or senegal* or seychelles or "sierra leone" } \\
\text { or somalia* or somaliland* or "south africa*" or "south sudan*" or } \\
\text { sudan* or swazi* or tanzania* or tchad* or togo* or tunisia* or } \\
\text { ugand* or zambia* or zimbabw*) }\end{array}$ \\
\hline $\begin{array}{l}\text { food and } \\
\text { feed }\end{array}$ & 3 & 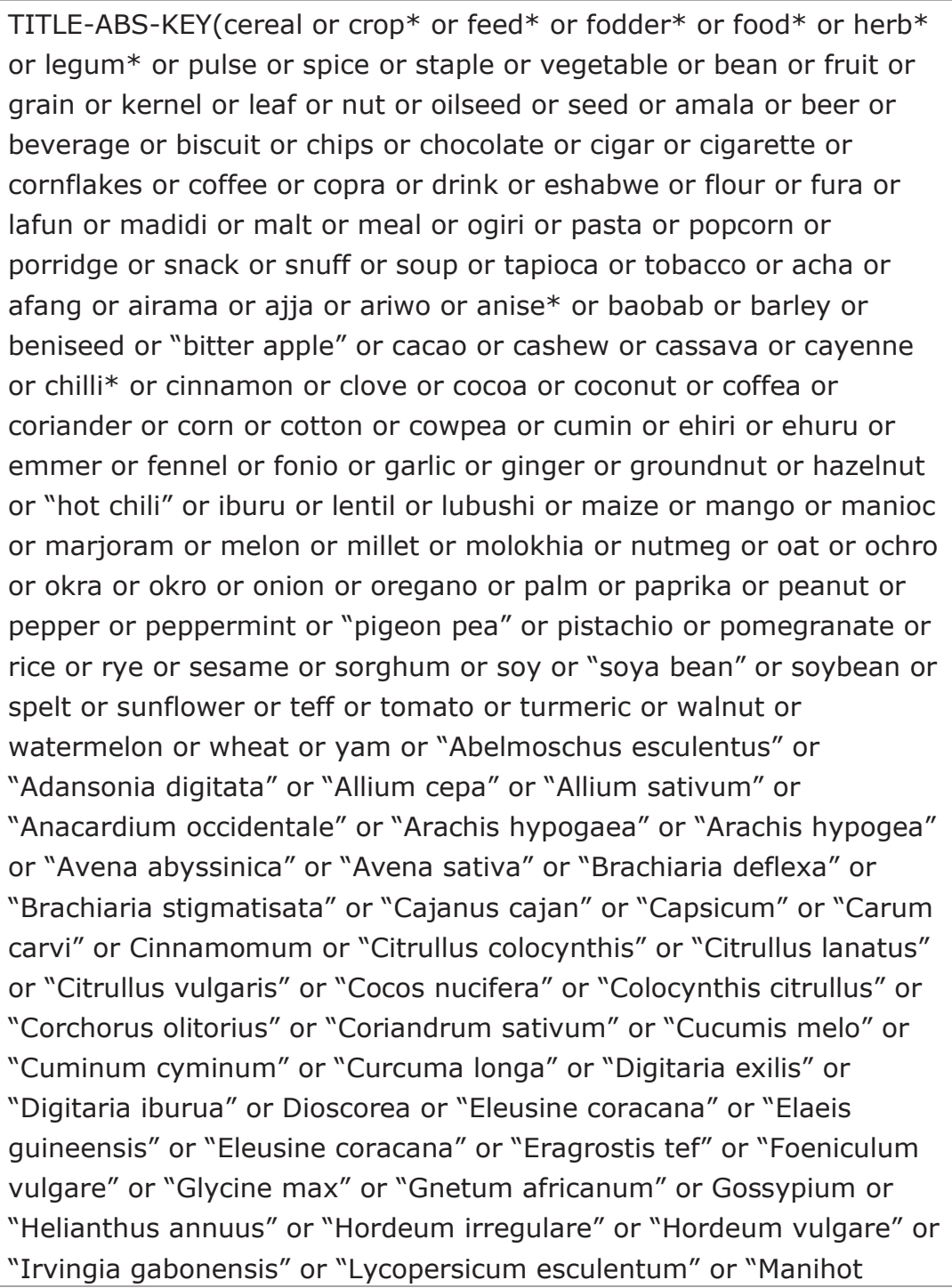 \\
\hline
\end{tabular}




\begin{tabular}{|c|c|c|}
\hline Concept & Line & Query \\
\hline & & 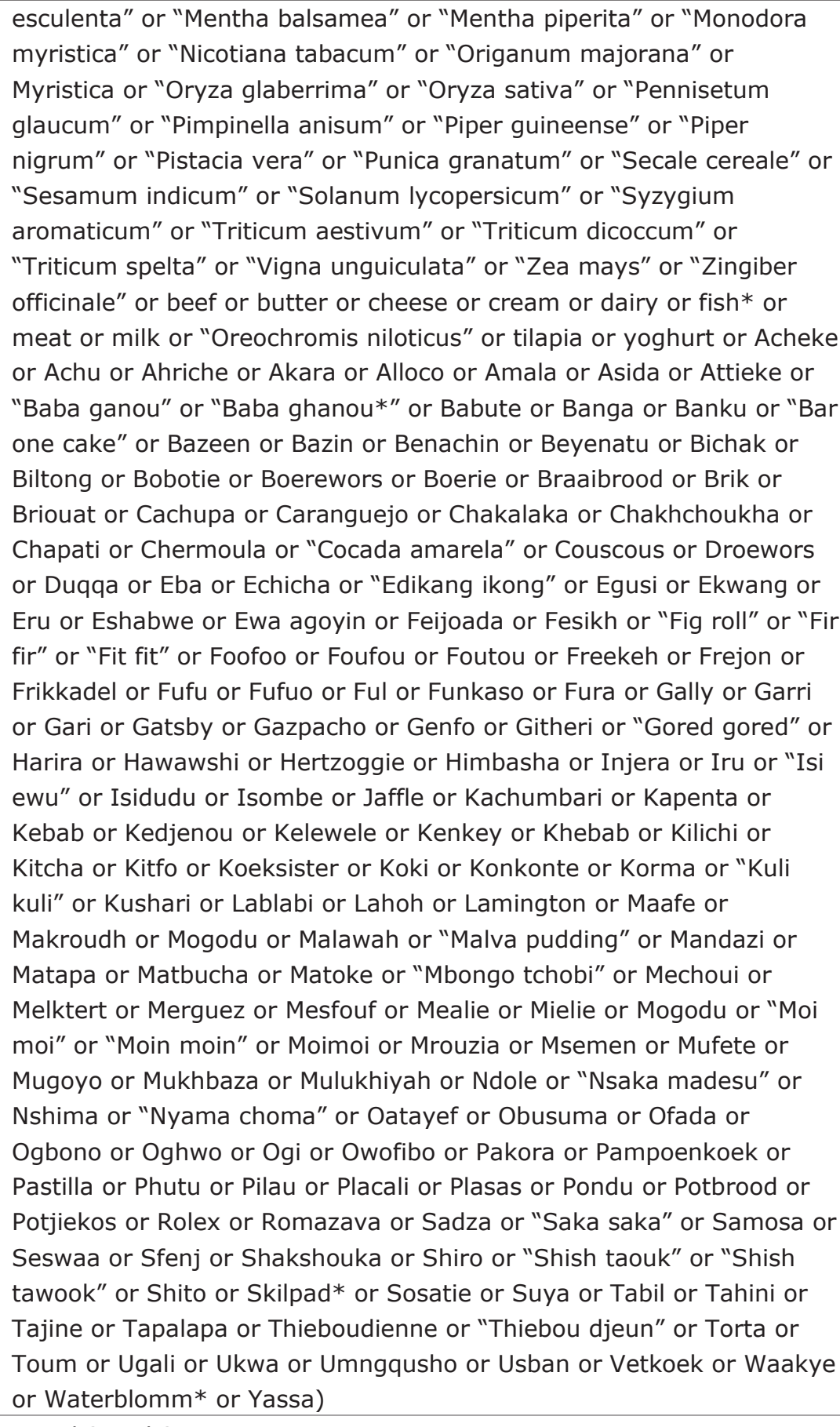 \\
\hline combination & 4 & 1 and 2 and 3 \\
\hline
\end{tabular}

Table 22: Search query for question \# 2 in CAB Abstracts

\begin{tabular}{|l|l|l|}
\hline Concept & Line & Query \\
\hline aflatoxin & 1 & $\begin{array}{l}\text { (Aflatoxi* or AFB1 or AFB2 or AFM1 or AFM2 or AFG1 or AFG2 or } \\
\text { AFQ1).mp1 }\end{array}$ \\
\hline Africa & 2 & $\begin{array}{l}\text { (exp africa or africa* or africa south of the sahara* or atlas or } \\
\text { igboland or maghreb or maghrib or maputaland or mayombe or nile or } \\
\text { nubia* or sahara* or sahel or sahrawi or sub-sahara* or subsahara* } \\
\text { or gariep or incomaputo or incomati or juba or shabelli or komati or } \\
\text { kunene or limpopo or okavango or orange river or ruvuma or (lake } \\
\text { adj1 victoria) or volta or zambezi or algeria* or angol* or ascension } \\
\text { island or benin* or botswan* or burkina fas* or burund* or } \\
\text { cameroon* or cameroun* or cabo verder or cape verd* or capeverd* }\end{array}$ \\
\hline
\end{tabular}




\begin{tabular}{|c|c|c|}
\hline Concept & Line & Query \\
\hline & & $\begin{array}{l}\text { or central african republic* or chad* or comor* or congo* or cote } \\
\text { d'ivoire or djibout* or egypt* or eritrea* or ethiopia* or gabon* or } \\
\text { gambia* or ghan* or guinea* or guinea-bissau or guine-bissau or } \\
\text { guinee or ivory coast* or kenya* or lesoth* or liberia* or libya* or } \\
\text { madagasc* or malawi* or mali* or maroc or marocco or morocc* or } \\
\text { maurice or mauritania* or mauriti* or mayott* or mo?ambiqu* or } \\
\text { namibia* or niger* or nigeria* or republique centrafricain* or reunion } \\
\text { or rhodesia* or rwand* or saint helena or (sao tome and principe) or } \\
\text { senegal* or seychelles or sierra leone or somalia* or somaliland* or } \\
\text { south africa* or south sudan* or sudan* or swazi* or tanzania* or } \\
\text { tchad* or togo* or tunisia* or ugand* or zambia* or zimbabw*).mp1 }\end{array}$ \\
\hline $\begin{array}{l}\text { health } \\
\text { burden }\end{array}$ & 3 & $\begin{array}{l}\text { (exp health OR health* OR exp Aflatoxicosis OR Aflatoxicosis OR } \\
\text { anemia OR exp neoplasms OR Neoplasm? OR (liver adj3 cancer?) OR } \\
\text { hepatitic cancer? OR hepatocellular carcinoma OR carcinogenesis OR } \\
\text { exp cirrhosis OR cirrhosis OR cirrhoses OR exp hepatic fibrosis OR } \\
\text { (liver adj3 fibrosis) OR (liver adj3 fibroses) OR exp oedema OR edema } \\
\text { OR oedema OR hydrops OR Dropsy OR anasarca OR exp gastritis OR } \\
\text { gastritis OR exp immune deficiency OR immune deficiency OR } \\
\text { immunologic* deficiency syndrome? OR exp growth disorders OR } \\
\text { growth disorder? OR stunted growth OR stunting OR (growth adj2 } \\
\text { impair*) OR exp infertility OR infertil* OR steril* OR subferti* OR } \\
\text { sub-fertil* OR exp kwashiorkor OR kwashiorkor OR exp malnutrition } \\
\text { OR malnutrition OR undernutrition OR malnourish* OR nutrition* } \\
\text { deficien* OR thinness OR underweight* OR exp kidney diseases OR } \\
\text { (kidney adj3 disorder?) OR (kidney adj3 disease?) OR nephropath* } \\
\text { OR renal disease? OR exp respiratory diseases OR (lung adj3 } \\
\text { disease?) OR respiration disorder? OR respiratory disease? OR reyes } \\
\text { syndrome? OR Reye Syndrome? OR reye?johnson syndrome OR exp } \\
\text { hepatitis OR hepatiti*).mp1 }\end{array}$ \\
\hline combination & 4 & 1 and 2 and 3 \\
\hline
\end{tabular}

Table 23: Search query for question \# 2 in PubMed

\begin{tabular}{|l|l|l|}
\hline Concept & Line & Query \\
\hline aflatoxin & 1 & $\begin{array}{l}\text { (aflatoxins[MeSH Terms] OR aflatoxin [tiab] OR aflatoxins [tiab] OR } \\
\text { AFB1 [tiab] OR AFB2 [tiab] OR AFM1 [tiab] OR AFM2[tiab] OR } \\
\text { AFG1[tiab] OR AFG2[tiab] OR AFQ1[tiab]) }\end{array}$ \\
\hline africa & 2 & $\begin{array}{l}\text { (Africa [MeSH] OR Africa [tiab] OR angola [tiab] OR Algeria [tiab] OR } \\
\text { ascension island [tiab] OR botswana [tiab] OR Benin [tiab]OR Burundi } \\
\text { [tiab] OR Burkina Faso [tiab] OR cameroon [tiab] or cameroun [tiab] } \\
\text { or cabo verder [tiab] OR cape verde [tiab] OR capeverde [tiab] OR } \\
\text { central african republic [tiab] OR chad [tiab] OR comoros [tiab] OR } \\
\text { Congo [tiab] OR Cote d'ivoire [tiab] OR Djiboutiab] [tiab] OR Egypt [tiab] } \\
\text { OR eritrea [tiab] OR Ethiopia [tiab] OR Equatorial guinea [tiab] OR } \\
\text { Gabon [tiab] OR Gambia [tiab] OR ghana [tiab] OR guinea [tiab] OR } \\
\text { guinee [tiab] OR guinea-bissau [tiab] OR ivory coast [tiab] OR Kenya } \\
\text { [tiab] OR Lesotho [tiab] OR Liberia [tiab] OR Libya [tiab] OR } \\
\text { madagascar [tiab] OR Mali [tiab] OR malawi [tiab] OR Mauritania OR } \\
\text { maurice [tiab] OR Morocco [tiab] OR Marocco [tiab] OR mozambique } \\
\text { [tiab] OR namibia [tiab] OR niger [tiab] OR Nigeria [tiab] OR } \\
\text { republique centrafricain [tiab] OR reunion [tiab] OR rhodesia [tiab] OR } \\
\text { rwanda [tiab] OR saint helana [tiab] OR senegal [tiab] OR seychelles } \\
\text { [tiab] OR sierra leone [tiab] OR somalia [tiab] OR somaliland [tiab] } \\
\text { OR South Africa [tiab] OR south sudan [tiab] OR Sudan [tiab] OR } \\
\text { swaziland [tiab] OR Tanzania [tiab] OR tchad [tiab] OR Togo [tiab] OR }\end{array}$ \\
&
\end{tabular}




\begin{tabular}{|c|c|c|}
\hline Concept & Line & Query \\
\hline & & $\begin{array}{l}\text { Tunisia [tiab] OR Uganda [tiab] OR Zambia [tiab] OR zimbabwe [tiab] } \\
\text { OR africa south of the sahara [tiab] OR anglophone africa [tiab] OR } \\
\text { atlas [tiab] OR central africa [tiab] OR east africa [tiab] OR eastern } \\
\text { africa [tiab] OR english speaking africa [tiab] OR francophone africa } \\
\text { [tiab] OR french speaking africa [tiab] OR igboland [tiab] OR Maghreb } \\
\text { [tiab] OR Maghrib [tiab] OR maputaland [tiab] OR mayombe [tiab] OR } \\
\text { Northern Africa [tiab] OR North Africa [tiab] OR nile [tiab] OR nubia } \\
\text { [tiab] OR portuguese speaking africa [tiab] OR sahara [tiab] OR sahel } \\
\text { [tiab] OR sahrawi [tiab] OR southern africa [tiab] OR Subsaharan } \\
\text { Africa [tiab] OR Sub-saharan Africa [tiab] OR tropical africa [tiab] OR } \\
\text { west africa [tiab] OR western africa [tiab] OR gariep [tiab] OR } \\
\text { incomaputo [tiab] OR incomati [tiab] OR juba [tiab] OR Sahara [tiab] } \\
\text { OR shabelli [tiab] OR komati [tiab] OR kunene [tiab] OR limpopo } \\
\text { [tiab] OR okavango [tiab] OR orange river [tiab] OR ruvuma [tiab] OR } \\
\text { lake victoria [tiab] OR victoria lake [tiab] OR volta [tiab] OR zambezi } \\
\text { [tiab]) }\end{array}$ \\
\hline $\begin{array}{l}\text { health } \\
\text { burden }\end{array}$ & 3 & 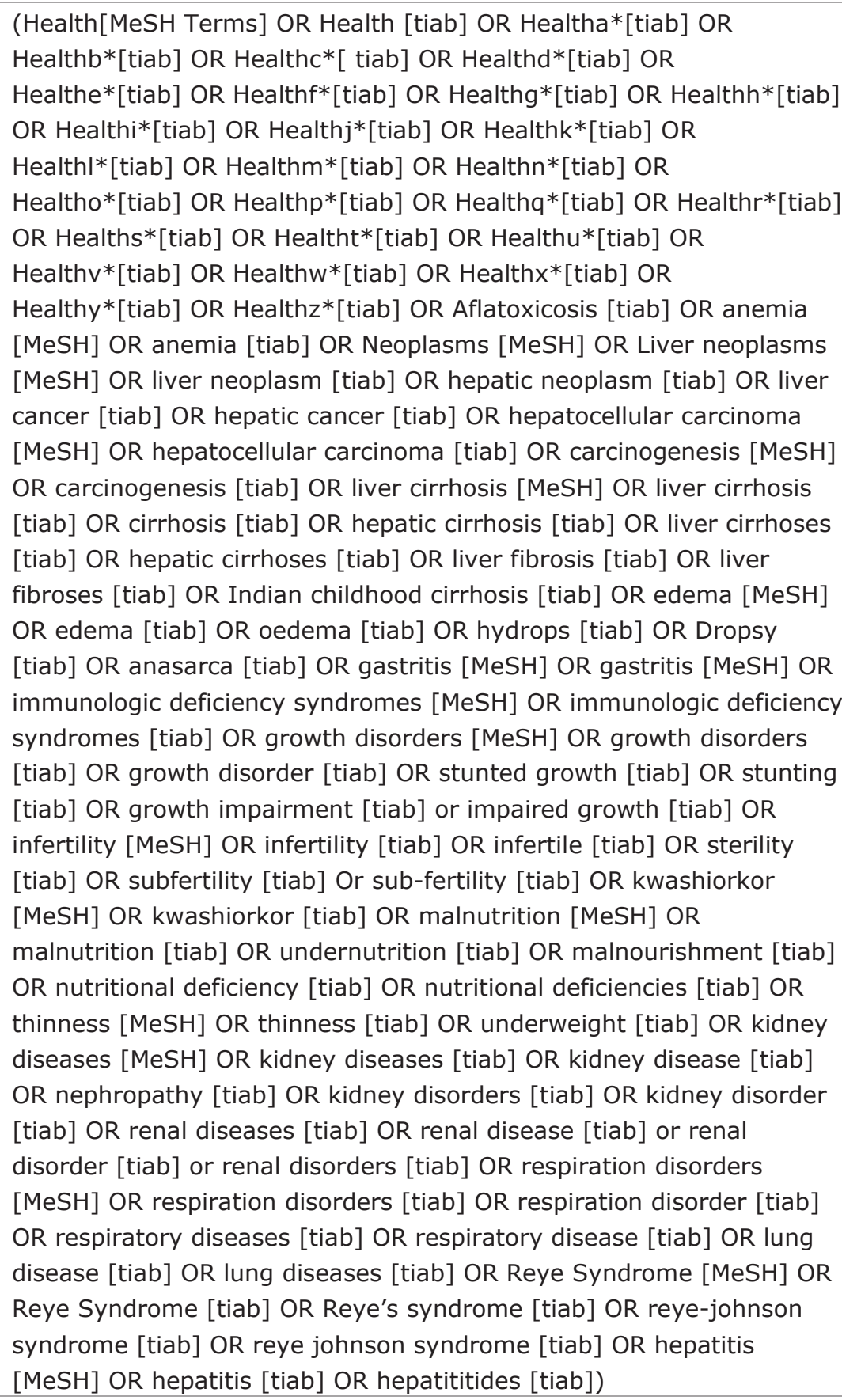 \\
\hline combination & 4 & 1 and 2 and 3 \\
\hline
\end{tabular}


Table 24: Search query for question \#2 in Scopus

\begin{tabular}{|c|c|c|}
\hline Concept & Line & Query \\
\hline aflatoxin & 1 & $\begin{array}{l}\text { TITLE-ABS-KEY(Aflatoxi* or AFB1 or AFB2 or AFM1 or AFM2 or AFG1 } \\
\text { or AFG2 or AFQ1) }\end{array}$ \\
\hline Africa & 2 & $\begin{array}{l}\text { TITLE-ABS-KEY(africa* or "africa south of the sahara*" or atlas or } \\
\text { igboland or maghreb or maghrib or maputaland or mayombe or nile or } \\
\text { nubia* or sahara* or sahel or sahrawi or "sub-sahara*" or subsahara* } \\
\text { or gariep or incomaputo or incomati or juba or shabelli or komati or } \\
\text { kunene or limpopo or okavango or "orange river" or ruvuma or (lake } \\
\text { W/1 victoria) or volta or zambezi or algeria* or angol* or "ascension } \\
\text { island" or benin* or botswan* or "burkina fas*" or burund* or } \\
\text { cameroon* or cameroun* or "cabo verder" or "cape verd*" or } \\
\text { capeverd* or "central african republic*" or chad* or comor* or congo* } \\
\text { or "cote d'ivoire" or djibout* or egypt* or eritrea* or ethiopia* or } \\
\text { gabon* or gambia* or ghan* or guinea* or "guinea-bissau" or "guine- } \\
\text { bissau" or guinee or "ivory coast*" or kenya* or lesoth* or liberia* or } \\
\text { libya* or madagasc* or malawi* or mali* or maroc or marocco or } \\
\text { morocc* or maurice or mauritania* or mauriti* or mayott* or } \\
\text { mozambiqu* or namibia* or niger* or nigeria* or "republique } \\
\text { centrafricain*" or reunion or rhodesia* or rwand* or "saint helena" or } \\
\text { "sao tome" and principe) or senegal* or seychelles or "sierra leone" } \\
\text { or somalia* or somaliland* or "south africa*" or "south sudan*" or } \\
\text { sudan* or swazi* or tanzania* or tchad* or togo* or tunisia* or } \\
\text { ugand* or zambia* or zimbabw*) }\end{array}$ \\
\hline $\begin{array}{l}\text { health } \\
\text { burden }\end{array}$ & 3 & $\begin{array}{l}\text { TITLE-ABS-KEY (health* OR Aflatoxicosis OR anemia OR Neoplasm OR } \\
\text { (liver W/2 cancer) OR "hepatitic cancer" OR "hepatocellular } \\
\text { carcinoma" OR carcinogenesis OR cirrhosis OR cirrhoses OR (liver W/2 } \\
\text { fibrosis) OR (liver W/2 fibroses) OR edema OR oedema OR hydrops } \\
\text { OR Dropsy OR anasarca OR gastritis OR "immune deficiency" OR } \\
\text { "immunologic* deficiency syndrome" OR "growth disorder" OR } \\
\text { "stunted growth" OR stunting OR (growth W/2 impair*) OR infertil* } \\
\text { OR steril* OR subfertil* OR "sub-fertil*" OR kwashiorkor OR } \\
\text { malnutrition OR undernutrition OR malnourish* OR "nutrition* } \\
\text { deficien*" OR thinness OR underweight* OR (kidney W/2 disorder) OR } \\
\text { (kidney W/2 disease) OR nephropath* OR "renal disease" OR } \\
\text { "respiratory diseases" OR (lung W/2 disease) OR "respiration disorder" } \\
\text { OR "respiratory disease" OR "reyes syndrome" OR "Reye Syndrome" } \\
\text { OR "reye johnson syndrome" OR hepatiti*) }\end{array}$ \\
\hline combination & 4 & 1 and 2 and 3 \\
\hline
\end{tabular}

Table 25: Search query for question \#3 in CAB Abstracts and AGRIS

\begin{tabular}{|l|l|l|}
\hline Concept & Line & Query \\
\hline aflatoxin & 1 & $\begin{array}{l}\text { (Aflatoxi* or AFB1 or AFB2 or AFM1 or AFM2 or AFG1 or AFG2 or } \\
\text { AFQ1).mp1 }\end{array}$ \\
\hline africa & 2 & $\begin{array}{l}\text { (exp africa or africa* or africa south of the sahara* or atlas or } \\
\text { igboland or maghreb or maghrib or maputaland or mayombe or nile or } \\
\text { nubia* or sahara* or sahel or sahrawi or sub-sahara* or subsahara* } \\
\text { or gariep or incomaputo or incomati or juba or shabelli or komati or } \\
\text { kunene or limpopo or okavango or orange river or ruvuma or (lake } \\
\text { adj1 victoria) or volta or zambezi or algeria* or angol* or ascension } \\
\text { island or benin* or botswan* or burkina fas* or burund* or } \\
\text { cameroon* or cameroun* or cabo verder or cape verd* or capeverd* } \\
\text { or central african republic* or chad* or comor* or congo* or cote }\end{array}$ \\
\hline
\end{tabular}




\begin{tabular}{|l|l|l|}
\hline Concept & Line & Query \\
\hline & & $\begin{array}{l}\text { d'ivoire or djibout* or egypt* or eritrea* or ethiopia* or gabon* or } \\
\text { gambia* or ghan* or guinea* or guinea-bissau or guine-bissau or } \\
\text { guinee or ivory coast* or kenya* or lesoth* or liberia* or libya* or } \\
\text { madagasc* or malawi* or mali* or maroc or marocco or morocc* or } \\
\text { maurice or mauritania* or mauriti* or mayott* or mo?ambiqu* or } \\
\text { namibia* or niger* or nigeria* or republique centrafricain* or reunion } \\
\text { or rhodesia* or rwand* or saint helena or (sao tome and principe) or } \\
\text { senegal* or seychelles or sierra leone or somalia* or somaliland* or } \\
\text { south africa* or south sudan* or sudan* or swazi* or tanzania* or } \\
\text { tchad* or togo* or tunisia* or ugand* or zambia* or zimbabw*).mp1 }\end{array}$ \\
\hline $\begin{array}{l}\text { economic } \\
\text { effect }\end{array}$ & 3 & $\begin{array}{l}\text { (economic assessment? or economic effect? or economic impact? or } \\
\text { economic output? or economic quantification? or economic situation? } \\
\text { or border control? or competitive* or health cost? or export* or } \\
\text { income? or price? or production or trade or poverty or farm* or rural } \\
\text { communit* or rural area? or village? or livelihood?).mp1 } \\
\text { 1 and } 2 \text { and } 3\end{array}$ \\
\hline combination & 4 & \\
\hline
\end{tabular}

${ }^{1} \mathrm{mp}$ : searching in abstract, title, original title, broad terms, heading words, identifiers, cabicodes

Table 26: Search query for question \#3 in Scopus

\begin{tabular}{|c|c|c|}
\hline Concept & Line & Query \\
\hline aflatoxin & 1 & $\begin{array}{l}\text { TITLE-ABS-KEY(Aflatoxi* or AFB1 or AFB2 or AFM1 or AFM2 or AFG1 } \\
\text { or AFG2 or AFQ1) }\end{array}$ \\
\hline Africa & 2 & $\begin{array}{l}\text { TITLE-ABS-KEY(africa* or "africa south of the sahara*" or atlas or } \\
\text { igboland or maghreb or maghrib or maputaland or mayombe or nile or } \\
\text { nubia* or sahara* or sahel or sahrawi or "sub-sahara*" or subsahara* } \\
\text { or gariep or incomaputo or incomati or juba or shabelli or komati or } \\
\text { kunene or limpopo or okavango or "orange river" or ruvuma or (lake } \\
\text { W/1 victoria) or volta or zambezi or algeria* or angol* or "ascension } \\
\text { island" or benin* or botswan* or "burkina fas*" or burund* or } \\
\text { cameroon* or cameroun* or "cabo verder" or "cape verd*" or } \\
\text { capeverd* or "central african republic*" or chad* or comor* or congo* } \\
\text { or "cote d'ivoire" or djibout* or egypt* or eritrea* or ethiopia* or } \\
\text { gabon* or gambia* or ghan* or guinea* or "guinea-bissau" or "guine- } \\
\text { bissau" or guinee or "ivory coast*" or kenya* or lesoth* or liberia* or } \\
\text { libya* or madagasc* or malawi* or mali* or maroc or marocco or } \\
\text { morocc* or maurice or mauritania* or mauriti* or mayott* or } \\
\text { mozambiqu* or namibia* or niger* or nigeria* or "republique } \\
\text { centrafricain*" or reunion or rhodesia* or rwand* or "saint helena" or } \\
\text { "sao tome" and principe) or senegal* or seychelles or "sierra leone" } \\
\text { or somalia* or somaliland* or "south africa*" or "south sudan*" or } \\
\text { sudan* or swazi* or tanzania* or tchad* or togo* or tunisia* or } \\
\text { ugand* or zambia* or zimbabw*) }\end{array}$ \\
\hline $\begin{array}{l}\text { economic } \\
\text { effect }\end{array}$ & 3 & $\begin{array}{l}\text { TITLE-ABS-KEY("economic assessment" or "economic effect" or } \\
\text { "economic impact" or "economic output" or "economic quantification" } \\
\text { or "economic situation" or "border control" or competitive* or "health } \\
\text { cost" or export* or income? or price? or production or trade or } \\
\text { poverty or farm* or "rural communit*" or "rural area" or village or } \\
\text { livelihood) }\end{array}$ \\
\hline combination & 4 & 1 and 2 and 3 \\
\hline
\end{tabular}


Table 27: Search query for question \#3 in EconLit

\begin{tabular}{|l|l|l|}
\hline Concept & Line & Query \\
\hline aflatoxin & 1 & $\begin{array}{l}\text { TX All Text (Aflatoxi* or AFB1 or AFB2 or AFM1 or AFM2 or AFG1 or } \\
\text { AFG2 or AFQ1) }\end{array}$ \\
\hline Africa & 2 & $\begin{array}{l}\text { TX All Text (africa* or "africa south of the sahara*" or atlas or } \\
\text { igboland or maghreb or maghrib or maputaland or mayombe or nile or } \\
\text { nubia* or sahara* or sahel or sahrawi or "sub-sahara*" or subsahara* } \\
\text { or gariep or incomaputo or incomati or juba or shabelli or komati or } \\
\text { kunene or limpopo or okavango or "orange river" or ruvuma or (lake } \\
\text { W/1 victoria) or volta or zambezi or algeria* or angol* or "ascension } \\
\text { island" or benin* or botswan* or "burkina fas*" or burund* or } \\
\text { cameroon* or cameroun* or "cabo verder" or "cape verd*" or } \\
\text { capeverd* or "central african republic*" or chad* or comor* or congo* } \\
\text { or "cote d'ivoire" or djibout* or egypt* or eritrea* or ethiopia* or } \\
\text { gabon* or gambia* or ghan* or guinea* or "guinea-bissau" or "guine- } \\
\text { bissau" or guinee or "ivory coast*" or kenya* or lesoth* or liberia* or } \\
\text { libya* or madagasc* or malawi* or mali* or maroc or marocco or } \\
\text { morocc* or maurice or mauritania* or mauriti* or mayott* or } \\
\text { mozambiqu* or namibia* or niger* or nigeria* or "republique } \\
\text { centrafricain*" or reunion or rhodesia* or rwand* or "saint helena" or } \\
\text { ("sao tome" and principe) or senegal* or seychelles or "sierra leone" } \\
\text { or somalia* or somaliland* or "south africa*" or "south sudan*" or } \\
\text { sudan* or swazi* or tanzania* or tchad* or togo* or tunisia* or } \\
\text { ugand* or zambia* or zimbabw*) }\end{array}$ \\
\hline combination & 3 & \begin{tabular}{l}
1 and 2 \\
\hline
\end{tabular} \\
\hline
\end{tabular}

Table 28: Search query for question \#4 in CAB Abstracts and AGRIS

\begin{tabular}{|c|c|c|}
\hline Concept & Line & Query \\
\hline mitigation & 1 & $\begin{array}{l}\text { (aeration or adsorbent* or AflaSafe or (aflatoxin* adj3 free) or airtight } \\
\text { stor* or alleviat* or amelior* or antagoni* or anti-aflatoxi* or anti- } \\
\text { fungal or antifungal or anti-oxidant* or aware* or baking or binder* } \\
\text { or binding or biocontrol or bio-control or certif* or chemopreventi* or } \\
\text { clay? or clean* or combat* or cool* or (crop* adj3 rotat*) or cultural } \\
\text { control* or decontaminat* or defen* or degrad* or detoxif* or drying } \\
\text { or early harvest* or educat* or eliminat* or enforce* or } \\
\text { enterosorbent* or fermentat* or flaking or flotat* or fumigation or } \\
\text { fungistat* or GHP? or GMP? or (good adj6 practice?) or grading or } \\
\text { GSP or GTP or HACCP or heat* or hermetic* stor* or hot water or } \\
\text { hygien* or intervent* or irradiat* or law or laws or legislat* or lower* } \\
\text { or manag* or maximum residu* limit? or milling or minimis* or } \\
\text { minimiz* or mitigat* or modified atmospher* or MRL* or (mycotoxin* } \\
\text { adj3 free) or natural enem* or nixtamali?ation or nonaflatoxigenic* or } \\
\text { non-aflatoxigenic* or (post-harvest adj3 control) or preserv* or } \\
\text { (proper* adj3 stor*) or (quality adj3 control) or radiat* or refrigerat* } \\
\text { or resist* or (risk* adj3 reduc*) or roast* or sanitat* or sequest* or } \\
\text { smoking or standard operating procedure? or subsid* or surveill* or } \\
\text { teach* or (toxin* adj3 free) or train* or vaccinat* or ventilat*).mp1 } \\
\text { or (control* or inhibit* or prevent* or protect* or reduc* or regulat* } \\
\text { or remov*).ti2 or CC100 or CC200 or DD500 }\end{array}$ \\
\hline $\begin{array}{l}\text { Combination } \\
\text { with } \\
\text { question \#1 }\end{array}$ & 2 & 1 and 4 (question $\# 1$ ) \\
\hline $\begin{array}{l}\text { Combination } \\
\text { with } \\
\text { question \# } 2\end{array}$ & 3 & 1 and 4 (question $\# 2$ )(not in AGRIS) \\
\hline
\end{tabular}




\begin{tabular}{|l|l|l|}
\hline Concept & Line & Query \\
\hline $\begin{array}{l}\text { Combination } \\
\text { with } \\
\text { question \#3 }\end{array}$ & 4 & 1 and 4 (question \#3) \\
\hline
\end{tabular}

${ }^{1} \mathrm{mp}$ : searching in abstract, title, original title, broad terms, heading words, identifiers, cabicodes

2ti: searching in title

Table 29: Search query for question \#4 in Scopus

\begin{tabular}{|c|c|c|}
\hline Concept & Line & Query \\
\hline mitigation & 1 & $\begin{array}{l}\text { TITLE-ABS-KEY(aeration or adsorbent or AflaSafe or (aflatoxin W/3 } \\
\text { free) or "airtight stor*" or alleviat* or amelior* or antagoni* or anti- } \\
\text { aflatoxi* or anti-fungal or antifungal or anti-oxidant or aware* or } \\
\text { baking or binder or binding or biocontrol or bio-control or certif* or } \\
\text { chemopreventi* or clay or clean* or combat* or cool* or (crop W/3 } \\
\text { rotat*) or "cultural control*" or decontaminat* or defen* or degrad* } \\
\text { or detoxif* or drying or "early harvest*" or educat* or eliminat* or } \\
\text { enforce* or enterosorbent* or fermentat* or flaking or flotat* or } \\
\text { fumigation or fungistat* or GHP or GMP or (good W/6 practice) or } \\
\text { grading or GSP or GTP or HACCP or heat* or "hermetic* stor*" or "hot } \\
\text { water" or hygien* or intervent* or irradiat* or law or legislat* or } \\
\text { lower* or manag* or "maximum residu* limit" or milling or minimis* } \\
\text { or mitigat* or "modified atmospher*" or MRL* or (mycotoxin W/3 } \\
\text { free) or "natural enem*" or nixtamalisation or nonaflatoxigenic* or } \\
\text { non-aflatoxigenic* or (post-harvest W/3 control) or preserv* or } \\
\text { (proper* W/3 stor*) or (quality W/3 control) or radiat* or refrigerat* } \\
\text { or resist* or (risk W/3 reduc*) or roast* or sanitat* or sequest* or } \\
\text { smoking or "standard operating procedure" or subsid* or surveill* or } \\
\text { teach* or (toxin W/3 free) or train* or vaccinat* or ventilat*) or } \\
\text { TITLE(control* or inhibit* or prevent* or protect* or reduc* or } \\
\text { regulat* or remov*) }\end{array}$ \\
\hline $\begin{array}{l}\text { Combination } \\
\text { with } \\
\text { question \#1 }\end{array}$ & 2 & 1 and 4 (question \#1) \\
\hline $\begin{array}{l}\text { Combination } \\
\text { with } \\
\text { question \#2 }\end{array}$ & 3 & 1 and 4 (question \#2) \\
\hline $\begin{array}{l}\text { Combination } \\
\text { with } \\
\text { question \#3 }\end{array}$ & 4 & 1 and 4 (question \#3) \\
\hline
\end{tabular}

Table 30: Search query for question \#4 in PubMed

\begin{tabular}{|l|l|l|}
\hline Concept & Line & Query \\
\hline mitigation & 1 & $\begin{array}{l}\text { ((aeration [tiab] or adsorbent [tiab] or AflaSafe [tiab] or "aflatoxin } \\
\text { free" [tiab] or "airtight storage" [tiab] or alleviat* [tiab] or ameliorat* } \\
\text { [tiab] or antagoni* [tiab] or "anti aflatoxin" [tiab] or "anti fungal" } \\
\text { [tiab] or antifungal [tiab] or "anti oxidant" [tiab] or antioxidant [tiab] } \\
\text { or aware* [tiab] or baking [tiab] or binder [tiab] or binding [tiab] or } \\
\text { biocontrol [tiab] or "bio control" [tiab] or certif* [tiab] or } \\
\text { chemopreventi* [tiab] or clay [tiab] or clean* [tiab] or combat* [tiab] } \\
\text { or cool* [tiab] or "crop rotation" [tiab] or "cultural control" [tiab] or } \\
\text { decontaminat* [tiab] or defen* [tiab] or degrad* [tiab] or detoxif* } \\
\text { [tiab] or drying [tiab] or "early harvesting" [tiab] or "early harvest" } \\
\text { [tiab] or educat* [tiab] or eliminat* [tiab] or enforce* [tiab] or } \\
\text { enterosorbent* [tiab] or fermentat* [tiab] or flaking [tiab] or flotat* }\end{array}$ \\
&
\end{tabular}




\begin{tabular}{|c|c|c|}
\hline Concept & Line & Query \\
\hline & & $\begin{array}{l}\text { [tiab] or fumigation [tiab] or fungistat* [tiab] or GHP [tiab] or GMP } \\
\text { [tiab] or "good practice" [tiab] or "good practices" [tiab] or grading } \\
\text { [tiab] or GSP [tiab] or GTP [tiab] or HACCP [tiab] or heat* [tiab] or } \\
\text { "hermetic storage" [tiab] or "hermetically stored" [tiab]or "hot water" } \\
\text { [tiab] or hygiene [tiab] or hygienic [tiab] or intervent* [tiab] or } \\
\text { irradiat* [tiab] or legislat* [tiab] or lower* [tiab] or manag* [tiab] or } \\
\text { "maximum residue limit" [tiab] or "maximum residue limits" [tiab] or } \\
\text { milling [tiab] or minimis* [tiab] or mitigat* [tiab] or "modified } \\
\text { atmosphere" [tiab] or MRL* [tiab] or "mycotoxin free" [tiab] or } \\
\text { "natural enemy" [tiab] or "natural enemies" [tiab] or nixtamalisation } \\
\text { [tiab] or nonaflatoxigenic* [tiab] or "non-aflatoxigenic" [tiab] or "post } \\
\text { harvest control" [tiab] or preserv* [tiab] or proper storage [tiab] or } \\
\text { properly stored [tiab] or "quality control" [tiab] or radiat* [tiab] or } \\
\text { refrigerat* [tiab] or resist* [tiab] or "risk reduction" [tiab] or roast* } \\
\text { [tiab] or sanitat* [tiab] or sequest* [tiab] or smoking [tiab] or } \\
\text { "standard operating procedure" [tiab] or subsid* [tiab] or surveill* } \\
\text { [tiab] or teach* [tiab] or "toxin free" [tiab] or train* [tiab] or } \\
\text { vaccinat*) or (control* [ti] or inhibit* [ti] or prevent* [ti] or protect* } \\
\text { [ti] or reduc* [ti] or regulat* [ti] or remov* [ti]) or (antioxidants } \\
\text { [MeSH] or "antifungal agents" [MeSH] or awareness [MeSH] or } \\
\text { certification [MeSH] or chemoprevention [MeSH] or decontamination } \\
\text { [MeSH] or desiccation [MeSH] or "disease resistance" [MeSH] or } \\
\text { education [MeSH] or fermentation [MeSH] or "food irradiation" } \\
\text { [MeSH] or "food preservation" [MeSH] or fumigation [MeSH] or } \\
\text { heating [MeSH] or hygiene [MeSH] or "inactivation, metabolic" } \\
\text { [MeSH] or "law enforcement" [MeSH] or "legislation, food" [MeSH] or } \\
\text { "organization and administration" [MeSH] or "public health } \\
\text { surveillance" [MeSH] or "quality control" [MeSH] or refrigeration } \\
\text { [MeSH] or sanitation [MeSH] or "sequestering agents" [MeSH] or } \\
\text { "sorption detoxification" [MeSH] or teaching [MeSH] or vaccination } \\
\text { [MeSH] or ventilation [MeSH])) }\end{array}$ \\
\hline $\begin{array}{l}\text { Combination } \\
\text { with } \\
\text { question \#1 }\end{array}$ & 2 & 1 and 4 (question \#1) \\
\hline $\begin{array}{l}\text { Combination } \\
\text { with } \\
\text { question \#2 }\end{array}$ & 3 & 1 and 4 (question \#2) \\
\hline $\begin{array}{l}\text { Combination } \\
\text { with } \\
\text { question \#3 }\end{array}$ & 4 & 1 and 4 (question \#3) \\
\hline
\end{tabular}




\section{Annex 4 Benchmark citations}

\section{Question \#1: What is the scale and geographical spread of aflatoxin contamination in food, feed, and associated commodities/key value chains, in African countries?}

- $\quad$ Atongbiik Achaglinkame, M., Opoku, N., Kweku Amagloh, F., 2017. Aflatoxin contamination in cereals and legumes to reconsider usage as complementary food ingredients for Ghanaian infants: A review. Journal of Nutrition \& Intermediary Metabolism 10: 1-7.

- Hove, M., De Boevre, M., Lachat, C., Jacxsens, L., Nyanga, L.K., De Saeger, S., 2016. Occurrence and risk assessment of mycotoxins in subsistence farmed maize from Zimbabwe. Food Control 69: 36-44

- Kachapulula, P.W., Akello, J., Bandyopadhyay, R., Cotty, P.J., 2017. Aflatoxin contamination of groundnut and maize in Zambia: observed and potential concentrations. Journal of Applied Microbiology 122: 1471-1482.

- Kamika, I., Ngobolua, K.N., Tekere, M., 2016. Occurrence of aflatoxin contamination in maize throughout the supply chain in the Democratic Republic of Congo. Food Control 69:292-296.

- Mutiga, S.K., Hoffmann, V., Harvey, J.W., Milgroom, M.G., Nelson, R.J., 2015. Assessment of aflatoxin and fumonisin contamination of maize in Western Kenya. Phytopathology 105: 12501261.

\section{Question \# 2: What is the scale of aflatoxin disease burden for African countries?}

- Adetuniji, M.C., Atanda, O.O., Ezekiel, C.N., Dipeolu, A.O., Uzochukwu, S.V.A., Oyedepo, J., Chilaka, C.A., 2014. Distribution of mycotoxins and risk assessment of maize consumers in five agro-ecological zones of Nigeria. European Food Research and Technology 239(2), 287296

- $\quad$ Gong, Y.Y., Wilson, S., Mwatha, J.K., Routledge, M.N., Castelino, J.M., Zhao, B., Kimani, G., Kariuki, H.C., Vennervald, B.J., Dunne, D.W., Wild, C.P., 2012. Aflatoxin exposure may contribute to chronic hepatomegaly in Kenyan school children. Environmental Health Perspectives 120(6): 893-896. DOI: 10.1289/ehp.1104357

- Watson, S., Gong, Y.Y., Routledge, M.N., 2017. Interventions targeting child undernutrition in developing countries may be undermined by dietary exposure to aflatoxin. Critical Reviews in Food Science and Nutrition 57(9), 1963-1975. DOIi: 10.1080/10408398.2015.1040869.

- $\quad$ Liu, Y., Wu, F., 2010. Global burden of aflatoxin-induced hepatocellular carcinoma: A risk assessment. Environmental Health Perspectives 118, 818-824.

- Magoha, H., Kimanya, M., De Meulenaer, B., Roberfroid, D., Lachat, C., Kolsteren, P., 2014. Association between aflatoxin $\mathrm{M} 1$ exposure through breast milk and growth impairment in infants from Northern Tanzania. World Mycotoxin Journal 7(3), 277-284. DOI: 10.3920/WMJ2014.1705

\section{Question \#3: What are the economic effects of aflatoxins on African countries?}

- $\quad$ Bley N'dede, C., Jolly, C.M., Vodouhe, S.D., Jolly, P.E., 2012. Economic risks of aflatoxin contamination in marketing of peanut in Benin. Economics Research International 2012, 230638. DOI: $10.1155 / 2012 / 230638$

- De Groote, H., Narrod, C., Kimenju, S.C., Bett, C., Scott, R.P.B., Tiongco, M.M., Gitonga, Z.M., 2016. Measuring rural consumers' willingness to pay for quality labels using experimental auctions: the case of aflatoxin-free maize in Kenya. Agricultural Economics 47(1), 33-45. DOI: 10.1111/agec.12207

- Gebrehiwet, Y., Ngqangweni, S., Kirsten, J.F., 2007. Quantifying the trade effect of sanitary and phytosanitary regulations of OECD countries on South African food exports, Agrekon 46(1), 1-17. DOI: 10.1080/03031853.2007.9523759

- Wu, F., 2015. Global impacts of aflatoxin in maize: trade and human health. World Mycotoxin Journal 8(2), 137-142. 
- Xiong, B., Beghin, J., 2012. Does European aflatoxin regulation hurt groundnut exporters from Africa? European Review of Agricultural Economics 39, 589-609.

\section{Question \#4: What are the possible mitigation measures and what is the cost-effectiveness of mitigation of aflatoxin contamination in key commodities / value chains in African countries?}

- $\quad$ Xu, Y., Doel, A., Watson, S., Routledge, M.N., Elliott, C.T., Moore, S.E., Gong, Y.Y., 2017. Study of an educational hand sorting intervention for reducing aflatoxin b1 in groundnuts in rural Gambia. Journal of Food Protection 80: 44-49.

- Khlangwiset, P., Wu, F., 2010. Costs and efficacy of public health interventions to reduce aflatoxin-induced human disease. Food Additives and Contaminants Part A 27, 998-1014.

- Maina, A.W., Wagacha, J.M., Mwaura, F.M., Muthomi, J.W., Woloshuk, C.P., 2016. Postharvest practices of maize farmers in Kaiti District, Kenya and the impact of hermetic storage on populations of Aspergillus spp. and aflatoxin contamination. Journal of Food Research 5: 5366

- Matumba, L., Van Poucke, C., Ediage, E.N., De Saeger, S., 2017. Keeping mycotoxins away from the food: Does the existence of regulations have any impact in Africa? Critical Reviews in Food Science and Nutrition 57, 1584-1592

- Wu, F., Khlangwiset, P., 2010. Health economic impacts and cost-effectiveness of aflatoxinreduction strategies in Africa: case studies in biocontrol and post-harvest interventions. Food Additives and Contaminants Part A 27, 496-509. 


\section{Annex 5 Selection criteria (screening)}

Pre-defined screening questions guide the initial screening of retrieved records from bibliographies and grey literature for their relevance to the particular research questions (1-4) for which these references had been searched. Based on the answers entered for a particular reference, it was classified as "relevant", "potentially relevant", or "not relevant".

Screening steps were conducted twice; screening title and abstract and screening full text. Each step was screened with pre-defined exclusion criteria. If a study meets one of the exclusion criteria, it is not further considered.

\section{Exclusion criteria for screening title and abstract}

1. A study was not written in English

2. A study was not on aflatoxins

3. A study was not conducted in African countries

4. A study was published before 2010

5. A study focused on general health effects, rather than the disease burden to African population

6. A study was relevant for mitigation measures, but not conducted in African countries

\section{Exclusion criteria for screening full text}

1. A study was not written in English

2. A study was not on aflatoxins

3. A study was not conducted in African countries

4. Samples or data were taken before 2009

5. A study presented insufficient evidences (poor quality, no result presented)

6. A study was a literature review

7. A study was conducted on laboratory animal test or non-livestock study

8. A study focused on phytopathology of aflatoxin

9. A study focused on biomarkers of exposure rather than the disease

An option is also available to indicate if a study is a grey literature. A grey literature study can be included for full text coding if it is deemed relevant. Besides exclusion criteria, categorisation is applied during screening full text for included studies. Categorisation indicates to which research question(s) a study is assigned.

\section{Categorisation}

Does the study concern one or multiple relevant themes of this review?

a. Contamination of food?

b. Disease burden?

c. Economic impact of aflatoxins?

d. Mitigation measures? 


\section{Annex 6 Additional searches for studies on the economic impact of aflatoxin}

The bibliographic searches for studies on the economic impact were complemented by additional searches as described below. First, snowballing from included studies. Second, excluded studies for literature reviews and lack of evidences were scanned and considered. Studies excluded for other criteria were not considered. Subsequently, snowballing references were searched for these studies. Third, grey literatures were searched in various international organizations or research institute working in food safety economics.

\section{Snowballing from included studies}

The screening of the studies identified in the bibliographic searches by the library experts resulted in 3 studies on the economic effects of aflatoxin as shown in the Table 31 below.

Table 31: Studies identified from snowballing from included studies

\begin{tabular}{|c|c|c|c|}
\hline Study & $\begin{array}{l}\text { Relevant studies identified in the } \\
\text { snowballing }\end{array}$ & $\begin{array}{l}\text { Contents of the studied } \\
\text { identified in the } \\
\text { snowballing }\end{array}$ & $\begin{array}{l}\text { Included } \\
\text { in EPPI } \\
\text { for coding }\end{array}$ \\
\hline $\begin{array}{l}\text { Hoffmann } \\
\text { et al. } \\
2017\end{array}$ & $\begin{array}{l}\text { Dohlman, E., 2003. Mycotoxin hazards } \\
\text { and regulations. International Trade } \\
\text { and Food Safety: Economic Theory and } \\
\text { Case Studies, p. } 97 .\end{array}$ & $\begin{array}{l}\text { Discussed impact of } \\
\text { mycotoxin regulations to } \\
\text { international trade; pinpoint } \\
\text { the impact to developing } \\
\text { countries and the constraint } \\
\text { to estimate the economic } \\
\text { impacts in consistent and } \\
\text { uniform way. }\end{array}$ & $\begin{array}{l}\text { No, } \\
\text { reasons: } \\
\text { year of } \\
\text { publication }\end{array}$ \\
\hline $\begin{array}{l}\text { N'dede et } \\
\text { al. } 2012\end{array}$ & $\begin{array}{l}\text { Attah, A. et al., } 2007 . \text { Cost } \\
\text { effectiveness of selected post-harvest } \\
\text { pod handling techniques against } \\
\text { damage, moldiness and aflatoxin } \\
\text { contamination of shelled groundnut in } \\
\text { Ghana. Journal of Science and } \\
\text { Technology, vol. } 27, \text { no. } 1, \text { pp. } 1-17 \text {, }\end{array}$ & Relevant for mitigation & $\mathrm{n} / \mathrm{a}$ \\
\hline $\begin{array}{l}\text { Mtimet, et } \\
\text { al. } 2015\end{array}$ & $\begin{array}{l}\text { USAID Kenya, } 2010 \text {. Consumer milk } \\
\text { quality perception/preferences and an } \\
\text { assessment of willingness to pay for } \\
\text { quality. USAID Kenya Dairy Sector } \\
\text { Competitiveness Program, 623-C-00- } \\
08-00020-00 .\end{array}$ & $\begin{array}{l}\text { Pdf not found/available } \\
\text { USAID study } 2010 \\
\text { apparently mentions WTP } \\
\text { for better quality that } \\
\text { includes aflatoxin-free } \\
\text { certificate }\end{array}$ & $\mathrm{n} / \mathrm{a}$ \\
\hline
\end{tabular}


In the literature review found for the systematic review, we have identified 5 reviews investigated at the economic effects of aflatoxin. Literature for studies with original research on the topic were checked in snowballing references.

Table 32: Literature reviews

\begin{tabular}{|c|c|c|c|}
\hline Study & $\begin{array}{l}\text { Type of } \\
\text { publication }\end{array}$ & Content & $\begin{array}{l}\text { Included } \\
\text { in EPPI } \\
\text { for coding }\end{array}$ \\
\hline $\begin{array}{l}\text { LindahI J F; Grace D ; } 2013 \\
\text { Aflatoxins, major contributions } \\
\text { to harvest loss - what do we } \\
\text { know and not know? }\end{array}$ & $\begin{array}{l}\text { Presentation for } \\
\text { conference; } \\
\text { ILRI } \\
\text { Limited } \\
\text { elaboration; } \\
\text { focus on Kenya }\end{array}$ & $\begin{array}{l}\text { Discussed effect of } \\
\text { aflatoxin regulations } \\
\text { worldwide and their } \\
\text { impact on trade from } \\
\text { developing countries } \\
\text { Cited some studies } \\
\text { identified in EPPI; one } \\
\text { study relevant for } \\
\text { economic already included } \\
\text { in EPPI (Mtimet et al., } \\
\text { 2015) }\end{array}$ & No \\
\hline $\begin{array}{l}\text { Senerwa D M; Mtimet N ; Lindahl } \\
\text { J ; Kang'ethe E K; Grace D; } 2013 \\
\text { Levels of aflatoxins in the } \\
\text { Kenyan dairy value chain: How } \\
\text { can we assess the economic } \\
\text { impact? }\end{array}$ & $\begin{array}{l}\text { Research Poster; } \\
\text { ILRI } \\
\text { Very limited } \\
\text { elaboration }\end{array}$ & $\begin{array}{l}\text { Shows the formula to } \\
\text { estimate the economic } \\
\text { loss from health cost, but } \\
\text { did not perform the } \\
\text { calculation. }\end{array}$ & No \\
\hline $\begin{array}{l}\text { Suleiman R ; Rosentrater K ; } \\
2015 \\
\text { Current maize production, } \\
\text { postharvest losses and the risk } \\
\text { of Mycotoxins contamination in } \\
\text { Tanzania }\end{array}$ & $\begin{array}{l}\text { Conference } \\
\text { proceeding } \\
\text { (ASABE meeting } \\
\text { presentation) }\end{array}$ & $\begin{array}{l}\text { Discuss trade-related } \\
\text { economic impact due to } \\
\text { mycotoxin in general } \\
\text { (including aflatoxin). } \\
\text { See page } 38-39 \\
\text { Discussed various ways to } \\
\text { assess economic impact } \\
\text { of mycotoxin } \\
\text { contamination, but did } \\
\text { not perform the } \\
\text { calculation }\end{array}$ & No \\
\hline $\begin{array}{l}\text { Udomkun P ; Wiredu A N; Nagle } \\
\text { M ; Bandyopadhyay R ; Muller J ; } \\
\text { Vanlauwe B ; 2017: Mycotoxins } \\
\text { in Sub-Saharan Africa: present } \\
\text { situation, socio-economic } \\
\text { impact, awareness, and outlook }\end{array}$ & Journal & $\begin{array}{l}\text { Discuss the occurrence of } \\
\text { mycotoxin in Sub- } \\
\text { Saharan Africa; economic } \\
\text { losses were discussed in } \\
\text { general, not specifcially } \\
\text { for Africa }\end{array}$ & No \\
\hline $\begin{array}{l}\text { Unnevehr Laurian J; } 2015 \\
\text { Aflatoxins: Finding solutions for } \\
\text { improved food safety }\end{array}$ & $\begin{array}{l}\text { Brief report on } \\
\text { various studies } \\
\text { on aflatoxins } \\
\text { IFPRI }\end{array}$ & $\begin{array}{l}\text { Relevant Chapter: } \\
\text { Trade Impacts of Aflatoxin } \\
\text { Standards (Devesh Roy) }\end{array}$ & No \\
\hline
\end{tabular}




\begin{tabular}{|c|c|c|c|}
\hline Study & $\begin{array}{l}\text { Relevant studies identified in } \\
\text { the snowballing }\end{array}$ & $\begin{array}{l}\text { Contents of the studied } \\
\text { identified in the } \\
\text { snowballing }\end{array}$ & $\begin{array}{l}\text { Included in } \\
\text { EPPI for } \\
\text { coding }\end{array}$ \\
\hline \multirow[t]{5}{*}{$\begin{array}{l}\text { Unnevehr, } \\
\text { L. } 2015\end{array}$} & $\begin{array}{l}\text { Bhat, R. and S. Vasanthi. } 1999 . \\
\text { "Mycotoxin Contamination of } \\
\text { Foods and Feeds: Overview, } \\
\text { Occurrence and Economic Impact } \\
\text { on Food Availability, Trade, } \\
\text { Exposure of Farm Animals and } \\
\text { Related Economic Losses." Paper } \\
\text { presented at the third joint } \\
\text { FAO/WHO/UNEP International } \\
\text { Conference on Aflatoxins, Tunis, } \\
\text { Tunisia, March 3-6. }\end{array}$ & $\mathrm{n} / \mathrm{a}$ & $\begin{array}{l}\text { No, reason: year } \\
\text { of publication }\end{array}$ \\
\hline & $\begin{array}{l}\text { Otsuki, T. et al. 2001b. "What } \\
\text { Price Precaution? European } \\
\text { Harmonization of Aflatoxins } \\
\text { Regulations and African Groundnut } \\
\text { Exports." European Review of } \\
\text { Agricultural Economics } 28 \text { (3): } \\
263-284 \text {. }\end{array}$ & $\begin{array}{l}\text { With EU implement more } \\
\text { strict aflatoxin standard than } \\
\text { CODEX would decrease } \\
\text { African groundnut exports } \\
\text { by } 63 \% \text {. }\end{array}$ & $\begin{array}{l}\text { No, reason: year } \\
\text { of publication }\end{array}$ \\
\hline & $\begin{array}{l}\text { Otsuki, T. et al. 2001a. "Saving } \\
\text { Two in a Billion: Quantifying the } \\
\text { Trade Effect of European Food } \\
\text { Safety Standards on African } \\
\text { Exports." Food Policy, 26(5), 495- } \\
514 .\end{array}$ & $\begin{array}{l}\text { With EU implement more } \\
\text { strict aflatoxin standard than } \\
\text { CODEX would decrease } \\
\text { African exports by } 64 \% \text { or } \\
\text { USD } 670 \text { million. }\end{array}$ & $\begin{array}{l}\text { No, reason: year } \\
\text { of publication }\end{array}$ \\
\hline & $\begin{array}{l}\text { Wu, F. } 2015 \text {. Global impacts of } \\
\text { aflatoxin in maize: trade and } \\
\text { human health. World Mycotoxin } \\
\text { Journal } 8(2), 137-142 \text {. }\end{array}$ & $\begin{array}{l}\text { Discuss economic and health } \\
\text { impact of aflatoxin in global } \\
\text { level }\end{array}$ & $\begin{array}{l}\text { No, since } \\
\text { literature review }\end{array}$ \\
\hline & $\begin{array}{l}\text { Wu, F. (2004) Mycotoxin Risk } \\
\text { Assessment for the Purpose of } \\
\text { Setting International Regulatory } \\
\text { Standards. Environ SciTechnol 38: } \\
\text { 4049-55. }\end{array}$ & $\begin{array}{l}\text { Losses of African exporter } \\
\text { due to EU regulation on } \\
\text { aflatoxin is lower due to } \\
\text { trade between EU and Africa } \\
\text { was not as large as } \\
\text { estimated by Otsuki (2001) }\end{array}$ & $\begin{array}{l}\text { No, reason: year } \\
\text { of publication }\end{array}$ \\
\hline $\begin{array}{l}\text { Suleiman, } \\
\text { R. } 2015\end{array}$ & $\begin{array}{l}\text { Wu, F. and Guclu, H. } 2012 \text {. } \\
\text { Aflatoxin regulations in a network } \\
\text { of global maize trade. PloS one } \\
7(9) \text { : e45151. }\end{array}$ & $\begin{array}{l}\text { Countries tend to trade with } \\
\text { other countries with similar } \\
\text { or nearly-similar aflatoxin } \\
\text { regulations. Due to } \\
\text { relatively low amount of } \\
\text { maize import from Africa to } \\
\text { EU, it is not likely that } \\
\text { African maize export would } \\
\text { be adversely affected by EU } \\
\text { aflatoxin standard stringent } \\
\text { than CODEX. }\end{array}$ & $\begin{array}{l}\text { No since the } \\
\text { study does not } \\
\text { focus on Africa, } \\
\text { no specific } \\
\text { results for Africa } \\
\text { reported }\end{array}$ \\
\hline $\begin{array}{l}\text { Udomkun } \\
\text { P, } 2017\end{array}$ & $\begin{array}{l}\text { Coulibaly, O. et al. } 2008 . \\
\text { Economic impact of aflatoxin } \\
\text { contamination in sub-Saharan } \\
\text { Africa. In Leslie, J. F., } \\
\text { Bandyopadhyay, R. and A. Visconti } \\
\text { (Eds.), Mycotoxins: Detection } \\
\text { methods, management, public } \\
\text { health and agricultural trade, } \\
\text { Chapter 7. Cambridge, USA: CABI. }\end{array}$ & $\begin{array}{l}\text { Chapter } 7 \text { discusses the } \\
\text { effect of EU/ international } \\
\text { aflatoxin regulation to } \\
\text { African farmers, as well as } \\
\text { the data required for } \\
\text { estimating economic impact } \\
\text { of aflatoxin, the challenge in } \\
\text { SSA including expertise and } \\
\text { lack of data, even for trade } \\
\text { data. }\end{array}$ & $\begin{array}{l}\text { No since the } \\
\text { methodology is } \\
\text { discussed but no } \\
\text { results are } \\
\text { reported for } \\
\text { Africa }\end{array}$ \\
\hline
\end{tabular}


One study discussed economic impact of aflatoxin in Africa was identified: Senerwa D, et al. 2016. Direct market costs of aflatoxins in Kenyan dairy value chain. Presentation for ANH Academy Week. 20-24 June 2016, Addis Ababa, Ethiopia.

This study estimating direct market loss from dairy value chain. Lack of elaboration on method and results, but indeed mentioned the estimated loss using annual feed and milk production, market cost of feed and milk, and proportion of samples exceeding Aflatoxins limits. No reference list, thus no snowballing.

\section{Hand search of international organizations or research institutes}

The first 100 studies were considered but most searches resulted in only a few studies to be checked for their relevance to the systemic literature review question on the economic impact of aflatoxin. Search terms: Africa, aflatoxin, (economic) impact (and also effect)

Table 34: Result for searching of international organisations

\begin{tabular}{|c|c|c|c|}
\hline $\begin{array}{l}\text { Institution } \\
\text { (webpage) }\end{array}$ & $\begin{array}{l}\text { Relevant studies } \\
\text { identified }\end{array}$ & Findings of the studies & $\begin{array}{l}\text { Included in } \\
\text { EPPI for } \\
\text { coding }\end{array}$ \\
\hline \multirow[t]{2}{*}{ IFPRI } & $\begin{array}{l}\text { Unnevehr, L. and D. } \\
\text { Grace. 2015. Aflatoxin } \\
\text { solutions for improved } \\
\text { food safety. IFPRI - Vision } \\
2020\end{array}$ & $\mathrm{n} / \mathrm{a}$ & $\begin{array}{l}\text { No since } \\
\text { literature } \\
\text { review, } \\
\text { already } \\
\text { identified in } \\
\text { the searches }\end{array}$ \\
\hline & $\begin{array}{l}\text { Florkowski, Wojciech J. \& } \\
\text { Kolavalli, Shashidhara, } \\
\text { 2014. "Strategies to } \\
\text { control aflatoxin in } \\
\text { groundnut value chains: ," } \\
\text { IFPRI discussion papers } \\
\text { 1369, International Food } \\
\text { Policy Research Institute } \\
\text { (IFPRI). }\end{array}$ & $\begin{array}{l}\text { The working paper examines } \\
\text { production and marketing } \\
\text { practices, particularly grading } \\
\text { methods, in Ghana's groundnut } \\
\text { value chain. All parts of the chain } \\
\text { are considered. Sources, levels of } \\
\text { aflatoxin contamination as well as } \\
\text { solutions to reduce contaminations } \\
\text { are elaborated. Costs are } \\
\text { mentioned in the narrative, but no } \\
\text { details and specific analysis on the } \\
\text { economic effects/costs is } \\
\text { conducted. }\end{array}$ & $\begin{array}{l}\text { No, reason: } \\
\text { insufficient } \\
\text { information }\end{array}$ \\
\hline World Bank* & $\begin{array}{l}\text { Diaz Rios, L. B. and S. } \\
\text { Jaffee. 2008. Barrier, } \\
\text { Catalyst or Distraction? } \\
\text { Standards, } \\
\text { Competitiveness and } \\
\text { Africa's Groundnut Exports } \\
\text { to Europe. Agriculture and } \\
\text { Rural Development } \\
\text { Discussion Paper } 39 . \\
\text { Washington, DC: World } \\
\text { Bank. }\end{array}$ & $\begin{array}{l}\text { See section } 2 \\
\text { Estimating the economic loss } \\
\text { resulting from EU regulation to } \\
\text { groundnut exporters worldwide, } \\
\text { using notification data from RASFF } \\
\text { over period 2000-2006. Also } \\
\text { discussed if the EU regulation } \\
\text { adopted CODEX (more lenient) } \\
\text { and its impact to the exporters. } \\
\text { Result: } 83 \% \text { of African exporters } \\
\text { were still incompliant. Thus, even } \\
\text { less restrictive standard might not } \\
\text { cause a better impact for the } \\
\text { trade as the contamination level is } \\
\text { relatively high. }\end{array}$ & $\begin{array}{l}\text { No, reason: } \\
\text { year of } \\
\text { publication }\end{array}$ \\
\hline
\end{tabular}




\begin{tabular}{|c|c|c|c|}
\hline $\begin{array}{l}\text { Institution } \\
\text { (webpage) }\end{array}$ & $\begin{array}{l}\text { Relevant studies } \\
\text { identified }\end{array}$ & Findings of the studies & $\begin{array}{l}\text { Included in } \\
\text { EPPI for } \\
\text { coding }\end{array}$ \\
\hline $\begin{array}{l}\text { ILRI } \\
\text { (www.ilri.org) }\end{array}$ & $\begin{array}{l}\text { Senerwa D. et al. } 2014 . \\
\text { Costs of aflatoxin in the } \\
\text { Kenyan dairy value chain. }\end{array}$ & $\begin{array}{l}\text { Presentations about the economic } \\
\text { effect of aflatoxin and milk in } \\
\text { Africa were found, not sufficient } \\
\text { information provided, see grey } \\
\text { literature }\end{array}$ & $\begin{array}{l}\text { Already } \\
\text { identified in } \\
\text { the other } \\
\text { searches } \\
\text { coded as grey } \\
\text { literature }\end{array}$ \\
\hline CTA & $\begin{array}{l}\text { Narayan, T., Belova, A. } \\
\text { and J. Haskell, } 2014 . \\
\text { "Aflatoxins: A Negative } \\
\text { Nexus between } \\
\text { Agriculture, Nutrition and } \\
\text { health," 2014 Annual } \\
\text { Meeting, July 27-29, 2014, } \\
\text { Minneapolis, Minnesota, } \\
\text { Agricultural and Applied } \\
\text { Economics Association. }\end{array}$ & $\begin{array}{l}\text { Estimating interrelated impact of } \\
\text { aflatoxin contamination in maize } \\
\text { and groundnut to public health, } \\
\text { trade, and agriculture in Nigeria } \\
\text { and Tanzania: Economic } \\
\text { estimation focused on health } \\
\text { impact that is aflatoxin-related } \\
\text { liver cancer. Monetary value of } \\
\text { liver cancer burden is estimated } \\
\text { by extrapolating value from US } \\
\text { with adjustment using transfer } \\
\text { approach. }\end{array}$ & $\begin{array}{l}\text { Yes } \\
\text { (conference } \\
\text { paper) }\end{array}$ \\
\hline \multirow[t]{3}{*}{ PACA } & $\begin{array}{l}\text { Ndenn, J., Papa Diedhiou, } \\
\text { Cabinet , A. Olusegun, } \\
\text { 2015: "The economic } \\
\text { impact of aflatoxins in } \\
\text { West Africa: the case of } \\
\text { Gambia, Nigeria and } \\
\text { Senegal". Presentation at } \\
\text { the PACA Groundnut } \\
\text { workshop. }\end{array}$ & $\begin{array}{l}\text { Presentation without presenting } \\
\text { details of the analysis. Results on } \\
\text { the effect presented: } \\
\text { The Gambia: Average price losses } \\
\text { per annum: US } \$ 1.5 \mathrm{M} \text { ( } 2000- \\
2014 \text { ), Average annual loss from } \\
\text { rejected exports: US } \$ 62,854 \\
\text { (2012-2015) } \\
\text { Nigeria: } 7,761 \text { cases of liver } \\
\text { cancer -> resulting in a total } \\
\text { burden of } 100,965 \text { DALYs; given } \\
\text { prevalence rate of } 20 \mu \text { g } / \mathrm{kg}, \text { the } \\
\text { monetised burden of aflatoxin } \\
\text { contamination was between } \$ 112 \\
\text { and } \$ 942 \text { million ( } 2010 \text { US } \\
\text { dollars), about } 0.5 \% \text { of GDP of } \\
\text { Nigeria } \\
\text { Senegal: DALY: } 98304 \\
\text { VSL (min) } 91,930,917 \$ \text { US } 2013 \text {, } \\
\text { VSL (max) } 161,426,809 \text { } \$ \text { US } 2013 \\
\text { Costs of aflatoxin contamination: } \\
46 \text { billion - } 81 \text { billion CFA } \\
\text { Costs of mitigation: to achieve } \\
\text { MRL of } 20 \mu \text { g } / \mathrm{kg} \text {, costs would } \\
\text { amount to } 21 \text { billion CFA }\end{array}$ & $\begin{array}{l}\text { No, reason: } \\
\text { insufficient } \\
\text { information }\end{array}$ \\
\hline & $\begin{array}{l}\text { Hell, K. 2015: Policy and } \\
\text { Regulations for Aflatoxin } \\
\text { Control in ECOWAS. }\end{array}$ & $\begin{array}{l}\text { Presentation without presenting } \\
\text { details of the analysis. }\end{array}$ & $\begin{array}{l}\text { No, reason: } \\
\text { insufficient } \\
\text { information }\end{array}$ \\
\hline & $\begin{array}{l}\text { Kimanya, M. et al. 2015: } \\
\text { Economic Impact of } \\
\text { Aflatoxins to Africa: The } \\
\text { case of Malawi, Tanzania } \\
\text { and Uganda. First Africa } \\
\text { Symposium of } \\
\text { Mycotoxicology, } 26 \text { May } \\
\text { 2015, Zambia. }\end{array}$ & $\begin{array}{l}\text { Presentation without presenting } \\
\text { details of the analysis } \\
\text { Malawi: neligible effect, no effect } \\
\text { presented } \\
\text { Tanzania: total economic loss due } \\
\text { to aflatoxin exposure has a } \\
\text { median of US } \$ 332,500,000 ; \\
\text { ranging }\end{array}$ & $\begin{array}{l}\text { No, reason: } \\
\text { insufficient } \\
\text { information }\end{array}$ \\
\hline
\end{tabular}




\begin{tabular}{|c|c|c|c|}
\hline $\begin{array}{l}\text { Institution } \\
\text { (webpage) }\end{array}$ & $\begin{array}{l}\text { Relevant studies } \\
\text { identified }\end{array}$ & Findings of the studies & $\begin{array}{l}\text { Included in } \\
\text { EPPI for } \\
\text { coding }\end{array}$ \\
\hline & & $\begin{array}{l}\text { between US } \$ 92,890,000 \text { and } \\
757,900,000 \\
\text { Uganda: results of a CGE model } \\
\text { are presented, simulation model. }\end{array}$ & \\
\hline & $\begin{array}{l}\text { Several Country } \\
\text { Assessment for Aflatoxin } \\
\text { Contamination and Control } \\
\text { in certain African countries }\end{array}$ & $\mathrm{n} / \mathrm{a}$ & $\begin{array}{l}\text { No, reason: } \\
\text { insufficient } \\
\text { information }\end{array}$ \\
\hline
\end{tabular}

Note: Searches of studies by FAO are included in the bibliographic searches of the library via AGRIS. $*$ in addition to the series of World Bank econonometic estimations presented in studies in the year 2001.

\section{Hand search of online search repository}

Search terms: Africa, aflatoxin, (economic) impact (and also effect)

Table 35: Results of online search repository

\begin{tabular}{|c|c|c|c|}
\hline Webpage & Relevant studies identified & Findings of the studies & $\begin{array}{l}\text { Included } \\
\text { in EPPI } \\
\text { for coding }\end{array}$ \\
\hline \multirow[t]{3}{*}{ REPEC } & $\begin{array}{l}\text { Narayan, T., Belova, A. and J. } \\
\text { Haskell, 2014. "Aflatoxins: A } \\
\text { Negative Nexus between } \\
\text { Agriculture, Nutrition and } \\
\text { health," 2014 Annual Meeting, } \\
\text { July 27-29, 2014, Minneapolis, } \\
\text { Minnesota, Agricultural and } \\
\text { Applied Economics Association. }\end{array}$ & See above & $\begin{array}{l}\text { Yes, } \\
\text { already } \\
\text { identified in } \\
\text { the } \\
\text { additional } \\
\text { searches }\end{array}$ \\
\hline & $\begin{array}{l}\text { Gebrehiwet, Y., Ngqangweni, S. } \\
\text { and J. F. Kirsten, } 2007 . \\
\text { "Quantifying the Trade Effect of } \\
\text { Sanitary and Phytosanitary } \\
\text { Regulations of OECD Countries on } \\
\text { South African Food Exports," } \\
\text { Agrekon, Agricultural Economics } \\
\text { Association of South Africa } \\
\text { (AEASA), vol. 46(1), March }\end{array}$ & $\mathrm{n} / \mathrm{a}$ & $\begin{array}{l}\text { No, reason: } \\
\text { year of } \\
\text { publication }\end{array}$ \\
\hline & $\begin{array}{l}\text { Florkowski, Wojciech J. \& } \\
\text { Kolavalli, Shashidhara, } 2014 . \\
\text { "Strategies to control aflatoxin in } \\
\text { groundnut value chains:," IFPRI } \\
\text { discussion papers 1369, } \\
\text { International Food Policy } \\
\text { Research Institute (IFPRI). }\end{array}$ & See above & $\begin{array}{l}\text { No, reason: } \\
\text { insufficient } \\
\text { information }\end{array}$ \\
\hline \multirow[t]{3}{*}{ AGECON } & $\begin{array}{l}\text { Munasib, Abdul B.A. \& Roy, } \\
\text { Devesh, 2011. Non Barriers as } \\
\text { Bridge to Cross. Agricultural \& } \\
\text { Applied Economics Association's } \\
2013 \text { AAEA \& CAES Joint Annual } \\
\text { Meeting Washington, DC, August } \\
\text { 4-6, } 2013 \text {. }\end{array}$ & $\begin{array}{l}\text { Assessed the effect of SPS } \\
\text { standards on trade export using a } \\
\text { new concept- bridge to cross- in } \\
\text { particular SPS regulation relating to } \\
\text { aflatoxins level in maize. African } \\
\text { exporters were main interest in this } \\
\text { study. }\end{array}$ & No \\
\hline & $\begin{array}{l}\text { Agyekum, Michael; Curtis M. } \\
\text { Jolly. } 2016 \text {. Peanut trade and } \\
\text { aflatoxin standards in } \\
\text { Europe: Economic effects on } \\
\text { trading countries. Journal of } \\
\text { Policy Modeling } 39 \text { (2017) 114- } \\
128 .\end{array}$ & $\begin{array}{l}\text { Assessed the effect of EU aflatoxin } \\
\text { standards to peanut exporting } \\
\text { countries: sample includes some } \\
\text { African countries as major peanut } \\
\text { exporters to EU; Egypt, South } \\
\text { Africa, Senegal, Sudan, Malawi, and } \\
\text { Gambia. }\end{array}$ & No \\
\hline & $\begin{array}{l}\text { Narayan, T., Belova, A. and J. } \\
\text { Haskell, 2014. "Aflatoxins: A } \\
\text { Negative Nexus between } \\
\text { Agriculture, Nutrition and } \\
\text { health," } 2014 \text { Annual Meeting, }\end{array}$ & See above & $\begin{array}{l}\text { Yes, } \\
\text { already } \\
\text { identified in } \\
\text { the }\end{array}$ \\
\hline
\end{tabular}




\begin{tabular}{|l|l|l|l|}
\hline Webpage & Relevant studies identified & Findings of the studies & $\begin{array}{l}\text { Included } \\
\text { in EPPI } \\
\text { for coding }\end{array}$ \\
\hline & $\begin{array}{l}\text { July 27-29, 2014, Minneapolis, } \\
\text { Minnesota, Agricultural and } \\
\text { Applied Economics Association. }\end{array}$ & $\begin{array}{l}\text { additional } \\
\text { searches }\end{array}$ \\
\hline $\begin{array}{l}\text { Gebrehiwet, Y., Ngqangweni, S. } \\
\text { and J. F. Kirsten, 2007. } \\
\text { "Quantifying the Trade Effect of } \\
\text { Sanitary and Phytosanitary } \\
\text { Regulations of OECD Countries on } \\
\text { South African Food Exports," } \\
\text { Agrekon, Agricultural Economics } \\
\text { Association of South Africa } \\
\text { (AEASA), vol. 46(1), March }\end{array}$ & See above & $\begin{array}{l}\text { No, reason: } \\
\text { year of } \\
\text { publication }\end{array}$ \\
\hline
\end{tabular}

Note: Other relevant repositories are covered in the bibliographic searches, see chapter 2.6.s 


\section{Annex 7 Data extraction (coding) questionnaire questions}

Both mapping questions on the nature of the publication as well as detailed extraction questions on the technical-scientific contents addressing the research question are to be answered. The second category of questions will inform the systematic review, providing not only data on design of the studies but also their outcomes.

\section{General extraction questions (for each of the four research questions)}

1. Type of publication (drop down list):
a. Article in a scientific journal
b. Professional journal article
c. Report
d. Book / book chapter
e. Website
f. Conference proceedings (book / chapter)
g. Dissertation, thesis
h. Guidelines, code of practice
i. Other

2. Which aflatoxins were studied? (multiple choices possible)
a. AFB1
b. $A F B 2$
c. AFG1
d. AFG2
e. AFM1
f. Other aflatoxins (please specify)
g. Aflatoxins, general (not further specified in record)
h. Not applicable (please specify)

Question 1: What is the scale and geographical spread of aflatoxin contamination in food, feed, and associated commodities/key value chains, in African countries?

Study objects and scope

1. Which details on geography of origin are provided?
a. Egypt
b. Kenya
c. Mali
d. Nigeria
e. Other (please specify)

2. Which part of the production chain is considered:
a. Crop in the field
b. Harvested / stored product (vegetable, animal)
c. Processing stage
d. Transport, handling, import/export/trade, border detention
e. Processed / retail / marketed product
f. Household (food) / animal farm (feed)
g. Other (please specify)

Products sampled and analysed (multiple answers possible) -

3. From which generic category were samples taken? a. Plants or plant parts (raw or stored commodity) 
b. Animal parts, tissues, fluids (raw, non-processed, and/or stored)

c. Foods and drinks for human consumption (semi-processed and processed)

d. Animal feeds

e. Others (please specify)

4. For plants as raw agricultural commodity

a. Cereals
i. Maize
ii. Barley
iii. Millet
iv. Rice
v. Sorghum
vi. Wheat
vii. Other (please specify)

b. Cocoa

c. Coconut

d. Coffee

e. Fruits
i. Bitter apple
ii. Mango
iii. Pomegranate
iv. Tomato
v. Other (please specify)

f. Legumes and oilseed
i. Beans
ii. Sesame \& sesame oil
iii. Soybean \& soybean oil
iv. Sunflower \& sunflower oil
v. Other (please specify)

g. Nuts

i. Peanut / groundnut

ii. Other (please specify)

h. Tuber crops
i. Cassava / manioc / tapioca
ii. Yam
iii. Other (please specify)

i. Spices
i. Anise
ii. Black pepper $\&$ hot chili pepper
iii. Cumin
iv. Ginger
v. Nutmeg
vi. Turmeric
vii. Walnut
viii. Other (please specify)

j. Others (please specify)

5. For Animal product (raw)
a. Milk
b. Meat
c. Fish
d. Other (please specify)

6. For Human foods
a. African dishes (please specify)
b. Beverages and drinks (e.g. beer, coffee) (please specify)
c. Fruits (fresh and processed, e.g. fruit juices)
d. Spices (e.g. pepper, nutmeg) (please specify)
e. Dairy
i. Milk
ii. Processed, e.g. cheese (please specify)

f. Meat
i. Meat 
ii. Processed / reconstituted, etc. (please specify)

g. Fish

i. Fish (whole, fillet)

ii. Processed (please specify)

h. Breakfast products (e.g. cornflakes, porridge) (please specify)

i. Snacks (e.g. biscuits, chips, chocolate) (please specify)

j. Soups

k. Other (please specify)

7. For Animal feeds (please specify)

\section{Methods \& results}

8. Which methods were used for the analysis ?
a. Immunochemistry (ELISA, dip stickdip stick tests, sensor)
b. TLC : Thin-layer chromatography
c. LC : Liquid chromatography (HPLC) with fluorescence detection or post-column derivatization
d. LC-MS : Liquid chromatography coupled to mass-spectrometric detection, such as LC-MS/MS
e. Other (please specify)

9. What was the nature (qualitative / quantitative) of the outcomes? (multiple options possible)
a. Qualitative (yes/no for incidence of aflatoxins based on, for example, fluorescence or qualitative test)
b. Quantitative (for example, levels of aflatoxins measured using laboratory assays such as HPLC)
c. Not applicable / other (please specify)

Quality appraisal

1. Sampling: Which conditions apply?
a. Clear, general details of the sampling provided (for example: which materials were sampled, how were samples taken, size and number of samples)
b. Both sample size / number and total volume of the sampled consignment / population are given
c. Storage conditions after sampling was preventive of artificial mycotoxin formation (e.g. refrigeration)
d. Other (please specify)

2. Analytical method: Which conditions apply?
a. Clear details of the analytical method are provided
If so:
i.An appropriate analytical method has been used (for example validated, official)
ii.Calibration of the method has been done

3. Presentation of results: How are results presented?

a. Quantitative data are reported (for example, as range, average, median, variance)

b. Extractable quantitative data are provided (such as a supplementary spreadsheet)

\section{Question 2: What is the scale of aflatoxin disease burden for African countries?}

Study objects and scope

1. Which populations were studied? (multiple choices possible)
a. General (human)
b. Infants \& children (human)
c. Adults (human)
d. Production animals (human)
e. Other specific subpopulations (please specify) (for example, based on socio-economic status)

2. Which details on geography of the population are provided?
a. Egypt
b. Kenya
c. Mali
d. Nigeria 
3. Which route of exposure to aflatoxins was considered (multiple answers possible):
a. Not specified
b. Plant foods (e.g. peanut, cereals)
c. Dairy (e.g. milk)
d. Breast milk
e. Other (please specify)

4. Which disease symptom is investigated?
a. Hepatocellular carcinoma
b. Growth impairment / stunting
c. Liver/spleen enlargement
d. Acute aflatoxicosis
e. Death
f. Compromised immunological defence
g. Decreased productivity / performance (livestock)
h. Other (please specify)

\section{Methods \& results}

5. How was exposure to aflatoxin estimated?
a. Not applicable (no estimate of exposure)
b. Biomarkers (e.g. aflatoxin metabolites in serum, urine; haemoglobin adduct)
c. Consumption data for aflatoxin-contaminated foods
d. Others (please specify)

6. What outcomes are used for disease occurrence?
a. Not applicable
b. Epidemiology (incidence/prevalence)
c. Physical (body height, weight)
d. Clinical (liver / spleen size)
e. Other (please specify)

7. Are the following parameters provided (for DALY calculation): (please mark the text)
a. Incidence of aflatoxin-related mortality within a given population for a given period [for YLL]
b. Incidence (per year) and time span of aflatoxin-induced illness within a given population [for YLD]
c. YLL related to aflatoxin
d. YLD related to aflatoxin
e. DALY related to aflatoxin

8. Are the following parameters provided (for QALY calculation): (please mark the text)
a. Health utility index (HUI) scores related to aflatoxin exposure and/or mitigating measures?
b. Duration in certain health states
c. QALYs related to aflatoxin

\section{Quality appraisal}

1. Selection of populations:
a. A rationale for the selection of the population (e.g. high-risk, history of disease incidence) is provided
b. Other (please specify)

2. Disease prevalence/incidence (multiple choices possible):

a. The disease is clearly linked to aflatoxin exposure (e.g. correlation with biomarkers or with consumption of aflatoxin-contaminated foods)

b. The disease occurrence has truly been measured (rather than being estimated)

c. Other possible causes (e.g. malaria) or interacting factors (e.g. hepatitis) have been taken into account

d. Other (please specify)

3. Disease burden

a. The impact of disease is expressed quantitatively beyond prevalence/incidence alone as DALYS/QALYS, VSLs, etcetera 
b. Other (please specify)

4. Presentation of results: How are results presented?

a. Quantitative data are reported (for example, as range, average, median, variance)

b. Extractable quantitative data are provided (such as a supplementary spreadsheet)

\section{Question 3: What is the economic impact of aflatoxins to African countries?}

1. Which details on geography of the population are provided?
a. Egypt
b. Kenya
c. Mali
d. Nigeria
e. Other (please specify)

2. What economic impact is analysed?
a. Trade-related impact (studies of trade effect)
b. Firm level impact
c. Health effect

3. Info about trade-related effects

a. Effect- please tick and provide with the text (coding the text)
i. Exports reduced due to domestic measures, contamination
ii. Export reduced due to MRLs of other in developing countries (importing countries)
iii. Export reduced due to MRLs of other in developing countries (importing countries)
iv. Exports loss due to detection of aflatoxin at the border
v. Other, please specify

b. Method
i. Econometric estimation
ii. Simulation model
iii. Combined econometric and simulation
iv. Quantitative - questionnaire e.g.
v. Other, please specify

4. Info about the impact at the firm level, domestic production-level (studies of farm economics, business and technologies)

c. Effect- please tick and provide with the text (coding the text)
i. Loss of crops to be sold in the domestic market
ii. Costs of managing aflatoxin at the farm level - compliance costs
iii. Productivity losses
iv. Other, please specify

d. Method- please tick and provide with the text (coding the text)
i. Econometric estimation
ii. Simulation model
iii. Combined econometric and simulation
iv. Quantitative - questionnaire e.g.
v. Other, please specify

5. Info about Health impact (studies of health economics)

e. Effect - please tick and provide with the text (coding the text)
i. Health cost in terms of treatment
ii. Productivity losses, reduced contribution of ill people, household income
iii. Death
iv. Other, please specify

f. Method- please tick and provide with the text

i. VSL calculation: (please mark the text)

1) Willingness to pay for reduced death risk caused by aflatoxin exposure

2) Reduction in mortality risk related to aflatoxin exposure

3) Number of population

4) VSL based on WTP for reduced risk of death due to aflatoxin 
ii. Cost of Illness calculation: (please mark the text)

5) Number of aflatoxin-related illnesses for which medical service support is provided (annual); number of medical services per case; cost per medical service (for Direct Medical Cost calculation)

6) Number of aflatoxin-related illnesses for which non-medical service was provided/ used (annual) for example transportation cost to hospital/ doctor; number of non-medical services per case; cost per non-medical service (for Direct Non-Medical Cost calculation)

7) Number of sickness leave; duration of sickness leave; wage cost per day (for Indirect Non-medical cost calculation)

8) Cost of Illness for aflatoxin-related illness

iii. Other, please specify

6. What are the benefits of aflatoxin management - please mark in the text.

Quality appraisal

1. The study focuses on agricultural commodities, food and feed products for which aflatoxins are known to be problematic

2. The outcomes are representative of or can be extrapolated to a sufficiently large scale within Africa (national, regional, continental)

3. A clearly described conceptual framework is part of the study

4. An adequate sampling strategy for collection of data/feedback was followed

5. Sufficient details are provided on the model used for estimating impacts

6. The assumptions underlying the estimates are well described

7. An appropriate comparison was made to estimate losses or costs foregone

8. A suitable model was used for estimation of the impact

9. Possible confounding factors are taken into account

10.The statistics used were appropriate and robust

11. The presentation of results was sufficiently comprehensive, at least comprising absolute quantitative monetary terms on impacts (in common currencies, e.g. USD)

Question 4: What are the existing and possible mitigation measures and what is the costeffectiveness of mitigation of aflatoxin contamination in key commodities / value chains in African countries?

Study objects and scope

1. Economic operators' characteristics

a. Small, local: Smallholder farms, village processing, local middlemen and vendors, etc.

b. Large-scale, industrial

c. Other (please specify)

2. At which production stage was mitigation applied? (multiple choices possible)

a. Agricultural production (e.g. resistant crop varieties, pre-harvest crop production, on-farm animal husbandry)

b. Post-harvest storage

c. Logistics/transport

d. Food and feed processing

e. Consumption and diet (e.g. raising consumers' awareness of toxicity of mold-infected foods; mitigation of aflatoxin bioavailability through enterosorption)

f. Clinical (e.g. immunization against aflatoxins in livestock and vaccination against hepatitis acting synergistically with aflatoxins in humans)

g. Retailers

h. Other (please specify)

3. What kind of mitigation measure is described? (multiple choices possible)
a. Cultural practice (e.g. crop rotation, irrigation, tillage, dry storage)
b. Biological (e.g. antagonistic non-toxigenic moulds; resistant crop varieties)
c. Chemical (e.g. aflatoxin binders, aflatoxin-toxicity-mitigating food compounds)
d. Vaccination (to prevent aflatoxin-related affections in humans and animals)
e. Governance, regulation, legislation, private standards
f. Creating awareness, education 


\section{g. Other (please specify)}

4. Which details on geography of the affected product/consumers/actors are provided?
a. Egypt
b. Kenya
c. Mali
d. Nigeria
e. Other (please specify)

5. Which types of outcomes were used to measure the impact of mitigation? (multiple answers possible):
a. Aflatoxin production (by isolated fungi)
b. Aflatoxin contamination
c. Aflatoxin bioavailability, level of biomarkers in e.g. sera, urine
d. Stunting, undernutrition, disease, mortality
e. Export rejections, threshold exceeded
f. Income losses?
g. Other (please specify)

Methods \& results

6. How are mitigation impacts described (only for cost-effectiveness)?
a. Monetary
b. DALYs/QALYs
c. VSL
d. Other non-monetary (e.g. multi-criteria sorting)
e. Other (please specify)

7. What baseline / comparator was used to analyse the effect of the mitigation measure?
a. Sequential: change from previous situation in same population
b. Parallel: Non-treated control samples / populations
c. Other (please specify)

8. How are costs / inputs described (only for cost-effectiveness)?
a. Monetary
b. Non-monetary (e.g. multi-criteria sorting)
c. Other (please specify)

9. How is cost effectiveness described?
a. Cost per intervention
b. DALY saved/ QALY gained
c. Cost per DALY saved/QALY gained
d. Others (please specify)

\section{Quality appraisal}

1. The study focuses on agricultural commodities, food and feed products for which aflatoxins are known to be problematic, or on human or animal health problems to which aflatoxins are known to substantially contribute

2. The proposed mitigating measures are relevant to or have already been tested under African conditions

3. Appropriate input data, methods and comparisons were used to establish effectiveness of the mitigating measures in terms of reduction of aflatoxin contamination and/or related impacts on economy and/or health

4. Results are presented in absolute, quantitative terms

5. Cost effectiveness is expressed as investment per benefit gained (e.g. USD/DALY)

6. The presentation of results was sufficiently comprehensive

7. Other observations 
1. Which details on geography of the population are provided?
a) Egypt
b) Kenya
c) Mali
d) Nigeria
e) Other (please specify)

2. Which populations were studied? (multiple choices possible)
a) General (human)
b) Infants \& children (human)
c) Adults (human)
d) Production animals (human)
e) Other specific subpopulations (please specify) (for example, based on socio-economic status)

3. Which route of exposure to aflatoxins was considered (multiple answers possible):
a) Plant foods (e.g. peanut, cereals)
b) Dairy (e.g. milk)
c) Breast milk
d) Not specified
e) Other (please specify)

4. How was the biomarker estimated?
a) Urinary
b) Serum (e.g. Albumin-adduct)
c) Others (please specify)

5. Which methods were used for the analysis?
a) Immunochemistry (ELISA, dip stickdip stick tests, sensor)
b) TLC: Thin-layer chromatography
c) LC : Liquid chromatography (HPLC) with fluorescence detection or post-column derivatization
d) LC-MS : Liquid chromatography coupled to mass-spectrometric detection, such as LC-MS/MS
e) Other (please specify)

6. What was the nature (qualitative / quantitative) of the outcomes? (multiple options possible) (please mark the text)
a) Qualitative (yes/no for aflatoxin metabolites detected in serum/ urine)
b) Quantitative (for example, levels of aflatoxin- metabolites in serum)
c) Not applicable / other (please specify)

Quality appraisal

1. Selection of populations:
a) A rationale for the selection of the population (e.g. high-risk, history of disease incidence) is provided
b) Other (please specify)

2. Analytical method: Which conditions apply?
a) Clear details of the analytical method are provided
If so:
I. An appropriate analytical method has been used (for example validated, official)
II. Calibration of the method has been done
a) Other (please specify)

3. Presentation of results: How are results presented?

a) Quantitative data are reported (for example, as range, average, median, variance)

b) Extractable quantitative data are provided (such as a supplementary spreadsheet) 


\section{Annex 8 List of publications of which the full text could not be located}

\begin{tabular}{|c|c|c|}
\hline Authors & Title & Year \\
\hline Abeer H ; Abd-Allah E F; & $\begin{array}{l}\text { Natural occurrence of aflatoxin M1 in Egyptian } \\
\text { milk and cheese }\end{array}$ & 2013 \\
\hline Alhanshoul A M; & $\begin{array}{l}\text { Associated fungi within maize kernels and their } \\
\text { control }\end{array}$ & 2011 \\
\hline $\begin{array}{l}\text { Amare Ayalew ; Kimanya M ; } \\
\text { Matumba L ; Bandyopadhayay R ; } \\
\text { Menkir A ; Cotty P ; }\end{array}$ & $\begin{array}{l}\text { Controlling aflatoxins in maize in Africa: } \\
\text { strategies, challenges and opportunities for } \\
\text { improvement. (Burleigh Dodds Series in } \\
\text { Agricultural Science Number 02) }\end{array}$ & 2017 \\
\hline Anwar W A; & $\begin{array}{l}\text { Hepatocellular carinoma in Africa with special } \\
\text { overview in Egypt }\end{array}$ & 2012 \\
\hline Averkieva $\mathrm{O}$; Abdellatif $\mathrm{H}$; & $\begin{array}{l}\text { Mycotoxin contamination of feed grade maize } \\
\text { imported to MENA region in } 2009-2010\end{array}$ & 2011 \\
\hline $\begin{array}{l}\text { Egbontan A O; Afolabi C G; Kehinde I } \\
\text { A; Enikuomehin O A; Ezekiel C N; } \\
\text { Sulyok M ; Warth B ; Krska R ; }\end{array}$ & $\begin{array}{l}\text { A mini-survey of moulds and mycotoxins in } \\
\text { locally grown and imported wheat grains in } \\
\text { Nigeria }\end{array}$ & 2017 \\
\hline $\begin{array}{l}\text { El-Sideek L E; Zaied S A. F; } \\
\text { Alkhalifah D H. M; }\end{array}$ & $\begin{array}{l}\text { Comparing effects of gamma irradiation on } \\
\text { microbiological analysis, aflatoxin, and } \\
\text { antioxidants of some Egyptian and Saudi Arabian } \\
\text { date palm varieties. (Phonex dactiliferal L.) }\end{array}$ & 2014 \\
\hline El-Tabiy A A. H; Hassan H M; & $\begin{array}{l}\text { Determination of aflatoxin } \mathrm{M}<\mathrm{sub}>1</ \text { sub }> \\
\text { levels in bovine farmed milk with special } \\
\text { reference to the levels of aflatoxin } \\
\mathrm{B}<\text { sub }>1</ \text { sub }>\text { in the animal feed }\end{array}$ & 2011 \\
\hline $\begin{array}{l}\text { Eltahan F H; Shetaia Y M; Elaziz M F. } \\
\text { A; }\end{array}$ & $\begin{array}{l}\text { Fungal profile of some selected Egyptian } \\
\text { medicinal plants and spices and estimation of } \\
\text { mycotoxin production }\end{array}$ & 2012 \\
\hline Filbert M E; Brown D L; & $\begin{array}{l}\text { Aflatoxin Contamination in Haitian and Kenyan } \\
\text { Peanut Butter and Two Solutions for Reducing } \\
\text { Such Contamination }\end{array}$ & 2012 \\
\hline $\begin{array}{l}\text { International Livestock Research; } \\
\text { Institute ; }\end{array}$ & $\begin{array}{l}\text { Fighting aflatoxins: Reducing risks in Kenya's } \\
\text { food chains }\end{array}$ & 2014 \\
\hline Kaaya A N; Eboku D ; & $\begin{array}{l}\text { Mould and aflatoxin contamination of dried } \\
\text { cassava chips in Eastern Uganda: association } \\
\text { with traditional processing and storage practices }\end{array}$ & 2010 \\
\hline $\begin{array}{l}\text { Kheseli P O; Ochanda J O; Okoth S } \\
\text { A; }\end{array}$ & $\begin{array}{l}\text { Evaluation of potency of native Bacillus } \\
\text { thuringiensis against maize insect pests and } \\
\text { aflatoxin producing fungi in Kenya }\end{array}$ & 2011 \\
\hline $\begin{array}{l}\text { Lee S M; Lee S H. R. D. A. Suwon } \\
\text { Republic of korea; Sserumaga J P; } \\
\text { Hwang N R; Park S Y; Yeo Y S; Kim H } \\
\text { J; Cho H S; }\end{array}$ & $\begin{array}{l}\text { Survey for Contamination of Aflatoxin in Uganda } \\
\text { Maize }\end{array}$ & 2013 \\
\hline $\begin{array}{l}\text { Malusha J ; Karama M ; Makokha A } \\
\text { N; }\end{array}$ & $\begin{array}{l}\text { Comparative analysis of aflatoxin contamination } \\
\text { of maize in two different physiographic zones } \\
\text { and maize seasons in Makueni County, Kenya }\end{array}$ & 2015 \\
\hline $\begin{array}{l}\text { Malusha J M; Karama M ; Makokha A } \\
\text {; }\end{array}$ & $\begin{array}{l}\text { The influence of household socio-economic } \\
\text { characteristics and awareness on aflatoxin } \\
\text { contamination of maize in Makueni County, } \\
\text { Kenya }\end{array}$ & 2015 \\
\hline
\end{tabular}




\begin{tabular}{|l|l|c|}
\hline Authors & Title & Year \\
\hline Mgbeahuruike A C; & $\begin{array}{l}\text { Aflatoxin contamination of poultry feeds in } \\
\text { Nigerian feed mills and the effect on the } \\
\text { performance of Abor Acre broilers }\end{array}$ & 2016 \\
\hline $\begin{array}{l}\text { Mohamed W G. M; Zayed M A. A; Abd } \\
\text { El-Kader ; D A ; }\end{array}$ & $\begin{array}{l}\text { Peanut pod and seed rots caused by Aspergillus } \\
\text { spp and their control }\end{array}$ & 2012 \\
\hline Rios C; & $\begin{array}{l}\text { Mycotoxins: Occurrence, toxicology and } \\
\text { management strategies }\end{array}$ & 2015 \\
\hline $\begin{array}{l}\text { Saad-Hussein A ; Elserougy S ; } \\
\text { Beshir S ; Ibrahim M I. M; Awad A H; } \\
\text { Abdel-Wahhab M A; }\end{array}$ & $\begin{array}{l}\text { Work - related airborne fungi and the biological } \\
\text { levels of mycotoxin in textile workers }\end{array}$ & 2012 \\
\hline Shabana E S. E; Hanaa S M; & $\begin{array}{l}\text { Mycological aspects of ostrich meat products } \\
\text { with special reference to toxigenic moulds }\end{array}$ & 2010 \\
\hline Shehata S A; Mohamed S M; & $\begin{array}{l}\text { Infeluence of synthetic 4-methyl-7 hydroxy } \\
\text { coumarin on minimizing the toxicity of aflatoxin } \\
\text { B<sub>1</sub> in Nile tilapia fish diets }\end{array}$ & 2012 \\
\hline Sirma A J; & $\begin{array}{l}\text { Risk assessment of aflatoxins in the Kenyan } \\
\text { dairy value chain }\end{array}$ & 2013 \\
\hline & Special issue & 2013 \\
\hline
\end{tabular}




\section{Annex 9 Distribution of publications per country, per research question}

\begin{tabular}{|c|c|c|c|c|}
\hline Country name & $\begin{array}{l}\text { Q1: } \\
\text { Contamination }\end{array}$ & $\begin{array}{l}\text { Q2: Disease } \\
\text { burden }\end{array}$ & $\begin{array}{l}\text { Q3: Economic } \\
\text { impact }\end{array}$ & Q4: Mitigation \\
\hline Algeria & 5 & 0 & 0 & 1 \\
\hline Angola & 0 & 0 & 0 & 0 \\
\hline Benin & 9 & 0 & 1 & 2 \\
\hline Botswana & 0 & 0 & 0 & 0 \\
\hline Burkina Faso & 3 & 0 & 0 & 1 \\
\hline Burundi & 0 & 0 & 0 & 0 \\
\hline Cabo Verde & 0 & 0 & 0 & 0 \\
\hline Cameroon & 6 & 4 & 0 & 0 \\
\hline $\begin{array}{l}\text { Central African } \\
\text { Republic (CAR) }\end{array}$ & 0 & 0 & 0 & 0 \\
\hline Chad & 0 & 0 & 0 & 0 \\
\hline Comoros & 0 & 0 & 0 & 0 \\
\hline $\begin{array}{l}\text { Democratic } \\
\text { Republic of Congo }\end{array}$ & 4 & 0 & 0 & 0 \\
\hline $\begin{array}{l}\text { Republic of } \\
\text { the Congo }\end{array}$ & 0 & 0 & 0 & 0 \\
\hline Cote d'Ivoire & 0 & 0 & 0 & 0 \\
\hline Djibouti & 0 & 0 & 0 & 0 \\
\hline Egypt & 41 & 8 & 1 & 8 \\
\hline Equatorial Guinea & 0 & 0 & 0 & 0 \\
\hline Eritrea & 0 & 0 & 0 & 0 \\
\hline Ethiopia & 10 & 0 & 0 & 1 \\
\hline Gabon & 0 & 0 & 0 & 0 \\
\hline Gambia & 0 & 2 & 0 & 0 \\
\hline Ghana & 12 & 5 & 0 & 4 \\
\hline Guinea & 0 & 1 & 0 & 0 \\
\hline Guinea-Bissau & 0 & 0 & 0 & 0 \\
\hline Kenya & 33 & 4 & 4 & 15 \\
\hline Lesotho & 0 & 0 & 0 & 0 \\
\hline Liberia & 0 & 0 & 0 & 0 \\
\hline Libya & 2 & 0 & 0 & 0 \\
\hline Madagascar & 0 & 0 & 0 & 0 \\
\hline Malawi & 10 & 1 & 2 & 3 \\
\hline Mali & 1 & 1 & 0 & 0 \\
\hline Mauritania & 0 & 0 & 0 & 0 \\
\hline Mauritius & 0 & 0 & 0 & 0 \\
\hline Morocco & 4 & 0 & 0 & 0 \\
\hline Mozambique & 2 & 0 & 0 & 0 \\
\hline Namibia & 0 & 0 & 0 & 0 \\
\hline Niger & 1 & 0 & 0 & 0 \\
\hline Nigeria & 56 & 6 & 2 a & 9 \\
\hline Rwanda & 5 & 0 & 0 & 0 \\
\hline $\begin{array}{l}\text { Sao Tome and } \\
\text { Principe }\end{array}$ & 0 & 0 & 0 & 0 \\
\hline Senegal & 2 & 0 & 0 & 0 \\
\hline
\end{tabular}




\begin{tabular}{|l|c|c|c|c|}
\hline Country name & $\begin{array}{l}\text { Q1: } \\
\text { Contamination }\end{array}$ & $\begin{array}{l}\text { Q2: Disease } \\
\text { burden }\end{array}$ & $\begin{array}{l}\text { Q3: Economic } \\
\text { impact }\end{array}$ & Q4: Mitigation \\
\hline Seychelles & 0 & 0 & 0 & 0 \\
\hline Sierra Leone & 0 & 0 & 0 & 0 \\
\hline Somalia & 0 & 0 & 0 & 0 \\
\hline South Africa & 15 & 0 & 0 & 2 \\
\hline South Sudan & 0 & 0 & 0 & 0 \\
\hline Sudan & 14 & 0 & 0 & 0 \\
\hline Swaziland & 0 & 0 & 0 & 0 \\
\hline Tanzania & 26 & 8 & $1^{\text {a }}$ & 0 \\
\hline Togo & 2 & 0 & 0 & 0 \\
\hline Tunisia & 6 & 0 & 0 & 2 \\
\hline Uganda & 3 & 1 & 0 & 0 \\
\hline Zambia & 5 & 0 & 0 & 0 \\
\hline Zimbabwe & 6 & 1 & 0 & 0 \\
\hline
\end{tabular}

a Additional study by Narayan et al. (2014)

One study by Havelaar et al. (2015)estimated disease burden in African regions based on mortality, i.e. AFR D and AFR E. All listed countries are included in the table. 


\section{Annex 10 Geographical spread of coded studies for contamination levels}

Table 36: Number of studies per country for type of aflatoxin for Q1: Contamination levels

\begin{tabular}{|l|c|c|c|c|c|c|c|}
\hline \multicolumn{1}{|c|}{$\begin{array}{c}\text { Country } \\
\text { name }\end{array}$} & a. AFB1 & b. AFB2 & C. AFG1 & d. AFG2 & e. AFM1 & $\begin{array}{c}\text { f. Other } \\
\text { aflatoxins }\end{array}$ & $\begin{array}{c}\text { g. } \\
\text { Aflatoxins, } \\
\text { general }\end{array}$ \\
\hline Algeria & 3 & 2 & 2 & 2 & 2 & 0 & 0 \\
\hline Benin & 7 & 5 & 5 & 5 & 0 & 0 & 2 \\
\hline Burkina Faso & 2 & 0 & 0 & 0 & 0 & 0 & 1 \\
\hline Cameroon & 5 & 3 & 2 & 2 & 0 & 0 & 1 \\
\hline Democratic & 3 & 2 & 2 & 2 & 0 & 0 & 1 \\
Republic of & & & & & & & \\
Congo & & & & & & & \\
\hline Egypt & 24 & 18 & 17 & 14 & 13 & 1 & 4 \\
\hline Ethiopia & 7 & 4 & 3 & 3 & 3 & 0 & 2 \\
\hline Ghana & 7 & 7 & 7 & 7 & 0 & 0 & 4 \\
\hline Kenya & 15 & 7 & 7 & 6 & 7 & 0 & 17 \\
\hline Libya & 2 & 2 & 2 & 2 & 0 & 0 & 0 \\
\hline Malawi & 5 & 3 & 3 & 3 & 1 & 0 & 5 \\
\hline Mali & 1 & 0 & 0 & 0 & 0 & 0 & 0 \\
\hline Morocco & 3 & 2 & 2 & 2 & 1 & 0 & 0 \\
\hline Mozambique & 2 & 1 & 1 & 1 & 1 & 0 & 0 \\
\hline Niger & 0 & 0 & 0 & 0 & 0 & 0 & 1 \\
\hline Nigeria & 36 & 26 & 27 & 24 & 12 & 3 & 18 \\
\hline Rwanda & 5 & 4 & 4 & 4 & 1 & 0 & 0 \\
\hline Senegal & 0 & 0 & 0 & 0 & 0 & 0 & 1 \\
\hline South Africa & 10 & 8 & 5 & 5 & 4 & 0 & 1 \\
\hline Sudan & 9 & 7 & 7 & 7 & 4 & 0 & 0 \\
\hline Tanzania & 16 & 8 & 8 & 8 & 4 & 0 & 7 \\
\hline Togo & 1 & 1 & 1 & 1 & 0 & 0 & 1 \\
\hline Tunisia & 6 & 5 & 5 & 4 & 1 & 0 & 0 \\
\hline Uganda & 1 & 1 & 1 & 1 & 0 & 0 & 0 \\
\hline Zambia & 3 & 0 & 0 & 0 & 0 & 0 & 2 \\
\hline Zimbabwe & 6 & 3 & 4 & 4 & 0 & 0 & 0 \\
\hline & & & & & & & \\
\hline
\end{tabular}


Table 37: Number of studies per country for part of the production chain Q1:

Contamination levels

\begin{tabular}{|l|c|c|c|c|c|c|c|}
\hline \multicolumn{1}{|c|}{$\begin{array}{c}\text { Country } \\
\text { name }\end{array}$} & $\begin{array}{c}\text { i. } \\
\text { Crop } \\
\text { in } \\
\text { the } \\
\text { field }\end{array}$ & $\begin{array}{c}\text { ii. } \\
\text { Harvested/ } \\
\text { stored } \\
\text { products }\end{array}$ & $\begin{array}{c}\text { iii. } \\
\text { Processing }\end{array}$ & $\begin{array}{c}\text { iv. } \\
\text { Transport, } \\
\text { handling, } \\
\text { import }\end{array}$ & $\begin{array}{c}\text { v. } \\
\text { Processed } \\
\text { /retail / } \\
\text { marketed } \\
\text { product }\end{array}$ & $\begin{array}{c}\text { vi. } \\
\text { household } \\
\text { (Food) / } \\
\text { animal } \\
\text { farm } \\
\text { (feed) }\end{array}$ & $\begin{array}{c}\text { other } \\
\text { Orii. }\end{array}$ \\
\hline Algeria & 0 & 1 & 2 & 0 & 3 & 1 & 0 \\
\hline Benin & 0 & 2 & 0 & 0 & 6 & 1 & 0 \\
\hline Burkina Faso & 0 & 0 & 1 & 0 & 2 & 0 & 0 \\
\hline Cameroon & 0 & 1 & 0 & 0 & 3 & 3 & 0 \\
\hline Democratic & 1 & 1 & 0 & 1 & 4 & 0 & 0 \\
\hline Republic of & & & & & & & \\
\hline Congo & & & & & & & \\
\hline Egypt & 2 & 4 & 1 & 0 & 31 & 7 & 2 \\
\hline Ethiopia & 0 & 9 & 2 & 0 & 4 & 0 & 0 \\
\hline Ghana & 1 & 3 & 2 & 1 & 8 & 2 & 0 \\
\hline Kenya & 1 & 11 & 11 & 2 & 16 & 13 & 1 \\
\hline Libya & 0 & 1 & 0 & 0 & 1 & 0 & 0 \\
\hline Malawi & 0 & 4 & 1 & 1 & 5 & 4 & 0 \\
\hline Mali & 0 & 1 & 0 & 0 & 0 & 0 & 0 \\
\hline Morocco & 0 & 1 & 0 & 0 & 3 & 0 & 0 \\
\hline Mozambique & 0 & 0 & 1 & 0 & 1 & 0 & 0 \\
\hline Niger & 0 & 0 & 0 & 0 & 1 & 0 & 0 \\
\hline Nigeria & 1 & 10 & 2 & 0 & 41 & 6 & 1 \\
\hline Rwanda & 0 & 0 & 0 & 0 & 4 & 2 & 0 \\
\hline Senegal & 0 & 2 & 0 & 0 & 0 & 0 & 0 \\
\hline South Africa & 0 & 5 & 3 & 1 & 3 & 8 & 0 \\
\hline Sudan & 0 & 3 & 4 & 0 & 4 & 4 & 2 \\
\hline Tanzania & 2 & 9 & 3 & 2 & 5 & 11 & 1 \\
\hline Togo & 0 & 0 & 0 & 0 & 2 & 0 & 0 \\
\hline Tunisia & 0 & 1 & 0 & 0 & 4 & 1 & 0 \\
\hline Uganda & 0 & 0 & 0 & 0 & 1 & 1 & 0 \\
\hline Zambia & 0 & 1 & 0 & 0 & 4 & 0 & 0 \\
\hline Zimbabwe & 1 & 2 & 0 & 0 & 1 & 2 & 0 \\
\hline & & & & & & & \\
\hline
\end{tabular}


Table 38: Number of studies per country for generic category of products for Q1: Contamination levels

\begin{tabular}{|c|c|c|c|c|c|}
\hline Country name & $\begin{array}{l}\text { i. plant or } \\
\text { plant parts }\end{array}$ & $\begin{array}{l}\text { ii. Animal } \\
\text { parts, } \\
\text { tissues, } \\
\text { fluids }\end{array}$ & $\begin{array}{l}\text { iii. Foods and } \\
\text { drinks for } \\
\text { human } \\
\text { consumption }\end{array}$ & $\begin{array}{l}\text { iv. Animal } \\
\text { feeds }\end{array}$ & v. Others \\
\hline Algeria & 2 & 1 & 3 & 1 & 0 \\
\hline Benin & 5 & 0 & 5 & 0 & 0 \\
\hline Burkina Faso & 2 & 0 & 2 & 0 & 0 \\
\hline Cameroon & 3 & 0 & 4 & 1 & 0 \\
\hline $\begin{array}{l}\text { Democratic } \\
\text { Republic of } \\
\text { Congo }\end{array}$ & 4 & 0 & 0 & 0 & 0 \\
\hline Egypt & 12 & 9 & 22 & 3 & 2 \\
\hline Ethiopia & 7 & 3 & 1 & 2 & 0 \\
\hline Ghana & 6 & 0 & 6 & 1 & 0 \\
\hline Kenya & 20 & 7 & 10 & 6 & 1 \\
\hline Libya & 0 & 1 & 1 & 0 & 0 \\
\hline Malawi & 8 & 0 & 4 & 0 & 0 \\
\hline Mali & 1 & 0 & 0 & 0 & 0 \\
\hline Morocco & 1 & 1 & 3 & 0 & 0 \\
\hline Mozambique & 1 & 1 & 1 & 1 & 0 \\
\hline Niger & 1 & 0 & 0 & 0 & 0 \\
\hline Nigeria & 23 & 4 & 30 & 7 & 1 \\
\hline Rwanda & 1 & 0 & 3 & 2 & 0 \\
\hline Senegal & 2 & 0 & 0 & 0 & 0 \\
\hline South Africa & 4 & 4 & 2 & 7 & 0 \\
\hline Sudan & 4 & 3 & 6 & 4 & 1 \\
\hline Tanzania & 11 & 1 & 9 & 5 & 2 \\
\hline Togo & 1 & 0 & 1 & 0 & 0 \\
\hline Tunisia & 5 & 1 & 3 & 1 & 0 \\
\hline Uganda & 1 & 0 & 1 & 1 & 0 \\
\hline Zambia & 3 & 0 & 1 & 0 & 0 \\
\hline Zimbabwe & 5 & 1 & 1 & 0 & 0 \\
\hline
\end{tabular}


Table 39: Number of studies per country for generic category of products: cereals studied for Q1: Contamination levels

\begin{tabular}{|l|c|c|c|c|c|c|c|}
\hline \multicolumn{1}{|c}{$\begin{array}{c}\text { Country } \\
\text { name }\end{array}$} & i. Maize & ii. Barley & $\begin{array}{c}\text { iii. } \\
\text { Millet }\end{array}$ & iv. Rice & $\begin{array}{c}\text { v. } \\
\text { Sorghum }\end{array}$ & $\begin{array}{c}\text { vi. } \\
\text { Wheat }\end{array}$ & $\begin{array}{c}\text { vii. } \\
\text { Other }\end{array}$ \\
\hline Benin & 3 & 0 & 0 & 0 & 0 & 0 & 0 \\
\hline Burkina Faso & 1 & 0 & 0 & 0 & 1 & 0 & 0 \\
\hline Cameroon & 3 & 0 & 0 & 0 & 0 & 0 & 1 \\
\hline $\begin{array}{l}\text { Democratic } \\
\text { Republic of } \\
\text { Congo }\end{array}$ & 2 & 0 & 0 & 0 & 0 & 0 & 0 \\
\hline Egypt & & & & & & & \\
\hline Ethiopia & 2 & 0 & 0 & 2 & 0 & 3 & 1 \\
\hline Ghana & 4 & 0 & 0 & 0 & 2 & 0 & 0 \\
\hline Kenya & 14 & 0 & 2 & 1 & 5 & 0 & 0 \\
\hline Malawi & 5 & 0 & 0 & 0 & 1 & 0 & 0 \\
\hline Morocco & 1 & 0 & 0 & 1 & 0 & 1 & 0 \\
\hline Mozambique & 1 & 0 & 1 & 1 & 1 & 1 & 0 \\
\hline Niger & 1 & 0 & 0 & 0 & 0 & 0 & 0 \\
\hline Nigeria & 8 & 0 & 2 & 2 & 1 & 2 & 1 \\
\hline Rwanda & 1 & 0 & 0 & 0 & 0 & 0 & 0 \\
\hline Senegal & 1 & 0 & 0 & 0 & 0 & 0 & 1 \\
\hline South Africa & 3 & 0 & 0 & 0 & 0 & 0 & 0 \\
\hline Sudan & 1 & 0 & 0 & 0 & 1 & 0 & 0 \\
\hline Tanzania & 11 & 0 & 0 & 0 & 1 & 0 & 0 \\
\hline Togo & 1 & 0 & 0 & 0 & 0 & 0 & 0 \\
\hline Tunisia & 2 & 3 & 0 & 1 & 2 & 3 & 0 \\
\hline Uganda & 1 & 0 & 0 & 0 & 0 & 0 & 0 \\
\hline Zambia & 1 & 0 & 0 & 0 & 0 & 0 & 0 \\
\hline Zimbabwe & 2 & 0 & 0 & 0 & 0 & 0 & 0 \\
\hline
\end{tabular}


Table 40: Number of studies per country for generic category of products: legumes and oilseed and nuts for Q1: Contamination levels

\begin{tabular}{|c|c|c|c|c|c|c|c|c|}
\hline \multirow{2}{*}{$\begin{array}{l}\text { Country } \\
\text { name }\end{array}$} & \multicolumn{5}{|c|}{ f. Legumes and oilseed } & \multicolumn{3}{|c|}{ g. Nuts } \\
\hline & $\begin{array}{c}i . \\
\text { Beans }\end{array}$ & $\begin{array}{c}\text { ii. } \\
\text { Sesame } \\
\text { and } \\
\text { sesame } \\
\text { oil }\end{array}$ & $\begin{array}{c}\text { iii. } \\
\text { Soybean } \\
\text { and } \\
\text { soybean } \\
\text { oil }\end{array}$ & $\begin{array}{c}\text { iv. } \\
\text { Sunflower } \\
\text { and } \\
\text { sunflower } \\
\text { oil }\end{array}$ & $\begin{array}{c}v . \\
\text { Other }\end{array}$ & $\begin{array}{l}\text { i. Peanut/ } \\
\text { Groundnut }\end{array}$ & $\begin{array}{c}\text { ii. } \\
\text { Walnut }\end{array}$ & $\begin{array}{l}\text { iii. } \\
\text { Other }\end{array}$ \\
\hline Algeria & 0 & 0 & 0 & 0 & 0 & 1 & 1 & 0 \\
\hline Benin & 0 & 0 & 0 & 0 & 0 & 0 & 0 & 1 \\
\hline Burkina Faso & 0 & 0 & 0 & 0 & 0 & 0 & 0 & 0 \\
\hline Cameroon & 0 & 0 & 0 & 0 & 0 & 3 & 0 & 0 \\
\hline $\begin{array}{l}\text { Democratic } \\
\text { Republic of } \\
\text { Congo }\end{array}$ & 1 & 0 & 0 & 0 & 0 & 3 & 0 & 0 \\
\hline Egypt & 1 & 1 & 1 & 0 & 1 & 2 & 0 & 1 \\
\hline Ethiopia & 0 & 0 & 0 & 0 & 0 & 3 & 0 & 0 \\
\hline Ghana & 0 & 0 & 0 & 0 & 0 & 1 & 0 & 0 \\
\hline Kenya & 0 & 0 & 0 & 0 & 0 & 4 & 0 & 0 \\
\hline Libya & 0 & 0 & 0 & 0 & 0 & 0 & 0 & 0 \\
\hline Malawi & 0 & 0 & 0 & 0 & 1 & 4 & 0 & 0 \\
\hline Mali & 0 & 0 & 0 & 0 & 0 & 1 & 0 & 0 \\
\hline Morocco & 0 & 0 & 0 & 0 & 0 & 0 & 0 & 0 \\
\hline Mozambique & 0 & 0 & 1 & 0 & 0 & 0 & 0 & 0 \\
\hline Niger & 0 & 0 & 0 & 0 & 0 & 0 & 0 & 0 \\
\hline Nigeria & 1 & 2 & 0 & 0 & 0 & 2 & 0 & 1 \\
\hline Rwanda & 0 & 0 & 0 & 0 & 0 & 0 & 0 & 0 \\
\hline Senegal & 0 & 1 & 0 & 0 & 0 & 1 & 0 & 0 \\
\hline South Africa & 0 & 0 & 0 & 0 & 0 & 1 & 0 & 0 \\
\hline Sudan & 0 & 1 & 0 & 0 & 1 & 2 & 0 & 0 \\
\hline Tanzania & 0 & 0 & 0 & 0 & 0 & 5 & 0 & 1 \\
\hline Togo & 0 & 0 & 0 & 0 & 0 & 0 & 0 & 0 \\
\hline Tunisia & 0 & 0 & 0 & 0 & 0 & 0 & 0 & 0 \\
\hline Uganda & 0 & 0 & 0 & 0 & 0 & 1 & 0 & 0 \\
\hline Zambia & 0 & 0 & 0 & 0 & 0 & 2 & 0 & 0 \\
\hline Zimbabwe & 2 & 0 & 0 & 0 & 1 & 3 & 0 & 2 \\
\hline
\end{tabular}


Table 41: Number of included studies per country for animal products (raw) and human foods from animal origin for Q1: Contamination levels

\begin{tabular}{|l|c|c|c|c|c|c|c|}
\hline $\begin{array}{c}\text { Country } \\
\text { name }\end{array}$ & $\begin{array}{c}\text { Animal } \\
\text { product } \\
\text { (Raw): } \\
\text { Milk }\end{array}$ & $\begin{array}{c}\text { Human } \\
\text { food: } \\
\text { Dairy }\end{array}$ & $\begin{array}{c}\text { Animal } \\
\text { product } \\
\text { (Raw): } \\
\text { Meat }\end{array}$ & $\begin{array}{c}\text { Human } \\
\text { food: } \\
\text { Meat }\end{array}$ & $\begin{array}{c}\text { Animal } \\
\text { product } \\
\text { (Raw): } \\
\text { Fish }\end{array}$ & $\begin{array}{c}\text { Human } \\
\text { food: } \\
\text { Fish }\end{array}$ & $\begin{array}{c}\text { Animal } \\
\text { product } \\
\text { (Raw): } \\
\text { Other }\end{array}$ \\
\hline Algeria & 1 & 1 & 0 & 0 & 0 & 0 & 0 \\
\hline Egypt & 4 & 7 & 3 & 1 & 1 & 0 & 1 \\
\hline Ethiopia & 1 & 0 & 0 & 0 & 0 & 0 & 1 \\
\hline Kenya & 6 & 1 & 0 & 0 & 1 & 0 & 0 \\
\hline Libya & 0 & 0 & 0 & 0 & 0 & 0 & 1 \\
\hline Morocco & 1 & 0 & 0 & 0 & 0 & 0 & 0 \\
\hline Mozambique & 0 & 0 & 0 & 0 & 0 & 0 & 1 \\
\hline Nigeria & 2 & 1 & 0 & 2 & 0 & 1 & 0 \\
\hline South Africa & 4 & 1 & 0 & 0 & 0 & 0 & 0 \\
\hline Sudan & 2 & 1 & 0 & 0 & 0 & 0 & 1 \\
\hline Tanzania & 1 & 0 & 0 & 0 & 0 & 0 & 0 \\
\hline Tunisia & 1 & 0 & 0 & 0 & 0 & 0 & 0 \\
\hline Zimbabwe & 0 & 0 & 0 & 0 & 0 & 0 & 1 \\
\hline
\end{tabular}




\section{Annex 11 Overview of contamination levels}

Table 42: Overview of contamination levels

\begin{tabular}{|c|c|c|c|c|c|c|c|c|c|c|c|c|c|c|}
\hline Reference & $\begin{array}{l}\text { Aflatoxin } \\
\text { type } \\
\text { studied }\end{array}$ & Country & $\begin{array}{l}\text { Product / } \\
\text { commodity }\end{array}$ & $\begin{array}{l}\text { Analytical } \\
\text { method used }\end{array}$ & $\begin{array}{l}\text { Number } \\
\text { of } \\
\text { samples } \\
(n)\end{array}$ & $\begin{array}{c}\text { LOQ } \\
(\mu \mathrm{g} / \mathbf{k g})\end{array}$ & $\begin{array}{c}\text { LOD } \\
(\mu \mathrm{g} / \mathbf{k g})\end{array}$ & $\begin{array}{c}\text { Positive } \\
\text { samples } \\
(\%)\end{array}$ & $\begin{array}{c}\text { Mean } \\
(\mu \mathrm{g} / \mathbf{k g})\end{array}$ & $\begin{array}{l}\text { Median } \\
(\mu \mathrm{g} / \mathrm{kg})\end{array}$ & SD & $\begin{array}{c}\text { Min } \\
(\mu \mathrm{g} / \mathbf{k g})\end{array}$ & $\begin{array}{c}\operatorname{Max} \\
(\mu \mathrm{g} / \mathrm{kg})\end{array}$ & Notes \\
\hline \multirow[t]{4}{*}{$\begin{array}{l}\text { Abdallah et } \\
\text { al. (2016) }\end{array}$} & B1 & Egypt & $\begin{array}{c}\text { Fruit } \\
\text { (sugarcane) }\end{array}$ & LC-MS/MS & 21 & 9.2 & 2.8 & $48 \%$ & 13.6 & 11.7 & & $<\mathrm{LOQ}$ & 30.6 & \\
\hline & G1 & & $\begin{array}{c}\text { Fruit } \\
\text { (sugarcane) }\end{array}$ & & 21 & 7.4 & 2.2 & $10 \%$ & 5.1 & 5.1 & & $<L O Q$ & 7.76 & \\
\hline & B1 & & $\begin{array}{l}\text { Fruit } \\
\text { (sugarcane } \\
\text { juice) }\end{array}$ & & 40 & 0.4 & 0.14 & $58 \%$ & 0.72 & 0.56 & & $<\mathrm{LOQ}$ & 2.1 & \\
\hline & G1 & & $\begin{array}{c}\text { Fruit } \\
\text { (sugarcane } \\
\text { juice) }\end{array}$ & & 40 & 0.01 & 0.004 & $18 \%$ & 0.3 & 0.1 & & $<$ LOQ & 1.34 & \\
\hline \multirow[t]{2}{*}{$\begin{array}{l}\text { Abdallah et } \\
\text { al. (2018) }\end{array}$} & B1 & Egypt & $\begin{array}{l}\text { Fruit (dried } \\
\text { dates) }\end{array}$ & LC-MS/MS & 28 & 0.2 & 0.05 & $4 \%$ & 14.4 & & & & & \\
\hline & B2 & Egypt & $\begin{array}{c}\text { Fruit (dried } \\
\text { dates) }\end{array}$ & & 28 & 0.1 & 0.03 & $4 \%$ & 2.44 & & & & & \\
\hline \multirow[t]{4}{*}{$\begin{array}{l}\text { Abia et al. } \\
\text { (2013b) }\end{array}$} & B1 & Cameroon & $\begin{array}{c}\text { dagwa } \\
\text { (groundnut } \\
\text { based snacks) }\end{array}$ & LC-MS/MS & 8 & & 0.13 & $100 \%$ & 45 & & & 2 & 224 & \\
\hline & B2 & Cameroon & $\begin{array}{c}\text { dagwa } \\
\text { (groundnut } \\
\text { based snacks) }\end{array}$ & & 8 & & 0.3 & $75 \%$ & 6 & & & $<\mathrm{LOQ}$ & 14 & \\
\hline & G1 & Cameroon & $\begin{array}{c}\text { dagwa } \\
\text { (groundnut } \\
\text { based snacks) }\end{array}$ & & 8 & & 0.3 & $100 \%$ & 24 & & & 2 & 149 & \\
\hline & G2 & Cameroon & $\begin{array}{c}\text { dagwa } \\
\text { (groundnut } \\
\text { based snacks) }\end{array}$ & & 8 & & 1.5 & $63 \%$ & 7 & & & $<$ LOQ & 12 & \\
\hline
\end{tabular}




\begin{tabular}{|c|c|c|c|c|c|c|c|c|c|c|c|c|c|c|}
\hline Reference & $\begin{array}{l}\text { Aflatoxin } \\
\text { type } \\
\text { studied }\end{array}$ & Country & $\begin{array}{l}\text { Product / } \\
\text { commodity }\end{array}$ & $\begin{array}{l}\text { Analytical } \\
\text { method used }\end{array}$ & $\begin{array}{l}\text { Number } \\
\text { of } \\
\text { samples } \\
\text { (n) }\end{array}$ & $\begin{array}{c}\text { LOQ } \\
(\mu \mathrm{g} / \mathbf{k g})\end{array}$ & $\begin{array}{c}\text { LOD } \\
(\mu \mathrm{g} / \mathbf{k g})\end{array}$ & $\begin{array}{c}\text { Positive } \\
\text { samples } \\
(\%)\end{array}$ & $\begin{array}{c}\text { Mean } \\
(\mu \mathrm{g} / \mathrm{kg})\end{array}$ & $\begin{array}{l}\text { Median } \\
(\mu \mathrm{g} / \mathbf{k g})\end{array}$ & SD & $\begin{array}{c}\text { Min } \\
(\mu \mathrm{g} / \mathbf{k g})\end{array}$ & $\begin{array}{c}\operatorname{Max} \\
(\mu \mathrm{g} / \mathbf{k g})\end{array}$ & Notes \\
\hline & B1 & Cameroon & $\begin{array}{c}\text { kuru-kuru } \\
\text { (groundnut } \\
\text { based snacks) }\end{array}$ & & 6 & & 0.13 & $100 \%$ & 52 & & & 46 & 65 & \\
\hline & B2 & Cameroon & $\begin{array}{c}\text { kuru-kuru } \\
\text { (groundnut } \\
\text { based snacks) }\end{array}$ & & 6 & & 0.3 & $100 \%$ & 7 & & & 5 & 9 & \\
\hline & G1 & Cameroon & $\begin{array}{l}\text { kuru-kuru } \\
\text { (groundnut } \\
\text { based snacks) }\end{array}$ & & 6 & & 0.3 & $100 \%$ & 9 & & & 8 & 10 & \\
\hline & G2 & Cameroon & $\begin{array}{c}\text { kuru-kuru } \\
\text { (groundnut } \\
\text { based snacks) }\end{array}$ & & 6 & & 1.5 & $100 \%$ & 7 & & & 5 & 9 & \\
\hline & B1 & Cameroon & maize & & 37 & & 0.13 & $30 \%$ & 4 & & & $<\mathrm{LOQ}$ & 12 & \\
\hline & B2 & Cameroon & maize & & 37 & & 0.3 & $16 \%$ & 1 & & & $<\mathrm{LOQ}$ & 1 & \\
\hline & G1 & Cameroon & maize & & 37 & & 0.3 & $22 \%$ & 3 & & & $<\mathrm{LOQ}$ & 6 & \\
\hline & $\mathrm{G} 2$ & Cameroon & maize & & 37 & & nd & nd & nd & & & nd & nd & \\
\hline & B1 & Cameroon & groundnut & & 35 & & 0.13 & $97 \%$ & 47 & & & $<\mathrm{LOQ}$ & 210 & \\
\hline & G1 & Cameroon & groundnut & & 35 & & 0.3 & $66 \%$ & 17 & & & $<L O Q$ & 48 & \\
\hline & G2 & Cameroon & groundnut & & 35 & & 1.5 & $60 \%$ & 9 & & & $<\mathrm{LOQ}$ & 15 & \\
\hline $\begin{array}{c}\text { Abia et al. } \\
(2017)\end{array}$ & B1 & Cameroon & $\begin{array}{l}\text { fufu (maize } \\
\text { dish) }\end{array}$ & LC-MS/MS & 50 & 0.5 & 0.15 & $24 \%$ & 0.9 & 0.9 & 0.4 & 0.3 & 1.8 & \\
\hline \multirow{4}{*}{$\begin{array}{l}\text { Adedeji et } \\
\text { al. (2017) }\end{array}$} & B1 & Nigeria & iru & LC-MS/MS & 9 & & 0.3 & $0 \%$ & $<L O D$ & & & $<L O D$ & $<L O D$ & \\
\hline & B2 & Nigeria & iru & & 9 & & 0.4 & $0 \%$ & $<L O D$ & & & $<L O D$ & $<$ LOD & \\
\hline & B1 & Nigeria & ogiri & & 9 & & 0.3 & $11 \%$ & 6.99 & & & $<$ LOD & 6.99 & \\
\hline & B2 & Nigeria & ogiri & & 9 & & 0.4 & $0 \%$ & $<$ LOD & & & $<L O D$ & & \\
\hline \multirow{3}{*}{$\begin{array}{l}\text { Adetunji et } \\
\text { al. (2014) }\end{array}$} & B1 & Nigeria & Maize & LC-MS/MS & 70 & & 0.4 & $67.10 \%$ & 394 & 74 & 1.033 & 4 & 6738 & \\
\hline & B2 & Nigeria & Maize & & 70 & & 0.6 & $54.30 \%$ & 44 & 12 & 108 & 1 & 644 & \\
\hline & G1 & Nigeria & Maize & & 70 & & 0.6 & $15.70 \%$ & 47 & 16 & 83 & 1 & 264 & \\
\hline
\end{tabular}




\begin{tabular}{|c|c|c|c|c|c|c|c|c|c|c|c|c|c|c|}
\hline Reference & $\begin{array}{l}\text { Aflatoxin } \\
\text { type } \\
\text { studied }\end{array}$ & Country & $\begin{array}{l}\text { Product / } \\
\text { commodity }\end{array}$ & $\begin{array}{l}\text { Analytical } \\
\text { method used }\end{array}$ & $\begin{array}{c}\text { Number } \\
\text { of } \\
\text { samples } \\
(n)\end{array}$ & $\begin{array}{c}\text { LOQ } \\
(\mu \mathrm{g} / \mathrm{kg})\end{array}$ & $\begin{array}{l}\text { LOD } \\
(\mu \mathrm{g} / \mathrm{kg})\end{array}$ & $\begin{array}{c}\text { Positive } \\
\text { samples } \\
(\%)\end{array}$ & $\begin{array}{c}\text { Mean } \\
(\mu \mathrm{g} / \mathrm{kg})\end{array}$ & $\begin{array}{l}\text { Median } \\
(\mu \mathrm{g} / \mathrm{kg})\end{array}$ & SD & $\begin{array}{c}\text { Min } \\
(\mu \mathrm{g} / \mathbf{k g})\end{array}$ & $\begin{array}{c}\text { Max } \\
(\mu \mathrm{g} / \mathbf{k g})\end{array}$ & Notes \\
\hline & G2 & Nigeria & Maize & & 70 & & 0.5 & $5.70 \%$ & 16 & 6 & 24 & 0.7 & 52 & \\
\hline $\begin{array}{l}\text { Azzoune et } \\
\text { al. (2016) }\end{array}$ & B1 & Algeria & spices & HPLC & 36 & 0.1 & 0.05 & $64 \%$ & & & & 0.1 & 26.5 & \\
\hline \multirow[t]{2}{*}{$\begin{array}{c}\text { Bakoye et al. } \\
\text { (2017) }\end{array}$} & $\begin{array}{c}\mathrm{AF} \\
\text { general }\end{array}$ & Benin & Maize & ELISA & 90 & & & & & & & 0 & 1000 & \\
\hline & $\begin{array}{c}\text { AF } \\
\text { general }\end{array}$ & Niger & Maize & & 22 & & & & & & & 0 & 3000 & \\
\hline \multirow{2}{*}{$\begin{array}{l}\text { Chilaka et al. } \\
\text { (2012) }\end{array}$} & B1 & South Africa & animal feeds & TLC & 40 & & & $70 \%$ & & & & 0 & 741 & \\
\hline & B2 & & & & 40 & & & $58 \%$ & & & & 0 & 54 & \\
\hline \multirow{2}{*}{$\begin{array}{c}\text { Dawit et al. } \\
\text { (2016) }\end{array}$} & M1 & Ethiopia & milk & ELISA & 110 & & & & 0.41 & 0.094 & 0.85 & 0.028 & 4.98 & \\
\hline & B1 & Ethiopia & animal feeds & & 156 & & & & 97 & 18 & 132 & 7 & 419 & \\
\hline \multirow[t]{10}{*}{$\begin{array}{l}\text { Diedhiou et } \\
\text { al. (2011) }\end{array}$} & B1 & Senegal & Maize & TLC & 25 & & & & 0.9 & & & 0 & 1.7 & $\begin{array}{l}\text { Senegal -SG- } \\
\text { Kolda }\end{array}$ \\
\hline & B1 & Senegal & Maize & & 25 & & & & 0.5 & & & 0 & 1.6 & $\begin{array}{l}\text { Senegal-SG- } \\
\text { Sedhiou }\end{array}$ \\
\hline & B1 & Senegal & Maize & & 25 & & & & 15.9 & & & 0 & 56.2 & $\begin{array}{l}\text { Senegal-SS- } \\
\text { kaffrine }\end{array}$ \\
\hline & B1 & Senegal & Maize & & 25 & & & & 188 & & & 0 & 582.2 & $\begin{array}{l}\text { Senegal-SS- } \\
\text { Nioro }\end{array}$ \\
\hline & B1 & Senegal & Maize & & 25 & & & & 0.7 & & & 0.2 & 1 & $\begin{array}{l}\text { Senegal-SS- } \\
\text { Tambacounda }\end{array}$ \\
\hline & B1 & Senegal & $\begin{array}{c}\text { Sesame and } \\
\text { sesame oil }\end{array}$ & & 25 & & & & 0.3 & & & 0 & 1 & $\begin{array}{l}\text { Senegal -SG- } \\
\text { Kolda }\end{array}$ \\
\hline & B1 & Senegal & $\begin{array}{l}\text { Sesame and } \\
\text { sesame oil }\end{array}$ & & 25 & & & & 0.1 & & & 0 & 0.2 & $\begin{array}{l}\text { Senegal-SG- } \\
\text { Sedhiou }\end{array}$ \\
\hline & B1 & Senegal & $\begin{array}{l}\text { Sesame and } \\
\text { sesame oil }\end{array}$ & & 25 & & & & 0.2 & & & 0 & 0.3 & $\begin{array}{l}\text { Senegal-SS- } \\
\text { kaffrine }\end{array}$ \\
\hline & B1 & Senegal & $\begin{array}{l}\text { Sesame and } \\
\text { sesame oil }\end{array}$ & & 25 & & & & 0.3 & & & 0 & 1.2 & $\begin{array}{l}\text { Senegal-SS- } \\
\text { Nioro }\end{array}$ \\
\hline & B11 & Senegal & $\begin{array}{l}\text { Sesame and } \\
\text { sesame oil }\end{array}$ & & 25 & & & & 0.1 & & & 0 & 0.2 & $\begin{array}{l}\text { Senegal-SS- } \\
\text { Tambacounda }\end{array}$ \\
\hline $\begin{array}{l}\text { Ediage et al. } \\
\text { (2014) }\end{array}$ & B1 & Cameroon & Maize & LC-MS/MS & 75 & 6 & 2 & & 35 & & & 6 & 345 & $\begin{array}{l}\text { Cameroon- } \\
\text { sampling } \\
2009\end{array}$ \\
\hline
\end{tabular}




\begin{tabular}{|c|c|c|c|c|c|c|c|c|c|c|c|c|c|c|}
\hline Reference & $\begin{array}{l}\text { Aflatoxin } \\
\text { type } \\
\text { studied }\end{array}$ & Country & $\begin{array}{l}\text { Product / } \\
\text { commodity }\end{array}$ & $\begin{array}{l}\text { Analytical } \\
\text { method used }\end{array}$ & $\begin{array}{c}\text { Number } \\
\text { of } \\
\text { samples } \\
(n)\end{array}$ & $\begin{array}{c}\text { LOQ } \\
(\mu \mathrm{g} / \mathrm{kg})\end{array}$ & $\begin{array}{c}\text { LOD } \\
(\mu \mathrm{g} / \mathrm{kg})\end{array}$ & $\begin{array}{c}\text { Positive } \\
\text { samples } \\
(\%)\end{array}$ & $\begin{array}{c}\text { Mean } \\
(\mu \mathrm{g} / \mathrm{kg})\end{array}$ & $\begin{array}{l}\text { Median } \\
(\mu \mathrm{g} / \mathrm{kg})\end{array}$ & SD & $\begin{array}{c}\text { Min } \\
(\mu \mathrm{g} / \mathrm{kg})\end{array}$ & $\begin{array}{c}\operatorname{Max} \\
(\mu \mathrm{g} / \mathbf{k g})\end{array}$ & Notes \\
\hline & B2 & Cameroon & Maize & & 75 & 2 & 0.5 & & 7 & & & 2 & 215 & $\begin{array}{l}\text { Cameroon- } \\
\text { sampling } \\
2009\end{array}$ \\
\hline & B1 & Cameroon & Maize & & 90 & 6 & 2 & & 81 & & & 6 & 645 & $\begin{array}{l}\text { Cameroon- } \\
\text { sampling } \\
2010-2011\end{array}$ \\
\hline & B2 & Cameroon & Maize & & 90 & 2 & 0.5 & & 22 & & & 2 & 225 & $\begin{array}{l}\text { Cameroon- } \\
\text { sampling } \\
2010-2011\end{array}$ \\
\hline & B1 & Cameroon & $\begin{array}{l}\text { Peanut/ } \\
\text { groundnut }\end{array}$ & & 90 & 0.8 & 0.2 & & 23 & & & 6 & 125 & $\begin{array}{l}\text { Cameroon- } \\
\text { sampling } \\
2010-2011\end{array}$ \\
\hline $\begin{array}{l}\text { El-Marnissi } \\
\text { et al. (2012) }\end{array}$ & M1 & Morocco & milk & $\begin{array}{l}\text { LC- } \\
\text { fluorescence } \\
\text { detection after } \\
\text { immunoaffinity } \\
\text { purification }\end{array}$ & 48 & 0.008 & & $27 \%$ & & & & 0.001 & 0.1 & \\
\hline \multirow{8}{*}{$\begin{array}{c}\text { El- } \\
\text { Shanshoury } \\
\text { et al. (2014) }\end{array}$} & B1 & Egypt & Maize & TLC & 13 & & & $54 \%$ & 440 & & & 280 & 720 & \\
\hline & G1 & Egypt & Maize & & 13 & & & $15 \%$ & 400 & & & 360 & 440 & \\
\hline & B1 & Egypt & $\begin{array}{l}\text { Peanut/ } \\
\text { groundnut }\end{array}$ & & 8 & & & $100 \%$ & 427 & & & 210 & 600 & \\
\hline & B2 & Egypt & $\begin{array}{l}\text { Peanut/ } \\
\text { groundnut }\end{array}$ & & 8 & & & $0 \%$ & 0 & & & 0 & 0 & \\
\hline & G1 & Egypt & $\begin{array}{l}\text { Peanut/ } \\
\text { groundnut }\end{array}$ & & 8 & & & $38 \%$ & 337 & & & 250 & 400 & \\
\hline & B1 & Egypt & Wheat & & 10 & & & $0 \%$ & 0 & & & 0 & 0 & \\
\hline & B2 & Egypt & Wheat & & 10 & & & $0 \%$ & 0 & & & 0 & 0 & \\
\hline & G1 & Egypt & Wheat & & 10 & & & $30 \%$ & 540 & & & 400 & 640 & \\
\hline \multirow{5}{*}{$\begin{array}{l}\text { Ezekiel et al. } \\
\quad(2012 a)\end{array}$} & B1 & Nigeria & animal feeds & LC-MS/MS & 58 & & 4 & $78 \%$ & 198 & & 246 & 6 & 1067 & \\
\hline & B2 & Nigeria & animal feeds & & 58 & & 10 & $50 \%$ & 34 & & 23 & 10 & 114 & \\
\hline & G1 & Nigeria & animal feeds & & 58 & & 6 & $60 \%$ & 45 & & 46 & 8 & 235 & \\
\hline & G2 & Nigeria & animal feeds & & 58 & & 10 & $10 \%$ & 13 & & 4 & 10 & 20 & \\
\hline & M1 & Nigeria & animal feeds & & 58 & & 10 & $26 \%$ & 15 & & 5 & 10 & 29 & \\
\hline
\end{tabular}




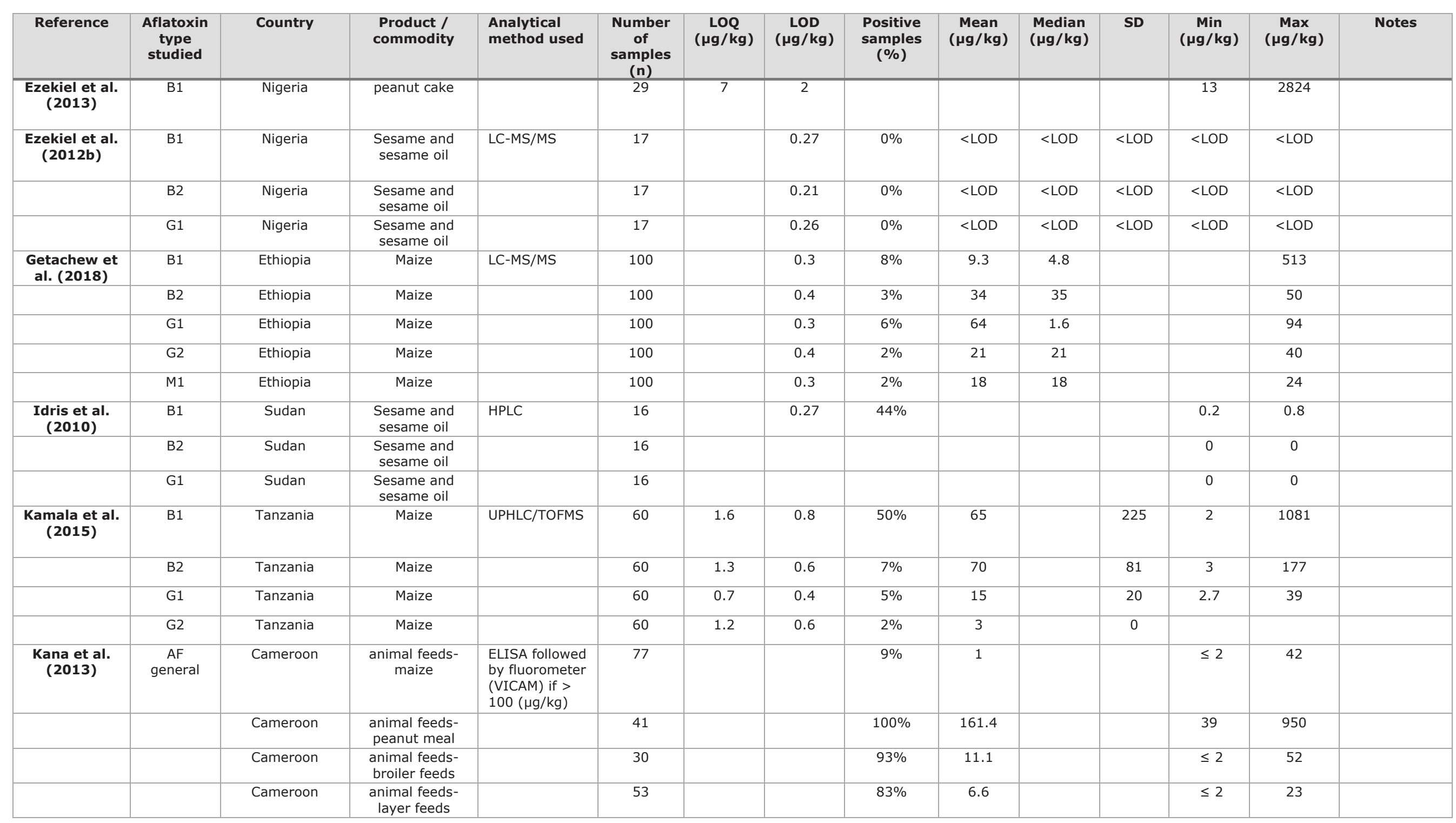




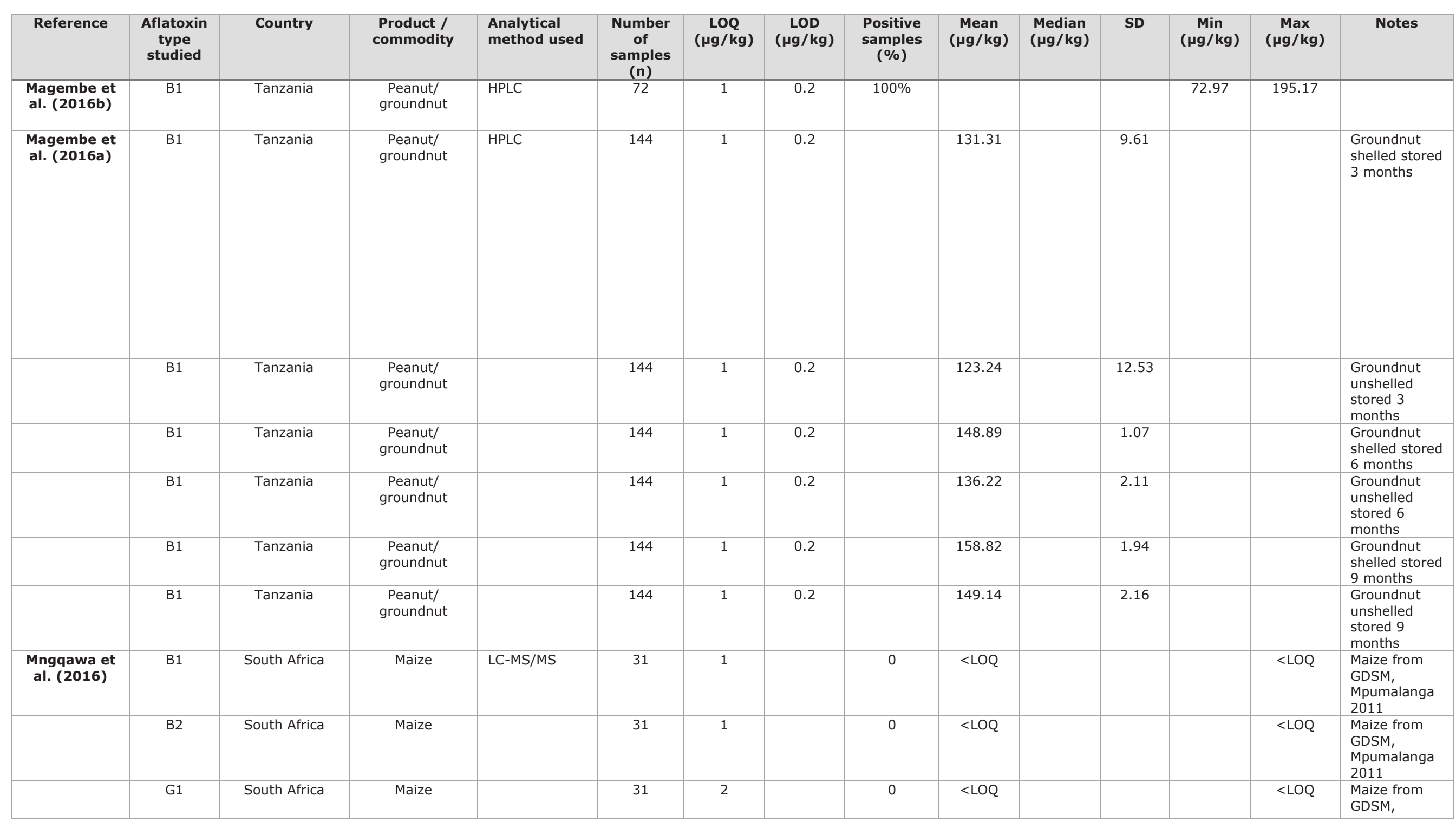




\begin{tabular}{|c|c|c|c|c|c|c|c|c|c|c|c|c|c|c|}
\hline Reference & $\begin{array}{l}\text { Aflatoxin } \\
\text { type } \\
\text { studied }\end{array}$ & Country & $\begin{array}{l}\text { Product / } \\
\text { commodity }\end{array}$ & $\begin{array}{l}\text { Analytical } \\
\text { method used }\end{array}$ & $\begin{array}{l}\text { Number } \\
\text { of } \\
\text { samples } \\
(n)\end{array}$ & $\begin{array}{c}\text { LOQ } \\
(\mu \mathrm{g} / \mathbf{k g})\end{array}$ & $\begin{array}{c}\text { LOD } \\
(\mu \mathrm{g} / \mathbf{k g})\end{array}$ & $\begin{array}{c}\text { Positive } \\
\text { samples } \\
(\%)\end{array}$ & $\begin{array}{c}\text { Mean } \\
(\mu \mathrm{g} / \mathbf{k g})\end{array}$ & $\begin{array}{l}\text { Median } \\
(\mu \mathrm{g} / \mathrm{kg})\end{array}$ & SD & $\begin{array}{c}\text { Min } \\
(\mu \mathrm{g} / \mathbf{k g})\end{array}$ & $\begin{array}{c}\text { Max } \\
(\mu \mathrm{g} / \mathrm{kg})\end{array}$ & Notes \\
\hline & & & & & & & & & & & & & & $\begin{array}{l}\text { Mpumalanga } \\
2011\end{array}$ \\
\hline & G2 & South Africa & Maize & & 31 & 2 & & $33 \%$ & 39 & & & & 93 & $\begin{array}{l}\text { Maize from } \\
\text { GDSM, } \\
\text { Mpumalanga } \\
2011\end{array}$ \\
\hline & B1 & South Africa & Maize & & 31 & 1 & & $6 \%$ & 1 & & & & 2 & $\begin{array}{l}\text { Maize from } \\
\text { GDSM, } \\
\text { Mpumalanga } \\
2012\end{array}$ \\
\hline & B2 & South Africa & Maize & & 31 & 1 & & 0 & $<\mathrm{LOQ}$ & & & & $<\mathrm{LOQ}$ & $\begin{array}{l}\text { Maize from } \\
\text { GDSM, } \\
\text { Mpumalanga } \\
2012\end{array}$ \\
\hline & G1 & South Africa & Maize & & 31 & 2 & & 0 & $<$ LOQ & & & & $<$ LOQ & $\begin{array}{l}\text { Maize from } \\
\text { GDSM, } \\
\text { Mpumalanga } \\
2012\end{array}$ \\
\hline & G2 & South Africa & Maize & & 31 & 2 & & 0 & $<L O Q$ & & & & $<\mathrm{LOQ}$ & $\begin{array}{l}\text { Maize from } \\
\text { GDSM, } \\
\text { Mpumalanga } \\
2012\end{array}$ \\
\hline & B1 & South Africa & Maize & & 29 & 1 & & $19 \%$ & 48 & & & & 133 & $\begin{array}{l}\text { Maise from } \\
\text { VDM, } \\
\text { Limpopo } \\
2011\end{array}$ \\
\hline & B2 & South Africa & Maize & & 29 & 1 & & $16 \%$ & 6 & & & & 15 & $\begin{array}{l}\text { Mzise from } \\
\text { VDM, } \\
\text { Limpopo } \\
2011\end{array}$ \\
\hline & G1 & South Africa & Maize & & 29 & 2 & & $6 \%$ & 18 & & & & 33 & $\begin{array}{l}\text { Mzise from } \\
\text { VDM, } \\
\text { Limpopo } \\
2011\end{array}$ \\
\hline & G2 & South Africa & Maize & & 29 & 2 & & $3 \%$ & 4 & & & & 4 & $\begin{array}{l}\text { Mzise from } \\
\text { VDM, } \\
\text { Limpopo } \\
2011\end{array}$ \\
\hline & B1 & South Africa & Maize & & 23 & 1 & & $23 \%$ & 20 & & & & 73 & $\begin{array}{l}\text { Mzise from } \\
\text { VDM, } \\
\text { Limpopo } \\
2012\end{array}$ \\
\hline & B2 & South Africa & Maize & & 23 & 1 & & $3 \%$ & 5 & & & & 5 & $\begin{array}{l}\text { Mzise from } \\
\text { VDM, } \\
\text { Limpopo } \\
2012\end{array}$ \\
\hline
\end{tabular}




\begin{tabular}{|c|c|c|c|c|c|c|c|c|c|c|c|c|c|c|}
\hline Reference & $\begin{array}{l}\text { Aflatoxin } \\
\text { type } \\
\text { studied }\end{array}$ & Country & $\begin{array}{l}\text { Product / } \\
\text { commodity }\end{array}$ & $\begin{array}{l}\text { Analytical } \\
\text { method used }\end{array}$ & $\begin{array}{c}\text { Number } \\
\text { of } \\
\text { samples } \\
(\mathbf{n})\end{array}$ & $\begin{array}{c}\text { LOQ } \\
(\mu \mathrm{g} / \mathbf{k g})\end{array}$ & $\begin{array}{c}\text { LOD } \\
(\mu \mathrm{g} / \mathrm{kg})\end{array}$ & $\begin{array}{c}\text { Positive } \\
\text { samples } \\
(\%)\end{array}$ & $\begin{array}{c}\text { Mean } \\
(\mu \mathrm{g} / \mathrm{kg})\end{array}$ & $\begin{array}{c}\text { Median } \\
(\mu \mathrm{g} / \mathrm{kg})\end{array}$ & SD & $\underset{(\mu \mathrm{gin} / \mathrm{kg})}{\operatorname{Min}}$ & $\begin{array}{c}\operatorname{Max} \\
(\mu \mathrm{g} / \mathbf{k g})\end{array}$ & Notes \\
\hline & G1 & South Africa & Maize & & 23 & 2 & & $10 \%$ & 43 & & & & 93 & $\begin{array}{l}\text { Mzise from } \\
\text { VDM, } \\
\text { Limpopo } \\
2012\end{array}$ \\
\hline & G2 & South Africa & Maize & & 23 & 2 & & $6 \%$ & 7 & & & & 12 & $\begin{array}{l}\text { Mzise from } \\
\text { VDM, } \\
\text { Limpopo } \\
2012\end{array}$ \\
\hline $\begin{array}{c}\text { Mwalwayo } \\
\text { and Thole } \\
(2016)\end{array}$ & $\begin{array}{c}\text { AF } \\
\text { General }\end{array}$ & Malawi & Maize & & 90 & & 2 & $100 \%$ & 8.3 & & 8.2 & 0.7 & 140 & \\
\hline \multirow{5}{*}{$\begin{array}{l}\text { Mwanza et } \\
\text { al. (2015) }\end{array}$} & M1 & South Africa & Milk (rural) & TLC & 125 & & & $21 \%$ & - & & & & & \\
\hline & M1 & & & $\begin{array}{l}\text { Fluorometer } \\
\text { (VICAM) }\end{array}$ & 125 & & & $86 \%$ & 2.38 & & 3.46 & 1 & 19 & \\
\hline & M1 & & & HPLC & 125 & & 0.00001 & $78 \%$ & 0.15 & & 2.09 & 0.01 & 0.2 & \\
\hline & M1 & & & $\begin{array}{l}\text { Fluorometer } \\
\text { (VICAM) }\end{array}$ & 85 & & & $96 \%$ & 1.59 & & 2.63 & 1 & 14 & \\
\hline & M1 & & & HPLC & 85 & & 0.00001 & $100 \%$ & 0.14 & & 0.28 & 0.03 & 0.19 & \\
\hline \multirow[t]{6}{*}{$\begin{array}{l}\text { Nishimwe et } \\
\text { al. (2017) }\end{array}$} & B1 & Rwanda & Maize & $\begin{array}{l}\text { ELISA followed } \\
\text { by fluorometer } \\
(\text { VICAM) if > } \\
100(\mu \mathrm{g} / \mathrm{kg})\end{array}$ & 78 & & & & 10.55 & 3.53 & 18.15 & & & $\begin{array}{l}\text { Nyabugogo } \\
\text { district - } \\
\text { round I }\end{array}$ \\
\hline & B1 & Rwanda & Maize & & 87 & & & & 8 & 6.93 & 5.57 & & & $\begin{array}{l}\text { Kimisagara } \\
\text { district - } \\
\text { round I }\end{array}$ \\
\hline & B1 & Rwanda & Maize & & 84 & & & & 11.74 & 7.28 & 14.79 & & & $\begin{array}{l}\text { Gikondo } \\
\text { district - } \\
\text { round I }\end{array}$ \\
\hline & B1 & Rwanda & Maize & & 45 & & & & 17.33 & 10.43 & 16.09 & & & $\begin{array}{l}\text { Nyamirambo } \\
\text { district - } \\
\text { round I }\end{array}$ \\
\hline & B1 & Rwanda & Maize & & 75 & & & & 17.79 & 12.57 & 14.48 & & & $\begin{array}{l}\text { Kicukiro - } \\
\text { round I }\end{array}$ \\
\hline & B1 & Rwanda & Maize & & 42 & & & & 14.93 & 13.98 & 7.31 & & & $\begin{array}{l}\text { Kimironko - } \\
\text { round I }\end{array}$ \\
\hline
\end{tabular}




\begin{tabular}{|c|c|c|c|c|c|c|c|c|c|c|c|c|c|c|}
\hline Reference & $\begin{array}{l}\text { Aflatoxin } \\
\text { type } \\
\text { studied }\end{array}$ & Country & $\begin{array}{l}\text { Product / } \\
\text { commodity }\end{array}$ & $\begin{array}{l}\text { Analytical } \\
\text { method used }\end{array}$ & $\begin{array}{l}\text { Number } \\
\text { of } \\
\text { samples } \\
\text { (n) }\end{array}$ & $\begin{array}{c}\text { LOQ } \\
(\mu \mathrm{g} / \mathbf{k g})\end{array}$ & $\begin{array}{c}\text { LOD } \\
(\mu \mathrm{g} / \mathbf{k g})\end{array}$ & $\begin{array}{c}\text { Positive } \\
\text { samples } \\
(\%)\end{array}$ & $\begin{array}{c}\text { Mean } \\
(\mu \mathrm{g} / \mathrm{kg})\end{array}$ & $\begin{array}{l}\text { Median } \\
(\mu \mathrm{g} / \mathrm{kg})\end{array}$ & SD & $\underset{(\mu \mathrm{gin} / \mathrm{kg})}{\operatorname{Min}}$ & $\begin{array}{c}\operatorname{Max} \\
(\mu \mathrm{g} / \mathbf{k g})\end{array}$ & Notes \\
\hline & B1 & Rwanda & Maize & & 63 & & & & 24.71 & 14.7 & 23.74 & & & $\begin{array}{l}\text { Nyarugenge } \\
\text { district - } \\
\text { round I }\end{array}$ \\
\hline & B1 & Rwanda & Maize & & 29 & & & & 21.41 & 18.77 & 19.1 & & & $\begin{array}{l}\text { Nyabugogo } \\
\text { district - } \\
\text { round II }\end{array}$ \\
\hline & B1 & Rwanda & Maize & & 30 & & & & 21.31 & 16.38 & 14.06 & & & $\begin{array}{l}\text { Kimisagara } \\
\text { district - } \\
\text { round II }\end{array}$ \\
\hline & B1 & Rwanda & Maize & & 30 & & & & 10.4 & 8.7 & 10.71 & & & $\begin{array}{l}\text { Gikondo } \\
\text { district - } \\
\text { round II }\end{array}$ \\
\hline & B1 & Rwanda & Maize & & 30 & & & & 25.69 & 22.25 & 25.85 & & & $\begin{array}{l}\text { Nyamirambo } \\
\text { district- } \\
\text { round II }\end{array}$ \\
\hline & B1 & Rwanda & Maize & & 30 & & & & 12.38 & 11.73 & 8.12 & & & $\begin{array}{l}\text { Kicukiro- } \\
\text { round II }\end{array}$ \\
\hline & B1 & Rwanda & Maize & & 30 & & & & 11.64 & 10.72 & 5.77 & & & $\begin{array}{l}\text { Kimironko- } \\
\text { round II }\end{array}$ \\
\hline & B1 & Rwanda & Maize & & 30 & & & & 10.24 & 6.85 & 8.4 & & & $\begin{array}{l}\text { Nyarugenge } \\
\text { district- } \\
\text { round II }\end{array}$ \\
\hline \multirow[t]{4}{*}{$\begin{array}{l}\text { Oueslati et } \\
\text { al. (2014) }\end{array}$} & B1 & Tunisia & Sorghum & LC-MS/MS & 60 & 0.1 & 0.03 & $38 \%$ & 1.49 & & & 0.07 & 8.23 & \\
\hline & B2 & Tunisia & Sorghum & & 60 & 0.62 & 0.19 & $1.70 \%$ & 0.82 & & & 0.82 & 0.82 & \\
\hline & G1 & Tunisia & Sorghum & & 60 & 1.73 & 0.72 & $0 \%$ & & & & & & \\
\hline & $\mathrm{G} 2$ & Tunisia & Sorghum & & 60 & 0.81 & 0.35 & $0 \%$ & & & & & & \\
\hline \multirow{5}{*}{$\begin{array}{l}\text { Oyedele et } \\
\text { al. (2017) }\end{array}$} & B1 & Nigeria & Peanut & LC-MS/MS & 84 & & 0.9 & $30 \%$ & 117.8 & & 194.4 & 0.9 & 710 & \\
\hline & B2 & Nigeria & Peanut & & 84 & & 0.4 & $18 \%$ & 30.8 & & 32.2 & 0.4 & 129 & \\
\hline & G1 & Nigeria & Peanut & & 84 & & 0.4 & $23 \%$ & 174.3 & & 366.6 & 0.4 & 1202 & \\
\hline & G2 & Nigeria & Peanut & & 84 & & 18.3 & $7 \%$ & 68.3 & & 44.4 & 18.3 & 123 & \\
\hline & Total & Nigeria & Peanut & & 84 & & nd & $39 \%$ & 216.1 & & 496.7 & 0.4 & 2076 & \\
\hline \multirow[t]{2}{*}{$\begin{array}{l}\text { Riba et al. } \\
(2013)\end{array}$} & B1 & Algeria & Peanut & HPLC & 8 & 0.1 & 0.05 & $100 \%$ & 6.3 & & 3.64 & 0.2 & 20.52 & $\begin{array}{l}\text { shelled } \\
\text { peanuts }\end{array}$ \\
\hline & AF total & Algeria & Peanut & & 8 & & & $100 \%$ & 7.1 & & 3.8 & 0.34 & 25.82 & $\begin{array}{l}\text { shelled } \\
\text { peanuts }\end{array}$ \\
\hline $\begin{array}{l}\text { Senerwa et } \\
\text { al. (2016) }\end{array}$ & M1 & Kenya & Milk & & 512 & & 0.002 & $103.7 \%$ & 0.0349 & 0 & & 0.002 & 6.999 & \\
\hline
\end{tabular}




\begin{tabular}{|c|c|c|c|c|c|c|c|c|c|c|c|c|c|c|}
\hline Reference & $\begin{array}{l}\text { Aflatoxin } \\
\text { type } \\
\text { studied }\end{array}$ & Country & $\begin{array}{l}\text { Product / } \\
\text { commodity }\end{array}$ & $\begin{array}{l}\text { Analytical } \\
\text { method used }\end{array}$ & $\begin{array}{c}\text { Number } \\
\text { of } \\
\text { samples } \\
\text { (n) }\end{array}$ & $\begin{array}{c}\text { LOQ } \\
(\mu \mathrm{g} / \mathrm{kg})\end{array}$ & $\begin{array}{c}\text { LOD } \\
(\mu \mathrm{g} / \mathrm{kg})\end{array}$ & $\begin{array}{c}\text { Positive } \\
\text { samples } \\
(\%)\end{array}$ & $\begin{array}{c}\text { Mean } \\
(\mu \mathrm{g} / \mathrm{kg})\end{array}$ & $\begin{array}{l}\text { Median } \\
(\mu \mathrm{g} / \mathrm{kg})\end{array}$ & SD & $\underset{(\mu \mathrm{Min} / \mathrm{kg})}{\operatorname{Min}}$ & $\begin{array}{c}\text { Max } \\
(\mu \mathrm{g} / \mathbf{k g})\end{array}$ & Notes \\
\hline & B1 & Kenya & $\begin{array}{l}\text { Animal feeds } \\
\text { (farmers) }\end{array}$ & & 144 & 1 & 1 & $77.8 \%$ & 196.4 & 17.2 & & & & \\
\hline & B1 & Kenya & $\begin{array}{l}\text { Animal feeds } \\
\text { (manufacturers) }\end{array}$ & & 102 & 5 & 1 & $61.8 \%$ & 108.9 & 11.8 & & $<1$ & 4682 & \\
\hline & B1 & Kenya & $\begin{array}{l}\text { Animal feeds } \\
\text { (retailers) }\end{array}$ & & 31 & 5 & 1 & $90.3 \%$ & 89.7 & 42.3 & & $<1$ & 1198 & \\
\hline $\begin{array}{l}\text { Suleiman et } \\
\text { al. (2017) }\end{array}$ & $\begin{array}{c}\mathrm{AF} \\
\text { general }\end{array}$ & Tanzania & Maize & ELISA & 30 & & & $100 \%$ & 4.2 & & 2.9 & 2 & 19.2 & \\
\hline \multirow[t]{6}{*}{$\begin{array}{l}\text { Wondimeneh } \\
\text { et al. (2016) }\end{array}$} & B1 & Ethiopia & $\begin{array}{c}\text { Sorghum } \\
\text { (fresh) }\end{array}$ & ELISA & 15 & & & $100 \%$ & & & & & 17 & Babile district \\
\hline & B1 & Ethiopia & $\begin{array}{l}\text { Sorghum } \\
\text { (fresh) }\end{array}$ & & 15 & & & $100 \%$ & & & & & 6.2 & Kersa district \\
\hline & B1 & Ethiopia & $\begin{array}{c}\text { Sorghum } \\
\text { (fresh) }\end{array}$ & & 15 & & & $100 \%$ & & & & & 2.2 & $\begin{array}{l}\text { Haramaya } \\
\text { district }\end{array}$ \\
\hline & B1 & Ethiopia & $\begin{array}{l}\text { Sorghum } \\
\text { (stored) }\end{array}$ & & 15 & & & $100 \%$ & & & & & 16.1 & Babile district \\
\hline & B1 & Ethiopia & $\begin{array}{l}\text { Sorghum } \\
\text { (stored) }\end{array}$ & & 15 & & & $100 \%$ & & & & & 33.1 & Kersa district \\
\hline & B1 & Ethiopia & $\begin{array}{l}\text { Sorghum } \\
\text { (stored) }\end{array}$ & & 15 & & & $100 \%$ & & & & & 11.8 & $\begin{array}{l}\text { Haramaya } \\
\text { district }\end{array}$ \\
\hline
\end{tabular}




\section{Annex 12 Overview of biomarker levels}

Table 43: Overview of biomarker levels (AFM1 in urine and AF-alb in serum)

\begin{tabular}{|c|c|c|c|c|c|c|c|c|c|c|c|c|c|c|c|c|c|}
\hline $\begin{array}{c}\text { Referenc } \\
\text { e }\end{array}$ & $\begin{array}{l}\text { Analyt } \\
\text { es } \\
\text { studie } \\
\text { d }\end{array}$ & $\underset{y}{\text { Countr }}$ & $\begin{array}{c}\text { Estimate } \\
\text { d } \\
\text { biomarke } \\
\text { rs }\end{array}$ & $\begin{array}{c}\text { Analytical } \\
\text { method used }\end{array}$ & Population & $\begin{array}{l}\text { Numb } \\
\text { er of } \\
\text { sampl } \\
\text { es }(n)\end{array}$ & $\begin{array}{l}\text { Positiv } \\
\text { e } \\
\text { sampl } \\
\text { es } \\
(\%) \\
\end{array}$ & & OD & Mean & & Median & SD & & $\operatorname{lin}$ & & $a x$ \\
\hline \multirow{2}{*}{$\begin{array}{l}\text { Abia et } \\
\text { al. } \\
\text { (2013a) }\end{array}$} & \multirow[t]{2}{*}{ AFM1 } & \multirow[t]{2}{*}{$\begin{array}{l}\text { Camero } \\
\text { on }\end{array}$} & \multirow[t]{2}{*}{ Urinary } & LC-Ms & HIV positive & 145 & $100 \%$ & $\begin{array}{r}0.0 \\
5\end{array}$ & $\mu \mathrm{g} / \mathrm{m}$ & 0.05 & $\mu \mathrm{g} / \mathrm{ml}$ & & & $\begin{array}{r}\mathrm{LO} \\
\mathrm{Q}\end{array}$ & $\mu \mathrm{g} / \mathrm{m}$ & $\begin{array}{r}1.3 \\
8\end{array}$ & $\mu \mathrm{g} / \mathrm{m}$ \\
\hline & & & & & $\begin{array}{l}\text { HIV sero- } \\
\text { negative }\end{array}$ & 30 & & $\begin{array}{r}0.0 \\
5\end{array}$ & $\mu \mathrm{g} / \mathrm{m}$ & $<\mathrm{LOQ}$ & $\mu \mathrm{g} / \mathrm{ml}$ & & & - & $\mu \mathrm{g} / \mathrm{m}$ & - & $\mu \mathrm{g} / \mathrm{m}$ \\
\hline \multirow[t]{2}{*}{$\begin{array}{l}\text { Castelino } \\
\text { et al. } \\
(2014)\end{array}$} & AF-alb & Gambia & Serum & $\begin{array}{l}\text { Immunochemis } \\
\text { try (ELISA, dip } \\
\text { stick test, } \\
\text { sensor) }\end{array}$ & $\begin{array}{l}\text { Early } \\
\text { pregnancy }\end{array}$ & 134 & & & & $\begin{array}{r}34.5(29.3 \\
40.7)^{*}\end{array}$ & $\mathrm{pg} / \mathrm{ml}$ & & & & & & \\
\hline & AF-alb & & & & $\begin{array}{l}\text { Late } \\
\text { pregnancy }\end{array}$ & 99 & $100 \%$ & & & $\begin{array}{r}41.8(34.7 \\
50.3)^{*}\end{array}$ & $\mathrm{pg} / \mathrm{ml}$ & & & & & & \\
\hline \multirow[t]{6}{*}{$\begin{array}{l}\text { Chen et } \\
\text { al. } \\
(2017)\end{array}$} & AFM1 & \multirow[t]{6}{*}{$\begin{array}{l}\text { Tanzani } \\
\text { a }\end{array}$} & \multirow[t]{6}{*}{$\begin{array}{l}\text { Urinary \& } \\
\text { Serum }\end{array}$} & \multirow[t]{6}{*}{$\begin{array}{l}\text { Immunochemis } \\
\text { try (ELISA, dip } \\
\text { stick test, } \\
\text { sensor) }\end{array}$} & $\begin{array}{l}\text { Children at } \\
\text { Kigwa } \\
\text { village (visit } \\
\text { 1) }\end{array}$ & & & 15 & $\mathrm{pg} / \mathrm{m}$ & $\begin{array}{c}42.5(27.2 \\
66.5)^{*}\end{array}$ & $\mathrm{pg} / \mathrm{ml}$ & & & ND & $\mathrm{pg}^{\mathrm{m}}$ & 886 & $\mathrm{pg}^{\mathrm{m}}$ \\
\hline & AF-alb & & & & $\begin{array}{l}\text { Children at } \\
\text { Kigwa } \\
\text { village (visit } \\
\text { 1) }\end{array}$ & & & 15 & $\mathrm{pg} / \mathrm{m}$ & $\begin{array}{c}9.3(6.6 \\
13.1)^{*}\end{array}$ & $\mathrm{pg} / \mathrm{ml}$ & & & & & & \\
\hline & AFM1 & & & & $\begin{array}{l}\text { Children at } \\
\text { Kigwa } \\
\text { village (visit } \\
\text { 2) }\end{array}$ & & $100 \%$ & 15 & $\mathrm{pg} / \mathrm{m}$ & $\begin{array}{c}71.0(44.7 \\
112.6)^{*}\end{array}$ & $\mathrm{pg} / \mathrm{ml}$ & & & $\begin{array}{r}15 . \\
1\end{array}$ & $\mathrm{pg} / \mathrm{m}$ & $\begin{array}{r}195 \\
0\end{array}$ & $\mathrm{pg}^{\mathrm{m} / \mathrm{m}}$ \\
\hline & AF-alb & & & & $\begin{array}{l}\text { Children at } \\
\text { Kigwa } \\
\text { village (visit } \\
\text { 2) }\end{array}$ & & $100 \%$ & 15 & $\mathrm{pg} / \mathrm{m}$ & $\begin{array}{r}47.3(29.7 \\
75.2)^{*}\end{array}$ & $\mathrm{pg} / \mathrm{ml}$ & & & & & & \\
\hline & AFM1 & & & & $\begin{array}{l}\text { Children at } \\
\text { Kigwa } \\
\text { village (visit } \\
3 \text { ) }\end{array}$ & & $100 \%$ & 15 & $\mathrm{pg} / \mathrm{m}$ & $\begin{array}{c}49.3(31.5 \\
77.3)^{*}\end{array}$ & $\mathrm{pg} / \mathrm{ml}$ & & & ND & $\mathrm{pg} / \mathrm{m}$ & $\begin{array}{r}284 \\
0\end{array}$ & $p^{p g / m}$ \\
\hline & AF-alb & & & & $\begin{array}{l}\text { Children at } \\
\text { Kigwa } \\
\text { village (visit } \\
\text { 3) }\end{array}$ & & $100 \%$ & 15 & $\mathrm{pg} / \mathrm{m}$ & $\begin{array}{c}52.7(35.4 \\
78.3)^{*}\end{array}$ & $\mathrm{pg} / \mathrm{ml}$ & & & & & & \\
\hline
\end{tabular}




\begin{tabular}{|c|c|c|c|c|c|c|c|c|c|c|c|c|c|c|c|c|c|c|}
\hline $\begin{array}{c}\text { Referenc } \\
\text { e }\end{array}$ & \multirow{2}{*}{$\begin{array}{c}\begin{array}{c}\text { Analyt } \\
\text { es } \\
\text { studie } \\
\text { d }\end{array} \\
\text { AFM1 }\end{array}$} & $\begin{array}{c}\text { Countr } \\
y\end{array}$ & $\begin{array}{c}\text { Estimate } \\
\text { d } \\
\text { biomarke } \\
\text { rs }\end{array}$ & $\begin{array}{l}\text { Analytical } \\
\text { method used }\end{array}$ & \multirow{2}{*}{$\begin{array}{l}\text { Population } \\
\\
\text { Children at } \\
\text { Nyabula } \\
\text { (Iringa) } \\
\text { village (visit } \\
\text { 2) }\end{array}$} & \multirow{2}{*}{$\begin{array}{l}\text { Numb } \\
\text { er of } \\
\text { sampl } \\
\text { es }(n)\end{array}$} & \multirow{2}{*}{$\begin{array}{l}\text { Positiv } \\
\text { e } \\
\text { sampl } \\
\text { es } \\
(\%) \\
100 \%\end{array}$} & \multicolumn{2}{|c|}{ LOD } & \multicolumn{2}{|l|}{ Mean } & \multirow[t]{2}{*}{ Median } & \multicolumn{2}{|c|}{ SD } & \multicolumn{2}{|c|}{ Min } & \multicolumn{2}{|c|}{ Max } \\
\hline & & & & & & & & 15 & $\mathrm{pg}_{\mathrm{l}} / \mathrm{m}$ & $\begin{array}{r}29.3(22.1 \\
38.9)^{*}\end{array}$ & $\mathrm{pg} / \mathrm{ml}$ & & & & ND & $\mathrm{pg}_{\mathrm{l}} \mathrm{m}$ & 281 & $\mathrm{pg}^{\mathrm{pg} / \mathrm{m}}$ \\
\hline & AF-alb & & & & $\begin{array}{l}\text { Children at } \\
\text { Nyabula } \\
\text { (Iringa) } \\
\text { village (visit } \\
\text { 2) }\end{array}$ & & $100 \%$ & 15 & $\mathrm{pg} / \mathrm{m}$ & $\begin{array}{c}12.4(8.1 \\
18.9)^{*}\end{array}$ & $\mathrm{pg} / \mathrm{ml}$ & & & & ND & $\mathrm{pg} / \mathrm{m}$ & 131 & $\mathrm{pg}_{1} / \mathrm{m}$ \\
\hline & AFM1 & & & & $\begin{array}{l}\text { Children at } \\
\text { Kikelelwa } \\
\text { (Kilimanjaro } \\
\text { ) village } \\
\text { (visit 2) }\end{array}$ & & $100 \%$ & 15 & $\mathrm{pg} / \mathrm{m}$ & $\begin{array}{r}12.9(9.6 \\
17.5)^{*}\end{array}$ & $\mathrm{pg} / \mathrm{ml}$ & & & & ND & $\mathrm{pg} / \mathrm{m}$ & $\begin{array}{r}30 . \\
6\end{array}$ & $\mathrm{pg} / \mathrm{m}$ \\
\hline & AF-alb & & & & $\begin{array}{l}\text { Children at } \\
\text { Kikelelwa } \\
\text { (Kilimanjaro } \\
\text { ) village } \\
\text { (visit 2) }\end{array}$ & & $100 \%$ & 15 & $\mathrm{pg} / \mathrm{m}$ & $\begin{array}{r}3.2(2.3 \\
4.3)^{*}\end{array}$ & $\mathrm{pg} / \mathrm{ml}$ & & & & ND & $\mathrm{pg} / \mathrm{m}$ & 15 & $\mathrm{pg} / \mathrm{m}$ \\
\hline & AFM1 & & & & $\begin{array}{l}\text { Children at } \\
\text { Kigwa } \\
\text { (Tabora) } \\
\text { village (visit } \\
\text { 2) }\end{array}$ & & $14 \%$ & 15 & $\mathrm{pg} / \mathrm{m}$ & $\begin{array}{c}71.0(44.7 \\
112.6)^{*}\end{array}$ & $\mathrm{pg} / \mathrm{ml}$ & & & & $\begin{array}{r}15 \\
1\end{array}$ & $\mathrm{pg} / \mathrm{m}$ & $\begin{array}{r}195 \\
0\end{array}$ & $\mathrm{pg} / \mathrm{m}$ \\
\hline & AF-alb & & & & $\begin{array}{l}\text { Children at } \\
\text { Kigwa } \\
\text { (Tabora) } \\
\text { village (visit } \\
\text { 2) }\end{array}$ & & $0 \%$ & 15 & $\mathrm{pg} / \mathrm{m}$ & $\begin{array}{r}47.3(29.7 \\
75.2)^{*}\end{array}$ & $\mathrm{pg} / \mathrm{ml}$ & & & & ND & $\mathrm{pg} / \mathrm{m}$ & 853 & $\mathrm{pg} / \mathrm{m}$ \\
\hline $\begin{array}{l}\text { Ediage et } \\
\text { al. } \\
(2014)\end{array}$ & AFM1 & $\begin{array}{l}\text { Camero } \\
\text { on }\end{array}$ & Urinary & LC-MS & $\begin{array}{l}\text { Children } \\
\text { aged } 1-5 \\
\text { years }\end{array}$ & 220 & $0 \%$ & $\begin{array}{r}0.0 \\
1\end{array}$ & $\mathrm{ng} / \mathrm{m}$ & $\begin{array}{r}0.33(0.06- \\
4.7)^{*}\end{array}$ & & & & & & & & \\
\hline $\begin{array}{l}\text { Ezekiel et } \\
\text { al. } \\
(2014)\end{array}$ & AFM1 & Nigeria & Urinary & LC-MS & $\begin{array}{l}\text { rural } \\
\text { residents }\end{array}$ & 120 & & $\begin{array}{r}0.0 \\
5\end{array}$ & $\mu \mathrm{g} / \mathrm{m}$ & 0.3 & $\mu \mathrm{g} / \mathrm{ml}$ & & 0.4 & $\mu g / m$ & & & 1.5 & $\mu \mathrm{g} / \mathrm{m}$ \\
\hline $\begin{array}{l}\text { Hernande } \\
\text { z-Vargas } \\
\text { et al. } \\
(2015)\end{array}$ & $\begin{array}{l}\text { AF-alb } \\
\text { AF-alb } \\
\text { AF-alb } \\
\text { AF-alb }\end{array}$ & Gambia & Serum & $\begin{array}{l}\text { Genome-wide } \\
\text { DNA } \\
\text { methylation }\end{array}$ & $\begin{array}{l}\text { Pregnant } \\
\text { women - } \\
\text { high AF } \\
\text { exposure } \\
\text { group - dry } \\
\text { season }\end{array}$ & 30 & $100 \%$ & 0.6 & $\begin{array}{l}\mathrm{pg} / \mathrm{m} \\
\mathrm{g}\end{array}$ & 75.83 & $\mathrm{pg} / \mathrm{mg}$ & & & & $\begin{array}{r}58 . \\
8\end{array}$ & $\begin{array}{l}\mathrm{pg} / \mathrm{m} \\
\mathrm{g}\end{array}$ & $\begin{array}{r}97 . \\
9\end{array}$ & $\begin{array}{l}\mathrm{pg} / \mathrm{m} \\
\mathrm{g}\end{array}$ \\
\hline
\end{tabular}




\begin{tabular}{|c|c|c|c|c|c|c|c|c|c|c|c|c|c|c|c|c|c|c|c|}
\hline \multirow{4}{*}{$\begin{array}{c}\text { Referenc } \\
\text { e }\end{array}$} & \multirow{4}{*}{$\begin{array}{l}\text { Analyt } \\
\text { es } \\
\text { studie } \\
\text { d }\end{array}$} & \multirow{4}{*}{$\begin{array}{c}\text { Countr } \\
y\end{array}$} & \multirow{4}{*}{$\begin{array}{c}\text { Estimate } \\
\text { d } \\
\text { biomarke } \\
\text { rs }\end{array}$} & \multirow{4}{*}{$\begin{array}{c}\text { Analytical } \\
\text { method used }\end{array}$} & \multirow{2}{*}{$\begin{array}{l}\text { Population } \\
\text { Pregnant } \\
\text { women - } \\
\text { high AF } \\
\text { exposure } \\
\text { group - } \\
\text { rainy season }\end{array}$} & \multirow{2}{*}{$\begin{array}{c}\begin{array}{c}\text { Numb } \\
\text { er of }\end{array} \\
\text { sampl } \\
\text { es }(\mathbf{n})\end{array}$} & \multirow{2}{*}{ 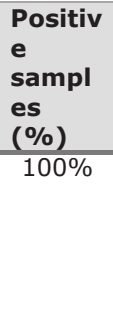 } & \multicolumn{2}{|c|}{ LOD } & \multicolumn{2}{|l|}{ Mean } & \multicolumn{2}{|c|}{ Median } & \multicolumn{2}{|c|}{ SD } & \multicolumn{2}{|c|}{ Min } & \multicolumn{2}{|c|}{ Max } \\
\hline & & & & & & & & 0.6 & $\begin{array}{l}\mathrm{pg} / \mathrm{m} \\
\mathrm{g}\end{array}$ & 78.96 & $\mathrm{pg} / \mathrm{mg}$ & & & & & $\begin{array}{r}60 . \\
9\end{array}$ & $\begin{array}{l}\mathrm{pg} / \mathrm{m} \\
\mathrm{g}\end{array}$ & 102 & $\begin{array}{l}\mathrm{pg} / \mathrm{m} \\
\mathrm{g}\end{array}$ \\
\hline & & & & & $\begin{array}{l}\text { Pregnant } \\
\text { women - low } \\
\text { AF exposure } \\
\text { group - dry } \\
\text { season }\end{array}$ & 27 & $100 \%$ & 0.6 & $\begin{array}{l}\mathrm{pg} / \mathrm{m} \\
\mathrm{g}\end{array}$ & 13.85 & $\mathrm{pg} / \mathrm{mg}$ & & & & & $\begin{array}{r}11 . \\
3\end{array}$ & $\begin{array}{l}\mathrm{pg} / \mathrm{m} \\
\mathrm{g}\end{array}$ & 17 & $\begin{array}{l}\mathrm{pg} / \mathrm{m} \\
\mathrm{g}\end{array}$ \\
\hline & & & & & $\begin{array}{l}\text { Pregnant } \\
\text { women - low } \\
\text { AF exposure } \\
\text { group - } \\
\text { rainy season }\end{array}$ & 33 & $100 \%$ & 0.6 & $\begin{array}{l}\mathrm{pg} / \mathrm{m} \\
\mathrm{g}\end{array}$ & 18.2 & $\mathrm{pg} / \mathrm{mg}$ & & & & & $\begin{array}{r}15 . \\
4\end{array}$ & $\begin{array}{l}\mathrm{pg} / \mathrm{m} \\
\mathrm{g}\end{array}$ & $\begin{array}{r}21 . \\
5\end{array}$ & $\begin{array}{l}\mathrm{pg} / \mathrm{m} \\
\mathrm{g}\end{array}$ \\
\hline \multirow[t]{3}{*}{$\begin{array}{l}\text { Jolly et } \\
\text { al. } \\
(2015)\end{array}$} & AF-alb & \multirow[t]{3}{*}{ Ghana } & \multirow[t]{3}{*}{ Serum } & \multirow[t]{3}{*}{ HPLC } & $\begin{array}{l}\text { Adults with } \\
\text { HIV positive } \\
\text { (baseline) }\end{array}$ & 307 & $96 \%$ & 0.6 & $\begin{array}{l}\mathrm{pg} / \mathrm{m} \\
\mathrm{g}\end{array}$ & 14.95 & $\mathrm{pg} / \mathrm{mg}$ & $\begin{array}{r}10.3 \\
6\end{array}$ & \multicolumn{2}{|l|}{$\mathrm{pg} / \mathrm{mg}$} & & 0.2 & $\begin{array}{l}\mathrm{pg} / \mathrm{m} \\
\mathrm{g}\end{array}$ & 110 & $\begin{array}{l}\mathrm{pg} / \mathrm{m} \\
\mathrm{g}\end{array}$ \\
\hline & AF-alb & & & & $\begin{array}{l}\text { Adults with } \\
\text { HIV positive } \\
\text { - Followup } 1 \\
\text { ( } 6 \text { month) }\end{array}$ & 169 & $100 \%$ & 0.6 & $\begin{array}{l}\mathrm{pg} / \mathrm{m} \\
\mathrm{g}\end{array}$ & 23.27 & $\mathrm{pg} / \mathrm{mg}$ & 16.7 & \multicolumn{2}{|l|}{$\mathrm{pg} / \mathrm{mg}$} & & 0.9 & $\begin{array}{l}\mathrm{pg} / \mathrm{m} \\
\mathrm{g}\end{array}$ & 198 & $\begin{array}{l}\mathrm{pg} / \mathrm{m} \\
\mathrm{g}\end{array}$ \\
\hline & AF-alb & & & & $\begin{array}{l}\text { Adults with } \\
\text { HIV positive } \\
\text { - Followup } 1 \\
\text { (12 month) }\end{array}$ & 114 & $100 \%$ & 0.6 & $\begin{array}{l}\mathrm{pg} / \mathrm{m} \\
\mathrm{g}\end{array}$ & 15.32 & $\mathrm{pg} / \mathrm{mg}$ & $\begin{array}{r}11.2 \\
9\end{array}$ & $\begin{array}{l}\mathrm{pg} / \mathrm{m} \\
\mathrm{g}\end{array}$ & & & $\begin{array}{r}0.6 \\
9\end{array}$ & $\begin{array}{l}\mathrm{pg} / \mathrm{m} \\
\mathrm{g}\end{array}$ & $\begin{array}{r}76 . \\
1\end{array}$ & $\begin{array}{l}\mathrm{pg} / \mathrm{m} \\
\mathrm{g}\end{array}$ \\
\hline \multirow{6}{*}{$\begin{array}{l}\text { Kumi et } \\
\text { al. } \\
\text { (2015) }\end{array}$} & AFM1 & \multirow[t]{6}{*}{ Ghana } & \multirow[t]{6}{*}{ Urinary } & \multirow[t]{6}{*}{ HPLC } & $\begin{array}{l}\text { Children day } \\
0 \text { - Ejura }\end{array}$ & \multirow[t]{3}{*}{28} & & 0.5 & $\begin{array}{l}\mathrm{pg} / \mathrm{m} \\
\mathrm{g}\end{array}$ & 2058 & $\mathrm{pg} / \mathrm{mg}$ & & & $\begin{array}{r}1509 . \\
7\end{array}$ & $\begin{array}{l}\mathrm{pg} / \mathrm{m} \\
\mathrm{g}\end{array}$ & $\begin{array}{r}13 \\
6\end{array}$ & $\begin{array}{l}\mathrm{pg} / \mathrm{m} \\
\mathrm{g}\end{array}$ & $\begin{array}{r}380 \\
4\end{array}$ & $\begin{array}{l}\mathrm{pg} / \mathrm{m} \\
\mathrm{g}\end{array}$ \\
\hline & AFM1 & & & & $\begin{array}{l}\text { Children day } \\
0- \\
\text { Hiawoawu }\end{array}$ & & $100 \%$ & 0.5 & $\begin{array}{l}\mathrm{pg} / \mathrm{m} \\
\mathrm{g}\end{array}$ & 208 & $\mathrm{pg} / \mathrm{mg}$ & & & 133.6 & $\begin{array}{l}\mathrm{pg} / \mathrm{m} \\
\mathrm{g}\end{array}$ & $\begin{array}{r}50 . \\
9\end{array}$ & $\begin{array}{l}\mathrm{pg} / \mathrm{m} \\
\mathrm{g}\end{array}$ & 441 & $\begin{array}{l}\mathrm{pg} / \mathrm{m} \\
\mathrm{g}\end{array}$ \\
\hline & AFM1 & & & & $\begin{array}{l}\text { Children day } \\
0- \\
\text { Dromamku } \\
\text { man }\end{array}$ & & & 0.5 & $\begin{array}{l}\mathrm{pg} / \mathrm{m} \\
\mathrm{g}\end{array}$ & 508 & $\mathrm{pg} / \mathrm{mg}$ & & & 536.4 & $\begin{array}{l}\mathrm{pg} / \mathrm{m} \\
\mathrm{g}\end{array}$ & $\begin{array}{r}24 . \\
7\end{array}$ & $\begin{array}{l}\mathrm{pg} / \mathrm{m} \\
\mathrm{g}\end{array}$ & $\begin{array}{r}105 \\
5\end{array}$ & $\begin{array}{l}\mathrm{pg} / \mathrm{m} \\
\mathrm{g}\end{array}$ \\
\hline & AFM1 & & & & $\begin{array}{l}\text { Children day } \\
21 \text { - Ejura }\end{array}$ & \multirow[t]{3}{*}{20} & & 0.5 & $\begin{array}{l}\mathrm{pg} / \mathrm{m} \\
\mathrm{g}\end{array}$ & 3583.3 & $\mathrm{pg} / \mathrm{mg}$ & & & $\begin{array}{r}3125 . \\
5\end{array}$ & $\begin{array}{l}\mathrm{pg} / \mathrm{m} \\
\mathrm{g}\end{array}$ & $\begin{array}{r}29 \\
4\end{array}$ & $\begin{array}{l}\mathrm{pg} / \mathrm{m} \\
\mathrm{g}\end{array}$ & $\begin{array}{r}836 \\
9 \\
\end{array}$ & $\begin{array}{l}\mathrm{pg} / \mathrm{m} \\
\mathrm{g}\end{array}$ \\
\hline & AFM1 & & & & $\begin{array}{l}\text { Children day } \\
21 \text { - } \\
\text { Hiawoawu }\end{array}$ & & $100 \%$ & 0.5 & $\begin{array}{l}\mathrm{pg} / \mathrm{m} \\
\mathrm{g}\end{array}$ & 1161.7 & $\mathrm{pg} / \mathrm{mg}$ & & & $\begin{array}{r}1015 . \\
2\end{array}$ & $\begin{array}{l}\mathrm{pg} / \mathrm{m} \\
\mathrm{g}\end{array}$ & $\begin{array}{r}59 . \\
8\end{array}$ & $\begin{array}{l}\mathrm{pg} / \mathrm{m} \\
\mathrm{g}\end{array}$ & $\begin{array}{r}298 \\
4\end{array}$ & $\begin{array}{l}\mathrm{pg} / \mathrm{m} \\
\mathrm{g}\end{array}$ \\
\hline & AFM1 & & & & $\begin{array}{l}\text { Children day } \\
21- \\
\text { Dromamku } \\
\text { man }\end{array}$ & & & 0.5 & $\begin{array}{l}\mathrm{pg} / \mathrm{m} \\
\mathrm{g}\end{array}$ & 1458 & $\mathrm{pg} / \mathrm{mg}$ & & & $\begin{array}{r}1256 . \\
3\end{array}$ & $\begin{array}{l}\mathrm{pg} / \mathrm{m} \\
\mathrm{g}\end{array}$ & $\begin{array}{r}18 \\
3\end{array}$ & $\begin{array}{l}\mathrm{pg} / \mathrm{m} \\
\mathrm{g}\end{array}$ & $\begin{array}{r}325 \\
8\end{array}$ & $\begin{array}{l}\mathrm{pg} / \mathrm{m} \\
\mathrm{g}\end{array}$ \\
\hline
\end{tabular}




\begin{tabular}{|c|c|c|c|c|c|c|c|c|c|c|c|c|c|c|c|c|c|c|}
\hline \multirow{2}{*}{$\begin{array}{l}\begin{array}{l}\text { Referenc } \\
\text { e }\end{array} \\
\text { Leroy et } \\
\text { al. } \\
(2015)\end{array}$} & \multirow{2}{*}{$\begin{array}{c}\begin{array}{c}\text { Analyt } \\
\text { es } \\
\text { studie } \\
\text { d }\end{array} \\
\text { AF-alb }\end{array}$} & \multirow{2}{*}{$\begin{array}{l}\underset{y}{\text { Countr }} \\
\text { Kenya }\end{array}$} & \multirow{2}{*}{$\begin{array}{l}\begin{array}{c}\text { Estimate } \\
\text { d } \\
\text { biomarke } \\
\text { rs }\end{array} \\
\text { Serum }\end{array}$} & \multirow{2}{*}{$\begin{array}{l}\begin{array}{c}\text { Analytical } \\
\text { method used }\end{array} \\
\text { HPLC }\end{array}$} & \multirow{2}{*}{$\begin{array}{l}\text { Population } \\
\text { Women in } \\
\text { Kenya and } \\
\text { specific } \\
\text { socio- } \\
\text { demographic } \\
\text { characteristi } \\
\text { cs }\end{array}$} & \multirow{2}{*}{$\begin{array}{c}\begin{array}{c}\text { Numb } \\
\text { er of } \\
\text { sampl } \\
\text { es }(\mathbf{n})\end{array} \\
884\end{array}$} & \multirow{2}{*}{$\begin{array}{l}\text { Positiv } \\
\text { e } \\
\text { sampl } \\
\text { es } \\
(\%)\end{array}$} & \multicolumn{2}{|c|}{ LOD } & \multicolumn{2}{|l|}{ Mean } & \multicolumn{2}{|c|}{ Median } & SD & \multicolumn{2}{|c|}{ Min } & \multicolumn{2}{|c|}{ Max } \\
\hline & & & & & & & & & & 7.82 & $\mathrm{pg} / \mathrm{mg}$ & $\begin{array}{r}7.47 \\
(6.0 \\
4- \\
8.9) \\
*\end{array}$ & $\begin{array}{l}\mathrm{pg} / \mathrm{m} \\
\mathrm{g}\end{array}$ & & & & & \\
\hline \multirow[t]{7}{*}{$\begin{array}{l}\text { McMillan } \\
\text { et al. } \\
\text { (2018) }\end{array}$} & AF-alb & \multirow[t]{7}{*}{ Nigeria } & \multirow[t]{7}{*}{ Serum } & \multirow[t]{7}{*}{ LC-MS } & $\begin{array}{l}\text { Children } \\
\text { with severe } \\
\text { malnutrition } \\
\text { (all- } \\
\text { general) }\end{array}$ & 58 & & 22 & $\mathrm{pg} / \mathrm{m}$ & & & 2.6 & $\mathrm{pg} / \mathrm{m}$ & & 0.2 & $\mathrm{pg} / \mathrm{m}$ & $\begin{array}{r}59 . \\
2\end{array}$ & $\mathrm{pg} / \mathrm{m}$ \\
\hline & AF-alb & & & & $\begin{array}{l}\text { Children } \\
\text { with SAM }\end{array}$ & 47 & & 22 & $\mathrm{pg} / \mathrm{m}$ & & & 4.3 & $\mathrm{pg} / \mathrm{m}$ & & 0.2 & $\mathrm{pg} / \mathrm{m}$ & $\begin{array}{r}59 . \\
5\end{array}$ & $\mathrm{pg} / \mathrm{m}$ \\
\hline & AF-alb & & & & $\begin{array}{l}\text { Chidlren } \\
\text { with } \\
\text { Kwashiorkor }\end{array}$ & 26 & & 22 & $\mathrm{pg} / \mathrm{m}$ & & & 6.3 & $\mathrm{pg} / \mathrm{m}$ & & 0.3 & $\mathrm{pg} / \mathrm{m}$ & $\begin{array}{r}27 . \\
6\end{array}$ & $\mathrm{pg} / \mathrm{m}$ \\
\hline & AF-alb & & & & $\begin{array}{l}\text { Children } \\
\text { with } \\
\text { Marasmus }\end{array}$ & 21 & & 22 & $\mathrm{pg} / \mathrm{m}$ & & & 0.9 & $\mathrm{pg} / \mathrm{m}$ & & 0.2 & $\mathrm{pg} / \mathrm{m}$ & $\begin{array}{r}15 . \\
6\end{array}$ & $\mathrm{pg} / \mathrm{m}$ \\
\hline & AF-alb & & & & $\begin{array}{l}\text { Children } \\
\text { (control) }\end{array}$ & 11 & & 22 & $\mathrm{pg} / \mathrm{m}$ & & & 0.8 & $\mathrm{pg} / \mathrm{m}$ & & 0.2 & $\mathrm{pg} / \mathrm{m}$ & 2.9 & $\mathrm{pg} / \mathrm{m}$ \\
\hline & AF-alb & & & & $\begin{array}{l}\text { Children } \\
\text { stunted }\end{array}$ & 43 & & 22 & $\mathrm{pg} / \mathrm{m}$ & & & 4.6 & $\mathrm{pg} / \mathrm{m}$ & & 0.2 & $\mathrm{pg} / \mathrm{m}$ & $\begin{array}{r}27 . \\
6\end{array}$ & $\mathrm{pg} / \mathrm{m}$ \\
\hline & AF-alb & & & & $\begin{array}{l}\text { Children non } \\
\text { stunted }\end{array}$ & 15 & & 22 & $\mathrm{pg} / \mathrm{m}$ & & & 1.2 & $\mathrm{pg} / \mathrm{m}$ & & 0.2 & $\mathrm{pg} / \mathrm{m}$ & $\begin{array}{r}59 . \\
2\end{array}$ & $\mathrm{pg} / \mathrm{m}$ \\
\hline $\begin{array}{l}\text { Ediage et } \\
\text { al. } \\
(2013)\end{array}$ & AFM1 & $\begin{array}{l}\text { Camero } \\
\text { on }\end{array}$ & Urinary & LC-MS & Children & 220 & & $\begin{array}{r}0.0 \\
1\end{array}$ & $\begin{array}{l}\mathrm{ng} / \mathrm{m} \\
1\end{array}$ & $\begin{array}{r}0.33(0.06- \\
4.7)\end{array}$ & $\mathrm{ng} / \mathrm{ml}$ & & & & & & & \\
\hline \multirow{2}{*}{$\begin{array}{l}\text { Obuseh } \\
\text { et al. } \\
\text { (2011) }\end{array}$} & AF-alb & Ghana & Serum & $\begin{array}{l}\text { radioimmunoas } \\
\text { say (RIA) }\end{array}$ & $\begin{array}{l}\text { HIV negative } \\
\text { adult }\end{array}$ & 147 & & & & 0.9 & $\begin{array}{l}\mathrm{pmol} / \\
\mathrm{mg}\end{array}$ & 0.8 & & 0.5 & & & & \\
\hline & AF-alb & & & & $\begin{array}{l}\text { HIV postive } \\
\text { adult }\end{array}$ & 158 & $84 \%$ & & & 1.1 & $\begin{array}{l}\mathrm{pmol} / \\
\mathrm{mg}\end{array}$ & 0.9 & & 0.6 & & & & \\
\hline \multirow[t]{4}{*}{$\begin{array}{l}\text { Oluwafe } \\
\text { mi } \\
\text { (2012) }\end{array}$} & AFB1 & \multirow[t]{4}{*}{ Nigeria } & \multirow[t]{4}{*}{ Serum } & \multirow[t]{4}{*}{ HPLC } & $\begin{array}{l}\text { Feed mill } \\
\text { workers } \\
\text { (male) }\end{array}$ & \multirow[t]{4}{*}{28} & $59 \%$ & 0.6 & $l^{\mathrm{ng} / \mathrm{m}}$ & $73.4-189.2$ & $\mathrm{ng} / \mathrm{ml}$ & & & & & & & \\
\hline & AFB2 & & & & $\begin{array}{l}\text { Feed mill } \\
\text { workers } \\
\text { (male) }\end{array}$ & & $73 \%$ & 0.1 & $\begin{array}{l}\mathrm{ng} / \mathrm{m} \\
\mathrm{l}\end{array}$ & $<0.1-0.5$ & $\mathrm{ng} / \mathrm{ml}$ & & & & & & & \\
\hline & AFG1 & & & & $\begin{array}{l}\text { Feed mill } \\
\text { workers } \\
\text { (male) }\end{array}$ & & $86 \%$ & 0.1 & $\mathrm{ng} / \mathrm{m}$ & $0.3-1.9$ & $\mathrm{ng} / \mathrm{ml}$ & & & & & & & \\
\hline & AFG2 & & & & $\begin{array}{l}\text { Feed mill } \\
\text { workers } \\
\text { (male) }\end{array}$ & & $30 \%$ & 0.1 & $\begin{array}{l}\mathrm{ng} / \mathrm{m} \\
\mathrm{l}\end{array}$ & $<0.1-3.4$ & $\mathrm{ng} / \mathrm{ml}$ & & & & & & & \\
\hline
\end{tabular}




\begin{tabular}{|c|c|c|c|c|c|c|c|c|c|c|c|c|c|c|c|c|c|}
\hline \multirow[t]{5}{*}{$\begin{array}{c}\text { Referenc } \\
\text { e }\end{array}$} & \multirow[t]{2}{*}{$\begin{array}{c}\begin{array}{c}\text { Analyt } \\
\text { es } \\
\text { studie } \\
\text { d }\end{array} \\
\text { AFB1 }\end{array}$} & $\begin{array}{c}\text { Countr } \\
y\end{array}$ & $\begin{array}{c}\text { Estimate } \\
\text { d } \\
\text { biomarke } \\
\text { rs }\end{array}$ & $\begin{array}{l}\text { Analytical } \\
\text { method used }\end{array}$ & \multirow{2}{*}{ 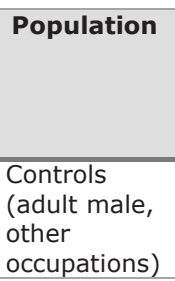 } & \multirow[t]{2}{*}{$\begin{array}{l}\text { Numb } \\
\text { er of } \\
\text { sampl } \\
\text { es }(n)\end{array}$} & \multirow[t]{2}{*}{$\begin{array}{l}\text { Positiv } \\
\text { e } \\
\text { sampl } \\
\text { es } \\
(\%) \\
\end{array}$} & & DD & \multicolumn{2}{|l|}{ Mean } & \multirow[t]{2}{*}{ Median } & \multirow[t]{2}{*}{ SD } & \multicolumn{2}{|c|}{ Min } & \multicolumn{2}{|c|}{ Max } \\
\hline & & & & & & & & 0.6 & $\mathrm{ng}_{1}$ & $<0.6$ & $\mathrm{ng} / \mathrm{ml}$ & & & & & & \\
\hline & AFB2 & & & & $\begin{array}{l}\text { Controls } \\
\text { (adult male, } \\
\text { other } \\
\text { occupations) }\end{array}$ & & $88 \%$ & 0.1 & $\mathrm{ng}_{1} \mathrm{~m}$ & $<0.1-0.3$ & $\mathrm{ng} / \mathrm{ml}$ & & & & & & \\
\hline & AFG1 & & & & $\begin{array}{l}\text { Controls } \\
\text { (adult male, } \\
\text { other } \\
\text { occupations) }\end{array}$ & & $93 \%$ & 0.1 & $\mathrm{ng}_{\mathrm{i}}$ & $04-1.5$ & $\mathrm{ng} / \mathrm{ml}$ & & & & & & \\
\hline & AFG2 & & & & $\begin{array}{l}\text { Controls } \\
\text { (adult male, } \\
\text { other } \\
\text { occupations) }\end{array}$ & & & 0.1 & $\mathrm{ng}_{\mathrm{l}} \mathrm{m}$ & $<0.1-0.3$ & $\mathrm{ng} / \mathrm{ml}$ & & & & & & \\
\hline \multirow[t]{2}{*}{$\begin{array}{l}\text { Piekkola } \\
\text { et al. } \\
\text { (2012) }\end{array}$} & AF-alb & \multirow[t]{2}{*}{ Egypt } & \multirow[t]{2}{*}{$\begin{array}{l}\text { Urinary \& } \\
\text { serum }\end{array}$} & \multirow[t]{2}{*}{ LC-MS } & $\begin{array}{l}\text { diet and } \\
\text { socioeconom } \\
\text { ic status }\end{array}$ & 98 & & & & $\begin{array}{r}2.25(1.98- \\
2.56)^{*}\end{array}$ & $\mathrm{pg} / \mathrm{mg}$ & & & 3 & $\begin{array}{l}\mathrm{pg} / \mathrm{m} \\
\mathrm{g}\end{array}$ & $\begin{array}{r}35 . \\
1\end{array}$ & $\begin{array}{l}\mathrm{pg} / \mathrm{m} \\
\mathrm{g}\end{array}$ \\
\hline & AFM1 & & & & $\begin{array}{l}\text { diet and } \\
\text { socioeconom } \\
\text { ic status }\end{array}$ & 93 & & & & $\begin{array}{r}5.48(4.12- \\
7.28)^{*}\end{array}$ & $\mathrm{ng} / \mathrm{mg}$ & & & 4.1 & $\begin{array}{l}\mathrm{ng} / \mathrm{m} \\
\mathrm{g}\end{array}$ & 409 & $\begin{array}{l}\mathrm{ng} / \mathrm{m} \\
\mathrm{g}\end{array}$ \\
\hline $\begin{array}{l}\text { Routledg } \\
\text { e et al. } \\
\text { (2014) }\end{array}$ & AF-alb & $\begin{array}{l}\text { Tanzani } \\
\text { a }\end{array}$ & Urinary & HPLC & $\begin{array}{l}\text { Children } \\
\text { consuming } \\
\text { weaning } \\
\text { food } \\
\text { containing } \\
\text { groundnut } \\
\text { and maize }\end{array}$ & 148 & & & & $\begin{array}{r}23.4(19.9- \\
27.7)^{*}\end{array}$ & $\mathrm{pg} / \mathrm{mg}$ & & & & & & \\
\hline \multirow[t]{4}{*}{$\begin{array}{l}\text { Saad- } \\
\text { Hussein } \\
\text { et al. } \\
(2013 b)\end{array}$} & AFM1 & \multirow[t]{4}{*}{ Egypt } & \multirow[t]{4}{*}{$\begin{array}{l}\text { Urinary \& } \\
\text { serum }\end{array}$} & \multirow[t]{4}{*}{ HPLC } & $\begin{array}{l}\text { Flour milling } \\
\text { workers } \\
\text { (storage } \\
\text { workres) }\end{array}$ & & & & & 0.077 & $\mathrm{ng} / \mathrm{mg}$ & & & & & & \\
\hline & AFM1 & & & & $\begin{array}{l}\text { Flour milling } \\
\text { workers } \\
\text { (garbling } \\
\text { workers) }\end{array}$ & & & & & 0.098 & $\mathrm{ng} / \mathrm{mg}$ & & & & & & \\
\hline & AFM1 & & & & $\begin{array}{l}\text { Flour milling } \\
\text { workers } \\
\text { (grinding } \\
\text { workers) }\end{array}$ & & & & & 0.313 & $\mathrm{ng} / \mathrm{mg}$ & & & & & & \\
\hline & AFM1 & & & & $\begin{array}{l}\text { Flour milling } \\
\text { workers }\end{array}$ & & & & & 0.064 & $\mathrm{ng} / \mathrm{mg}$ & & & & & & \\
\hline
\end{tabular}




\begin{tabular}{|c|c|c|c|c|c|c|c|c|c|c|c|c|c|c|c|c|c|}
\hline \multirow[t]{2}{*}{$\begin{array}{c}\text { Referenc } \\
\text { e }\end{array}$} & \multirow[t]{2}{*}{$\begin{array}{l}\text { Analyt } \\
\text { es } \\
\text { studie } \\
\text { d }\end{array}$} & \multirow[t]{2}{*}{$\underset{y}{\text { Countr }}$} & \multirow[t]{2}{*}{$\begin{array}{c}\text { Estimate } \\
\text { d } \\
\text { biomarke } \\
\text { rs }\end{array}$} & \multirow[t]{2}{*}{$\begin{array}{l}\text { Analytical } \\
\text { method used }\end{array}$} & \multirow{2}{*}{$\begin{array}{l}\text { Population } \\
\text { (packaging } \\
\text { workers) }\end{array}$} & \multirow[t]{2}{*}{$\begin{array}{l}\text { Numb } \\
\text { er of } \\
\text { sampl } \\
\text { es }(n)\end{array}$} & \multirow[t]{2}{*}{$\begin{array}{l}\text { Positiv } \\
\text { e } \\
\text { sampl } \\
\text { es } \\
(\%) \\
\end{array}$} & \multicolumn{2}{|c|}{ LOD } & \multicolumn{2}{|l|}{ Mean } & Me & dian & \multicolumn{2}{|c|}{ SD } & \multirow[t]{2}{*}{ Min } & \multirow[t]{2}{*}{ Max } \\
\hline & & & & & & & & & & & & & & & & & \\
\hline \multirow[t]{4}{*}{$\begin{array}{l}\text { Saad- } \\
\text { Hussein } \\
\text { et al. } \\
(2013 a)\end{array}$} & AFM1 & \multirow[t]{4}{*}{ Egypt } & \multirow[t]{4}{*}{ Serum } & \multirow[t]{4}{*}{$\begin{array}{l}\text { Immunochemis } \\
\text { try (ELISA, dip } \\
\text { stick test, } \\
\text { sensor) }\end{array}$} & $\begin{array}{l}\text { Textile } \\
\text { workers } \\
\text { (pre- } \\
\text { spinning) }\end{array}$ & 14 & & & & 554.2 & $\mathrm{pg} / \mathrm{ml}$ & 540 & $\mathrm{pg}^{\mathrm{p} / \mathrm{m}}$ & 346.2 & $\mathrm{pg} / \mathrm{m}$ & & \\
\hline & AFM1 & & & & $\begin{array}{l}\text { Textile } \\
\text { workers } \\
\text { (spinning) }\end{array}$ & 24 & & & & 459.1 & $\mathrm{pg} / \mathrm{ml}$ & 40 & $\mathrm{pg} / \mathrm{m}$ & 781.6 & $\mathrm{pg} / \mathrm{m}$ & & \\
\hline & AFM1 & & & & $\begin{array}{l}\text { Textile } \\
\text { workers } \\
\text { (weaving) }\end{array}$ & 20 & & & & 296.5 & $\mathrm{pg} / \mathrm{ml}$ & 170 & $\mathrm{pg}^{\mathrm{p} / \mathrm{m}}$ & 336.5 & $\mathrm{pg} / \mathrm{m}$ & & \\
\hline & AFM1 & & & & Controls & 64 & & & & 68.5 & $\mathrm{pg} / \mathrm{ml}$ & 0 & $\mathrm{pg} / \mathrm{m}$ & 136.8 & $\mathrm{pg} / \mathrm{m}$ & & \\
\hline \multirow[t]{2}{*}{$\begin{array}{l}\text { Saad- } \\
\text { Hussein } \\
\text { et al. } \\
(2014)\end{array}$} & AF-alb & Egypt & Serum & $\begin{array}{l}\text { Immunochemis } \\
\text { try (ELISA, dip } \\
\text { stick test, } \\
\text { sensor) }\end{array}$ & $\begin{array}{l}\text { Wheat } \\
\text { Milling } \\
\text { Workers }\end{array}$ & 35 & & & & 0.09 & $\mathrm{ng} / \mathrm{g}$ & & & 0.04 & $\mathrm{ng} / \mathrm{g}$ & & \\
\hline & AF-alb & & & & Control & 40 & & & & 0.04 & $\mathrm{ng} / \mathrm{g}$ & & & 0.01 & $\mathrm{ng} / \mathrm{g}$ & & \\
\hline \multirow[t]{3}{*}{$\begin{array}{l}\text { Saad- } \\
\text { Hussein } \\
\text { et al. } \\
(2016)\end{array}$} & AF-alb & \multirow[t]{3}{*}{ Egypt } & \multirow[t]{3}{*}{ Serum } & $\begin{array}{l}\text { Immunochemis } \\
\text { try (ELISA, dip } \\
\text { stick test, } \\
\text { sensor) }\end{array}$ & $\begin{array}{l}\text { flour milling } \\
\text { workers }\end{array}$ & 100 & & & & 0.06 & $\mathrm{ng} / \mathrm{g}$ & & & 0.003 & $\mathrm{ng} / \mathrm{g}$ & & \\
\hline & AF-alb & & & & bakers & 90 & & & & 0.1 & $\mathrm{ng} / \mathrm{g}$ & & & 0.008 & $\mathrm{ng} / \mathrm{g}$ & & \\
\hline & AF-alb & & & & control & 100 & & & & 0.04 & $\mathrm{ng} / \mathrm{g}$ & & & 0.01 & $\mathrm{ng} / \mathrm{g}$ & & \\
\hline $\begin{array}{l}\text { Shirima } \\
\text { et al. } \\
\text { (2013) }\end{array}$ & AF-alb & $\begin{array}{l}\text { Tanzani } \\
\text { a }\end{array}$ & Serum & $\begin{array}{l}\text { Immunochemis } \\
\text { try (ELISA, dip } \\
\text { stick test, } \\
\text { sensor) }\end{array}$ & $\begin{array}{l}\text { children } \\
\text { between } 12 \\
-22 \text { month } \\
\text { old }\end{array}$ & 146 & & & & $\begin{array}{c}12.9(9.9- \\
16.7)^{*}\end{array}$ & $\mathrm{pg} / \mathrm{mg}$ & & & & & & \\
\hline \multirow[t]{3}{*}{$\begin{array}{l}\text { Shirima } \\
\text { et al. } \\
\text { (2015) }\end{array}$} & AF-alb & \multirow[t]{3}{*}{$\begin{array}{l}\text { Tanzani } \\
\text { a }\end{array}$} & \multirow[t]{3}{*}{ Serum } & \multirow[t]{3}{*}{$\begin{array}{l}\text { Immunochemis } \\
\text { try (ELISA, dip } \\
\text { stick test, } \\
\text { sensor) }\end{array}$} & $\begin{array}{l}\text { children } \\
\text { between 6- } \\
14 \text { month } \\
\text { old }\end{array}$ & 166 & & 3 & $\begin{array}{l}\mathrm{pg} / \mathrm{m} \\
\mathrm{g}\end{array}$ & $4.7(3.95 .6)^{*}$ & $\mathrm{pg} / \mathrm{mg}$ & & & & & & \\
\hline & AF-alb & & & & $\begin{array}{l}\text { children } \\
\text { between 6- } \\
14 \text { month } \\
\text { old (follow } \\
\text { up } 1-6 \\
\text { month) }\end{array}$ & 166 & & 3 & $\begin{array}{l}\mathrm{pg} / \mathrm{m} \\
\mathrm{g}\end{array}$ & $\begin{array}{c}12.9(9.9 \\
16.7)^{*}\end{array}$ & $\mathrm{pg} / \mathrm{mg}$ & & & & & & \\
\hline & AF-alb & & & & $\begin{array}{l}\text { children } \\
\text { between 6- } \\
14 \text { month } \\
\text { old (follow }\end{array}$ & 166 & & 3 & $\begin{array}{l}\mathrm{pg} / \mathrm{m} \\
\mathrm{g}\end{array}$ & $\begin{array}{r}23.5(19.9 \\
27.7)^{*}\end{array}$ & $\mathrm{pg} / \mathrm{mg}$ & & & & & & \\
\hline
\end{tabular}




\begin{tabular}{|c|c|c|c|c|c|c|c|c|c|c|c|c|c|c|c|c|c|}
\hline \multirow[t]{2}{*}{$\begin{array}{c}\text { Referenc } \\
\text { e }\end{array}$} & \multirow[t]{2}{*}{$\begin{array}{l}\text { Analyt } \\
\text { es } \\
\text { studie } \\
\text { d }\end{array}$} & \multirow[t]{2}{*}{$\underset{y}{\text { Countr }}$} & \multirow[t]{2}{*}{$\begin{array}{c}\text { Estimate } \\
\text { d } \\
\text { biomarke } \\
\text { rs }\end{array}$} & \multirow[t]{2}{*}{$\begin{array}{l}\text { Analytical } \\
\text { method used }\end{array}$} & \multirow{2}{*}{$\begin{array}{l}\text { Population } \\
\text { up 2-12 } \\
\text { month) }\end{array}$} & \multirow[t]{2}{*}{$\begin{array}{l}\text { Numb } \\
\text { er of } \\
\text { sampl } \\
\text { es }(n)\end{array}$} & \multirow[t]{2}{*}{$\begin{array}{l}\text { Positiv } \\
\text { e } \\
\text { sampl } \\
\text { es } \\
(\%) \\
\end{array}$} & \multirow[t]{2}{*}{ LOD } & \multicolumn{2}{|c|}{ Mean } & \multicolumn{2}{|c|}{ Median } & \multirow[t]{2}{*}{ SD } & \multicolumn{2}{|c|}{ Min } & \multicolumn{2}{|c|}{ Max } \\
\hline & & & & & & & & & & & & & & & & & \\
\hline $\begin{array}{l}\text { Smith et } \\
\text { al. } \\
(2017)\end{array}$ & AFM1 & $\begin{array}{l}\text { Zimbab } \\
\text { we }\end{array}$ & Urinary & $\begin{array}{l}\text { Immunochemis } \\
\text { try (ELISA, dip } \\
\text { stick test, } \\
\text { sensor) }\end{array}$ & $\begin{array}{l}\text { pregnant } \\
\text { women }\end{array}$ & 1580 & & & & & 162 & $\mathrm{pg} / \mathrm{mg}$ & & 30 & $\begin{array}{l}\mathrm{pg} / \mathrm{m} \\
\mathrm{g}\end{array}$ & $\begin{array}{r}604 \\
6\end{array}$ & $\begin{array}{l}\mathrm{pg} / \mathrm{m} \\
\mathrm{g}\end{array}$ \\
\hline \multirow[t]{2}{*}{$\begin{array}{l}\text { Watson } \\
\text { et al. } \\
(2016)\end{array}$} & AF-alb & \multirow[t]{2}{*}{ Guinea } & \multirow[t]{2}{*}{ Serum } & \multirow[t]{2}{*}{$\begin{array}{l}\text { Immunochemis } \\
\text { try (ELISA, dip } \\
\text { stick test, } \\
\text { sensor) }\end{array}$} & $\begin{array}{l}\text { children } \\
\text { (recruited at } \\
\text { rainy } \\
\text { season) }\end{array}$ & 305 & & & $\begin{array}{r}12.7(10.9 \\
14.7)^{*}\end{array}$ & $\mathrm{pg} / \mathrm{mg}$ & & & & & & & \\
\hline & AF-alb & & & & $\begin{array}{l}\text { children } \\
\text { (follow up }+ \\
6 \text { month) }\end{array}$ & 288 & & & $\begin{array}{r}16.3(14.4,18 \\
5)^{*}\end{array}$ & $\mathrm{pg} / \mathrm{mg}$ & & & & & & & \\
\hline
\end{tabular}




\section{Annex 13 Studies published after the literature review screening}

\begin{tabular}{|c|c|}
\hline Citation & Primary conclusion \\
\hline $\begin{array}{l}\text { Agbetiameh, D., Ortega-Beltran, A., Awuah, R. T., Atehnkeng, } \\
\text { J., Cotty, P. J., \& Bandyopadhyay, R. (2018). Prevalence of } \\
\text { aflatoxin contamination in maize and groundnut in Ghana: } \\
\text { population structure, distribution, and toxigenicity of the } \\
\text { causal agents. Plant Disease, 102(4), 764-772. }\end{array}$ & $\begin{array}{l}\text { Within the } L \text { morphotype, the proportion of toxigenic members was significantly }(P<0.05) \text { higher than } \\
\text { that of atoxigenic members across AEZs. Observed and potential aflatoxin concentrations indicate that } \\
\text { on-field aflatoxin management strategies need to be implemented throughout Ghana. The recovered } \\
\text { atoxigenic } L \text { morphotype fungi are genetic resources that can be employed as biocontrol agents to limit } \\
\text { aflatoxin contamination of maize and groundnut in Ghana. }\end{array}$ \\
\hline $\begin{array}{l}\text { Ahlberg, S., Grace, D., Kiarie, G., Kirino, Y., \& Lindahl, J. } \\
\text { (2018). A risk assessment of aflatoxin M1 exposure in low } \\
\text { and mid-income dairy consumers in Kenya. Toxins, 10(9), } \\
348 .\end{array}$ & $\begin{array}{l}\text { We assessed the risk of cancer and stunting as a result of AFM1 consumption in Nairobi, Kenya, using } \\
\text { worst case assumptions of toxicity and data from previous studies. [..] Overall, } 2.7 \% \text { of children could } \\
\text { hypothetically be stunted due to AFM1 exposure from milk. [..] Our paper shows that concern over } \\
\text { aflatoxins in milk in Nairobi is disproportionate if only risk of cancer is considered, but that the effect on } \\
\text { stunting children might be much more significant from a public health perspective; however, there is } \\
\text { still insufficient data on the health effects of AFM1. }\end{array}$ \\
\hline $\begin{array}{l}\text { Chen, C., Mitchell, N. J., Gratz, J., Houpt, E. R., Gong, Y., } \\
\text { Egner, P. A., ... \& Mduma, E. R. (2018). Exposure to aflatoxin } \\
\text { and fumonisin in children at risk for growth impairment in } \\
\text { rural Tanzania. Environment international, 115, 29-37. }\end{array}$ & $\begin{array}{l}\text { Relatively low aflatoxin exposure at } 24 \text { months was not linked with growth impairment, while fumonisin } \\
\text { exposure at } 24-36 \text { months based on the UFB } 1 \text { biomarkers may contribute to the high growth } \\
\text { impairment rate among children of Haydom, Tanzania; which may be associated with their breast } \\
\text { feeding and weaning practices. }\end{array}$ \\
\hline $\begin{array}{l}\text { Danso, J. K., Osekre, E. A., Opit, G. P., Manu, N., Armstrong, } \\
\text { P., Arthur, F. H., ... \& McNeill, S. G. (2018). Post-harvest } \\
\text { insect infestation and mycotoxin levels in maize markets in } \\
\text { the Middle Belt of Ghana. Journal of Stored Products } \\
\text { Research, 77, 9-15. }\end{array}$ & $\begin{array}{l}\text { Aflatoxin levels of } 2.9 e 3.4 \mu \mathrm{g} / \mathrm{kg} \text { were found in all markets in the minor season maize samples, but } \\
\text { levels ranging from } 38.2 \text { to } 64.0 \mu \mathrm{g} / \mathrm{kg} \text { were found in the major season samples. Fumonisin levels for } \\
\text { all markets ranged between } 0.7 \text { and } 2.3 \mathrm{ppm} \text {. Environmental conditions favor insect } \\
\text { pest population development throughout the year in maize stored in markets in Ghana, thus the maize } \\
\text { must be monitored regularly and appropriate interventions implemented to avoid product loss. }\end{array}$ \\
\hline $\begin{array}{l}\text { Ezekiel, C. N., Oyeyemi, O. T., Oyedele, O. A., Ayeni, K. I., } \\
\text { Oyeyemi, I. T., Nabofa, W., ... \& Dada, A. (2018). Urinary } \\
\text { aflatoxin exposure monitoring in rural and semi-urban } \\
\text { populations in Ogun state, Nigeria. Food Additives \& } \\
\text { Contaminants: Part A, (just-accepted). }\end{array}$ & $\begin{array}{l}\text { There were, however, no significant differences in mean urinary AFM1 levels of males and females, and } \\
\text { among children, adolescents and adults. This study indicates high aflatoxin exposure to the extent of } \\
\text { public health concerns in the studied populations. Thus, more efforts are required for aflatoxin } \\
\text { exposure monitoring and control in high-risk regions. }\end{array}$ \\
\hline
\end{tabular}


FAO JECFA [Joint FAO/WHO Expert Committee on Food Additives]. (2018). Safety evaluation of certain

contaminants in food. WHO food additives series: 74
Johnson, A. M., Fulton, J. R., Abdoulaye, T., Ayedun, B., Widmar, N. J. O., Akande, A., ... \& Manyong, V. (2018). Aflatoxin awareness and AflaSafe adoption potential of Nigerian smallholder maize farmers. World Mycotoxin Journal, 11(3), 437-446.

Kachapulula, P. W., Akello, J., Bandyopadhyay, R., \& Cotty, P. J. (2018). Aflatoxin Contamination of Dried Insects and Fish in Zambia. Journal of food protection, 81(9), 1508-1518. Lindahl, J. F., Kagera, I. N., \& Grace, D. (2018). Aflatoxin M 1 levels in different marketed milk products in Nairobi, Kenya. Mycotoxin research, 34(4), 289-295.

Mutegi, C. K., Cotty, P. J., \& Bandyopadhyay, R. (2018). Prevalence and mitigation of aflatoxins in Kenya (1960-to date). World Mycotoxin Journal, 11(3), 341-357.

Obonyo, M. A., \& Salano, E. N. (2018). Perennial and seasonal contamination of maize by aflatoxins in eastern Kenya. International Journal of Food Contamination, 5(1), 6.
The Committee recommends that efforts continue to reduce aflatoxin exposure using valid intervention strategies, including the development of effective, sustainable and universally applicable preharvest prevention strategies (e.g. Wild, Miller \& Groopman, 2015).

Based on their contribution to dietary aflatoxin exposure in some areas of the world, rice, wheat and sorghum need to be considered in future riskmanagement activities for aflatoxins.

The Committee recommends further research and efforts to alleviate stunting taking aflatoxin exposure into consideration as a possible contributing factor.

The Committee recommends that if additional epidemiological studies are conducted, they should be prospective studies and performed in a high exposure area (e.g. in Africa).

The Committee advises the development of surveillance programmes for regions for which currently little information on occurrence of aflatoxins exists, carefully considering the impact of these programmes on food security.

Results suggest that the level of awareness of aflatoxin was very high in states where AflaSafe was promoted as an intervention for aflatoxin management. In Kaduna state, the region with the longest intervention, there was a consistent increase in the usage of AflaSafe since its introduction in 2010. Furthermore, farmers who purchase AflaSafe bundled (combined) with other inputs were more likely to persist in using the product. Education was found to significantly and positively impact continued usage of AflaSafe. Continued interventions, promotion and general education of the public are recommended for increased awareness, trial, and adoption of AflaSafe in Nigeria.

The current study shows the need for proper storage and testing of dried insects and fish before consumption as measures to mitigate human exposure to aflatoxins through consumption in Zambia.

In conclusion, this study shows that milk purchased by a consumer is likely to contain AFM1 above 50 $\mathrm{ng} / \mathrm{kg}$, and that further research is needed to find ways to mitigate AFM1 contamination through working with farmers and milk processors both in the formal and informal sectors.

This review discusses the scope of the aflatoxins problem and management efforts by various players in Kenya. [..]The review proposes improved linkages between agriculture, nutrition and health sectors to address aflatoxins contamination better. Sustained public awareness at all levels, capacity building and aflatoxins related policies are necessary to support management initiatives.

In Eastern Kenya, consumption of maize harvested in the long rain season presents a recurrent risk of exposure to low levels of AFB1; while consumption of maize harvested after the short rain season presents a risk of seasonal exposure to high levels and mixed type of toxins However, this long term 
Ojuri, O. T., Ezekiel, C. N., Sulyok, M., Ezeokoli, O. T., Oyedele, O. A., Ayeni, K. I., ... \& Nwangburuka, C. C. (2018). Assessing the mycotoxicological risk from consumption of complementary foods by infants and young children in Nigeria. Food and chemical toxicology, 121, 37-50.

Opoku, N., Achaglinkame, M. A., \& Amagloh, F. K. (2018). Aflatoxin content in cereal-legume blends on the Ghanaian market far exceeds the permissible limit. Food Security, 1-7.

Udomkun, P., Wossen, T., Nabahungu, N. L., Mutegi, C., Vanlauwe, B., \& Bandyopadhyay, R. (2018). Incidence and farmers' knowledge of aflatoxin contamination and control in Eastern Democratic Republic of Congo. Food Science \& Nutrition, 6(6), 1607-1620.

Voth-Gaeddert, L. E., Stoker, M., Torres, O., \& Oerther, D. B. (2018). Association of aflatoxin exposure and height-for-age among young children in Guatemala. International journal of environmental health research, 1-13.

Watson, Sinead, et al. "Impaired growth in rural Gambian infants exposed to aflatoxin: a prospective cohort study." BMC public health 18.1 (2018): 1247.

Xu, Y., Gong, Y. Y., \& Routledge, M. N. (2018). Aflatoxin exposure assessed by aflatoxin albumin adduct biomarker in populations from six African countries. World Mycotoxin Journal, 11(3), 411-419. risk of exposure to aflatoxins is poorly documented hence these findings necessitate mitigation measures because AFB1 - is a potent class 1 mutagenic toxin likely to cause liver cancer.

This study assessed, for the first time, the mycotoxicological risks from consumption of complementary foods by infants and young children in Nigeria. [..]Chronic exposure estimate to carcinogenic aflatoxin was high causing low margin of exposure (MOE). Exposures to other mycotoxins either exceeded the established reference values by several fold or revealed low MOEs, pointing to important health risks in this highly vulnerable population. The observed mycotoxin mixtures may further increase risks of adverse health outcomes of exposure; this warrants urgent advocacy and regulatory interventions.

The lowest aflatoxin concentrations were recorded in samples from the Upper East region with a mean of $1.5 \mu \mathrm{g} / \mathrm{kg}$ (1 to $3.8 \mu \mathrm{g} / \mathrm{kg}$ ) while the highest were in samples from the Central region with a mean

concentration of $457 \mu \mathrm{g} / \mathrm{kg}(6.6-1094 \mu \mathrm{g} / \mathrm{kg})$. Aflatoxin concentrations in approximately a third of the infant formulations sampled exceeded the acceptable standard of $20 \mu \mathrm{g} / \mathrm{kg}$, some by a factor of over 5 $(100 \mu \mathrm{g} / \mathrm{kg})$, and may contribute to the perennial malnutrition (stunting and iron deficiency) prevalent among children in Ghana.

In this study, 300 samples of cassava, maize, and groundnut were collected from farmers' households in Eastern DRC and analyzed for incidence of aflatoxins. In addition, the farmers' level of knowledge of the causes and consequences of contamination and the measures for prevention were also examined by administering questionnaires to a cross section of 150 farmers. [..]The result further suggests that an adoption of pre-and postharvest technologies together with awareness creation is still required to reduce aflatoxin contamination in the country.

Results suggest that there was a significant negative correlation between the putative aflatoxin exposure level and child height-for-age $z$-score $(-0.073, p=0.030)$, but not for EED. Furthermore, aflatoxin exposure was significantly correlated with aflatoxin symptoms only at the same time point (0.123, $p=0.026)$.

This study found a small but significant effect of aflatoxin exposure on the growth of Gambian infants. This relationship is not apparently explained by aflatoxin induced changes in the IGF-axis.

Here, we review our recent studies of human exposure in six African countries; Gambia, Guinea, Kenya, Senegal, Tanzania and Uganda. This data shows the widespread exposure of vulnerable populations to aflatoxin. Geometric mean (95\% confidence interval) levels of the biomarker ranged from $9.7 \mathrm{pg} / \mathrm{mg}(8.2,11.5)$ in Ugandan children to $578.5 \mathrm{pg} / \mathrm{mg}(461.4,717.6)$ in Kenyan adolescents during an acute aflatoxicosis outbreak year. 
Zhou, J., Tang, L., \& Wang, J. S. (2019). Assessment of the adverse impacts of aflatoxin B1 on gut-microbiota dependent metabolism in F344 rats. Chemosphere, 217, 618-628.
The adverse impacts of AFB1 on gut-microbiota dependent metabolism in F344 rats 3 were assessed via ultra-high performance liquid chromatography (UHPLC)-profiling and 4 UHPLC-mass spectrometry (MS) metabolomic analyses. [..]These data suggest that AFB1 could significantly reduce the variety of 19 nutrients in gut and disrupt a number of gut-microbiota dependent metabolic pathways, 20 which may contribute to the AFB1-associated stunted growth, liver diseases and the 21 immune toxic effects that have been observed in animal models and human populations. 
RIKILT Wageningen University \& Research P.O. Box 230

6700 AE Wageningen

The Netherlands

$\mathrm{T}+31(0) 317480256$

www.wur.eu/rikilt

RIKILT report 2018.010
The mission of Wageningen University and Research is "To explore the potential of nature to improve the quality of life". Under the banner Wageningen University \& Research, Wageningen University and the specialised research institutes of the Wageningen Research Foundation have joined forces in contributing to finding solutions to important questions in the domain of healthy food and living environment. With its roughly 30 branches, 5,000 employees and 10,000 students, Wageningen University \& Research is one of the leading organisations in its domain. The unique Wageningen approach lies in its integrated approach to issues and the collaboration between different disciplines. 